\author{
UNIVERSIDADE DE SÃO PAULO \\ INSTITUTO DE FÍSICA DE SÃO CARLOS
}

ADALBERTO PICININ

Caracterização estrutural e dinâmica de sistemas

$\mathrm{Cd}_{\mathrm{x}} \mathrm{Pb}_{1-\mathrm{x}} \mathrm{F}_{2}$ : Um estudo por dinâmica molecular 


\section{ADALBERTO PICININ}

\section{Caracterização estrutural e dinâmica de sistemas}

\section{$\mathrm{Cd}_{\mathrm{x}} \mathrm{Pb}_{1-\mathrm{x}} \mathrm{F}_{2}$ : Um estudo por dinâmica molecular}

Tese apresentada ao Instituto de Física de São Carlos, da Universidade de São Paulo, para obtenção do título de Doutor em Ciências.

Área de concentração: Física Básica

Orientador: Prof. Dr. Antonio Carlos Hernandes 


\section{AUTORIZO A REPRODUÇÃO E DIVULGAÇÃO TOTAL OU PARCIAL DESTE TRABALHO, POR QUALQUER MEIO CONVENCIONAL OU ELETRÔNICO, PARA FINS DE ESTUDO E PESQUISA, DESDE QUE CITADA A FONTE.}

Picinin, Adalberto

Caracterização estrutural e dinâmica de sistemas $\mathrm{Cd}_{x} \mathrm{~Pb}_{1-x} \mathrm{~F}_{2}$ : um estudo por dinâmica molecular./Adalberto Picinin; orientador Antonio Carlos Hernandes.-- São Carlos, 2007.

$79 p$.

Tese (Doutorado em Ciências - Área de concentração: Física Básica ) - Instituto de Física de São Carlos da Universidade de São Paulo.

1. Dinâmica molecular 2. Fluoretos 3. Sistemas vítreos 4. Sólidos superiônicos. I. Título. 

Esta tese é dedicada aos meus pais Celso e Maria Helena 


\section{AGRADECIMENTOS}

É difícil agradecer de forma justa às pessoas que se fizeram presentes ao longo deste árduo trabalho, no entanto não poderia furtar-me desta difícil tarefa e mantendo a tradição citarei algumas delas- sempre alguém fica de fora -, se você foi esquecido, sinta-se lembrado.

Quero expressar a minha maior gratidão ao Rino que construiu um ambiente formidável de estudo e discussão, do qual tive o privilégio de participar. Agradeço também a sua amizade, paciência, enorme disponibilidade e boa vontade, excelente orientação e motivação. Agradeço ainda a infraestrutura computacional do grupo GSimCo da UFSCar, coordenado pelo Rino, que foi fundamental para se obter o grande número de resultados que apresento nesta tese.

Agradeço a disponibilidade do Antônio Carlos em me receber para horas de discussão, suas sugestões e críticas foram de grande valia.

Os meus sinceros agradecimentos ao Maurício e ao Sidney pela proposta deste trabalho e por me ensinarem tudo que sei sobre os materiais vítreos. Colaboradores sagazes forneceram os dados experimentais que enriqueceram em muito esse trabalho.

Não posso esquecer do bom amigo Italiano o Pizani, sempre animado me ensinou muito sobre como olhar para as medidas experimentais. Aos professores Donoso e Eckert que aumentaram o entendimento experimental do trabalho.

Ao meu grande amigo Nelson Studart, que desde a graduação vem contribuindo para a minha formação.

Aos meus pais por me guiarem sempre pelo melhor caminho e permitirem que eu chega-se até aqui. Afinal, o maior risco da vida é não fazer nada, mas o carinho e a atenção dos meus pais são clarividentes e foram a estrutura para alcançar tantos objetivos que almejei e agora me sentir realizado. Eles sempre trouxeram para mim a experiência da paz e me fazem viver sorrindo.

Felizmente o número de amigos que fiz é muito grande, mas infelizmente não terei como agradecer a todos, mesmo assim não gostaria de deixar de falar muito obrigado aos companheiros de sala Denilson, Rita, Cláudio e Marcelo. A todos os colaboradores do grupo GsimCo que já não se encontram mais em São Carlos e aos que ainda se encontram: Barretos, Paulo, Branício, Hélio, Luis, James e o Pablo.

E quase por último, mas não menos importante, agradeço a minha namorada Juliana não somente pelo auxílio e paciência durante a execução deste trabalho, mas sim por participar da minha vida.

Ao centro de pesquisa de Juelich por ampliar meus conhecimentos computacionais. Ao IFSC-USP, a UFSCar e aos órgãos de fomento: FAPESP, CAPES, CNPq e FINEP. 


\section{RESUMO}

PICININ, A. Caracterização Estrutural e Dinâmica de Sistemas $C d_{x} P b_{1-x} F_{2}$ : Um Estudo por Dinâmica Molecular. 2007. 80 f. Tese (Doutorado) - Instituto de Física de São Carlos, Universidade de São Paulo, São Carlos, 2007.

Estudos experimentais de sistemas mistos contendo os fluoretos $P b F_{2}$ e $C d F_{2}$ vêm revelando o importante potencial tecnológico desses materiais. No entanto, o comportamento tanto estrutural quanto dinâmico desses materiais ainda não é completamente compreendido. A proposta desta tese é a contribuição no entendimento amplo desses sistemas utilizando uma simulação atomística feita por Dinâmica Molecular. Com uso de um potencial efetivo de pares promissor foi possível descrever as propriedades estruturais, dinâmicas e térmicas destes sistemas avaliando-se também a dependência da composição nestas propriedades. As simulações foram realizadas no ensemble NPT (número de partículas, pressão e temperatura constantes) permitindo acompanhar as variações de energia e volume do sistema durante os processos de aquecimento e resfriamento. Foram observadas as descontinuidades nas transições sólido-líquido e líquido-sólido durante estes processos. Esse ensemble aproxima a simulação da realidade experimental uma vez que em geral experimentos são realizados a pressão atmosférica. Na primeira parte dos resultados foram criadas soluções sólidas ideais construídas a partir da rede perfeita do $\mathrm{PbF}$ onde são escolhidos alguns dos íons de $P b$ que são substituídos aleatoriamente por íons de $C d$. Os resultados da caracterização estrutural destes sistemas foram comparados com medidas de EXAFS mostrando excelente acordo e validando o potencial proposto. Uma vez que o potencial mostrou-se coerente na descrição das interações destes três íons, foram analisados os efeitos da temperatura nestes sistemas. Tanto o $P b F_{2}$ quanto o $C d F_{2}$ são sólidos condutores superiônicos onde os íons de flúor apresentam alta mobilidade iônica. O sistema misto composto por estes dois fluoretos, $C d_{x} P b_{1-x} F_{2}$, também é um material superiônico. As propriedades superiônicas do sistema binário foram obtidas pelas simulações mostrando excelente acordo com os dados experimentais. A fusão desses sistemas considerando-se diferentes concentrações dos fluoretos, apresentou um diagrama de fase com menor temperatura de fusão para as composições em torno de $35 \%$ de $C d F_{2}$, o que está em perfeito acordo com o observado experimentalmente. Sistemas essencialmente diferentes quanto à organização estrutural e homogeneidade, foram obtidos a partir da fusão seguida de diferentes taxas de resfriamento. O resfriamento do líquido feito com taxas rápidas levou a formação de vidros homogênos. Taxas mais lentas de resfriamento levam a formação de vidros que passam a exibir regiões mais ricas em $P b F_{2}$ e outras em $C d F_{2}$. Taxas de resfriamento ainda mais lentas levam a cristalização dos líquidos, a qual ocorre com tendência de separação de fases e geração de defeitos. Os vidros homogêneos foram aquecidos novamente e apresentaram separação de fase seguida da devitrificação. Essencialmente devido aos defeitos gerados durante os processos de vitrificação, cristalização e devitrificação os vidros e os cristais apresentam maiores mobilidades dos íons fluoretos que os sistemas ideais primeiramente avaliados. Os cristais com separação de fases apresentam também composições que possuem menores valores de temperatura de transição iônica-superiônica. O comportamento de máxima mobilidade em função da temperatura é observado para as composições em torno de $30 \%$ de $C d F_{2}$ em acordo com dados experimentais. A simulação clássica realizada permitiu o acesso microscópico do sistema sugerindo uma descrição para esses sistemas que é de grande valia e nem sempre possível experimentalmente.

Palavras-chave: Dinâmica Molecular. Fluoretos. Sistemas vítreos. Sólidos superiônico 


\begin{abstract}
PICININ, A. Dynamical and structural characterization of $C d_{x} P b_{1-x} F_{2}$ systems: A molecular dynamics study. 2007. 80 f. Thesis (Doctoral) - Instituto de Física de São Carlos, Universidade de São Paulo, São Carlos, 2007.

Experimental studies of binary systems of $\mathrm{PbF}_{2}$ and $C d F_{2}$ display important technological potential of these materials. Besides that, its structural and dynamical behavior is not well understood. The aim of this theses is to bring a contribution for understand these materials through molecular dynamics simulations. With an adequate interatomic pair potential it was possible to describe the structural, dynamical and thermal properties of the pure systems as well as for solid solutions. All simulations were performed in NPT ensemble (constant number of particle, pressure, and temperature) which allows observing and analyses the energy and volume variation during process of heating and cooling. Solid-liquid and liquid-solid transitions discontinuity were observed during these process. This ensemble resembles experimental reality, once in general experiments are done at atmospheric pressure. Initially, ideal solid-solutions were obtained from perfect $\mathrm{PbF}_{2}$ lattice, where $\mathrm{Pb}$ ions were randomly replaced by $\mathrm{Cd}$ ions. The molecular dynamics structural characterizations were compared with EXAFS results in excellent agreement, which validates the proposed interatomic potential. Further, thermal effects were also analyzed. Both $\mathrm{PbF}_{2}$ and $C d F_{2}$ are super ionic solid conductors, where the $\mathrm{F}$ ions shows high ionic mobility, The binary system, $C d_{x} P b_{1-x} F_{2}$, is also a super ionic conductor. The super ionic properties for the binary system were simulated displaying excellent agreements with experimental available data. Melting temperature as a function of the $C d F_{2}$ concentration shows a phase diagram in which the melting temperature has a minimum around $35 \%$ of $C d F_{2}$, in accord with experimental data. Using different cooling rates, cooling from the melt, result in systems with different structural organization and homogeneity. Cooling from the liquid, with fast cooling rates, results in homogeneous glass. Slow cooling rates produce glass in which there is regions rich in $P b F_{2}$ and other rich in $C d F_{2}$. Slower cooling rates results in the crystallization of the liquid, which large tendency of phase separation and defects. Homogeneous glasses were re-heated resulting in a phase separated system followed by devitrification. Due to the presence of defects during the process of vitrification, crystallization and devitrification, glasses and crystals display greater mobility of $F$ ions than the initial solid solution initially analyzed. The ionic-super ionic temperature occurs for smaller temperatures for some composition of the crystals with phase separation. Maximum mobility as a function of temperature was observed for composition around $30 \% C d F_{2}$, in agreement with experiments. The classical simulation performed allows detailed microscopic description of the system in which, in general, are not possible experimentally.
\end{abstract}

Keywords: Molecular Dynamic. Fluorides. Vitreous systems. Superionic solids. 


\section{Lista de Figuras}

2.1 Termo Coulombico do potencial de pares para o $\mathrm{PbF}_{2}$. A linha contínua representa a repulsão dos pares FF. A linha pontilhada representam a atração $\mathrm{PbF}$ e os pontos representam a repulsão dos pares $\mathrm{PbPb}$. . . . . . 31

2.2 Termo estereométrico do potencial de pares para o $\mathrm{PbF}_{2} \ldots \ldots$. . . . . . 32

2.3 Termo dipolar do potencial de pares para o $\mathrm{PbF}_{2} \ldots \ldots \ldots$. . . . . . 33

2.4 Potencial de Buckingham dos pares $i j$ para o $P b F_{2} \ldots \ldots . \ldots . . . . . .34$

2.5 Sistema periódico em duas dimensões. As partículas podem entrar e sair pelas quatro paredes da caixa. . . . . . . . . . . . . . . 43

2.6 A convenção de imagem mínima em duas dimensões. A caixa montada ao redor da partícula 6 mostra as partículas que serão consideradas no cálculo da sua força e energia potencial. . . . . . . . . . . . . . . . . 44

3.1 Visão frontal da célula unitária do $\mathrm{PbF}_{2} \ldots \ldots \ldots \ldots$. . . . . . . 57

3.2 Fig. 3.1 com uma pequena rotação . . . . . . . . . . . . . . 57

3.3 Visão frontal da caixa tridimensional da SSI $x=0,40$ em T=50K. . . . . . . 60

3.4 Figura 3.3 com rotação de $5^{\circ}$ para a esquerda, em torno do eixo y . . . . . 60

3.5 Figura 3.3 com rotação de $18^{\circ}$ para a esquerda, em torno do eixo y . . . . 60

3.6 Figura 3.3 com rotação de $22^{\circ}$ para a esquerda, em torno do eixo y . . . . 60

3.7 Figura 3.3 com rotação de $14^{\circ}$ para a esquerda em torno do eixo y e $14^{\circ}$ para baixo em torno do eixo $\mathrm{x} \ldots \ldots . \ldots$. . . . . . . . . 60

3.8 Figura 3.3 com rotação de $19^{\circ}$ para a esquerda em torno do eixo y e $19^{\circ}$ para baixo em torno do eixo $\mathrm{x} \ldots \ldots$. . . . . . . . . . 60 
$3.9 \mathrm{~g}_{\alpha \beta}(r)$ em $\mathrm{T}=100 \mathrm{~K}$ das SSI com $x=0,10 ; x=0,35$ e $x=0,80$. Em (a) é mostrado o par $\mathrm{Cd}-\mathrm{Cd}$, em (b) o par $\mathrm{Cd}-\mathrm{Pb}$, em (c) o par $\mathrm{Pb}-\mathrm{Pb}$, em (d) o par Cd-F, em (e) o par Pb-F e em (f) o par F-F. . . . . . . . . . . 63

3.10 Comparação das funções de correlação de pares parciais dos fluoretos puros com as da ISS $x=0,5$ ambos em T=50K.

3.11 Alturas das $g_{\alpha \beta}(r)$ em função da composição das SSI em T=100K. Em (a) são mostradas as alturas dos $1^{0}$ picos do par $\mathrm{Cd}-\mathrm{Cd}$, em (b) dos $1^{0}$ picos do par Cd-Pb, em (c) dos $2^{0}$ picos do par Pb-F, em (d) dos $2^{0}$ picos do par $\mathrm{Cd}-\mathrm{F}$, em (e) os $1^{0}$ picos do par $\mathrm{Pb}-\mathrm{Pb}$ e em (f) os $1^{0}$ picos do par F-F. . . 68

3.12 Comprimentos das ligações das SSI obtidos por DM. EM (a) são mostradas ligações do tipo cation-anion, em (b) cation-cation e em (c) anion-anion. . 70

3.13 Medidas dos comprimentos das ligações obtidas por EXAFS.[72] Em (a) são mostradas ligações cation-anion e em (b) cation-cation. . . . . . . . . . 70

3.14 Parâmetro de rede em função da concentração. Comparação entre DM e dados experimentais. . . . . . . . . . . . . . . . . 72

3.15 Parâmetro de rede obtido do segundo pico das $\mathrm{g}_{P b-P b}(\mathrm{r})\left(\mathrm{d}_{P b P b}\right)$ e $\mathrm{g}_{C d-C d}(\mathrm{r})$ $\left(\mathrm{d}_{C d C d}\right)$, comparados com as média simples $\left(\mathrm{m}_{s}\right)$ e a média ponderada $\left(\mathrm{m}_{p}\right) .73$

3.16 Funções de correlação de pares parciais e totais para as SSI $x=0,1$ e $x=0,8$ em $\mathrm{T}=100 \mathrm{~K}$.

3.17 Função de correlação de pares total em função da distância para todas as SSI em $\mathrm{T}=100 \mathrm{~K}$.

3.18 Célula unitária do $\mathrm{PbF}_{2}$ (Fig.3.1) destacando o buraco tetraédrico ocupado pelo Fluor. . . . . . . . . . . . . . . . . . . . . . . . . . . 80

3.19 Tetraedro formado pelos cátions $1,2,3$ e 4 visto de outro ângulo. . . . . . 80

3.20 Identificação do tipo de tetraedro que o Fluor está inserido nas SSI em $\mathrm{T}=50 \mathrm{~K}$.

3.21 Ângulos das SSI entre os $\mathrm{F}$ e os cátions em $\mathrm{T}=50 \mathrm{~K} . \quad \ldots . . . . . .83$

3.22 Ângulos formados pelos cátions da SSI em $\mathrm{T}=50 \mathrm{~K} . \quad \ldots . . . . . .85$

3.23 Ângulos formados pelos Fluors da SSI em $\mathrm{T}=50 \mathrm{~K}$ para três diferentes concentrações deCdF $\mathrm{de}_{2} \ldots \ldots \ldots \ldots \ldots$. . . . . . . . . . . 86

3.24 Coeficientes de difusão do $\mathrm{F}, \mathrm{Pb}$ e do $\mathrm{Cd}$ destacando a região de superionicidade da SSI com $x=0,50$. 
$3.25 \mathrm{~g}(\mathrm{r})$ parcial da SSI $x=0,50$ mostrando o cristal iônico em $\mathrm{T}=400 \mathrm{~K}$ (linha contínua) e o super-iônico em $\mathrm{T}=800 \mathrm{~K}$ (pontilhada). . . . . . . . . . 88

3.26 Comparação entre experimento e simulação da difusão do Fluor no $P b F_{2}$. . 93

$3.27 \mathrm{~g}_{F-F}(\mathrm{r})$ da SSI com $x=0,50$ para várias temperaturas na região super-iônica. 93

3.28 Coeficiente de difusão do F em função de $x$. Em (a)são mostradas as temperaturas necessárias para atingir 3 valores diferentes de difusão do F. Em (b)são mostrados os valores da difusão do F em 4 diferentes temperaturas.

3.29 Condutividade do fluoreto puro $\mathrm{PbF}_{2}$. Comparação entre Dinâmica Molecular e resultados experimentais da literatura. . . . . . . . . . . . . 95

3.30 Condutividade da SSI $x=0,30$ em comparação com resultados experimentais da literatura . . . . . . . . . . . . . . . . . . . 96

3.31 Condutividade em função da concentração para temperaturas fixas. . . 97

3.32 Difusão do $\mathrm{Pb}$, do $\mathrm{Cd}$ e a descontinuidade do volume na região de fusão.

3.33 Descontinuidade da energia na região de fusão para três diferentes concentrações de $C d F_{2}$. . . . . . . . . . . . . . . . . . . . . 99

3.34 Temperatura de Fusão como função da concentração de $\mathrm{CdF}_{2}$. Os asteriscos e os triângulos são dados experimentais de Podsiadlo[68] e Trnovcová[69]. respectivamente. Os quadrados são resultados da simulação por Dinâmica Molecular. . . . . . . . . . . . . . . . . . . . 100

3.35 Função de correlação de pares total para os líquidos em T=3500K. . . . . 102

3.36 Volume como função da temperatura durante o resfriamento da concentração $x=0,40 \ldots \ldots \ldots \ldots$. . . . . . . . . . . . . . . . . . . . . . .

3.37 Energia por partícula da concentração $x=0,40$ para diferentes taxas de resfriamento em função da temperatura. . . . . . . . . . . . . . . . . . . . 104

3.38 Visão frontal da caixa tridimensional do líquido com $x=0,50$ resfriado com $\mathrm{q}=-25 \mathrm{~K} / \mathrm{ps}$ em $\mathrm{T}=50 \mathrm{~K} \ldots \ldots \ldots \ldots$. . . . . . . . . . . . . . . . . . .

3.39 Figura 3.38 com rotação de $19^{\circ}$ para a esquerda em torno do eixo y e $19^{\circ}$

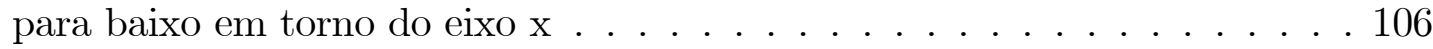

3.40 Somente os Cd da Fig. 3.38 . . . . . . . . . . . . . . . . 106

3.41 Somente os Cd da Fig. 3.39 . . . . . . . . . . . . . . . 106

3.42 Somente os Pb da Fig. 3.38 . . . . . . . . . . . . . . . . . 106 
3.43 Somente os $\mathrm{Pb}$ da Fig. $3.39 \quad \ldots \ldots \ldots$. . . . . . . . . . 106

3.44 Função de correlação de pares total dos vidros homogêneos em T=100K 107

3.45 Estatística do ambiente em que os $\mathrm{F}$ se encontram. Comparação entre os vidros homogêneos $(q=-25 K / p s)$ e os não homogêneos $(q=-1 K / p s)$ em $\mathrm{T}=50 \mathrm{~K} \ldots \ldots \ldots \ldots \ldots \ldots$

3.46 Sistema com $x=0,40$ resfriado com $\mathrm{q}=-1 \mathrm{~K} / \mathrm{ps}$ em $\mathrm{T}=50 \mathrm{~K} . \quad \ldots \ldots$

3.47 Sistema com $x=0,40$ resfriado com $\mathrm{q}=-0,5 \mathrm{~K} / \mathrm{ps}$ em $\mathrm{T}=100 \mathrm{~K} . \ldots . . . \quad \ldots 110$

3.48 Somente os Cd da Fig. 3.46 . . . . . . . . . . . . . . . . . 110

3.49 Somente os Cd da Fig. 3.47 . . . . . . . . . . . . . . . . 110

3.50 Somente os $\mathrm{Pb}$ da Fig. $3.46 \ldots \ldots$. . . . . . . . . . . . 110

3.51 Somente os $\mathrm{Pb}$ da Fig. 3.47 . . . . . . . . . . . . . . . . . . 110

3.52 Sistema com $x=0,10$ resfriado do líquido com $\mathrm{q}=-0,2 \mathrm{~K} / \mathrm{ps}$ em $\mathrm{T}=50 \mathrm{~K}$. . . 112

3.53 Sistema com $x=0,50$ resfriado do líquido com $\mathrm{q}=-0,2 \mathrm{~K} / \mathrm{ps}$ em $\mathrm{T}=50 \mathrm{~K}$. . . 112

3.54 Somente os Cd da Fig. 3.52 . . . . . . . . . . . . . . . . . . . 112

3.55 Somente os Cd da Fig. 3.53. . . . . . . . . . . . . . . . . 112

3.56 Somente os Pb da Fig. 3.52. . . . . . . . . . . . . . . . . 112

3.57 Somente os $\mathrm{Pb}$ da Fig. 3.53. . . . . . . . . . . . . . . . . . . 112

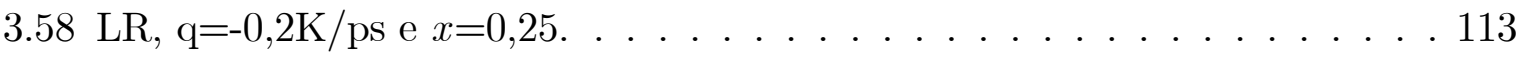

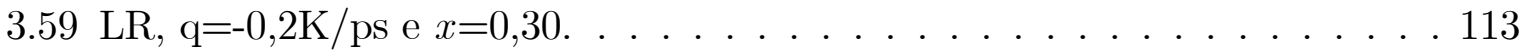

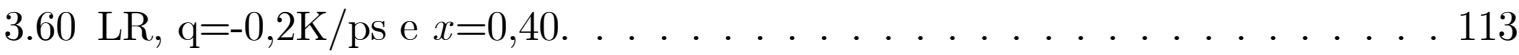

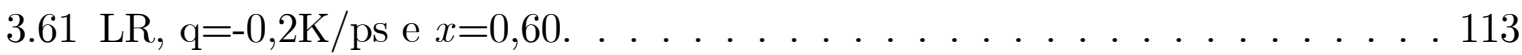

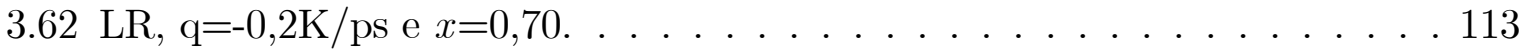

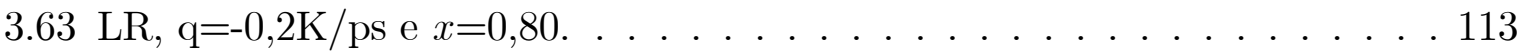

3.64 Comparação das $\mathrm{g}_{\alpha \beta}(\mathrm{r})$ em $\mathrm{T}=50 \mathrm{~K}$ para os cristais LR e SSI com $x=0,50$ e os fluoretos puros. . . . . . . . . . . . . . . . . . . 115

$3.65 \mathrm{~g}_{\alpha \beta}(\mathrm{r})$ do líquido resfriado com $q=-0,2 \mathrm{Kps}^{-1}$ para três diferentes concentrações. . . . . . . . . . . . . . . . . . . . 116 
3.66 Comparação dos $\mathrm{n}_{\alpha \beta}(\mathrm{r})$ em $\mathrm{T}=50 \mathrm{~K}$ para os sistemas LR e SSI com $x=0,50$ e os fluoretos puros. . . . . . . . . . . . . . . . . . . 118

3.67 Coeficientes de difusão para a concentração $x=0,40$ em função da temperatura para diferentes taxas de resfriamento. Em (a) são mostrado os dados para o F, em (b) para o $\mathrm{Cd}$ e em (c) para o Pb. . . . . . . . . . . . 119

3.68 Comparação do coeficiente de difusão do Cd e do Pb durante a cristalização do resfriamento $q=-0,5 \mathrm{Kps}^{-1}$.

3.69 Comparação do coeficiente de difusão do $\mathrm{Cd}$ e do $\mathrm{Pb}$ durante o resfriamento com $q=-0,2 \mathrm{Kps}^{-1} \ldots \ldots \ldots \ldots$. . . . . . . . . . . . 120

3.70 Posição dos segundos picos das $\mathrm{g}_{C d-C d}(\mathrm{r})\left(d_{C d C d}\right)$ e $\mathrm{g}_{P b-P b}(\mathrm{r})\left(d_{P b P b}\right)$ em $\mathrm{T}=50 \mathrm{~K}$ dos LR em comparação com as SSI. . . . . . . . . . . . . . . . 122

3.71 Tentativa de estimar os parâmetros de rede para os LR feita por médias em comparação com o parâmetro de rede das SSI. Todos os dados são para $\mathrm{T}=50 \mathrm{~K}$.

3.72 Comparação do tipo de tetraedro que o Fluor está inserido entre LR e a SSI. Ambos os sistemas estão em T=50K.

3.73 Cd após a termalização em T=800K do LSRT com $x=0,35 \ldots$. . . . . . . 126

$3.74 \mathrm{~Pb}$ após a termalização em $\mathrm{T}=800 \mathrm{~K}$ do LSRT com $x=0,35 \ldots$. . . . . . . 126

3.75 Cd após a termalização em T=800K do LSRT com $x=0,50 \ldots \ldots$. . . . . . 126

$3.76 \mathrm{~Pb}$ após a termalização em $\mathrm{T}=800 \mathrm{~K}$ do LSRT com $x=0,50 \ldots \ldots$. . . . . . 126

3.77 Cd após a termalização em T=800K do LSRT com $x=0,80 \ldots$. . . . . . . . 126

$3.78 \mathrm{~Pb}$ após a termalização em $\mathrm{T}=800 \mathrm{~K}$ do LSRT com $x=0,80 \ldots \ldots$. . . . . . 126

3.79 Evolução temporal da porcentagem de ocorrência dos Qi durante a termalização do líquido super-resfriado homogêneo em $\mathrm{T}=800 \mathrm{~K}$. De (a) a (e) $x=0,10$ e $(\mathrm{f})$ a $(\mathrm{j}) x=0,35 \ldots \ldots \ldots \ldots \ldots$

3.80 Evolução temporal da porcentagem de ocorrência dos Qi durante a termalização do líquido super-resfriado homogêneo em $\mathrm{T}=800 \mathrm{~K}$. De (a) a (e) $x=0,50$ e $(\mathrm{f})$ a $(\mathrm{j}) x=0,80 \ldots \ldots \ldots \ldots$

3.81 Comparação dos $\mathrm{Q}_{i}$ dos LSRT em $\mathrm{t}=0$ ps e $\mathrm{t}=3500$ ps para $\mathrm{T}=800 \mathrm{~K} . \ldots$

$3.82 \mathrm{~g}_{\alpha \beta}(\mathrm{r})$ da parte catiônica dos LSRT em comparação com as SSI. Tanto o sistema $x=0,10$ quanto o $x=0,35$ estão em $\mathrm{T}=800 \mathrm{~K}$. . . . . . . . . . . . . . 132 
$3.83 \mathrm{~g}_{\alpha \beta}(\mathrm{r})$ da parte catiônica dos LSRT em comparação com as SSI. Tanto o sistema $x=0,50$ quanto o $x=0,80$ estão em $\mathrm{T}=800 \mathrm{~K} \ldots \ldots \ldots$. . . . . . . 133

3.84 Difusão dos átomos durante a termalização do líquido super resfriado em

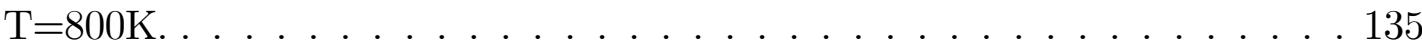

3.85 Energia e volume como função da temperatura durante a recristalização do

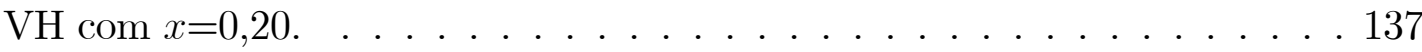

3.86 Devitrificação do sistema com $x=0,10$ em $\mathrm{T}=100 \mathrm{~K}$. . . . . . . . . . . . . 139

3.87 Sistema com $x=0,20 \ldots \ldots \ldots \ldots$

3.88 Sistema com $x=0,25 \ldots \ldots \ldots$. . . . . . . . . . . . . . . 139

3.89 Sistema com $x=0,30 \ldots \ldots$. . . . . . . . . . . . . 139

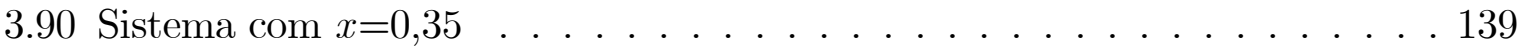

3.91 Sistema com $x=0,35$ em outro ângulo . . . . . . . . . . . . . . . 139

3.92 Devitrificação do sistema com $x=0,40$ em $\mathrm{T}=100 \mathrm{~K}$. . . . . . . . . . . . . . 140

3.93 Sistema com $x=0,40$ em outro ângulo . . . . . . . . . . . . . . . . . 140

3.94 Sistema com $x=0,50 \ldots \ldots \ldots \ldots \ldots$. . . . . . . . . . . . . . . . . . . . .

3.95 Sistema com $x=0,60 \ldots \ldots \ldots \ldots \ldots$

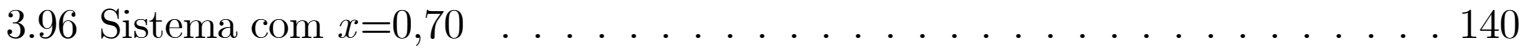

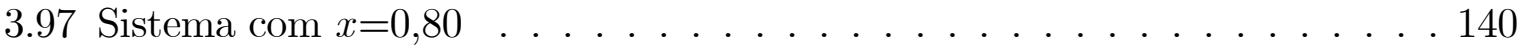

3.98 Posição dos segundos picos dos pares Cd-Cd (a) e Pb-Pb (b) em T=100K. 141

3.99 Identificação do tipo de tetraedro que o Fluor está inserido nas SSI, VC e

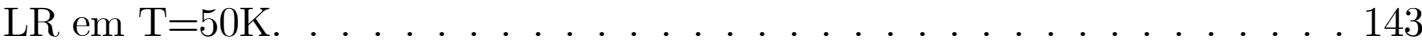

3.100Comparação da difusão do $\mathrm{F}$ durante o aquecimento e resfriamento do sistema com $x=0,20$. . . . . . . . . . . . . . . . . . . . . 144

3.101Difusão do $\mathrm{F}$ como função da concentração de $\mathrm{CdF}_{2}$ para os sólidos: SSI, $\mathrm{LR}, \mathrm{VH}$ e VC . . . . . . . . . . . . . . . . . . . . 146 


\section{Lista de Tabelas}

3.1 Posição dos picos em $\AA$ das $\mathrm{g}_{\alpha \beta}(r)$ das SSI dos pares $\mathrm{Cd}-\mathrm{Cd}, \mathrm{Cd}-\mathrm{Pb}$ e $\mathrm{Cd}-\mathrm{Cd}$ em $\mathrm{T}=50 \mathrm{~K} . \ldots \ldots \ldots \ldots \ldots \ldots$

3.2 Posição dos picos em $\AA$ das $\mathrm{g}_{\alpha \beta}(r)$ das SSI dos pares Cd-F, Pb-F e F-F em

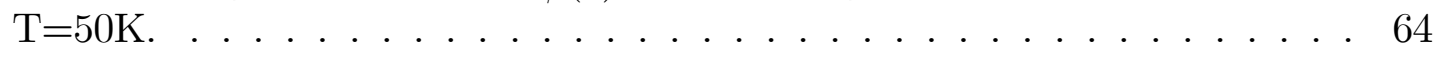

3.3 Número de vizinhos dos pares $\mathrm{Cd}-\mathrm{Cd}, \mathrm{Cd}-\mathrm{Pb}$ e $\mathrm{PbPb}$. A coluna identificada por EX representa os dados obtidos por EXAFS e todos os outros são obtidos da DM. . . . . . . . . . . . . . . . . . . . . 74

3.4 Número de vizinhos dos pares Cd-F, Pb-F e FF. A coluna identificada por EX representa os dados obtidos por EXAFS e todos os outros são obtidos

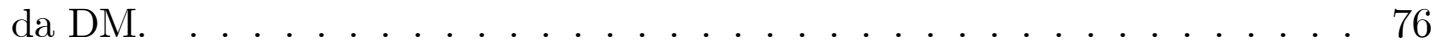




\section{Sumário}

$\begin{array}{lll}1 & \text { Introdução } & 17\end{array}$

2 Modelagem Matemática 24

2.1 Dinâmica Molecular . . . . . . . . . . . . . . . . . . . . . 24

2.2 O potencial empírico . . . . . . . . . . . . . . . . . . . . 27

2.3 Integração das equações de movimento . . . . . . . . . . . . . . . . . . . . . . . . . . . 37

2.3.1 O algoritmo de Verlet . . . . . . . . . . . . . . 37

2.4 Condições iniciais . . . . . . . . . . . . . . . . . . . . . . . . 40

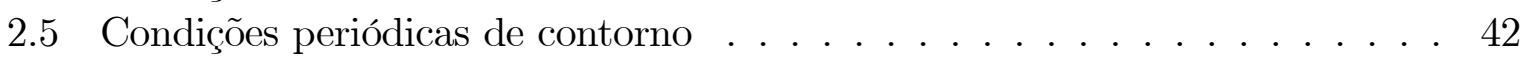

2.6 Algoritmos para outros ensembles . . . . . . . . . . . . . . . . . . . . . . . . . . . . . . 44

2.6.1 Ensemble NVT . . . . . . . . . . . . . . . . . . 45

2.6 .2 Ensemble NPT . . . . . . . . . . . . . . . . . . 47

2.7 Cálculo de quantidades físicas . . . . . . . . . . . . . . . . . . . . . . . . . . . . . . . . 49

2.7.1 Propriedades termodinâmicas . . . . . . . . . . . . . 50

2.7.2 Propriedades estruturais . . . . . . . . . . . . . . . . 52

2.7.3 Propriedades dinâmicas . . . . . . . . . . . . . . . 53

3 Resultados e Discussões $\quad 56$

3.1 Descrição preliminar e preparação dos sistemas . . . . . . . . . . . . . . . . . 56

3.2 Solução Sólida Inicial . . . . . . . . . . . . . . . . . . . . . . . . . 62

3.2.1 Função de correlação de pares parcial. . . . . . . . . . . . . . . . 62

3.2 .2 Relaxação da ligação . . . . . . . . . . . . . . . . . . . . . . 67

3.2 .3 Parâmetro de rede . . . . . . . . . . . . . . . . . . . . . 70

3.2.4 Número de vizinhos . . . . . . . . . . . . . . . . . . . . . . . . . . . . . . . . . . . . . . . . . 73

3.2.5 Função de correlação de pares Total . . . . . . . . . . . . . . . . . 76

3.2.6 Posição do Flúor numa rede do tipo $\mathrm{PbF}_{2}$. . . . . . . . . . . . . . 79

3.2 .7 Ângulos de ligação . . . . . . . . . . . . . . . . . . . . . . . . . . . . . . . . . 81

3.2 .8 Cristal super-iônico . . . . . . . . . . . . . . . . . . . 84

3.2 .9 Transição Sólido-Líquido . . . . . . . . . . . . . . . . . . . . . . . 98

3.3 Resfriamento partindo do líquido . . . . . . . . . . . . . . . . . . . 101

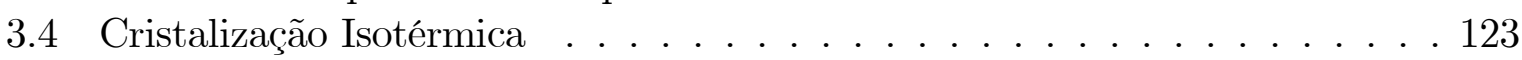

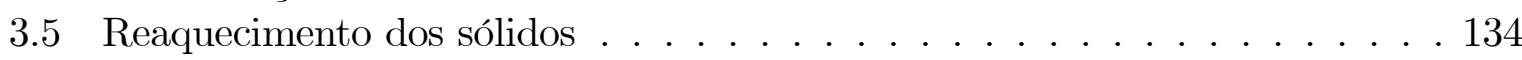

3.5.1 Recristalização do vidro . . . . . . . . . . . . . . . . . 134

3.5.2 Difusão do F nos sólidos . . . . . . . . . . . . . . . . . . . . . . . . 144

4 Conclusões e perspectivas futuras $\quad 147$ 
Referências Bibliográficas 


\section{Capítulo 1}

\section{Introdução}

Em toda a história do homem tentou-se entender a natureza e criar modelos que reproduzam as suas façanhas. Porém, a necessidade incessante de novos materiais ou o aprimoramento dos materiais já conhecidos coloca o homem diante do desafio de criar modelos mais eficazes e abrangentes. Modelos que permitam unir o conhecimento da ciência experimental ao da ciência teórica. Um ponto crítico para a física da matéria condensada é o progresso no conhecimento da estrutura interna e das propriedades destes materiais, assim como dos processos envolvidos, quando estes interagem com diferentes ambientes externos. Este conhecimento é crucial para a indústria, quando da seleção dos materiais mais adequados ao desenvolvimento de novos produtos, necessários ou desejados pela sociedade. Muitas vezes, pesquisa e desenvolvimento de produtos trabalham juntos na criação de novos materiais ou na mudança de propriedades de materiais existentes. São muitas as necessidades do homem relacionadas a novos materiais. Os aviões necessitam de materiais com alta razão resistência/peso para a sua construção. E ainda bons materiais a altas temperaturas que possam ser utilizados com grande eficiência na construção de novas turbinas. As indústrias químicas procuram por materiais altamente resistentes à corrosão. A busca por novos materiais com aplicações em tecnologias de telecomunicações 
é suportada pela grande demanda mundial em conseguir trafegar o máximo de informações em menor tempo e, consequentemente, sem perdas significativas e assim por diante.

Neste ambiente de procura e desenvolvimento de novos materiais e produtos as técnicas de simulação computacional tornaram-se ferramentas essenciais. Devido aos avanços em algoritmos matemáticos, métodos numéricos e construção de computadores de alto desempenho, o cálculo computacional de propriedades dos materiais está se tornando cada vez mais preciso e prático [1]. Várias indústrias, como a farmacêutica, microeletrônica e automobilística, já estão experimentando o impacto das técnicas de simulação computacional.

É essencial reconhecer que a simulação científica não substitui a teoria e a experiência, mas contribui enormemente para o avanço de ambas [2]. Pode-se dizer que tais técnicas se tornaram populares porque buscam preencher o vazio entre a teoria, que muitas vezes é limitada por modelos muito simplificados, e o experimento, que é limitado pelos parâmetros físicos. As simulações podem em parte tratar estes problemas, pois, são baseadas em teorias e de certa forma executam um experimento, porém, sob parâmetros arbitrários. No estudo dos materiais, que são geralmente sistemas complexos, a formulação teórica nunca foi capaz de descrever toda a extensão das escalas de comprimento e tempo envolvidas no seu comportamento. Entretanto, técnicas de simulação sofisticadas foram desenvolvidas para descrever adequadamente as propriedades dos materiais, dentro de certos regimes.

A simulação computacional especialmente em combinação com dados experimentais, pode servir como a fonte de nova informação física a qual é difícil (e frequentemente impossível) se obter em experimentos no laboratório. Além disso, em alguns casos, os resultados da simulação computacional são usados para verificar diferentes modelos físicos e aproximações. Geralmente, os computadores não são apenas uma poderosa ferramenta para resolver problemas teóricos mas também um componente essencial em afirmações a 
respeito de um novo problema científico [3].

Na escala microscópica, por exemplo, as interações entre os núcleos e os elétrons são computadas diretamente da descrição quântica fundamental. Várias abordagens ab initio podem ser empregadas para este fim, tais como o cálculo de orbitais moleculares (MO), teoria da densidade funcional (DFT) $[4,5]$, etc. As propriedades físicas e químicas de novos medicamentos, por exemplo, são atualmente calculadas desta maneira (através de MO) pela indústria farmacêutica, antes de serem testadas experimentalmente. As propriedades de materiais policristalinos com muitos defeitos também podem ser tratadas desta maneira. Entretanto, o custo computacional limita de maneira drástica a possibilidade de simular a dinâmica dos sistemas e constitui uma séria restrição à aplicação das técnicas ab initio. Para resolver este impasse, uma abordagem combinada de DFT e Dinâmica Molecular (DM) foi proposta por Car e Parrinello [6]. Nesta abordagem, o movimento dos núcleos é computado através de DM clássica enquanto os graus de liberdade eletrônicos são considerados utilizando DFT. No entanto, mesmo sendo muito preciso na descrição dos materiais, a aplicação dos métodos ab initio ainda é muito restrita. Como o esforço computacional é muito intenso, as simulações devem ser limitadas a sistemas pequenos, tipicamente da ordem de 100 átomos, e nem todas as propriedades dos materiais reais podem ser calculadas.

Com o intuito de simular sistemas maiores e continuar considerando os efeitos quânticos, o método de DM por tight-binding (TBMD) $[8,7]$ foi desenvolvido. Neste método os cálculos ab initio são aproximados, considerando uma base limitada a interações localizadas para os graus de liberdade eletrônicos. TBMD não envolve a função de onda eletrônica explicitamente mas resolve um problema de autovalores para uma matriz que representa a interferência entre orbitais eletrônicos. A implementação direta envolve diagonalização de matrizes, o que faz com que o tempo computacional seja proporcional a $O\left(N^{3}\right)$, porém 
novos algoritmos de TBMD proporcionais a $O(N)$ foram propostos, tornando possível simular sistemas grandes, com até $10^{3}$ átomos $[9,10,11]$. Maiores detalhes sobre métodos híbridos envolvendo modelos clássicos e quânticos podem ser encontrados no artigo de Nakano.[12]

Para a simulação de sistemas grandes é necessário utilizar uma abordagem diferente. O passo seguinte é a modelagem das interações entre átomos utilizando um potencial empírico. Nesta abordagem, conhecida como Dinâmica Molecular (DM), cada átomo é tratado como uma massa pontual e as equações de movimento de Newton resultantes são integradas para obter as trajetórias no espaço de fase. A simulação usando DM aplicada neste trabalho é uma simulação atomística, clássica que fornece a posição e a velocidade de cada uma das partículas do sistema simultaneamente permitindo descrever a evolução temporal do sistema como um todo. A evolução temporal considerando um número razoável de partículas é uma das qualidades da DM que a torna uma importante ferramenta na árdua tarefa de entender a Natureza. Entende-se por número razoável de partículas um sistema que contenha alguns milhares de partículas, que é uma simulação factível em qualquer computador de baixo poder computacional. A referência que torna esse número razoável é, por exemplo, uma simulação de primeiros princípios que simula algo em torno de 100 partículas estáticas a um custo computacional muito maior. Em situações extremas, utilizando clusters de máquinas com alto poder computacional, um cálculo quântico pode chegar a 500 partículas enquanto um cálculo clássico com DM pode chegar a centenas de bilhões de partículas [13].

Os potenciais empíricos utilizados nas simulações são formulados com base em teorias microscópicas e compreendem formas funcionais com as principais contribuições atômicas para a coesão de um material. Os parâmetros destes potenciais são ajustados a dados experimentais e de cálculos ab initio. Usualmente, as simulações por DM são feitas no 
ensemble microcanônico, ou seja, com energia, volume e número de partículas constantes. Com os avanços na formulação, as simulações podem ser feitas agora em diferentes ensembles, como temperatura constante e/ou pressão constante $[14,15,16,17]$. Com estas extensões é possível estudar, por exemplo, fenômenos como a fusão e as transições de fase estruturais induzidas por pressão entre outros fenômenos que exibem variação no volume. É possível também considerar uma variação dinâmica da carga das partículas e se estudar fenômenos como a oxidação[18].

Além de calcular detalhadamente a parte estrutural do sistema a grande vantagem da DM é descrever o sistema como função do tempo. Com isso pode-se calcular diretamente fenômenos que tem dependência temporal tais como propriedades de transporte, difusão, viscosidade, espectro de infravermelho, densidade de estados vibracionais entre outras. A evolução temporal digna de apreço na DM, é parte de um modelo matemático que usualmente tem limitações. Mas é limitada pelas relativamente curtas escalas de tempo, associadas ao movimento atômico [3]. Usualmente o passo de integração, menor entidade na discretização do tempo, está na casa dos pico segundos (femto-segundos) de modo a manter a estabilidade da integração numérica. Uma simulação factível tem algo em torno de milhões de passos que leva a um tempo de existência do sistema na casa dos nano segundos. Fenômenos reais que levam minutos ou até horas para acontecer são reproduzidos utilizando DM em escalas de tempo bem mais curtas. Uma possível explicação dessa limitação do modelo é que os sistemas simulados têm comprimento característico relativamente pequeno. Nas simulações dessa tese os tamanhos variam entre 40 a $100 \AA$. Essa é uma discussão em aberto mas acredita-se que nessas escalas o tempo deve fluir de uma maneira diferente.

Por ser uma simulação clássica, uma outra limitação da DM é não conseguir descrever ligações químicas, pois estas envolvem explicitamente o comportamento dos elétrons e são 
fenômenos essencialmente quânticos.

O desenvolvimento e caracterização de novos sistemas que possam ser utilizados como fibras ópticas, que promovem a amplificação da luz, vêm crescendo devido a necessidade de transitar um número de informação cada vez maior. No entanto, para se obter esses novos dispositivos é necessário que se entenda melhor o processo estrutural destes materiais. Um dos sistemas vítreos que vem se apresentando como promissor na preparação de novos dispositivos ópticos é aquele que possui na sua constituição compostos fluoretos. A versatilidade da relação composição/propriedades é a principal responsável pela importância destes materiais, uma vez que variando a composição pode-se obter as características desejadas (propriedades ópticas, resistência à ataques químicos e a vitrificação). Um exemplo importante é a obtenção de vitrocerâmicas dopadas com íons terras-raras nas quais esses íons apresentam-se preferencialmente na fase cristalina, composta por fluoretos de metais pesados, dispersa em uma matriz vítrea formada por óxidos. Os vidros fluoretos possuem baixas energias dos modos vibracionais e com isso uma maior eficiência das emissões dos íons terras-raras. Portanto as aplicações tecnológicas envolvem fibras ópticas, lasers, amplificadores ópticos entre outras. A condutividade de natureza iônica desses materiais é também de grande interesse tecnológico na construção de baterias de estado sólido. Diante desse amplo interesse tecnológico surgiu um grande estudo experimental desses vidros fluoretos que foi escopo das teses de doutorado de Silva [21] e Bueno $[22]$

Neste contexto o tema desta tese é a modelagem do comportamento estrutural e das propriedades físicas de sistemas contendo os fluoretos $P b F_{2}$ e $C d F_{2}$ sob condições variadas, utilizando simulações por DM. A combinação de um simples e bastante efetivo potencial interatômico com a técnica de DM produziu excelentes resultados na investigação de sistemas contendo os fluoretos $\mathrm{PbF}_{2}$ e $C d F_{2}$ e contribuiu para o entendimento dos processos 
microscópicos que ocorrem nestes materiais.

Experimentalmente soluções sólidas contendo os fluoretos $\mathrm{PbF}_{2}$ e $C d F_{2}$ foram identificadas após tratamento térmico na amostra de vidros desses materiais [21]. No presente trabalho, o primeiro objetivo foi a simulação da parte estrutural dessas soluções sólidas. Soluções sólidas formadas por fluoretos de Cádmio e Chumbo possuem altos índices de difusão aniônica (Flúor) e devido a sua extraordinária condução aniônica são chamados de materiais superiônicos. O segundo objetivo dessa tese foi estudar a superionicidade dessas soluções sólidas. Na sequência estudou-se a fusão desse sistema e a dependência da temperatura de fusão como função da concentração de $C d F_{2}$. Após a fusão foi obtido um líquido de composição homogênea que quando resfriado a diferentes taxas resultou em vidros homogêneos, vidros com separação de fase e cristais com separação de fase. O reaquecimento desses sistemas também foi simulado e todos os detalhes das simulações estão no capítulo 3 onde serão mostrados os resultados das simulações.

O texto está organizado em 4 capítulos. No capítulo 2, é descrito a modelagem matemática utilizada. A técnica de simulação por DM é discutida em seus aspectos essenciais, discorrendo sobre as condições iniciais da simulação, sobre os procedimentos padrões, tais como, a implementação das condições periódicas de contorno e as equações de movimento para diferentes ensembles. Também é feita uma descrição com as principais idéias sobre o potencial empírico. E por último, são mostradas algumas propriedades físicas que podem ser calculadas a partir das simulações. No capítulo 3, o sistema de interesse é apresentado e são discutidos os resultados obtidos e mostrada a comparação com dados experimentais. No capítulo 4 são sintetizados os resultados principais dos trabalhos e discutidas as perspectivas futuras. 


\section{Capítulo 2}

\section{Modelagem Matemática}

A pesquisa envolvendo simulação computacional começa com a escolha do modelo matemático adequado, o qual deve descrever o maior número de propriedades dos materiais os quais se tem interesse. Quanto melhor o modelo, maior será o número de resultados quantitativos e mais próximo da realidade pode-se chegar. O modelo matemático usado nesta tese é a representação das interações atômicas através de um potencial efetivo de pares. As equações que surgem desta modelagem são resolvidas pela técnica de simulação DM. Nas próximas seções serão feitas explanações com os principais constituintes do modelo onde também serão elucidados: o método de DM, o algoritmo de integração e a implementação para diferentes ensembles. Para o leitor com interesse em uma discussão mais detalhada serão indicadas as referências.

\subsection{Dinâmica Molecular}

A técnica computacional conhecida como DM é hoje uma ferramenta padrão de estudo em vários campos da ciência, como a física da matéria condensada, ciência dos materiais, química, etc. Ela consiste em seguir a evolução temporal de um conjunto de partículas, que interagem de acordo com um certo potencial de interação. As equações de movimento 
das partículas são integradas numericamente e, com isto, a trajetória no espaço de fase é obtida e quantidades físicas podem ser calculadas a partir das informações microscópicas. Como na maioria dos casos, os átomos podem ser tratados como partículas clássicas, com massa e carga elétrica, pode-se utilizar a técnica de DM para simular o comportamento da maioria dos sistemas físicos.

A simulação computacional teve o seu primórdio no ano de 1953 com Metropolis [25] e o método Dinâmica Molecular com Alder e Wainwright [26] que em 1957 estudaram um sistema de esferas rígidas. Neste sistema as partículas movem-se com velocidade constante entre colisões perfeitamente elásticas. Alder e Wainwright descobriram a existência de uma transição de fase sólido-líquido neste sistema. Hoje esta transição é conhecida como a transição Alder e é importante, pois mostra que um sistema sem força atrativa pode ter uma fase coesa. A primeira aplicação do método de DM ao estudo de materiais foi feita por Vineyard et al. [27] através da investigação do processo de dano no material por radiação usando um potencial repulsivo de curto alcance e um potencial responsável pela coesão do cristal. Em seguida, Rahman [28] foi o primeiro a investigar sistemas descritos por potenciais contínuos simulando o argônio líquido. Foi surpreendente observar que um sistema com um número reduzido de partículas poderia reproduzir satisfatoriamente as propriedades termodinâmicas de sistemas reais. Alguns dados da parte histórica da DM podem ser encontrados no livro de Leach[29]. Ainda sobre a história e uma coletânia de artigos sobre a aplicação de DM em sólidos podem ser encontradas no artigo de Rino e Studart [2].

Para o sistema estudado por Rahman [28], alguma aproximação deve ser utilizada na integração das equações de movimento, pois as partículas movem-se sob a ação de um potencial contínuo e portanto a força resultante em cada uma delas muda continuamente. Sob a influência de um potencial contínuo os movimentos de todas as partículas 
são acoplados, originando um problema de muitos corpos que não pode ser resolvido analiticamente. É necessário uso de métodos núméricos para discretizar as equações de movimento e então integrá-las. A partir deste trabalho, sistemas com potencial de interação de Lennard-Jones passaram a ser intensamente investigados através desta técnica, a começar pelos trabalhos de Verlet [30, 31] e Nicolas et al. [32].

Após essa etapa, a simulação computacional desenvolveu-se rapidamente e surgiram aplicações em sistemas atômicos [33, 34], seguido por trabalhos sobre moléculas diatômicas (água) [35].

A partir da década de 70, com o desenvolvimento de computadores de alta velocidade e de menor custo, o uso das simulações por DM foi popularizado e estendido a uma infinidade de problemas. Encontra-se na literatura aplicações de DM em vários campos, desde o estudo de líquidos monoatômicos até grandes e complicadas moléculas, como as proteínas, passando pelo estudo de hidrocarbonetos flexíveis, condutores superiônicos, superfícies, interfaces, entre outros $[36,37,38,39,40]$. Na década de 90, o aumento progressivo na velocidade dos computadores e o uso de processamento paralelo tornaram possível a simulação de sistemas com milhões de partículas $[41,42,43,44,45]$, o que viabilizou, por exemplo, o estudo de materiais porosos e a propagação de quebras em materiais, nos quais o número de átomos que constituem o sistema é muito importante.

Uma série de referências é indicada para um leitor com interesse em saber mais do método. Para um nível introdutório a indicação é o livro de Haile[46], e para um leitura mais completa as três referências mais indicados são os livros de Allen \& Tildesley[47], Rapaport[48], e Frenkel \& Smit[49]. 


\subsection{O potencial empírico}

A expressão mais geral para a energia de coesão de um cristal formado de $N$ íons com parâmetro de rede $R$ pode ser dada como uma soma de contribuições de um corpo, dois corpos e termos de mais alta ordem se necessário:

$$
\mathbf{E}(\mathbf{R})=\sum_{i=1}^{N} E_{i}(R)+\sum_{i<j}^{N} V\left(r_{i j}\right)+\ldots
$$

As contribuições de um - corpo dependem exclusivamente das posições atômicas e representam os efeitos da aplicação de um campo externo. As interações de dois - corpos são representadas pelos potenciais empíricos de pares os quais tem sido uma excelente aproximação para descrever a interação entre os átomos. Em alguns casos são necessárias as contribuições de três - corpos as quais permitem modelar sistemas compostos por átomos com a camada eletrônica incompleta, nos quais são encontradas fortes ligações localizadas (ligações covalentes).

A área de Mecânica Quântica aplicada à Ciência dos Materiais exige métodos numéricos sofisticados, um esforço computacional incomensurável para simulações realísticas, paralelismo em larga escala, etc. Porém são imprescindíveis quando se trata de materiais onde a distribuição eletrônica ou a ligação química em torno do átomo muda significativamente durante os movimentos dos átomos que são de interesse na simulação. Por outro lado, uma grande quantidade de materiais pode ser simulada e muitas de suas propriedades dinâmicas interpretadas em termos dos movimentos de seus constituintes que interagem entre si através de potenciais efetivos dependentes explicitamente de suas posições nucleares. Estes potenciais interatômicos são muitas vezes chamados de potenciais empíricos, clássicos ou ainda analíticos. Não existe um método prático que diga qual o potencial efetivo de cada material que se deseja simular. Estes potenciais podem ser construídos com uma boa intuição física em termos das distribuições de carga e características químicas dos átomos envolvidos. Neste caso, o velho e tradicional método 
da Dinâmica Molecular Clássica ainda se constitui numa poderosa ferramenta na investigação das propriedades de materiais numa extensa classe que inclui, dentre outros, os materiais estruturais cerâmicos (sólidos iônicos, óxidos, silicatos), vidros e mesmo supercondutores de alta temperatura crítica [2]. Toda a essência de uma simulação usando DM está inserida no potencial empírico. Usualmente é a parte mais trabalhosa de uma simulação.

A simulação usando DM depende somente do conhecimento da lei de força interatômica. As grandezas físicas de interesse em um sistema resultantes de uma formulação teórica podem agora ser calculadas na simulação usando DM. O experimento de computador, como é chamada a simulação por muitos autores, é completamente independente de qualquer teoria [51]. Portanto, o potencial de interação é a parte fundamental na DM e determina o quão realista será a simulação. Segundo Brenner [20], para ser realista e eficaz um potencial interatômico efetivo deve possuir as seguintes propriedades:

1. Flexibilidade: O potencial deve ser suficientemente flexível tal que forneça resultados que possibilitem a comparação a um grande número de dados experimentais. Em sistemas sólidos, esses dados podem compreender a constante de rede cristalina, energia coesiva, propriedades elásticas, energia de formação de vacância e energia de superfície.

2. Precisão: O potencial deve ser capaz de reproduzir precisamente um dado experimental. Não apenas qualitativamente mas quantitativamente.

3. transferabilidade: O potencial deve ser capaz de descrever pelo menos qualitativamente, se não com precisão quantitativa, propriedades não incluídas no ajuste do potencial de interação.

4. Eficiência Computacional: A evolução da simulação deve ser relativamente eficiente dependendo de quantidades tais como tamanho do sistema e escalas de tempo de interesse, bem como do poder computacional disponível. 
Seguindo os requesitos de Brenner conclui-se que um bom potencial é aquele em que se utiliza de alguns dados experimentais para a sua construção e depois de construido ele fornece uma série de resultados adicionais sobre o sistema. Na seção de resultados será mostrado que o potencial proposto satisfaz os 4 quesitos de Brenner. Para o caso de estudo desta tese a transferabilidade do potencial proposto permitiu simular o sistema misto composto por $C d F_{2}$ e $P b F_{2}$ para todas as concentrações desejadas entre 0 e $100 \%$ de $C d F_{2}$. O primeiro passo foi determinar os parâmetros do potencial que descreve-se o $C d F_{2}$. O segundo passo foi então simular o $P b F_{2}$, que foi feito utilizando o potencial proposto por Walker [50]. Ambos ajustados com base em dados experimentais. Com os dados destes dois potenciais isolados, foi feito uso da transferabilidade e proposto o potencial mais geral que descreve o sistema misto de três componentes que contém Cádmio, Chumbo e Flúor sem necessitar de nenhum parâmetro adicional experimental para o ajuste ou alteração da expressão funcional do potencial original. O potencial proposto descreve de maneira brilhante o sistema misto, para qualquer concentração desejada dos cátions, incluindo resultados quantitativos conforme será mostrado nas seções seguintes. Se mostrou adequado tanto na descrição das propriedades estáticas quanto dinâmicas. Foi possível descrever tanto os cristais quanto o líquido e até mesmo o estado vítreo. Além das separações de fase ou homogeneidades do sistema quanto submetido a diferentes condições físicas.

Como Brenner [20] diz em seu artigo, o processo de construção de um potencial frequentemente requer um certo nível de discernimento da intuição química, muita tentativa e erro, e bastante persistência. Devido a não existir uma rigorosa metodologia nesse processo com o qual todos os sistemas possam ser ajustados, ele é frequentemente chamado de "arte".

As simulações atomísticas usando o método da DM usam potenciais empíricos de pares 
para descrever a interação entre as moléculas, que são uma conveniente forma funcional com parâmetros ajustados por dados experimentais ou obtidos de cálculos quânticos. O potencial de pares proposto e utilizado nesta tese inclui várias contribuições como as interações Coulombianas resultantes da transferência de carga entre íons, a repulsão estereométrica devido aos tamanhos atômicos dos mesmos, e interações de dipolo-dipolo para incluir os efeitos da polarizabilidade eletrônica dos átomos.

O sistema é formado por uma coleção de íons não superpostos que são mantidos juntos devido as interações acima mencionadas. A palavra íon deve ser interpretada aqui no sentido de que as ligações são majoritariamente iônicas, mas não necessariamente correspondem ao caso iônico extremo [2]. No caso da DM clássica, a carga do íon pode ser um pouco diferente do valor encontrado na tabela periódica no intuito de incluir essa parcialidade. Em simulações quânticas esta transferência parcial de carga é obtida naturalmente.

A forma funcional do potencial utilizado para o presente trabalho é chamada de potencial de Buckingham e é expresso por:

$$
V_{i j}\left(r_{i j}\right)=\frac{q_{i} q_{j}}{r_{i j}}+A_{i j} \exp \left(-\frac{r_{i j}}{\rho i j}\right)-\frac{C_{i j}}{r_{i j}^{6}}
$$

onde $i$ e $j$ denotam as espécies de íons e $r_{i j}$ é a distância entre eles. O primeiro termo representa a interação de Coulomb com $q_{i}$ e $q_{j}$ sendo as cargas efetivas dos íons. Os valores das cargas dos íons são parâmetros ajustáveis no modelo uma vez que a carga iônica não é precisamente determinada e é considerado um valor efetivo. Para pequenas distâncias, as camadas eletrônicas dos átomos começam a se sobrepor, e como decorrência do princípio de exclusão de Pauli, surge uma forte interação repulsiva que cresce drasticamente quando a distância entre os íons decresce e diminui rapidamente quando $r_{i j}$ aumenta. Essa repulsão estereométrica é expressa pelo segundo termo do potencial, sendo a intensidade $A_{i j}$ um parâmetro ajustável do modelo e o raio iônico $\rho_{i j}$ conhecido na literatura. Finalmente o 
terceiro termo considera as interações de van der Waals (forças causadas por deformações mútuas de átomos e moléculas). Apesar de sua origem dever-se essencialmente a efeitos quânticos (a existência de uma energia de nível zero finita) são comumente descritas em termos da interação clássica dipolo-dipolo induzida pelas polarizações produzidas pelos íons. A intensidade da interação é diretamente proporcional às polarizabilidades $C_{i j}$ que são conhecidas na literatura.

Nas figuras 2.1, 2.2 e 2.3 é feita uma ilustração qualitativa de cada um dos termos do potencial de Buckingham proposto para o $\mathrm{PbF}_{2}$. Na figura 2.1 é mostrado o termo coulombiano dos pares $i j$, mostrando a repulsão para átomos de mesma carga e a atração para átomos com cargas contrárias. Para o caso do sistema misto contendo $\mathrm{PbF}_{2}$ e $\mathrm{CdF} F_{2}$ embora os outros termos tenham magnitudes diferentes as curvas apresentam o mesmo comportamento. Assim os pares $\mathrm{CdCd}$ e $\mathrm{CdPb}$ apresentam repulsões parecidas com a do $\mathrm{PbPb}$ e do $\mathrm{FF}$ e o par $\mathrm{CdF}$ tem comportamento atrativo semelhante ao do $\mathrm{PbF}$.

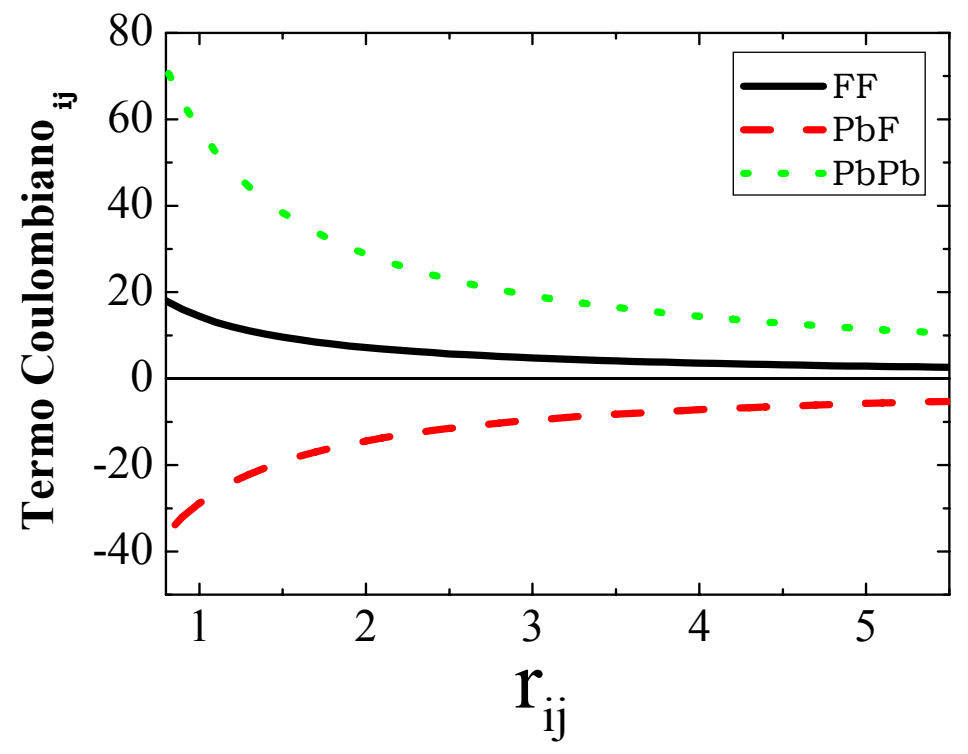

Figura 2.1: Termo Coulombico do potencial de pares para o $P b F_{2}$. A linha contínua representa a repulsão dos pares FF. A linha pontilhada representam a atração $\mathrm{PbF}$ e os pontos representam a repulsão dos pares $\mathrm{PbPb}$.

A Figura 2.2 mostra o segundo termo do potencial de Buckingham, chamado de termo 
estereométrico que é repulsivo e contribui para que o sistema não colapse.

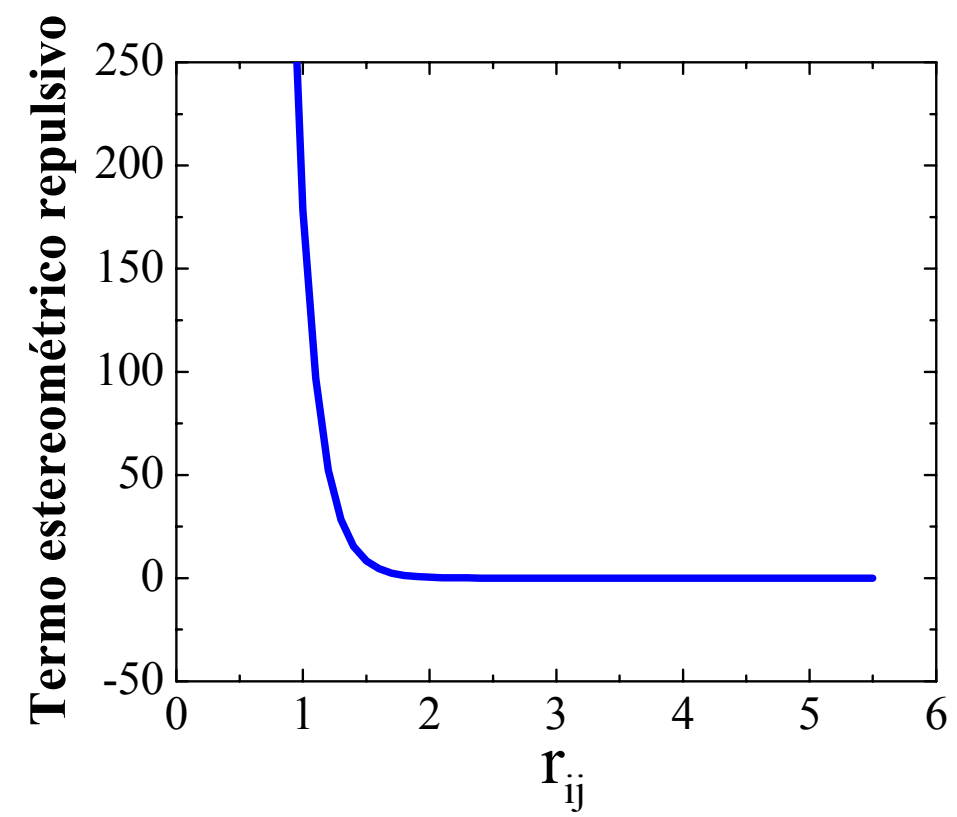

Figura 2.2: Termo estereométrico do potencial de pares para o $P b F_{2}$.

Na figura 2.3 o terceiro termo do potencial de Buckingham é ilustrado e é possível notar seu comportamento de curto alcance.

O potencial de Buckingham para um dado par $i j$ do sistema $P b F_{2}$ está ilustrado na figura 2.4 mostrando a soma dos seus três termos apresentados anteriormente (Fig. 2.1, 2.2 e 2.3$)$

Existem outros termos que podem ser adicionados ao potencial dependendo do material que se queira descrever. Existem também outras propostas de expressar a repulsão estereométrica que são bem discutidos no artigo de Rino e Studart [2] onde se tem também as referências para uma discussão mais ampla da justificativa de cada termo do potencial.

O cálculo da força resultante em cada partícula e da energia potencial em cada passo da integração das equações de movimento é a parte que requer o maior tempo computacional numa simulação por DM. Esse cálculo é efetuado geralmente dezenas de milhares de vezes, constituindo a essência da simulação. Tomando um potencial de interação de dois corpos 


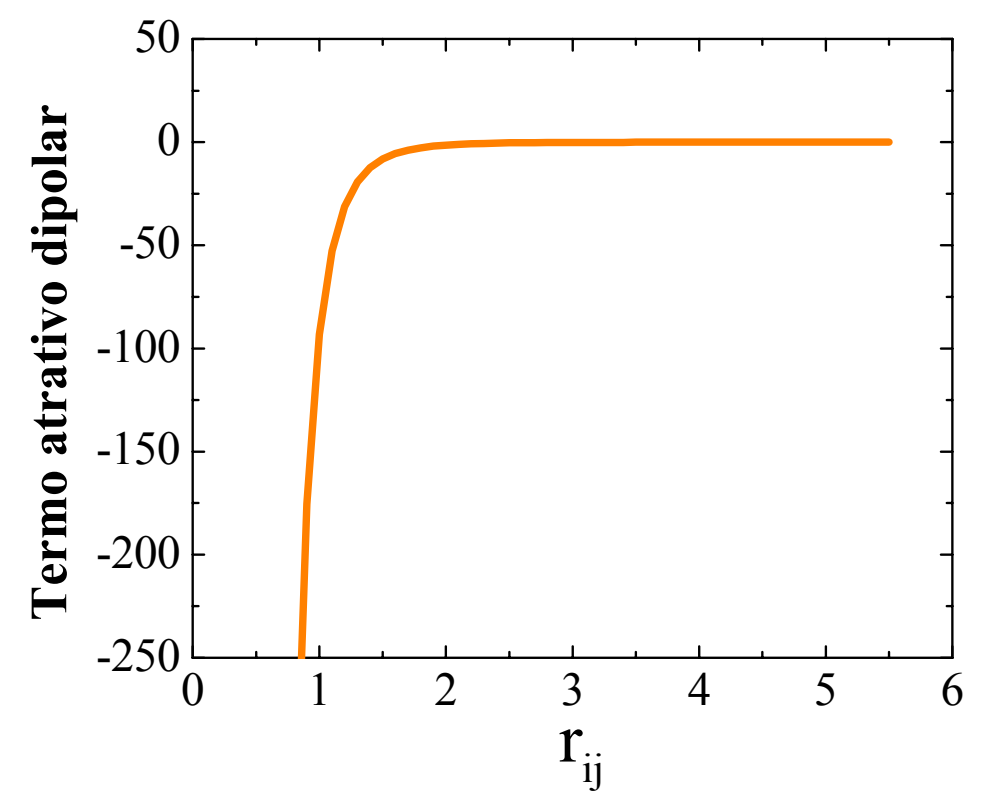

Figura 2.3: Termo dipolar do potencial de pares para o $\mathrm{PbF}_{2}$.

$V\left(r_{i j}\right)$, a energia potencial total, será dada por:

$$
U=\left(\sum_{i=1}^{N-1} \sum_{j=i+1}^{N} V\left(\left|\mathbf{r}_{i j}\right|\right)\right)
$$

e a força em cada partícula por

$$
F_{i}=-\left(\sum_{j=1}^{N} \nabla_{r_{i j}} V\left(\left|\mathbf{r}_{i j}\right|\right)\right)
$$

Os termos que compõem o potencial podem ser classificados em de curto alcance e longo alcance. No livro de Allen \& Tildesley [47] a força de longo alcance é definida como uma função que vai a zero lentamente com um decaimento do tipo $1 / r^{d}$ onde $d$ é a dimensionalidade do sistema. Uma maneira alternativa de quantificar o longo alcance é a definição do livro de Frenkel \& Smith [49]. Eles avaliam a energia desprezada quando se usa o raio de corte. A energia pode ser escrita em termos da função de correlação de pares, $g(r)$, pela seguinte expressão: 


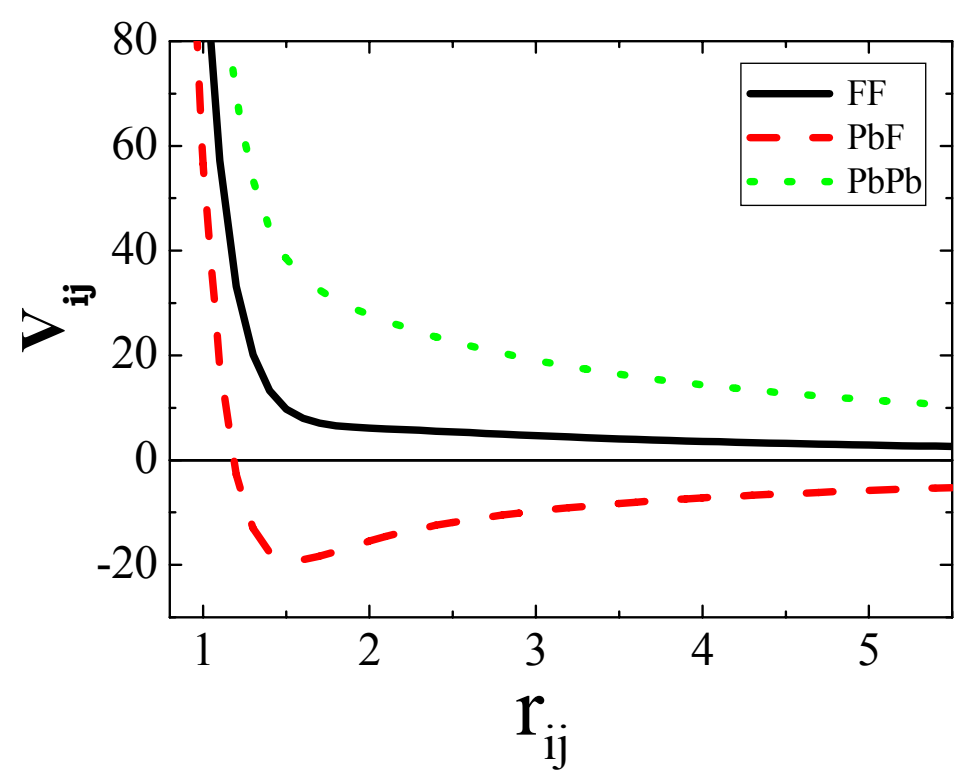

Figura 2.4: Potencial de Buckingham dos pares ij para o $\mathrm{PbF}_{2}$.

$$
E=\frac{N \rho}{2} \int_{0}^{\infty} d r u(r) g(r) 4 \pi r^{2}
$$

onde $N$ é o número total de partículas, $\rho$ é densidade de partículas e $u(r)$ é o termo do potencial de pares a ser avaliado. Desejando-se desprezar a energia a partir de um certo raio de corte, pode-se realizar a integração acima com o limite inferior sendo o raio de corte, o superior sendo infinito e considerar a $g(r)$ com o valor unitário para longas distâncias e então avaliar o que está sendo desprezado. Note que se $u(r)$ for do tipo $1 / r$, $1 / r^{2}$ ou $1 / r^{3}$ a integral diverge e essa contribuição não pode ser desprezada, necessitando de um tratamento matemático mais adequado. Portanto as forças de curto alcance são do tipo $1 / r^{4}$ ou com decaimento mais rápido que esse.

A soma das forças de curto alcance pode ser realizada no espaço real e normalmente é convergente, sendo que os termos se tornam desprezíveis dentro de uma precisão desejada. No entanto, os termos de longo alcance os quais decaem lentamente com a distância necessitam de um tratamento diferente. Em particular, como o termo coulômbico fornece a 
maior contribuição para a energia do sistema ele necessita ser tratado com maior precisão. As contribuições para distâncias longas devem ser sempre incluídas nos cálculos, pois o alcance dessas forças pode compreender o comprimento de muitas células unitárias. Uma condição necessária para a convergência dessa soma é a de que o sistema seja eletricamente neutro. Mas ainda assim ela apresenta o problema de ser lentamente convergente. A série apresentada pelo termo de Coulomb converge apenas considerando-se infinitos termos. Uma solução para realizar essa soma com precisão seria aumentar a caixa de simulação para milhares de células unitárias mas isso torna a simulação impraticável. Em uma forma muito geral Leeuw, Perram e Smith[53][54] mostram em seus trabalhos que o problema de somar estes termos até o infinito não pode ser eliminado pelas condições de contorno. Uma outra maneira mais eficiente para otimizar a convergência dessa soma é através do método de Ewald[52]. Este método usa a teoria eletrostática e a periodicidade da rede para reescrever a soma original dos termos coulombianos. O inverso da distância é reescrito como uma transformada de Fourier e então se divide em duas séries que convergem condicionalmente, uma no espaço recíproco e a outra no espaço real. Os detalhes matemáticos e dicas para a implementação podem ser vistos de uma maneira bem didática e com muitos detalhes no livro de Frenkel \& Smith[49] e de uma maneira mais sintética no livro de Allen \& Tildesley[47].

No método de Ewald, cada carga puntual é circundada por uma distribuição de carga gausssiana de igual magnitude e sinal oposto. Essa distribuição extra age como uma atmosfera iônica, para blindar a interação entre cargas vizinhas e por isso recebe o nome de função de blindagem. Essa interação blindada é agora de curto alcance e o potencial total blindado é calculado somando-se sobre todas as partículas da caixa central e todas as suas imagens. A natureza física do problema é expressa matematicamente na multiplicação por uma função de erro complementar. Deste modo, pode-se truncar a soma no espaço 
real em um determinado raio de corte. Entretanto, o interesse não é pelo potencial de um conjunto de cargas blindadas e sim de cargas puntuais. Para compensar a adição da função de blindagem, uma distribuição com sinal igual à carga original é adicionada, e esta é chamada de função compensadora. Este cancelamento das distribuições adicionais faz com que o potencial em todo o sistema se reduza a aquele devido a configuração de cargas original. O potencial devido a estas gaussianas é obtido a partir da equação de Poisson, a qual é resolvida como uma série de Fourier no espaço recíproco. As transformadas de Fourier das distribuições de cancelamento (uma para cada carga original) são adicionadas, e a transformada total é trazida de volta para o espaço real. Existe uma importante correção a ser feita: o método inclui a energia de auto-interação entre as partículas, a qual deve ser excluída. Existem três contribuições para a energia eletrostática: a primeira devido a carga puntual, uma segunda devido a interação entre a função de blindagem e a carga puntual, e finalmente uma devido a interação entre a função compensadora e a carga puntual. Para excluir a auto-interação coulombiana, não se deve incluir nenhuma dessas três contribuições para o potencial eletrostático na posição de um dado íon $i$. Portanto, o método de Ewald substitui a soma infinita no espaço real por duas somas finitas: uma no espaço real e outra no espaço recíproco e ainda a correção da alto-energia. Assim a energia coulombiana total fica escrita como:

$$
\begin{aligned}
U_{\text {coul }}= & \frac{1}{2 V \epsilon_{0}} \sum_{k \neq 0}^{\infty} \frac{\exp \left(-k^{2} / 4 \alpha^{2}\right)}{k^{2}}\left|\sum_{j=1}^{N} q_{j} \exp \left(-i \mathbf{k} \cdot \mathbf{r}_{j}\right)\right|^{2}+\frac{1}{4 \pi \epsilon_{0}} \sum_{i<j}^{N} \frac{q_{i} q_{j}}{r_{i j}} \operatorname{erf} c\left(\alpha r_{i j}\right) \\
& -\frac{\alpha}{4 \pi^{3 / 2} \epsilon_{0}} \sum_{j=1}^{N} q_{j}^{2}
\end{aligned}
$$

onde $N$ e $V$ são o número total de partículas e o volume do sistema respectivamente, k é o vetor da rede recíproca definido por: 


$$
\mathbf{k}=l \mathbf{u}+m \mathbf{v}+n \mathbf{w}
$$

onde $l, m, n$ são inteiros e $\mathbf{u}, \mathbf{v}, \mathbf{w}$ são os vetores da base no espaço recíproco. A função erf $c\left(\alpha r_{i j}\right)$ é a função erro complementar que vai a zero com o aumento de $r_{i j}$.

Na prática a convergência da soma de Ewald é controlada por três variáveis: o raio de corte no espaço real, o parâmetro de convergência (dispersão da carga) $\alpha$ e o maior vetor do espaço recíproco $K_{\max }$ usado na soma do espaço recíproco.

\subsection{Integração das equações de movimento}

Para se saber a posição e a velocidade das N partículas que constituem o sistema, deve-se integrar as 3N equações diferenciais de segunda ordem não lineares e acopladas, fornecidas pelas equações de Newton. Chamando de $V$ a energia potencial do sistema, $\mathbf{r}_{i}$ a posição da partícula i, $m_{i}$ sua massa e $\mathbf{f}_{i}$ a força atuando nela, tem-se:

$$
m_{i} \frac{d^{2} \mathbf{r}_{i}}{d t^{2}}=\mathbf{f}_{i}=-\nabla_{i} V
$$

sendo $\mathrm{i}=1,2,3, \ldots, \mathrm{N}$.

Não existe solução analítica para este sistema, mas pode-se resolvê-lo numericamente através de vários algoritmos obtidos a partir da expansão em série de Taylor para as posições e velocidades das partículas a tempos diferentes.

\subsubsection{O algoritmo de Verlet}

O algoritmo de integração de tempo mais comumente usado é provavelmente o algoritmo denominado Verlet. A idéia básica é escrever duas expansões de Taylor até terceira ordem para as posições, uma em $t+\Delta t$ e outra em $t-\Delta t$, onde $\Delta t$ é o incremento de tempo. Chamando $\mathbf{v}$ as velocidades, $\mathbf{a}$ as acelerações, e $\mathbf{b}$ as terceiras derivadas com 
respeito a $t$, tem-se:

$$
\begin{aligned}
\mathbf{r}(t+\Delta t) & =\mathbf{r}(t)+\mathbf{v}(t) \Delta t+(1 / 2) \mathbf{a}(t) \Delta t^{2}+(1 / 6) \mathbf{b}(t) \Delta t^{3}+o\left(\Delta t^{4}\right) \\
\mathbf{r}(t-\Delta t) & =\mathbf{r}(t)-\mathbf{v}(t) \Delta t+(1 / 2) \mathbf{a}(t) \Delta t^{2}-(1 / 6) \mathbf{b}(t) \Delta t^{3}+o\left(\Delta t^{4}\right)
\end{aligned}
$$

Adicionando 2.9 e 2.10 tem-se:

$$
\mathbf{r}(t+\Delta t)=2 \mathbf{r}(t)-\mathbf{r}(t-\Delta t)+\mathbf{a}(t) \Delta t^{2}+o\left(\Delta t^{4}\right)
$$

Desde que se esteja integrando as equações de Newton, $\mathbf{a}(t)$ é a força dividida pela massa, e a força é por sua vez uma função das posições $\mathbf{r}(t)$ :

$$
\mathbf{a}(t)=-(1 / m) \nabla U(r(t))
$$

Como se pode ver, na eq. 2.11 o erro do algoritmo é da ordem de $\Delta t^{4}$, uma vez que as derivadas ímpares desaparecem. Este algoritmo é ao mesmo tempo simples de implementar e preciso, o que explica sua grande popularidade, além de ser exatamente reversível no tempo e, utilizando forças conservativas, conservar o volume no espaço de fase[49].

Um problema com o algoritmo de Verlet é que as velocidades não são geradas diretamente. Embora elas não sejam imprescindíveis para a evolução temporal das posições, conhecê-las, torna-se necessário. Além disso, essas velocidades também são necessárias no cálculo da energia cinética $K$ cuja avaliação é importante para testar a conservação da energia total, $E=K+U$. Este é um dos testes mais importantes para verificar se a simulação está sendo feita corretamente. Subtraindo a eq. 2.9 de 2.10 tere-se a velocidade,

$$
\mathbf{v}(t)=\frac{\mathbf{r}(t+\Delta t)-\mathbf{r}(t-\Delta t)}{2 \Delta t}
$$

Porém, o erro associado a esta expressão é da ordem de $\Delta t^{2}$. Outro problema desse algoritmo é que o primeiro e o segundo termos na eq. 2.11 são de ordem $\Delta t^{0}$, ao passo que o terceiro é de ordem $\Delta t^{2}$. Esta adição de termos muito grandes com termos muito pequenos 
introduz erros numéricos que podem se acumular durante a simulação, podendo gerar erros consideráveis no resultado final. Para superar esta dificuldade, foram desenvolvidas algumas variantes do algoritmo de Verlet. Uma implementação melhorada do algoritmo básico é o algoritmo de meio passo "leap-frog". Ela é bastante simples, reversível no tempo e conserva a energia total, $E=K+U$. A idéia geral do "leap-frog"é estimar o valor da velocidade em $\frac{\Delta t}{2}$ a frente do tempo atual $\left(t+\frac{\Delta t}{2}\right)$ e usar esse valor para calcular a nova posição em $t+\Delta t$. Para deduzir o "leap-frog"usando o esquema de Verlet, é necesário definir as velocidades em $\frac{\Delta t}{2}$ antes e depois do tempo atual:

$$
\mathbf{v}\left(t-\frac{\Delta t}{2}\right)=\frac{\mathbf{r}(t)-\mathbf{r}(t-\Delta t)}{\Delta t}
$$

e

$$
\mathbf{v}\left(t+\frac{\Delta t}{2}\right)=\frac{\mathbf{r}(t+\Delta t)-\mathbf{r}(t)}{\Delta t}
$$

O primeiro passo do algoritmo é obter a velocidade em $t+\frac{\Delta t}{2}$ integrando a força:

$$
\mathbf{v}\left(t+\frac{\Delta t}{2}\right)=\mathbf{v}\left(t-\frac{\Delta t}{2}\right)+\Delta t \mathbf{a}(t)
$$

Uma vez que se conhece a posição no tempo $t$ e a nova velocidade em $t+\frac{\Delta t}{2}$, utiliza-se a eq. 2.15 para obter-se a nova posição em $t+\Delta t$ :

$$
\mathbf{r}(t+\Delta t)=\mathbf{r}(t)+\Delta t \mathbf{v}\left(t+\frac{\Delta t}{2}\right)
$$

Note que o "leap-frog"permite conhecer a posição e a velocidade mas não no mesmo tempo $t$. Após um passo obtém-se a posição em $t+\Delta t$ e velocidade em $t+\frac{\Delta t}{2}$. A velocidade no tempo $t$ é obtida de uma média das velocidades nos tempos $\frac{\Delta t}{2}$ antes e após $t$ :

$$
\mathbf{v}(t)=\frac{1}{2}\left[\mathbf{v}\left(t-\frac{\Delta t}{2}\right)+\mathbf{v}\left(t+\frac{\Delta t}{2}\right)\right]
$$


Uma grande vantagem do "leap-frog"é que as velocidades aparecem no cálculo das novas posições, o que torna o sistema acoplável a um banho térmico por correções nas velocidades.

Existe ainda uma série de outros métodos para se integrar numericamente as equações de movimento. Algumas implementações são também baseadas no algoritmo de Verlet, como "velocity-Verlet ". Outras são baseadas nos métodos "predictor-corrector "que essencialmente prediz as posições, velocidades e etc e depois as corrige fazendo uso da aceleração predita e da aceleração analítica. Esses métodos são amplamente discutidos e comparados no livro de Allen \& Tildesley[47]. Os livros de Frenkel \& Smith[49], e o do Rapaport[48] também discutem os métodos de integração numérica. Para um nível mais introdutório a indicação é o livro de Pang[55].

\subsection{Condições iniciais}

O primeiro passo para que se comece uma simulação por DM é estabelecer as condições iniciais do sistema de partículas envolvendo principalmente a densidade, a estrutura, suas posições e a temperatura entre outras. A escolha do número de partículas, $N$, é uma delas e talvez a mais crucial, pois se o número de partículas é grande, o esforço computacional será enorme. Para a escolha de $N$ deve ser levado em conta o poderio computacional e o tempo disponível de simulação. Dependendo do tipo de potencial e método utilizado ele pode crescer à ordem de $N, N^{2}$ ou $N^{3}$. Por outro lado, se $N$ é pequeno, o sistema pode não reproduzir de forma confiável a realidade e os resultados deixarão de ser confiáveis. Geralmente, nas simulações por DM, $N$ é da ordem de $10^{3}$ a $10^{9}$, dependendo do sistema em questão e das propriedades a serem estudadas. Feita a escolha de $N$, o volume $V$ da caixa de simulação deve ser escolhido de modo a obter a densidade desejada. Escolhido $N$ e $V$, as partículas devem ser então distribuídas na caixa 
de simulação. A maneira mais fácil de fazer isto é adotando uma distribuição aleatória dentro da caixa. Contudo, a maneira usual é começar a simulação de uma rede periódica, já que a distribuição aleatória pode apresentar inconvenientes quando as partículas são distribuídas muito próximas umas das outras, causando erros na integração das equações de movimento. Além disto, a distribuição aleatória não representa uma configuração de equilíbrio para a maioria dos sistemas. A rede periódica a ser montada pode então ser escolhida a partir de informações prévias do sistema a ser estudado. Se a simulação for realista os primeiros resultados quantitativos decorrentes da escolha correta da estrutura e da densidade para um cristal, por exemplo, são os parâmetros de rede, comprimentos de ligação e distribuição de ângulos. A temperatura também deve ser escolhida, bastando para tanto, fixar a velocidade das partículas de acordo com uma distribuição de velocidades qualquer e posteriormente escalar tais velocidades, de modo a atingir a temperatura desejada. A temperatura do sistema se relaciona com as velocidades através do teorema da equipartição dada por:

$$
T=\frac{1}{d N k_{B}} \sum_{l=1}^{N} m_{l} \mathbf{v}_{l}^{2}
$$

sendo $k_{B}$ a constante de Boltzmann, $d$ a dimensão do sistema e $N, m$ e v o número total, a massa e a velocidade das partículas [49]. Através desta relação pode-se alterar uma temperatura inicial $T_{i}$ do sistema para uma temperatura final $T_{f}$, bastando para tanto multiplicar as velocidades pelo fator $\alpha=\sqrt{\frac{T_{i}}{T_{f}}}$. Não há grande preocupação quanto a distribuição de velocidades, pois com as colisões das partículas, em algumas centenas de passos a distribuição de Maxwell-Boltzmann é retomada.

Uma escolha importante que também deverá ser feita é a do incremento temporal usado na integração das equações de movimento. Esta escolha deverá refletir em uma boa conservação de energia e conseqüente estabilidade na integração das equações. Em geral, o $\Delta t$ varia de $10^{-9}$ a $10^{-15}$ segundos, o que garante uma conservação na energia de 
1 parte em $10^{4}$ sobre milhares de passos de integração.

\subsection{Condições periódicas de contorno}

Para estudar um sistema usando DM, deve-se tomá-lo como sendo finito, o que é feito usando uma caixa de volume $V$. Em princípio, pode-se fazer a simulação considerando uma caixa com paredes rígidas, estabelecendo um potencial que mantenha as partículas confinadas. Contudo, os efeitos de confinamento que aparecem da interação das partículas com as paredes da caixa de simulação podem predominar em sistemas pequenos. Esse problema se deve, essencialmente, a grande fração de partículas em contato com as paredes desta caixa. Considerando um sistema bidimensional de 100 partículas em uma caixa quadrada, por exemplo, cerca de 40 partículas estarão sempre em contato com as paredes e sofrendo um potencial distinto daquele sentido pelo resto das partículas. Os efeitos gerados nessa fração grande de partículas estendem-se por todo o sistema modificando as propriedades que seriam obtidas com o sistema no limite termodinâmico. Quando o estudo desses efeitos não é de interesse, é usual contorná-los usando condições periódicas de contorno (CPC). Em um sistema com CPC, tem-se a caixa original com $N$ partículas e réplicas desta em todas as direções possíveis de acordo com a dimensão do sistema. A caixa original não apresenta paredes e não existem partículas superficiais. Conforme uma partícula deixa a caixa original, uma de suas imagens entra instantaneamente pelo lado oposto mantendo o número de partículas constante. A posição das partículas no sistema passa a ser

$$
\mathbf{r}_{i}+\mathbf{m}
$$

com $\mathbf{m}=\left(m_{x} L_{x}, m_{y} L_{y}, m_{z} L_{z}\right), m_{i}$ inteiro e $L_{i}$ os lados da caixa de simulação. A Fig. 2.5 torna clara a idéia de um sistema com CPC em 2 dimensões. Em três dimensões, as partículas poderiam passar por qualquer uma das seis faces da caixa cúbica. 


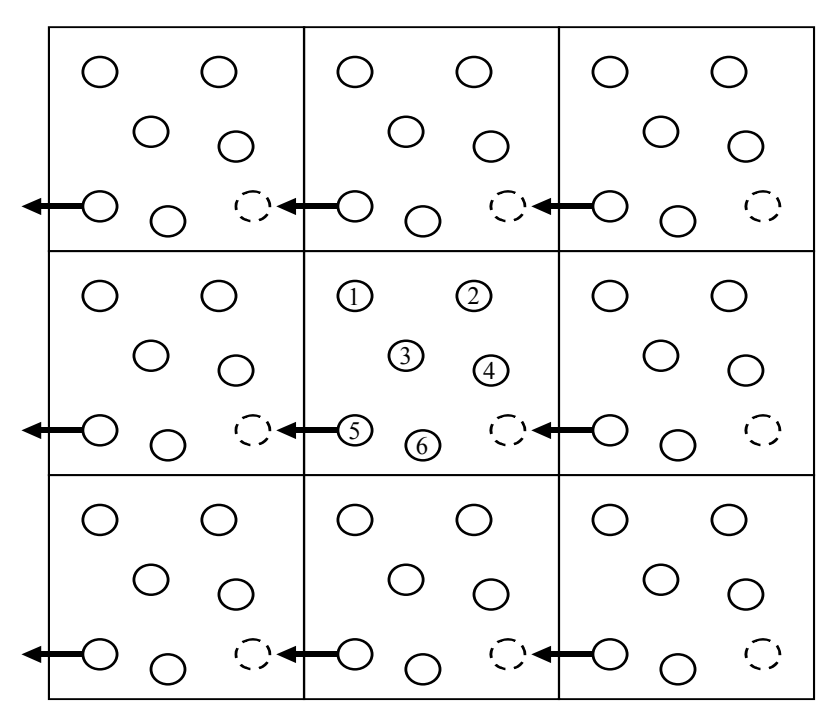

Figura 2.5: Sistema periódico em duas dimensões. As partículas podem entrar e sair pelas quatro paredes da caixa.

Com o uso de CPC em DM, os cálculos da força e energia potencial para cada partícula $i$ no sistema devem ser feitos considerando suas interações com todas as $N-1$ partículas vizinhas na caixa de simulação, além das infinitas partículas imagens nas caixas vizinhas. Pode-se, no entanto, restringir esta soma infinita se o potencial de interação é de curto alcance introduzindo um raio de corte neste potencial, a partir do qual este pode ser desprezado. Considere uma região fictícia, centrada na posição de uma partícula $i$ qualquer, com mesma forma e volume da caixa de simulação, como mostrado no caso de duas dimensões na Fig. 2.6. O cálculo da força e energia potencial são então realizados considerando apenas $N-1$ termos, correspondente às imagens mais próximas das partículas. Esta técnica é conhecida como convenção de imagem mínima. Para os casos em que o potencial não é de curto alcance outros tratamentos são propostos para realizar essa soma infinita e um deles é método da soma de Ewald mostrado anteriormente. 


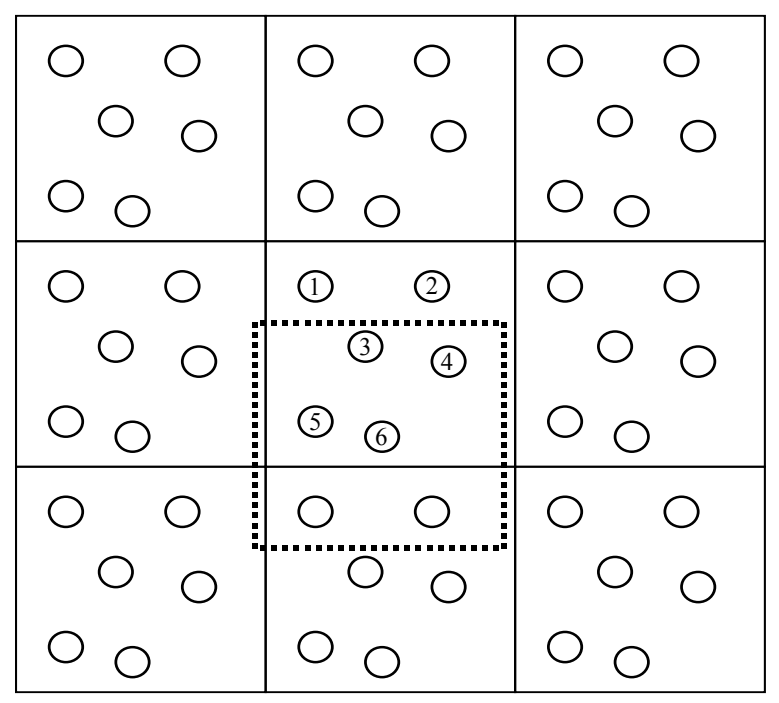

Figura 2.6: A convenção de imagem mínima em duas dimensões. A caixa montada ao redor da partícula 6 mostra as partículas que serão consideradas no cálculo da sua força e energia potencial.

\subsection{Algoritmos para outros ensembles}

Além do ensemble micro-canônico $(N, V, E)$, que corresponde fisicamente a um sistema isolado, existem também outros como o ensemble canônico $(N, V, T)$, que corresponde a um sistema fechado mas não isolado, o ensemble isotérmico isobárico $(N, P, T)$, que corresponde a um sistema fechado mas que pode realizar trabalho mecânico, entre outros que não são de interesse para o presente trabalho.

Da ligação entre a mecânica estatística com a termodinâmica nos é permitido concluir que no limite termodinâmico $(N \rightarrow \infty, V \rightarrow \infty, N / V=$ constante) as médias das várias propriedades são independentes do ensemble escolhido para o cálculo dessa propriedade. Deste modo, no que concerne o cálculo de médias de propriedades de primeira ordem obtidas diretamente como somas sobre as propriedades moleculares, a escolha do ensemble em que se deseja trabalhar é apenas uma questão de conveniência. No entanto, as flutuações das diferentes propriedades variam com o ensemble escolhido e deste modo as propriedades de segunda ordem que são obtidas a partir das flutuações das de primeira 
ordem variam com o ensemble[47].

Nas subseções seguintes será mostrada uma visão geral da implementação dos diferentes ensembles na física computacional. Inicialmente, a discussão se restringi ao ensemble microcanônico (NVE), tendo assim o número de partículas $\mathrm{N}$, o volume $\mathrm{V}$ e a energia $\mathrm{E}$ sempre fixos. Na sequência, é discutida a simulação em outros ensembles.

\subsubsection{Ensemble NVT}

Frequentemente as propriedades do sistema estudado são desejadas para diferentes conjuntos de restrições. Nesta seção será elucidado o caso em que é preferível ter a informação a temperatura constante ao invés de energia constante. Isso pode ser realizado de diferentes maneiras. A primeira maneira foi proposta por Andersen[60] onde simplesmente periodicamente se reescala as velocidades das partículas do sistema tal que a energia cinética total se mantenha constante. Esse método pode ser implementado de maneira estocástica na qual as velocidades de partículas escolhidas aleatoriamente são alteradas usando a distribuição Maxwell-Boltzmann. Isso corresponde a um contato com um banho térmico imaginário de partículas. Com esse intuito de manter a temperatura constante idéias mais refinadas utilizando DM surgiram em 1984 com Nosé[14, 15]. Ele propõe um termostato que adiciona um grau de liberdade ao sistema para fazer o papel de reservatório térmico. A simulação passa a envolver a integração temporal das equações de movimento para esse sistema estendido incluindo essas coordenadas e velocidades artificiais. O sistema estendido tem $6 N+2$ graus liberdade, sendo $3 N$ relacionados as posições e $3 N$ as velocidades das partículas, um grau de liberdade associado a coordenada adicional proposta por Nosé e um grau associado ao momento conjugado dessa coordenada adicional. O sistema estendido permite extrair ou introduzir energia do reservatório mantendo a temperatura do sistema fixa. O esquema de Nosé tem uma formulação generalizada a- 
presentada por Hoover[16, 17] que dá origem ao mais usado dos termostatos que recebeu o nome de Nosé-Hoover. As equações de movimento são então diferentes das expressões originais do ensemble microcanônico:

$$
\begin{aligned}
\frac{d \mathbf{r}(t)}{d t} & =\mathbf{v}(t) \\
\frac{d \mathbf{v}(t)}{d t} & =\frac{\mathbf{f}(t)}{m}-\chi(t) \mathbf{v}(t),
\end{aligned}
$$

onde, $\chi$, é chamado de coeficiente de atrito do termostato e é expresso pela equação diferencial de primeira ordem:

$$
\frac{d \chi(t)}{d t}=\frac{N_{f} k_{B}}{Q}\left(\Gamma(t)-T_{r e q}\right)
$$

onde $Q=N_{f} k_{B} T_{r e q} \tau_{T}^{2}$ é a "massa"efetiva do termostato, $\tau_{T}$ é uma constante específica de relaxação temporal, $T_{r e q}$ é a temperatura requerida, $\Gamma(t)$ é a temperatura instantânea, $N_{f}$ são os graus de liberdade do sistema e $k_{B}$ é a constante de Boltzmann. A integração utilizando o algoritmo de Verlet "leap-frog"passa a ser escrita como:

$$
\begin{aligned}
\chi\left(t+\frac{1}{2} \Delta t\right) & =\chi\left(t-\frac{1}{2} \Delta t\right)+\frac{\Delta t N_{f} k_{B}}{Q}\left(\Gamma(t)-T_{r e q}\right), \\
\chi(t) & =\frac{1}{2}\left[\chi\left(t-\frac{1}{2} \Delta t\right)+\chi\left(t+\frac{1}{2} \Delta t\right)\right] \\
\mathbf{v}\left(t+\frac{1}{2} \Delta t\right) & =\mathbf{v}\left(t-\frac{1}{2} \Delta t\right)+\Delta t\left[\frac{\mathbf{f}(t)}{m}-\chi(t) \mathbf{v}(t)\right], \\
\mathbf{v}(t) & =\frac{1}{2}\left[\mathbf{v}\left(t-\frac{1}{2} \Delta t\right)+\mathbf{v}\left(t+\frac{1}{2} \Delta t\right)\right] \\
\mathbf{r}(t+\Delta t) & =\mathbf{r}(t)+\Delta t \mathbf{v}\left(t+\frac{1}{2} \Delta t\right) .
\end{aligned}
$$

A quantidade conservada é obtida do Hamiltoniano estendido para o sistema o qual, mantém constante, a energia livre de Helmholtz: 


$$
F_{N V T}=U+K+\frac{1}{2} Q \chi(t)^{2}+\frac{Q}{\tau_{T}^{2}} \int_{0}^{t} \chi(s) d s
$$

onde $U+K=H_{N V E}$ é o Hamiltoniano do ensemble micro-canônico.

\subsubsection{Ensemble NPT}

Continuando a utilizar a idéia de método do sistema estendido, pioneiramente apresentado por Andersen[60], nesta seção será elucidado o caso em que é preferível ter a informação a temperatura constante e também a pressão constante. Esse ensemble leva os cálculos a serem mais realistas pois simula a situação de experimentos reais que são feitos por exemplo a temperatura e pressão ambiente, ou outro valor que se queira. A pressão pode ser mantida constante alterando-se o tamanho da caixa de simulação, e essa é a grande importância desse ensemble. Muitos fenômenos físicos apresentam variação de volume do sistema, por exemplo, durante o aquecimento ou mesmo uma descontinuidade do volume como ocorre na fusão ou ainda em uma transição de ordem estrutural entre outros. O volume passa a ser uma variável dinâmica do sistema que está acoplada a um barostato mantendo a pressão média constante no valor desejado. Assim como ocorre no ensemble $N V T$, existem várias implementações de diferentes autores para se construir o ensemble NPT. O algoritmo utilizado nas simulações do presente trabalho é o de Hoover[17] com as equações de movimento propostas por Melchionna[61]: 


$$
\begin{aligned}
\frac{d \mathbf{r}(t)}{d t} & =\mathbf{v}(t)+\eta\left(\mathbf{r}(t)-\mathbf{R}_{0}\right) \\
\frac{d \mathbf{v}(t)}{d t} & =\frac{\mathbf{f}(t)}{m}-[\chi(t)+\eta(t)] \mathbf{v}(t), \\
\frac{d \chi(t)}{d t} & =\frac{N_{f} k_{B}}{Q}\left(\Gamma(t)-T_{r e q}\right)+\frac{1}{Q}\left(W \eta(t)^{2}-k_{B} T_{r e q}\right), \\
\frac{d \eta(t)}{d t} & =\frac{3}{W} V(t)\left(P(t)-P_{r e q}\right)-\chi(t) \eta(t), \\
\frac{d V(t)}{d t} & =[3 \eta(t)] V(t),
\end{aligned}
$$

onde $Q=N_{f} k_{B} T_{r e q} \tau_{T}^{2}$ é a "massa"efetiva do termostato, $W=N_{f} k_{B} T_{r e q} \tau_{P}^{2}$ é a "massa"efetiva do barostato. $N_{f}$ são os graus de liberdade do sistema, $\eta$ é o coeficiente de atrito com o barostato, $\mathbf{R}_{0}$ é o centro de massa do sistema, $\tau_{T}$ e $\tau_{P}$ são constantes específicas temporais para flutuação da temperatura e pressão respectivamente. $T_{r e q}$ é a temperatura requerida ou desejada, $\Gamma(t)$ é a temperatura instantânea, $P(t)$ é a pressão instantânea, $P_{r e q}$ é a pressão requerida, $V$ é o volume do sistema e $k_{B}$ é a constante de Boltzmann.

A quantidade conservada é obtida do Hamiltoniano estendido para o sistema o qual, mantém constante, a energia livre de Gibbs:

$$
G_{N P T}=U+K+\frac{1}{2} Q \chi(t)^{2}+P_{r e q} V(t)+\frac{1}{2} W \eta(t)^{2}+\int_{0}^{t}\left(\frac{Q}{\tau_{T}^{2}} \chi(s)+k_{B} T_{r e q}\right) d s .
$$

A integração utilizando o algoritmo de Verlet "leap-frog"passa a ser escrita como: 


$$
\begin{aligned}
\chi\left(t+\frac{1}{2} \Delta t\right) & =\chi\left(t-\frac{1}{2} \Delta t\right)+\frac{\Delta t N_{f} k_{B}}{Q}\left(\Gamma(t)-T_{r e q}\right)+\frac{\Delta t}{Q}\left(W \eta(t)^{2}-k_{B} T_{r e q}\right) \\
\chi(t) & =\frac{1}{2}\left[\chi\left(t-\frac{1}{2} \Delta t\right)+\chi\left(t+\frac{1}{2} \Delta t\right)\right] \\
\eta\left(t+\frac{1}{2} \Delta t\right) & =\eta\left(t-\frac{1}{2} \Delta t\right)+\Delta t\left[\frac{3 V(t)}{W}\left(P(t)-P_{r e q}\right)-\chi(t) \eta(t)\right] \\
\eta(t) & =\frac{1}{2}\left[\eta\left(t-\frac{1}{2} \Delta t\right)+\eta\left(t+\frac{1}{2} \Delta t\right)\right] \\
\mathbf{v}\left(t+\frac{1}{2} \Delta t\right) & =\mathbf{v}\left(t-\frac{1}{2} \Delta t\right)+\Delta t\left[\frac{\mathbf{f}(t)}{m}-[\chi(t)+\eta(t)] \mathbf{v}(t)\right] \\
\mathbf{v}(t) & =\frac{1}{2}\left[\mathbf{v}\left(t-\frac{1}{2} \Delta t\right)+\mathbf{v}\left(t+\frac{1}{2} \Delta t\right)\right] \\
\mathbf{r}(t+\Delta t) & =\mathbf{r}(t)+\Delta t\left\{\mathbf{v}\left(t+\frac{1}{2} \Delta t\right)+\eta\left(t+\frac{1}{2} \Delta t\right)\left[\mathbf{r}\left(t+\frac{1}{2} \Delta t\right)-\mathbf{R}_{0}\right]\right\} \\
\mathbf{r}\left(t+\frac{1}{2} \Delta t\right) & =\frac{1}{2}[\mathbf{r}(t)+\mathbf{r}(t+\Delta t)]
\end{aligned}
$$

Maiores detalhes tanto dos barostatos quanto dos termostatos e recomendações para a implemetação dessas equações são encontradas no livro de Frenkel \& Smit[49] e também no livro de Allen \& Tildesley[47].

\subsection{Cálculo de quantidades físicas}

Para um sistema com $N$ partículas clássicas, o espaço de fase consiste em um hiperespaço com dimensão $6 N$, consistindo das posições e momenta de todas as partículas para todos os tempos. Um ponto neste espaço de fase, será chamado de $\Gamma$, e representa um estado instantâneo do sistema. Uma propriedade macroscópica qualquer $A$ pode, então, ser calculada da média temporal do valor instantâneo $A(\Gamma)$ :

$$
A=\langle A(\Gamma)\rangle_{t}=\frac{1}{\tau} \lim _{\tau \rightarrow \infty} \int_{0}^{\tau} A(\Gamma(t)) d t
$$


sendo $\tau$ o tempo que o sistema evolui no espaço de fase. Nas simulações por DM a eq. 2.44 é calculada sobre milhares de passos temporais, $N_{\mathrm{p}}$, de tamanho $\Delta t$ :

$$
A=\langle A(\Gamma)\rangle_{t}=\frac{1}{N_{p}} \sum_{i=1}^{N_{p}} A\left(\Gamma_{i}\right) .
$$

Na mecânica estatística, as quantidades termodinâmicas são calculadas usualmente pela média no ensemble. A equivalência da média temporal dada pela eq. 2.44 e a média no ensemble estatístico permite assim o cálculo das quantidades físicas nas simulações por DM. No entanto, esta equivalência somente é verdadeira se o sistema for ergódico, ou seja, dado um tempo suficientemente longo, a trajetória no espaço de fase visitará todos os estados acessíveis ao sistema.

A seguir serão discutidas algumas propriedades que podem ser obtidas com o uso das simulações por DM. Todas as médias indicadas são então as médias no ensemble, que durante as simulações são substituídas por médias temporais. Deduções mais elaboradas de algumas das expressões que serão discutidas podem ser obtidas em vários textos sobre mecânica estatística ou sobre simulação computacional, ver por exemplo Allen \& Tildesley $[47]$.

\subsubsection{Propriedades termodinâmicas}

\section{Energia interna E}

A energia interna é dada diretamente pela soma da energia cinética e potencial do sistema

$$
E=<\mathcal{K}>+<\mathcal{U}>
$$

A energia cinética vem da soma dos momentos de todas as partículas

$$
<\mathcal{K}>=<\sum_{i=1}^{N} \frac{\left|\mathbf{p}_{i}\right|^{2}}{2 m}>
$$


ao passo que a energia potencial vem da soma da interação sobre todos os pares, tripletos, etc. de partículas dependendo do potencial de interação em uso.

\section{Temperatura $\mathbf{T}$}

A temperatura pode ser calculada diretamente através da energia cinética das partículas, usando o teorema de equipartição de energia. Para o caso tridimensional tem-se:

$$
T=\frac{2<\mathcal{K}>}{3 N k_{B}}
$$

que relaciona $k_{B} T / 2$ de energia média para cada grau de liberdade.

\section{Pressão P}

A pressão pode ser calculada utilizando o virial

$$
P V=N k_{B} T+<\frac{1}{3} \sum_{i=1}^{N} \mathbf{r}_{i} \mathbf{f}_{i}>
$$

Em DM é aconselhável, no entanto, utilizar a expressão

$$
P V=N k_{B} T+<\frac{1}{3} \sum_{i=1}^{N-1} \sum_{j=i+1}^{N} \mathbf{r}_{i j} \mathbf{f}_{i j}>
$$

para agilizar seu cálculo. Sendo $\mathbf{r}_{i j}=\mathbf{r}_{i}-\mathbf{r}_{j}$ e $\mathbf{f}_{i j}$ a força na partícula $i$ devido a partícula $j$.

\section{Calor específico a volume constante $\mathbf{C}_{v}$}

$\mathrm{C}_{v}$ é obtido no ensemble canônico diretamente através da definição

$$
C_{v}=\left(\frac{\partial E}{\partial T}\right)_{v}
$$

No ensemble microcanônico $\mathrm{C}_{v}$ pode ser calculado utilizando a flutuação da energia cinética ou potencial.

$$
<\delta V^{2}>=<\delta K^{2}>=\frac{3}{2} N\left(k_{B} T\right)^{2}\left[1-\frac{3}{2} \frac{N k_{B}}{C_{v}}\right]
$$


Assim, medindo-se as flutuações da energia cinética, por exemplo, tem-se

$$
C_{v}=\frac{9 N^{2} k_{B}^{2} T^{2}}{6 N k_{B} T^{2}-4\left(<(K)^{2}>-<(K)>^{2}\right)}
$$

\subsubsection{Propriedades estruturais}

\section{Função de distribuição radial $\mathrm{g}(\mathrm{r})$ e número de coordenação $\mathrm{N}(\mathrm{r})$}

A função de correlação de pares, também conhecida como função de distribuição radial, é uma ferramenta importante na descrição das correlações estruturais de dois corpos. Ela fornece a probabilidade de se encontrar um par de átomos a uma dada distância $r$ em relação àquela encontrada em uma distribuição aleatória. Ela é definida por

$$
\left\langle n_{\alpha}\left(\mathbf{r}_{1}\right)\right\rangle g_{\alpha \beta}\left(\mathbf{r}_{1}, \mathbf{r}_{2}\right)\left\langle n_{\beta}\left(\mathbf{r}_{2}\right)\right\rangle=\sum_{i \in\{\alpha\}}^{N} \sum_{\substack{j \in\{\beta\} \\ j \neq i}}^{N} \delta\left(\mathbf{r}_{i}-\mathbf{r}_{1}\right) \delta\left(\mathbf{r}_{j}-\mathbf{r}_{2}\right)
$$

sendo $n_{\alpha}\left(\mathbf{r}_{1}\right)$ a densidade de átomos da espécie $\alpha$ na posição $\mathbf{r}_{1}$. Quando o sistema é translacionalmente invariante, a função $g_{\alpha \beta}\left(\mathbf{r}_{1}, \mathbf{r}_{2}\right)$ depende somente na separação relativa dos átomos $\mathbf{r}=\mathbf{r}_{1}-\mathbf{r}_{2}$

$$
\left\langle n_{\alpha}\right\rangle g_{\alpha \beta}(\mathbf{r})\left\langle n_{\beta}\right\rangle=\sum_{i \in\{\alpha\}}^{N} \sum_{\substack{j \in\{\beta\} \\ j \neq i}}^{N} \delta\left(\mathbf{r}-\mathbf{r}_{i j}\right)
$$

Para sistemas isotrópicos, pode-se fazer a média da Eq. 2.55 para todas as direções de r. Assim tem-se

$$
4 \pi r^{2} \Delta r\left\langle n_{\beta}(r)\right\rangle g_{\alpha \beta}(r)=\left\langle n_{\alpha \beta}(r)\right\rangle \Delta r
$$

sendo $\left\langle n_{\alpha \beta}(r)\right\rangle \Delta r$ o número médio de átomos da espécie $\beta$, numa camada de espessura $\Delta r$ a uma distância $r$ de um átomo da espécie $\alpha$.

Pode-se obter o número de coordenação de uma espécie $\alpha$ integrando a eq. 2.56:

$$
N_{\alpha \beta}(R)=4 \pi\left\langle n_{\beta}\right\rangle \int_{0}^{R} g_{\alpha \beta}(r) r^{2} d r
$$


$N_{\alpha \beta}(R)$ fornece o número de átomos da espécie $\beta$ dentro da esfera de raio $R$ ao redor de um átomo da espécie $\alpha$.

A função de distribuição de pares total é finalmente definida como

$$
g(r)=\sum_{\alpha, \beta} c_{\alpha} c_{\beta} g_{\alpha \beta}(r)
$$

sendo $c_{\alpha}=\frac{N_{\alpha}}{N}$ e $c_{\beta}=\frac{N_{\beta}}{N}$ as concentrações das espécies $\alpha$ e $\beta$ respectivamente.

\section{Correlações estruturais de três corpos}

A função de distribuição de ângulo de ligação entre três partículas é uma ferramenta muito conveniente na descrição da estrutura dos tripletos de partículas. Inicialmente considera-se um raio de corte para definir os primeiros vizinhos da espécie $\beta$ para os átomos da espécie $\alpha$. Geralmente, o raio de corte é fixado no primeiro mínimo da função $g_{\alpha \beta}(r)$. A quantidade de distribuições a considerar depende então da quantidade de átomos diferentes no sistema. Considerando um sistema com duas componentes $\mathcal{A}$ e $\mathcal{B}$ tem-se as seguintes distribuições de ângulos a considerar: B-A-B, A-B-A, A-A-B, B-B-A, A-A-A e B-B-B. Definida a distribuição a calcular, por exemplo A-B-A, todos os ângulos entre todos os átomos $\mathcal{A}$ e os átomos vizinhos $\mathcal{B}$ seriam computados em um histograma e a função a partir daí calculada. Para o caso de três componentes tem-se 27 distribuições de ângulos possíveis.

\subsubsection{Propriedades dinâmicas}

A correlação entre duas quantidades diferentes $\mathcal{A}$ e $\mathcal{B}$ pode ser medida através de flutuações no ensemble, calculando o coeficiente de correlação $c_{\mathcal{A B}}$

$$
c_{\mathcal{A B}}=\frac{\langle\delta \mathcal{A} \delta \mathcal{B}\rangle}{\sigma(\mathcal{A}) \sigma(\mathcal{B})}
$$

sendo $\delta \mathcal{A}=\mathcal{A}-\langle\mathcal{A}\rangle$ e $\sigma(\mathcal{A})^{2}=\left\langle\mathcal{A}^{2}\right\rangle-\langle\mathcal{A}\rangle^{2}$. O valor absoluto de $c_{\mathcal{A B}}$ varia de 0 a 1 , com valores próximos de 1 indicando um alto grau de correlação. Uma extensão do coeficiente 
de correlação surge quando as quantidades $\mathcal{A}$ e $\mathcal{B}$ são calculadas a tempos diferentes. Se medida a correlação da mesma quantidade a tempos diferentes $c_{\mathcal{A} \mathcal{A}}(t)$, tem-se então a função de autocorrelação.

\section{Deslocamento quadrático médio $\mathbf{R}^{2}(\mathbf{t})$}

O deslocamento quadrático médio é definido pela equação

$$
R_{\alpha}^{2}(t)=<\left|\mathbf{r}_{i}(t)-\mathbf{r}_{i}(0)\right|^{2}>_{\alpha}=\frac{1}{N_{\alpha}} \sum_{i \in \alpha}\left|\mathbf{r}_{i}(t)-\mathbf{r}_{i}(0)\right|^{2}
$$

sendo $N_{\alpha}$ o número de átomos da espécie $\alpha$.

Ele fornece de uma maneira explícita qual a magnitude do deslocamento das partículas no sistema a partir de sua posição inicial. Através dele, é possível distinguir claramente as fases sólida e líquida de um sistema. Na fase sólida, $R^{2}(t)$ tem valor praticamente constante para todo $t$, ao passo que cresce linearmente na fase líquida.

\section{Coeficiente de difusão $\mathrm{D}$}

O coeficiente de difusão, assim como o deslocamento quadrático médio, descreve a dinâmica das partículas no sistema. Eles se relacionam diretamente, através da equação

$$
D_{\alpha}=\lim _{t \rightarrow \infty} \frac{R^{2}(t)}{6 t}
$$

Pode-se também calcular o valor de $D_{\alpha}$ através da auto-correlação de velocidades através da expressão

$$
D_{\alpha}=\frac{1}{3} \int_{0}^{\infty}<\mathbf{v}_{i}(0) \cdot \mathbf{v}_{i}(t)>_{\alpha}=\frac{\left\langle\mathbf{v}_{i}^{2}(0)\right\rangle_{\alpha}}{3} \int_{0}^{\infty} Z_{\alpha}(t) d t
$$

Em todo o presente trabalho, a referência ao termo difusão deve ser entendida como a auto difusão de uma dada espécie. 


\section{Condutividade}

Conhecendo-se o coeficiente de difusão é possível usar a aproximação de Nerst-Einstein para determinar a condutividade iônica em $\omega=0$ :

$$
\sigma=\frac{n}{f}\left[\frac{D q^{2}}{\kappa_{B} T}\right]
$$

onde $n$ é o número de espécies móveis por volume, $f$ é o fator de correlação que depende da geometria da rede (para uma rede do tipo do fluoreto $P b F_{2}$ ele é $\simeq 1$ ), $q$ é a carga da partícula, $k_{B}$ é a constante de Boltzmann, $T$ é a temperatura, e $D$ é o coeficiente de difusão. Uma dedução mais geral para a condutividade, incluindo outras estruturas além da $c f c$, pode ser encontrada no livro editado por Perram[64] no capítulo escrito por Rahman \& Vashishta. 


\section{Capítulo 3}

\section{Resultados e Discussões}

\subsection{Descrição preliminar e preparação dos sistemas}

Sendo a simulação uma área que reside entre a teoria e o experimento, os termos, ou mesmo jargões, utilizados podem não ser tão familiares a ambas as áreas. Com o intuito de tornar esse trabalho mais claro para ambas as áreas, nessa parte introdutória serão apresentados os termos utilizados e juntamente será dada uma visão geral dos resultados indicando a sequência em que eles serão apresentados.

Na literatura as soluções sólidas são descritas como cristais com mais de uma componente, no presente trabalho são 3 componentes, onde as componentes são homogeneamente distribuídas[65]. O método adotado nas simulações para a formação da solução sólida parte de um cristal de duas componentes onde se adiciona um terceiro elemento mantendo sua estrutura original. A terceira componente é introduzida por substituição, mas existem sistemas onde o terceiro elemento pode ser introduzido intersticialmente. Devido a sua distribuição homogênea dos elementos muitos autores preferem chamar esse sistema de cristal misto.

Na sua definição mais formal as soluções sólidas devem ser homogêneas, assim o método 
de obtenção delas deve garantir isso. Na simulação é fácil garantir tal homogeneidade como será mostrado nas discussões abaixo, mas os métodos experimentais podem encontrar dificuldades para garantir a homogeneidade e a não contaminação das amostras.

O sistema inicial utilizado na simulação consiste de uma caixa tridimensional com condições periódicas de contorno que contém as partículas arranjadas na estrutura cristalina cúbica do $\beta-P b F_{2}$. A estrutura ortorrômbica é observada para o $P b F_{2}$ em baixas temperaturas e recebe o nome $\alpha-P b F_{2}$, mas essa se transforma na $\beta-P b F_{2}$ quando aquecida e essa fase $\beta$ é estável em altas temperaturas assim como em baixas temperaturas. No presente trabalho não houve interesse pela fase $\alpha$ portanto doravante quando for feita referência ao $\mathrm{PbF}_{2}$ estará sendo feito referência ao $\beta-P b F_{2}$. Tanto o $P b F_{2}$ quanto o $C d F_{2}$ têm 12 átomos na sua célula unitária onde os cátions $\left(\mathrm{Pb}^{+2} \mathrm{ou} \mathrm{Cd}^{+2}\right)$ formam uma sub-rede cúbica de face centrada (cfc) e os $F$ formam um sub-rede cúbica simples como pode ser visto nas Fig. 3.1 e 3.2. Nas Fig. 3.1 e 3.2 as bolas preenchidas com a cor preta representam os cátions $(\mathrm{Pb}$ ou $\mathrm{Cd})$ e as bolas vazias os $F$. A Fig. 3.1 é uma projeção da célula unitária exibindo uma visão frontal. Na Fig. 3.2 é mostrada uma pequena rotação da Fig. 3.1 exibindo tanto os cátions em sua rede cfc quanto os $F$ que estão conectados destacando a sua rede cúbica simples.

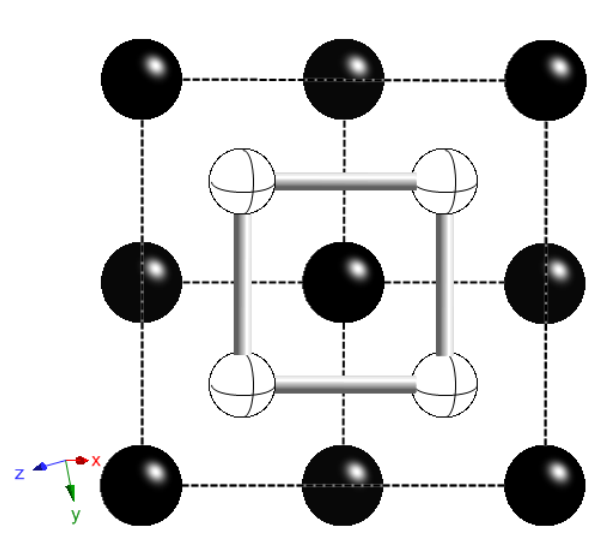

Figura 3.1: Visão frontal da célula unitária do $\mathrm{PbF}_{2}$

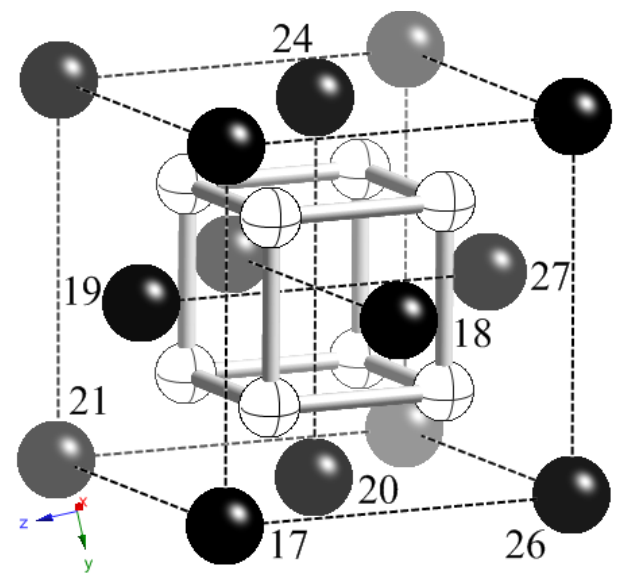

Figura 3.2: Fig. 3.1 com uma pequena rotação 
Para a construção da solução sólida inicial nas simulações utilizando DM, foi considerado um sistema $P b F_{2}$ puro onde alguns dos $P b$ são aleatoriamente escolhidos e substituídos por $C d$. Portanto, a caixa de simulaçãocontém a estrutura cristalina do $P b F_{2}$ mas é preenchida por $\mathrm{Pb}, \mathrm{Cd}$ e $\mathrm{F}$, e dessa maneira continua-se a ter um cristal ordenado porém de composição mista o qual, conforme já foi mencionado, costuma ser chamado de cristal misto. Dessa maneira é possível gerar um sistema totalmente homogêneo e com estequiometria muito precisa que será chamado doravante de solução sólida inicial (SSI).

Os sistemas são identificados pelas suas concentrações de $C d F_{2}$ representados pela notação $C d_{x} P b_{1-x} F_{2}$. Foram simuladas as concentrações com $x=0,1 ; x=0,2 ; x=0,25$; $x=0,30 ; x=0,35 ; x=0,40 ; x=0,45 ; x=0,50 ; x=0,60 ; x=0,70$ e $x=0,80$, além dos fluoretos puros $C d F_{2}, x=1$ e do $P b F_{2}, x=0$. Foram feitas simulações com 2592, 6144, 12000, 20736 e 32928 partículas. Nas Fig. 3.3, 3.4, 3.5, 3.6, 3.7 e 3.8 são mostradas seis fotos da SSI com $x=0,40$ na temperatura 50K com 2592 partículas. Para uma melhor visualização e destacar a homogeneidade catiônica do sistema os átomos de Flúor foram extraídos. Os átomos de $P b$ são as bolas preenchidas com a cor preta e os de $C d$ são as bolas vazias. Todas as outras concentrações seguem o mesmo padrão estrutural da $x=0,40$ e não serão mostradas. A Fig. 3.3 é a referência para gerar todas as outras figuras, mostrando a visão frontal da caixa com o eixo $z$ perpendicular a página. Cada átomo visto deste ângulo representa uma linha de átomos que estão superpostos nessa mesma direção. Todas as seis fotos têm rotação em torno dos eixos cartesianos com a intenção de mostrar os planos cristalinos. Como a temperatura é baixa é possível ver as linhas de átomos bem organizadas quase sem oscilação. Nas Figuras 3.3, 3.5, e 3.7 vê-se os planos e as linhas de átomos superpostos e nas Figuras 3.4, 3.6 e 3.8 ainda é possível ver os planos mas agora as linhas de átomos são vistas numa visão lateral e não mais superpostos. As Figuras 3.4, 3.6 e 3.8 têm uma pequena rotação adicional para mostrar 
os átomos pertencentes às linhas exibindo a homogeneidade do sistema, ficando claro que tanto os átomos de $\mathrm{Pb}$ quanto os de Cd estão uniformemente espalhados por toda a caixa.

As taxas envolvidas nos aquecimentos ou resfriamentos dizem o quanto de calor foi adicionado ou retirado do sistema em um dado intervalo de tempo, lembrando que o tempo foi discretizado em quantidades de $\Delta t=0,001 \mathrm{ps}$. Por exemplo, em um aquecimento podese aumentar de $1 K$ a temperatura do sistema e deixá-lo evoluir por $5000 \Delta t$ o que resulta em uma taxa $q=1 \mathrm{~K} /(5000 * 0,001 \mathrm{ps})=0,2 \mathrm{~K} / \mathrm{ps}$. Para o resfriamento a taxa seria $q=-1 \mathrm{~K} /(5000 * 0,001 \mathrm{ps})=-0,2 \mathrm{~K} / \mathrm{ps}$. As taxas utilizadas, levando em conta as curtas escalas de tempo oferecidas pela DM, estão listadas na tabela abaixo:

$\begin{array}{ccc}\text { variação de temperatura }(\mathrm{K}) & \text { número de passos }(0,001 \mathrm{ps}) & q(\mathrm{~K} / \mathrm{ps}) \\ 1 & 40000 & 0,025 \\ 1 & 20000 & 0,05 \\ 1 & 10000 & 0,1 \\ 1 & 5000 & 0,2 \\ 10 & 20000 & 0,5 \\ 10 & 10000 & 1 \\ 10 & 5000 & 2 \\ 20 & 5000 & 4 \\ 50 & 5000 & 10 \\ 50 & 2000 & 25\end{array}$

Na apresentação dos resultados serão feitas comparações com dados experimentais nos quais os cristais contendo os fluoretos $C d F_{2}$ e $P b F_{2}$ são obtidos por vários métodos. O método utilizado por Silva[21] e Bueno[22] consiste na obtenção do sistema policristalino por resfriamento a partir do estado líquido. Os autores utilizaram o método "Roller Quenching ", no qual o líquido é vertido entre dois cilindros metálicos giratórios, e lâminas de aproximadamente $0,1 \mathrm{~mm}$ foram obtidas.

Um segundo método de se obter as soluções sólidas experimentalmente é por crescimento de cristais. As amostras são crescidas por cristalização planar do líquido[70] ou pelo método de Bridgman[71, 69]. Os autores confirmam por raio-x que as soluções sólidas obtidas têm estrutura do tipo cúbica de face centrada (grupo espacial Fm3m) e que são homogêneas. Devido a homogeneidade os autores utilizam o nome "cristal simples "para 


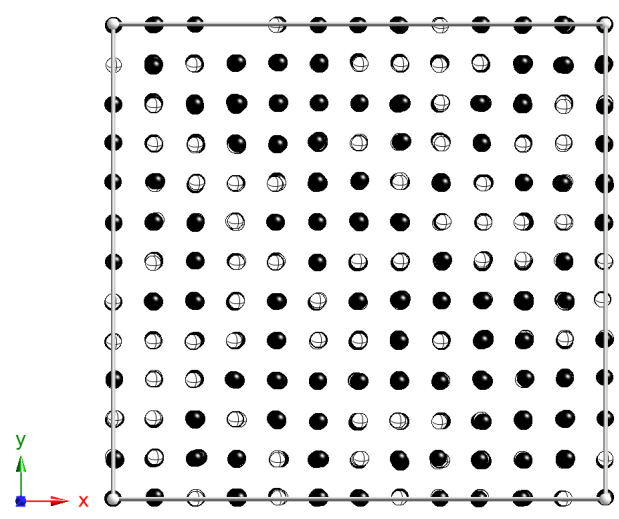

Figura 3.3: Visão frontal da caixa tridimensional da SSI $x=0,40$ em $\mathrm{T}=50 \mathrm{~K}$.

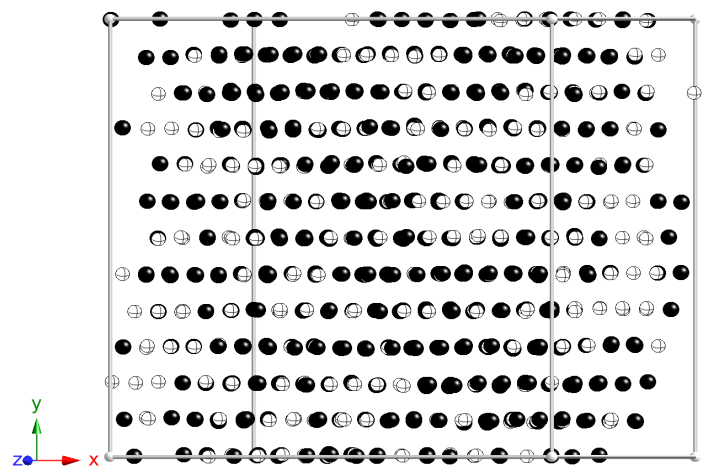

Figura 3.5: Figura 3.3 com rotação de $18^{\circ}$ para a esquerda, em torno do eixo y

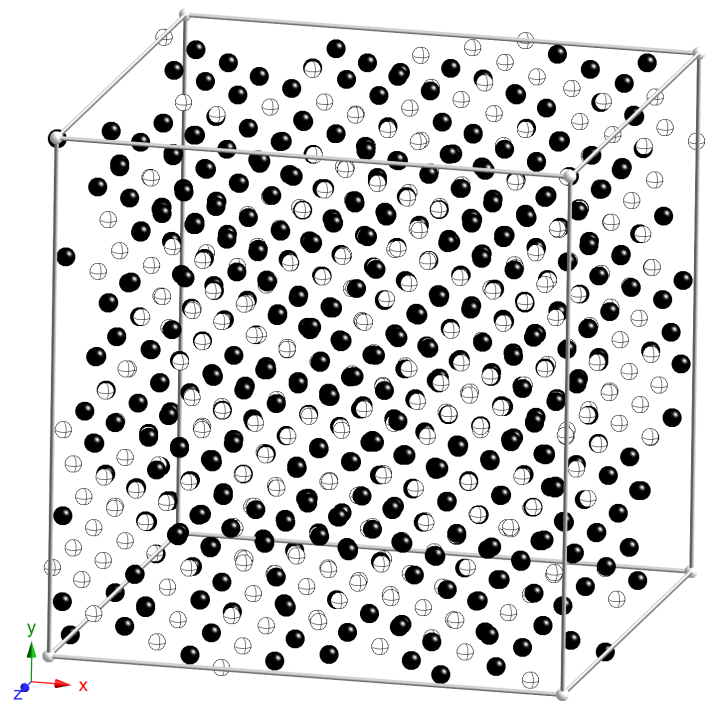

Figura 3.7: Figura 3.3 com rotação de $14^{\circ}$ para a esquerda em torno do eixo y e $14^{\circ}$ para baixo em torno do eixo $\mathrm{x}$

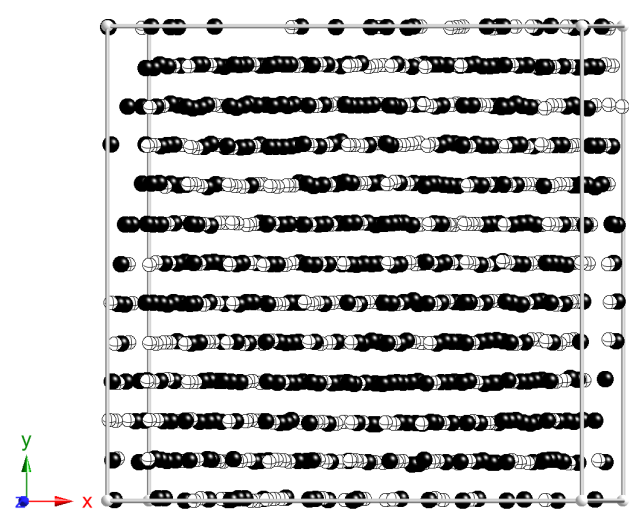

Figura 3.4: Figura 3.3 com rotação de $5^{\circ}$ para a esquerda, em torno do eixo y

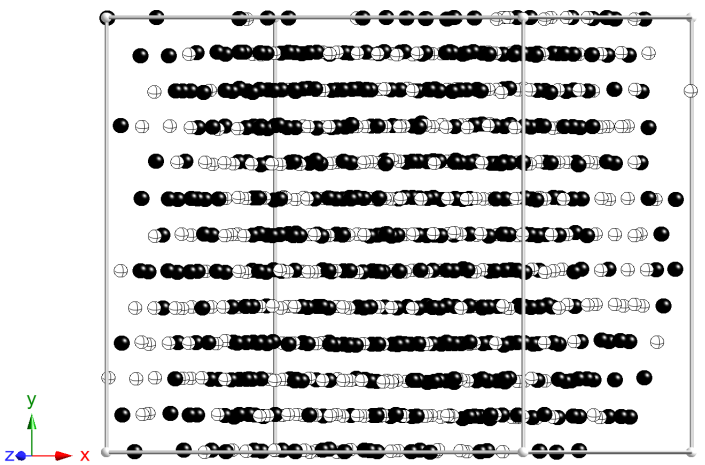

Figura 3.6: Figura 3.3 com rotação de $22^{\circ}$ para a esquerda, em torno do eixo y

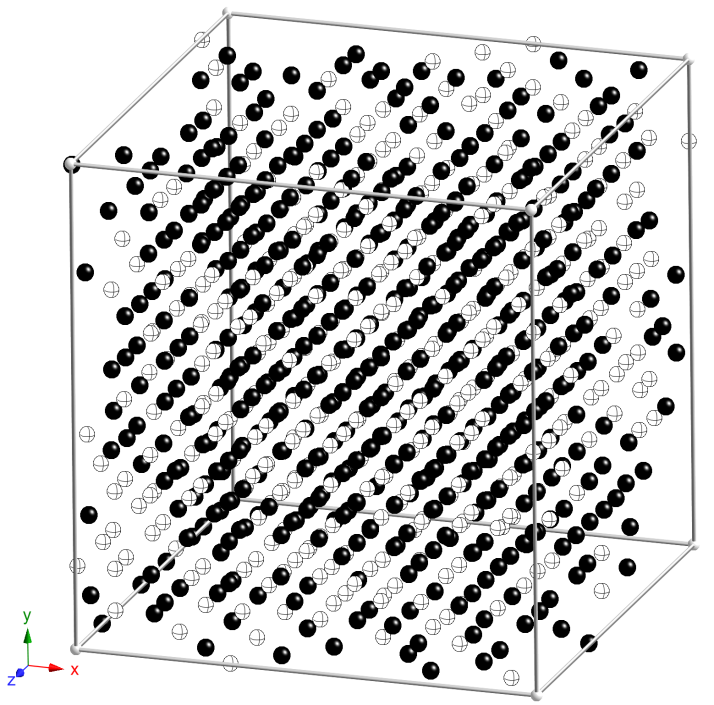

Figura 3.8: Figura 3.3 com rotação de $19^{\circ}$ para a esquerda em torno do eixo y e $19^{\circ}$ para baixo em torno do eixo $\mathrm{x}$ 
essas soluções.

O primeiro passo realizado nas simulações foi a construção da caixa de simulação para cada uma das concentrações em $\mathrm{T}=50 \mathrm{~K}$ utilizando o método de substituição aleatória descrito acima gerando as SSI. Construído o sistema foram extraídas todas as informações estruturais desses cristais perfeitos tais como funções de correlação de pares, número de coordenação e distribuição de ângulos dos átomos. Em seguida as SSI foram aquecidas adentrando na região de superionicidade onde a difusão de cada tipo de átomo do sistema foi obtida permitindo a descrição detalhada de cada uma das SSI. Um aquecimento adicional levou o sistema ao estado líquido. Os líquidos dessas SSI foram resfriados com várias das taxas acima mencionadas, obtendo-se ora um sólido amorfo ora um sólido cristalino. Quando submetido a um resfriamento lento o líquido homogêneo originou cristais com separação de fase, ou seja, os cristais obtidos por resfriamento do líquido não apresentam a mesma distribuição homogênea dos cátions obtida nas SSI. Os vidros obtidos de resfriamentos com taxas lentas apresentam separação de fase e os obtidos com taxas rápidas são homogêneos. Os vidros homogêneos foram reaquecidos e apresentaram devitrificação, ou cristalização, e foram novamente resfriados e reaquecidos para se fazer uma análise estrutural e dinâmica mais completa. Assim como os cristais obtidos por resfriamento do líquido os vidros cristalizados não apresentaram a mesma homogeneidade das SSI. Uma última maneira de se obter a cristalização do sistema foi através de um tratamento isotérmico por longos tempos do líquido super resfriado que também gera um sistema com separação de fase. Todo o histórico do sistema será fornecido juntamente com os seus resultados nas seções seguintes. 


\subsection{Solução Sólida Inicial}

Através do potencial de pares proposto e discutido anteriormente a estrutura e a estabilidade do sistema foi caracterizada para todas as SSI e também para os fluoretos puros. Foram feitas análises de dois corpos utilizando a função de correlação de pares e o número de coordenação e também análises de três corpos utilizando a distribuição angular. Os resultados para as SSI partem do sistema criado em $\mathrm{T}=50 \mathrm{~K}$ e são paulatinamente aquecidos até se obter uma fase líquida em $\mathrm{T}=3500 \mathrm{~K}$. Inicialmente foi feita uma análise estrutural estática, na sequência o sistema foi aquecido e foi avaliada a transição superiônica e por último foi descrito o comportamento de todas as SSI na fusão.

\subsubsection{Função de correlação de pares parcial.}

Nesta seção serão mostrados importantes resultados obtidos das simulações que dizem respeito a estrutura interna dos materiais. Tais resultados vão além da informação que diz respeito ao sólido como um todo descrito pelo seu comportamento médio. A função de correlação de pares é obtida de maneira relativamente simples durante a simulação, conforme descrito na seção 2.7. As $\mathrm{g}(\mathrm{r})$ parciais, identificadas pelo símbolo $\mathrm{g}_{\alpha \beta}(r)$, são importantes ferramentas para se obter o parâmetro de rede e os comprimentos de ligação, enchergar e descrever desordem estrutural e possíveis separações de fase, entre outros fenômenos que serão discutidos adiante. Um experimento que revele a correlação parcial dos pares pode ser feito utilizando a técnica de espalhando de nêutrons adicionando-se átomos isótopos ao sistema, mas o seu alto custo acaba por inviabilizar o procedimento nos laboratórios.

Na Fig. 3.9 são mostrados os comportamentos típicos das $\mathrm{g}_{\alpha \beta}(r)$ para os seis pares de átomos que compõe as SSI. Para evitar a superposição das curvas e tornar a figura mais clara são mostradas apenas 3 das 11 composições analisadas uma vez que todas seguem 
o mesmo padrão.
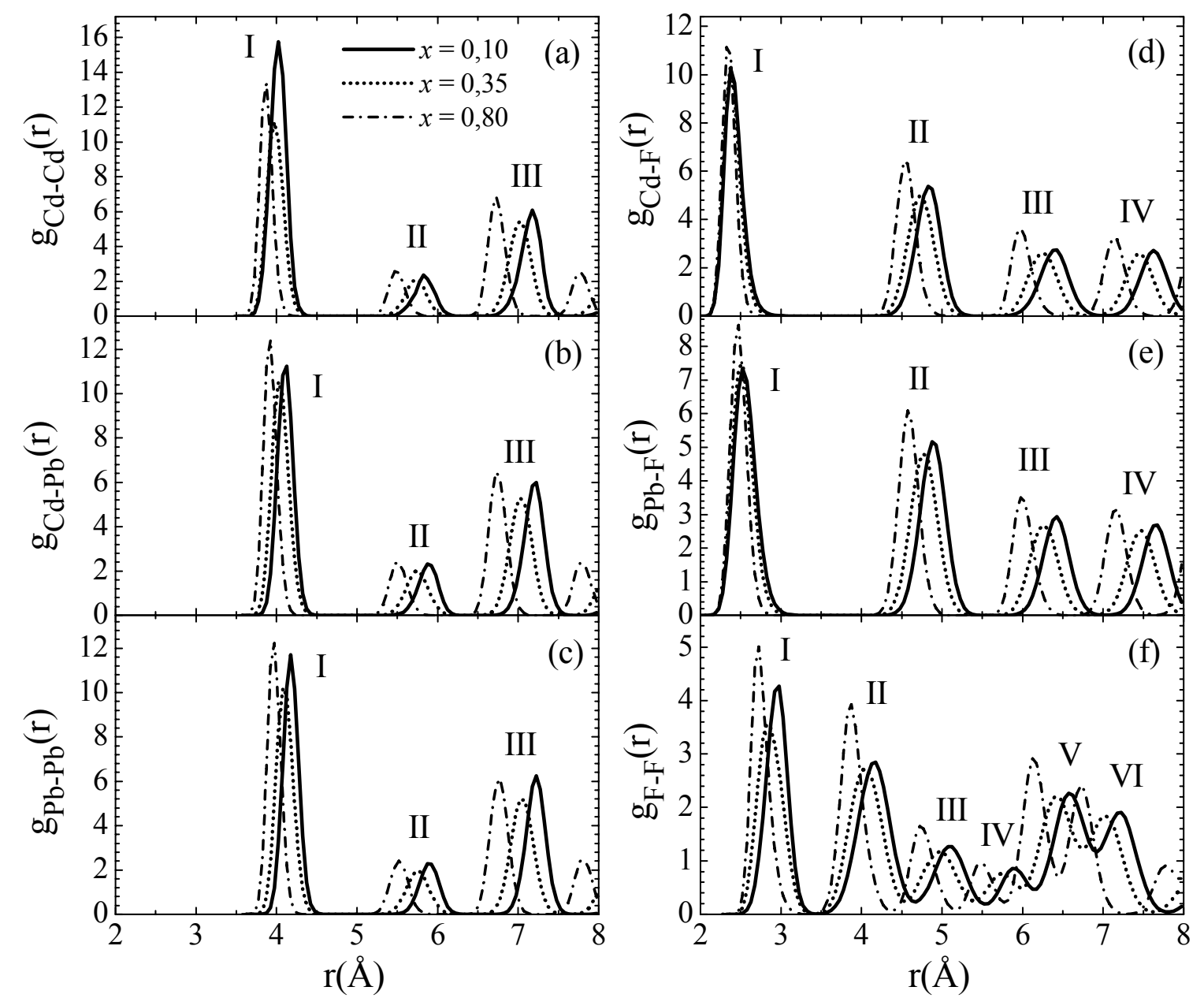

Figura 3.9: $\mathrm{g}_{\alpha \beta}(r)$ em $\mathrm{T}=100 \mathrm{~K}$ das SSI $\operatorname{com} x=0,10 ; x=0,35$ e $x=0,80$. Em (a) é mostrado o par Cd-Cd, em (b) o par Cd-Pb, em (c) o par Pb-Pb, em (d) o par Cd-F, em (e) o par Pb-F e em (f) o par F-F.

Todas as curvas na Fig. 3.9 mostram o comportamento típico de um cristal, com picos bem definidos e também regiões onde $\mathrm{a}_{\alpha \beta}(r)$ é nula, o que identifica que entre um plano cristalino e outro não existem átomos. As posições dos picos em $\AA$ das $g_{\alpha \beta}(r)$ da Fig. 3.9 para as 11 composições e os fluoretos puros podem ser vistas nas tabelas 3.1 e 3.2 onde I, II, III indicam os primeiros picos, segundos picos e assim por diante. Para os fluoretos puros alguns dos pares de átomos não existem e foi colocado um traço na coluna. $\mathrm{Na}$ tabela 3.1 os valores das posições dos picos em $\AA$ são mostrados para os pares $\mathrm{Cd}-\mathrm{Cd}$, $\mathrm{Cd}-\mathrm{Pb}$ e $\mathrm{Pb}-\mathrm{Pb}$. 
Tabela 3.1: Posição dos picos em $\AA$ das $\mathrm{g}_{\alpha \beta}(r)$ das SSI dos pares $\mathrm{Cd}-\mathrm{Cd}, \mathrm{Cd}-\mathrm{Pb}$ e Cd-Cd em $\mathrm{T}=50 \mathrm{~K}$.

\begin{tabular}{c|ccc|ccc|ccc}
$x$ & \multicolumn{3}{|c}{ Cd-Cd } & \multicolumn{9}{c}{ Cd-Pb } & \multicolumn{3}{c}{ Pb-Pb } \\
& I & II & III & I & II & III & I & II & III \\
0,00 & - & - & - & - & - & - & 4,19 & 5,93 & 7,26 \\
0,10 & 4,02 & 5,83 & 7,16 & 4,10 & 5,87 & 7,19 & 4,18 & 5,88 & 7,21 \\
0,20 & 4,00 & 5,78 & 7,09 & 4,07 & 5,81 & 7,12 & 4,14 & 5,82 & 7,14 \\
0,25 & 3,99 & 5,77 & 7,07 & 4,06 & 5,79 & 7,09 & 4,12 & 5,80 & 7,10 \\
0,30 & 3,99 & 5,75 & 7,04 & 4,05 & 5,77 & 7,06 & 4,11 & 5,77 & 7,08 \\
0,35 & 3,97 & 5,72 & 7,01 & 4,04 & 5,74 & 7,02 & 4,09 & 5,74 & 7,04 \\
0,40 & 3,96 & 5,69 & 6,97 & 4,02 & 5,71 & 6,98 & 4,08 & 5,71 & 7,00 \\
0,45 & 3,95 & 5,66 & 6,94 & 4,01 & 5,68 & 6,95 & 4,06 & 5,69 & 6,98 \\
0,50 & 3,94 & 5,63 & 6,91 & 4,00 & 5,66 & 6,93 & 4,05 & 5,66 & 5,94 \\
0,60 & 3,91 & 5,58 & 6,85 & 3,97 & 5,61 & 6,86 & 4,02 & 5,61 & 6,88 \\
0,70 & 3,89 & 5,53 & 6,78 & 3,94 & 5,55 & 6,80 & 3,99 & 5,55 & 6,81 \\
0,80 & 3,86 & 5,48 & 6,72 & 3,91 & 5,50 & 6,73 & 3,96 & 5,50 & 6,75 \\
1,00 & 3,81 & 5,39 & 6,60 & - & - & - & - & - & -
\end{tabular}

Na tabela 3.2 pode ser visto os valores da posição dos picos em $\AA$ para os pares Cd-F, $\mathrm{Pb}-\mathrm{F}$ e FF.

Tabela 3.2: Posição dos picos em $\AA$ das $\mathrm{g}_{\alpha \beta}(r)$ das SSI dos pares Cd-F, Pb-F e F-F em $\mathrm{T}=50 \mathrm{~K}$.

\begin{tabular}{c|cccc|cccc|cccccc}
$x$ & \multicolumn{10}{|c}{ Cd-F } & \multicolumn{10}{c}{ Pb-F } & \multicolumn{1}{c}{ F-F } \\
& I & II & III & IV & I & II & III & IV & I & II & III & IV & V & VI \\
0,00 & - & - & - & - & 2,56 & 4,92 & 6,46 & 7,70 & 2,97 & 4,19 & 5,13 & 5,93 & 6,63 & 7,26 \\
0,10 & 2,41 & 4,83 & 6,39 & 7,61 & 2,55 & 4,88 & 6,41 & 7,64 & 2,95 & 4,16 & 5,09 & 5,89 & 6,58 & 7,20 \\
0,20 & 2,40 & 4,78 & 6,33 & 7,54 & 2,53 & 4,83 & 6,35 & 7,56 & 2,91 & 4,11 & 5,04 & 5,83 & 6,51 & 7,11 \\
0,25 & 2,40 & 4,77 & 6,30 & 7,51 & 2,53 & 4,81 & 6,32 & 7,53 & 2,89 & 4,09 & 5,01 & 5,80 & 6,49 & 7,08 \\
0,30 & 2,39 & 4,75 & 6,27 & 7,48 & 2,53 & 4,79 & 6,29 & 7,50 & 2,88 & 4,07 & 4,99 & 5,77 & 6,46 & 7,05 \\
0,35 & 2,39 & 4,72 & 6,24 & 7,44 & 2,52 & 4,77 & 6,26 & 7,46 & 2,86 & 4,05 & 4,96 & 5,75 & 6,42 & 7,01 \\
0,40 & 2,38 & 4,70 & 6,21 & 7,40 & 2,51 & 4,74 & 6,22 & 7,42 & 2,84 & 4,02 & 4,93 & 5,71 & 6,39 & 6,97 \\
0,45 & 2,38 & 4,69 & 6,18 & 7,37 & 2,51 & 4,72 & 6,20 & 7,39 & 2,82 & 4,01 & 4,91 & 5,68 & 6,36 & 6,94 \\
0,50 & 2,38 & 4,66 & 6,15 & 7,33 & 2,50 & 4,70 & 6,17 & 7,36 & 2,81 & 3,98 & 4,89 & 5,65 & 6,32 & 6,91 \\
0,60 & 2,37 & 4,63 & 6,09 & 7,27 & 2,49 & 4,66 & 6,11 & 7,29 & 2,78 & 3,94 & 4,84 & 5,59 & 6,26 & 6,85 \\
0,70 & 2,36 & 4,58 & 6,03 & 7,20 & 2,48 & 4,62 & 6,05 & 7,22 & 2,75 & 3,90 & 4,79 & 5,54 & 6,20 & 6,78 \\
0,80 & 2,35 & 4,54 & 5,97 & 7,13 & 2,47 & 4,58 & 5,99 & 7,15 & 2,72 & 3,87 & 4,74 & 5,48 & 6,14 & 6,72 \\
1,00 & 2,33 & 4,47 & 5,87 & 7,00 & - & - & - & - & 2,69 & 3,81 & 4,67 & 5,39 & 6,02 & 6,60
\end{tabular}

Nas soluções sólidas do tipo $C d_{x} P b_{1-x} F_{2}$ os Flúors formam uma rede cúbica simples e os cátions $(\mathrm{Pb}$ e $\mathrm{Cd})$ formam uma rede cúbica de face centrada ( $\mathrm{cfc}$ ) conforme mostrada na Fig. 3.2 e 3.1 que pode ser confirmada com os valores dos picos da $g_{\alpha \beta}(r)$. Pode-se identificar a rede cfc dos cátions avaliando o par $\mathrm{Pb}-\mathrm{Pb}$ os quais tem os seus segundos vizinhos situados no canto do cubo da célula unitária. Por exemplo, na Fig. 3.2 o átomo de número 17 teria como segundos vizinhos os átomos 21, 26 entre outros. Portanto os segundos vizinhos determinam o parâmetro de rede, identificado por $a$. Os primeiros vizinhos estão situados na face do cubo da célula unitária, na metade da diagonal dessas 
faces mais próximas. Por exemplo, os primeiros vizinhos do átomos de número 17 na Fig. 3.2 seriam os átomos 19, 20, 18 entre outros. Assim os primeiros picos da $\mathrm{g}_{P b-P b}(r)$ na tabela 3.1 assumem valores iguais a $\frac{a \sqrt{2}}{2}$ que podem ser confirmados comparando a coluna do primeiro pico com os valores da coluna do segundo pico multiplicado por $\frac{\sqrt{2}}{2}$. Para identificar os terceiros vizinhos é necessário notar que eles pertencem ao vértice de um triângulo onde a posição do terceiro pico é a hipotenusa desse triângulo. Um dos lados do triângulo mede $\frac{a \sqrt{2}}{2}$, formado pelo átomos 17 e 20 na Fig. 3.2, e outro lado mede $a$, formado pelos átomos 20 e 24, portanto a posição do terceiro pico é dada por $\frac{a \sqrt{3}}{\sqrt{2}}$ que é a distância entre os átomos 17 e 24 .

Na tabela 3.2 é mostrado o comprimento de ligação F-F extraído do primeiro pico da $\mathrm{g}_{F-F}(r)$, que fornece o tamanho da aresta do cubo formado pelos Flúors. Nota-se que os valores dos segundos picos F-F que identificam os segundos vizinhos são distâncias iguais a diagonal da face desse cubo, ou seja, os valores dos primeiros picos multiplicados por $\sqrt{2}$. Os terceiros vizinhos situam-se na diagonal do cubo e são localizados pelo terceiro pico da $\mathrm{g}_{F-F}(r)$. Pode-se observar que os valores da coluna do terceiro pico são os valores da coluna do primeiro pico multiplicados por $\sqrt{3}$.

Na Fig. 3.9 existem alterações nos comprimentos das ligações de um dado par de átomos que é função da concentração de $C d F_{2}$ que serão discutidos na próxima subseção.

O sistema misto é naturalmente mais desorganizado que os fluoretos puros ainda que no caso ideal das SSI. Nas soluções sólidas têm-se átomos diferentes, com diferença nos tamanhos, massas, polarizabilidades entre outros, que são arranjados numa mesma rede e isso causa uma maior desordem em relação aos fluoretos puros. Para tornar a idéia mais clara nas Fig. 3.10 são comparadas as $\mathrm{g}_{\alpha \beta}(r)$ dos fluoretos puros com as $\mathrm{g}_{\alpha \beta}(r)$ da SSI com $x=0,50$ onde todos os sistemas foram analisados $\mathrm{T}=50 \mathrm{~K}$. Nas Fig. 3.10 é possível notar que os picos da SSI, identificados pela linha contínua, são mais baixos e mais largos 
que os dos fluoretos puros caracterizando a sua desordem estrutural intrínseca. Na Fig. 3.10 (a) são comparadas as partes estruturais catiônicas da SSI com a do $P b F_{2}$ puro e na Fig. 3.10 (b) as partes catiônicas da SSI com a do $C d F_{2}$ também puro. Nota-se que a linha contínua que descreve a SSI tanto na Fig. 3.10 (a) quanto na Fig. 3.10 (b) tem picos mais baixos e largos em comparação aos fluoretos puros. O mesmo comportamento é observado na parte aniônica como pode ser visto na Fig. 3.10 (c). O comportamento observado para a concentração $x=0,50$ ocorre para todas as composições intermediárias entre o $C d F_{2}$ e o $\mathrm{PbF}_{2}$.

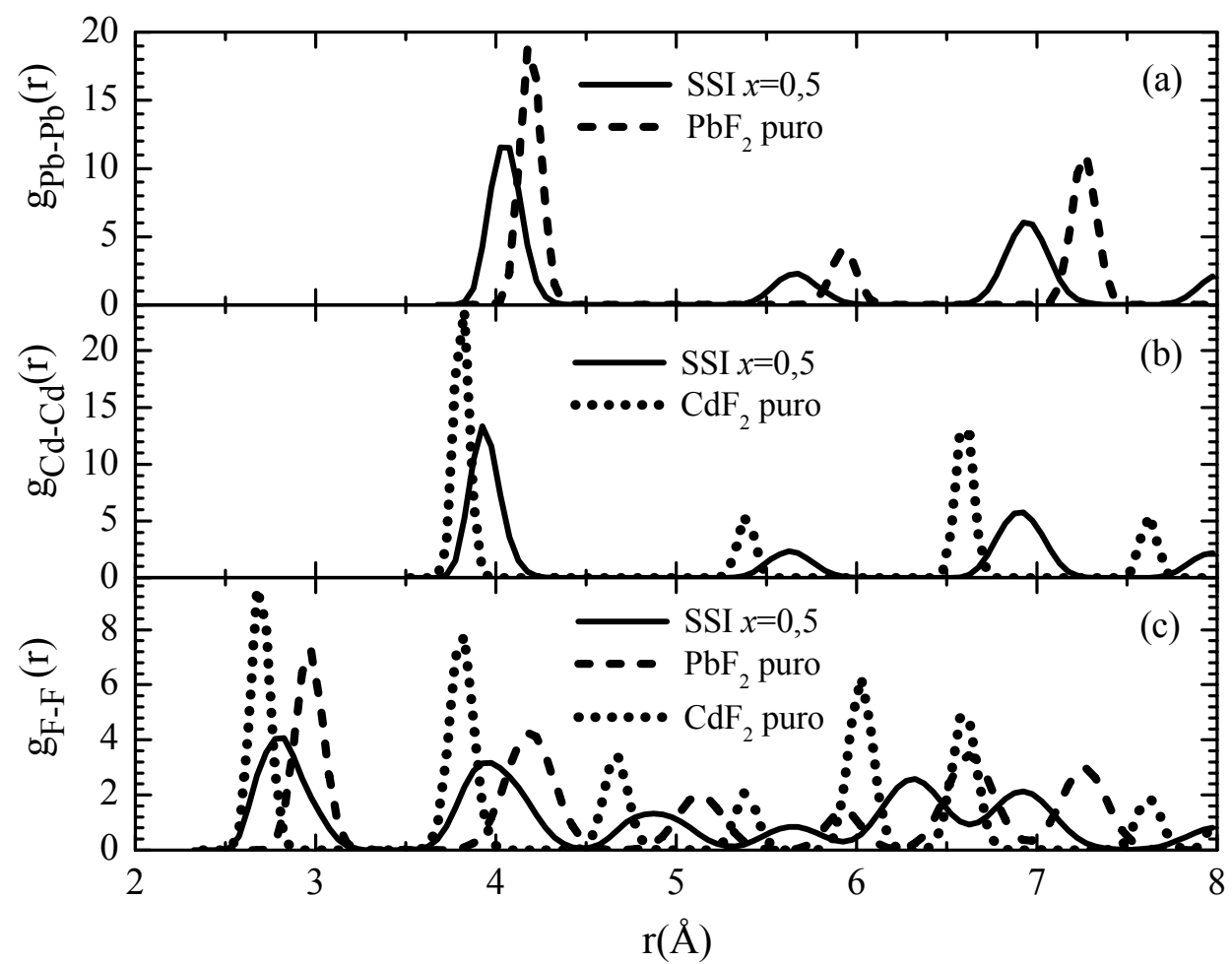

Figura 3.10: Comparação das funções de correlação de pares parciais dos fluoretos puros com as da ISS $x=0,5$ ambos em $\mathrm{T}=50 \mathrm{~K}$.

A desorganização estrutural intrínseca das soluções sólidas tem uma dependência com a composição. Dentre todas as composições existe uma região onde se têm uma desordem estrutural mais acentuada. Para ilustrar tal fato na Fig. 3.9 são mostradas as $\mathrm{g}_{\alpha \beta}(r)$ em $\mathrm{T}=100 \mathrm{~K}$ dos seis pares formadores das SSI. As composições em torno de $x=0,35$ 
identificadas pela linha pontilhada na Fig. 3.9 são as com maior desordem. As alturas de todos os picos das $\mathrm{g}_{\alpha \beta}(r)$ de todos os seis pares de átomos formadores dessas soluções sólidas apresentam tal comportamento de mínimo na região $x=0,35$. A formação das SSI ainda que no caso ideal de um sistema homogêneo, sem defeitos e com estequiometria muito precisa mostra uma desordem estrutural diferente para diferentes composições. Dessa maneira pode-se prever que a composição $x=0,35$ apresentará comportamento dinâmico diferente e essa maior desordem deverá ter influência na temperatura de fusão, conforme será discutido adiante.

A situação discutida na Fig. 3.9 foi ampliada e o comportamento da altura dos picos das $\mathrm{g}_{\alpha \beta}(r)$ para todas as SSI, incluindo os fluoretos puros quando for o caso, estão na Fig 3.11. Nas Fig. 3.11 são mostradas as alturas dos picos das funções de correlação de pares parciais como função da concentração de $C d F_{2}$ na temperatura $100 \mathrm{~K}$. Como todos os picos das $\mathrm{g}_{\alpha \beta}(r)$ dos seis pares de átomos têm comportamento semelhante foram escolhidos o pico mais expressivo de cada par de átomo e mostrados nas Fig. 3.11. A Fig. 3.11 (a) mostra os primeiros picos do par Cd-Cd, a 3.11 (b) os primeiros picos do par $\mathrm{Cd}-\mathrm{Pb}$ e a 3.11 (c) os primeiros picos do par Pb-Pb. Os dados da Fig. 3.11 (d) mostram os segundos pico do par Cd-F, na 3.11 (e) os segundos picos do par Pb-F e na 3.11 (f) os primeiros picos do par F-F. As alturas dos picos de todas as $\mathrm{g}_{\alpha \beta}(r)$ mostram um valor mínimo para as composições em torno de $x=0,35$, o que permite concluir que uma maior desordem em torno dessa composição está presente em todas as esferas de coordenação e envolve todos os tipos de átomos do sistema.

\subsubsection{Relaxação da ligação}

A inclusão de $\mathrm{Cd}$ na rede do $P b F_{2}$ originando a SSI altera os comprimentos de ligações dos seis pares de átomos envolvidos nesse sistema, tanto a parte catiônica que envolve os 

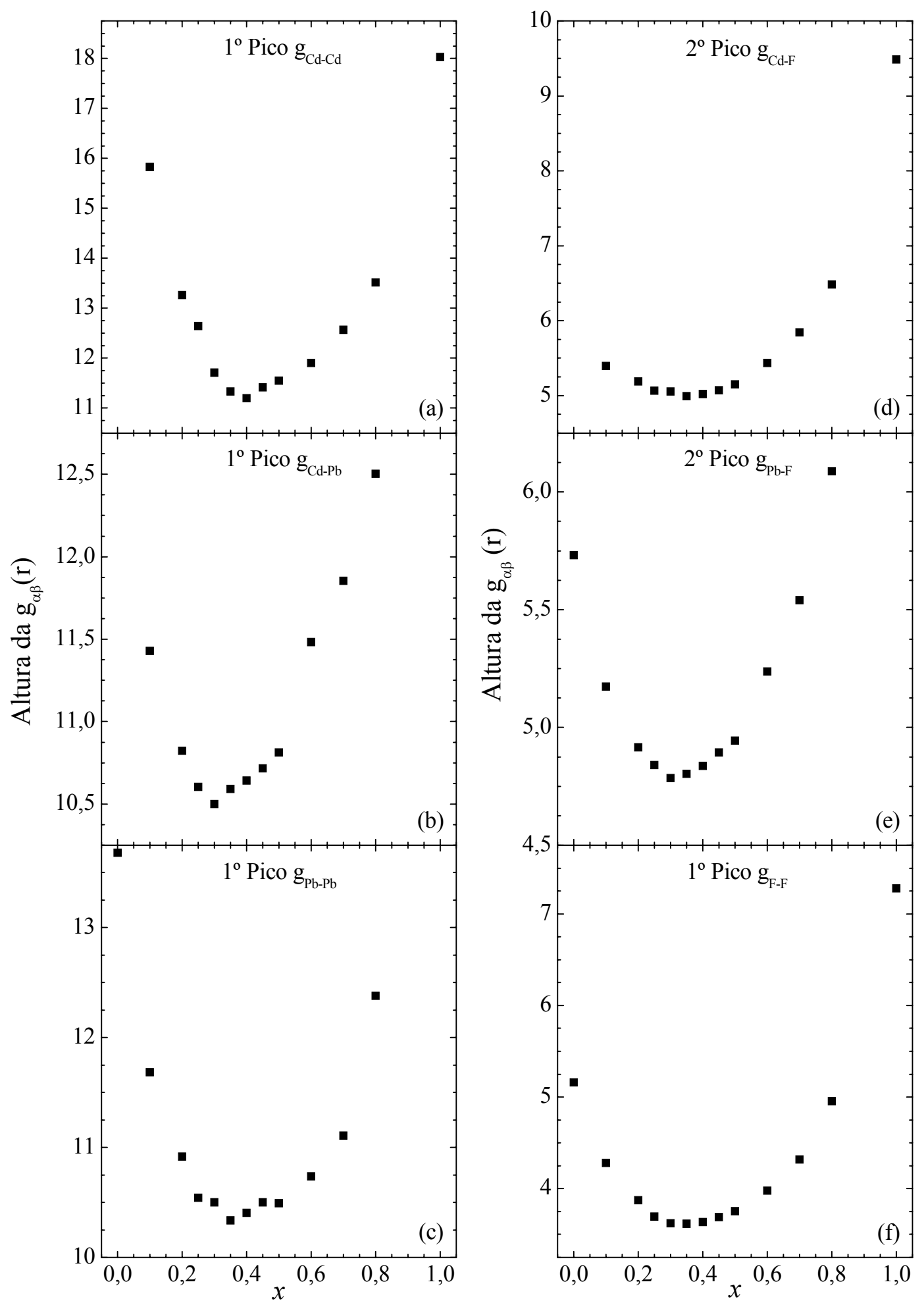

Figura 3.11: Alturas das $g_{\alpha \beta}(r)$ em função da composição das SSI em T=100K. Em (a) são mostradas as alturas dos $1^{0}$ picos do par $\mathrm{Cd}-\mathrm{Cd}$, em (b) dos $1^{0}$ picos do par Cd-Pb, em (c) dos $2^{0}$ picos do par Pb-F, em (d) dos $2^{0}$ picos do par Cd-F, em (e) os $1^{0}$ picos do par $\mathrm{Pb}-\mathrm{Pb}$ e em (f) os $1^{0}$ picos do par F-F. 
pares $\mathrm{Cd}-\mathrm{Cd}, \mathrm{Cd}-\mathrm{Pb}$ e $\mathrm{Pb}-\mathrm{Pb}$ quanto a parte que tem interação com os Flúors $\mathrm{Cd}-\mathrm{F}, \mathrm{Pb}-\mathrm{F}$ e F-F. O comprimento de ligação de um dado par de átomos depende do ambiente em que ele se encontra. A comparação das $\mathrm{g}_{\alpha \beta}(r)$ da SSI com os fluoretos puros mostrada na Fig. 3.10 mostra a relaxação da ligação onde se observa que a posição dos picos de um mesmo par de átomos depende do sistema. Para introduzir a discussão é interessante notar o exemplo das $\mathrm{g}_{\alpha \beta}(r)$ do pares Cd-Cd para qualquer uma das SSI as quais não tem a posição do máximo com os mesmos valores da $\mathrm{g}_{C d-C d}(\mathrm{r})$ do $C d F_{2}$ puro e as $\mathrm{g}_{\alpha \beta}(r)$ do pares $\mathrm{Pb}-\mathrm{Pb}$ de qualquer uma das SSI não tem os mesmos valores da posição do máximo da $\mathrm{g}_{P b-P b}(\mathrm{r})$ do $\mathrm{PbF}_{2}$ puro. O mesmo ocorre para o par $\mathrm{FF}$, em cada um dos três sistemas o comprimento de ligação é diferente. Isso ocorre devido ao sistema ter uma composição mista e decorre em parte do fato do parâmetro de rede do $C d F_{2}$ ser menor que do $P b F_{2}$. Para o caso da ligação Cd-Cd, observa-se que a SSI tem comprimento de ligação maior que o $C d F_{2}$ puro, o contrário do observado nas ligações $\mathrm{Pb}-\mathrm{Pb}$ em relação ao $\mathrm{PbF}$ puro. A explicação para essa situação é que o parâmetro de rede do $P b F_{2}$ é maior que o do $C d F_{2}$ o que causa alteração em todo o sistema. As SSI contém $\mathrm{Cd}$ e $\mathrm{Pb}$ e por isso têm um parâmetro de rede maior que o $C d F_{2}$ puro e menor que do que o do $\mathrm{PbF}_{2}$ puro, assim era de se esperar alterações nas ligações. Os valores dos primeiros picos, que são os comprimentos das ligações e todas as outras posições dos picos mostrados nas tabelas 3.1 e 3.2 mostram que os outros pares de ligações também sofrem alterações. A relaxação da ligação é estudada e conhecida para outros sistemas na literatura[67][66].

A Fig. 3.12 mostra os comprimentos das ligações das SSI obtidos por DM para os seis pares do sistema e a Fig. 3.13 mostra os comprimentos das ligações obtidos experimentalmente por EXAFS[72]. Tanto experimento quanto simulação mostra que as ligações apresentam relaxamento com uma dependência linear com a concentração de $C d F_{2}$. A diferença entre os valores experimentais e os da simulação para o par $\mathrm{Pb}-\mathrm{F}$ e para o par 
$\mathrm{Pb}-\mathrm{Pb}$ são menores que $1 \%$. O par $\mathrm{Cd}-\mathrm{Pb}$ apresenta uma diferença de $1,5 \%$ e o $\mathrm{Cd}-\mathrm{F}$ de $3 \%$.

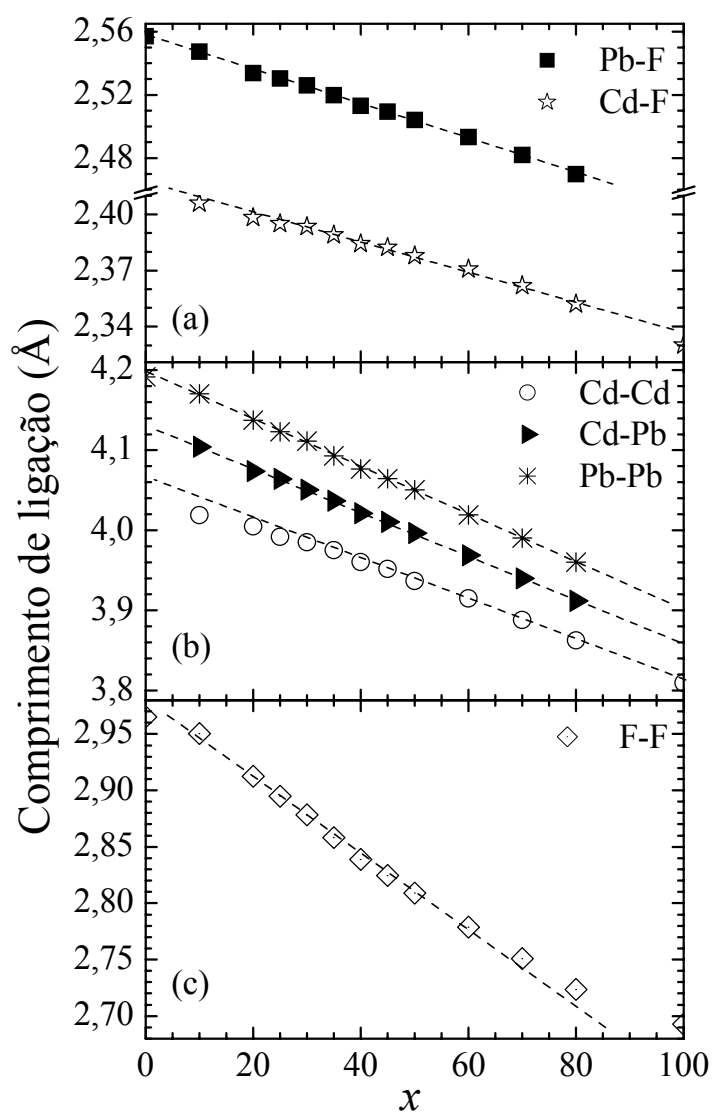

Figura 3.12: Comprimentos das ligações das SSI obtidos por DM. EM (a) são mostradas ligações do tipo cation-anion, em (b) cationcation e em (c) anion-anion.

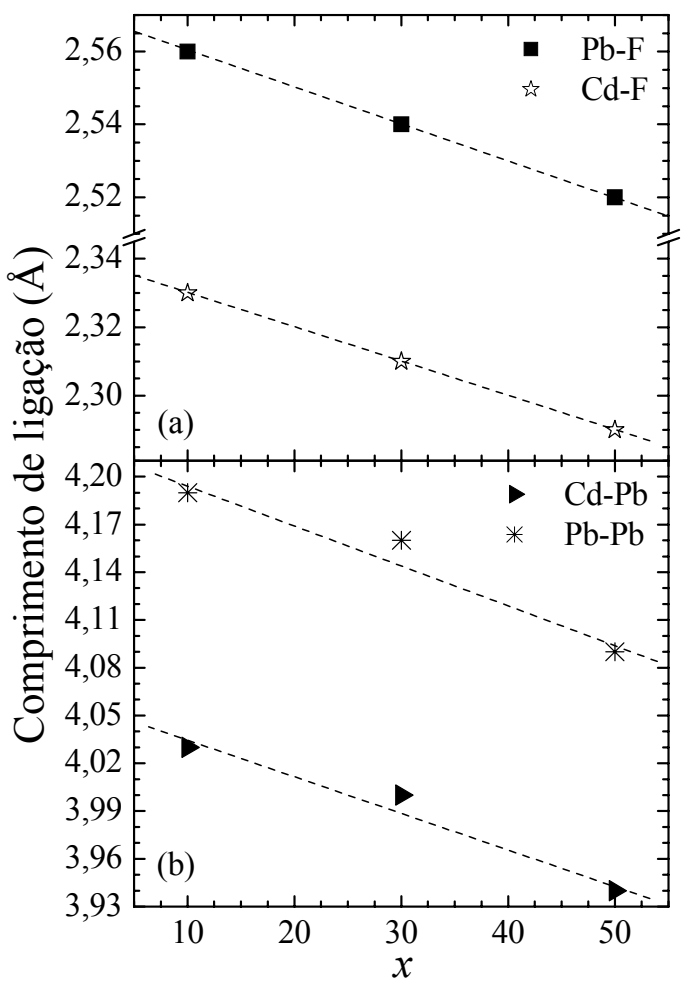

Figura 3.13: Medidas dos comprimentos das ligações obtidas por EXAFS.[72] Em (a) são mostradas ligações cation-anion e em (b) cation-cation.

\subsubsection{Parâmetro de rede}

Para o caso dos fluoretos puros os parâmetros dos potenciais de interação são ajustados de forma que reproduzam os parâmetros de rede conhecidos experimentalmente. Na solução sólida os potenciais de interação são propostos com base nos potenciais dos fluoretos puros sem nenhum ajuste adicional para que reproduzam os parâmetros de rede das SSI.

A comparação do parâmetro de rede da SSI obtido por simulação[24] e experimental- 
mente obtidos por difração de raio-x[72],[73] mostra um excelente acordo como pode ser visto na Fig. 3.14. Os autores dos dados experimentais sugerem que os sistemas obtidos são homogêneos. Os dados mostram a variação linear do parâmetro de rede devido ao aumento na concentração de $C d F_{2}$ seguindo a lei de Vegard. Na Fig. 3.14 os dados mostram os parâmetros de rede desde o $\mathrm{PbF}_{2}$ puro com $a=5,94$ A até o outro extremo o $C d F_{2}$ puro com $a=5,39 \AA$. Como o $C d F_{2}$ tem um parâmetro de rede menor que o do $\mathrm{PbF}_{2}$ a inclusão de $\mathrm{Cd}$ na rede do $P b F_{2}$ leva a diminuição do parâmetro de rede como um todo, conforme discutido na seção anterior.

É notável e de grande importância que o potencial de interação descreva com um pequeno erro o parâmetro de rede das SSI, o que traz credibilidade para o potencial e o torna confiável na descrição precisa das interações do sistema. Além disso, o potencial mostra-se bastante promissor quando consegue descrever os parâmetros de rede de todas as SSI quantitativamente, uma vez que ele não foi ajustado com base nesses dados. O sucesso em descrever a solução sólida baseando-se nos fluoretos puros mostra a transferabilidade do potencial que é o item 3 das características de Brenner[20], anteriormente discutido, para um potencial ser realista e eficaz.

O parâmetro de rede do sistema pode ser estimado de várias maneiras. Na Fig. 3.15, são mostradas quatro maneiras que permitem avaliar o parâmetro de rede. Para o caso ideal da SSI que é uma solução sólida totalmente homogênea e com estequiometria muito precisa, todas as maneiras de estimar o parâmetro de rêde são bastante coerentes e mostram a sua diminuição com comportamento linear com a adição de $C d F_{2}$. Partindo do $P b F_{2}$ puro com $a=5,93 \AA$ e chegando ao $C d F_{2}$ com $a=5,39 \AA$ o parâmetro de rede diminui linearmente cerca de $10 \%$. Devido a parte catiônica do sistema ser uma rede cfc e devido o sistema ser homogêneo o segundo pico da $\mathrm{g}_{\alpha \beta}(\mathrm{r})$ da rede catiônica, o qual fornece a distância entre segundos vizinhos, fornecem a posição da aresta de uma 


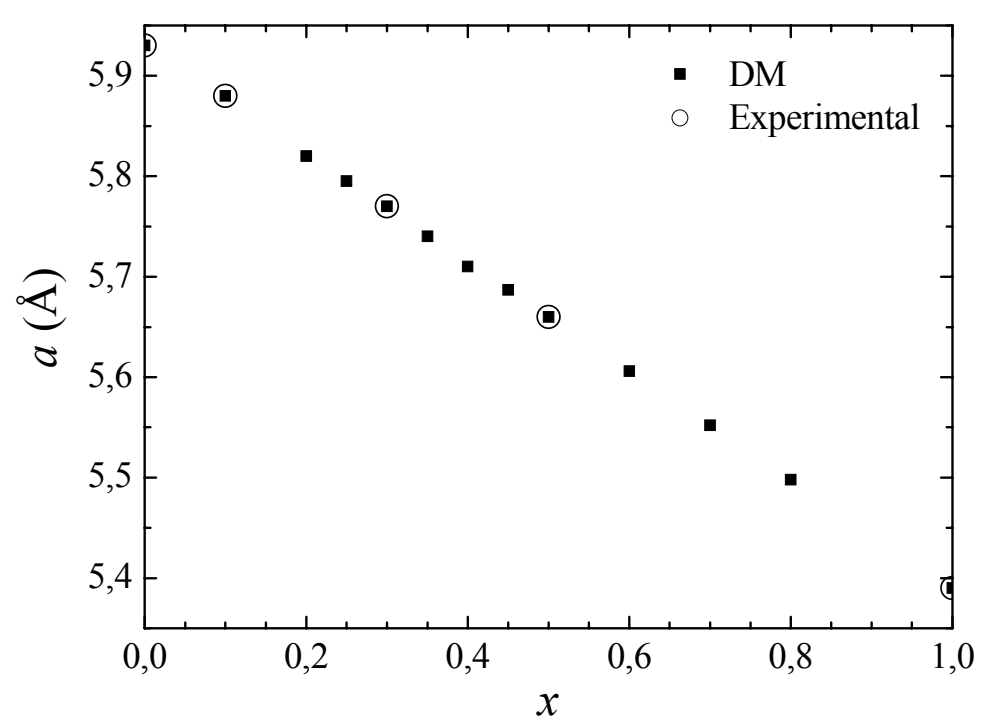

Figura 3.14: Parâmetro de rede em função da concentração. Comparação entre DM e dados experimentais.

célula unitária, ou seja, o parâmetro de rede. Na figura 3.15 os quadrados preenchidos e as estrelas abertas mostram os valores dos segundos picos das $\mathrm{g}_{\alpha \beta}(\mathrm{r})$ versus concentração para os pares $\mathrm{Cd}-\mathrm{Cd}$ e $\mathrm{Pb}-\mathrm{Pb}$ respectivamente. Uma vez que nas SSI são conhecidas as $\mathrm{g}_{\alpha \beta}(\mathrm{r})$ catiônicas, uma maneira alternativa para estimar o parâmetro de rede é fazer médias com as distâncias obtidas do segundo pico da $\mathrm{g}_{\alpha \beta}(\mathrm{r})$. A importância dessas médias é poder avaliar os parâmetros de rede observados experimentalmente que são sempre uma média dessas distâncias observadas nas $\mathrm{g}_{\alpha \beta}(\mathrm{r})$. Para o caso de um sistema com separação de fase, as médias podem trazer informações errôneas e não permitem identificar a não homogeneidade. As médias obtidas na DM também ocultam uma possível separação de fase, mas como são conhecidos os dados parciais que compõem a média pode-se prever corretamente a não homogeneidade e tal fato será discutido adiante quando os cristais analisados não forem mais homogêneos. Chamando de $d_{P b P b}$ a distância do segundo pico da $\mathrm{g}_{P b-P b}(\mathrm{r})$ e $d_{C d C d}$ a distância do segundo pico da $\mathrm{g}_{C d-C d}(\mathrm{r})$, a média simples é dada por:

$$
m_{s}=\frac{d_{C d C d}+d_{P b P b}}{2}
$$


A média simples está representada na figura 3.15 pelos asteriscos. A média ponderada, representada pelas bolas abertas na figura 3.15, leva em consideração a concentração de cada elemento da rede catiônica e é dada por:

$$
m_{p}=x\left(d_{C d C d}\right)+(1-x)\left(d_{P b P b}\right) .
$$

Para o caso da concentração $x=0,10$ ocorre a maior discrepância de todas as concentrações e métodos, e a variação entre $d_{P b P b}$ e $d_{C d C d}$ é de $0,94 \%$. A maior variação está associada a menor concentração de $C d F_{2}$ que leva a uma $\mathrm{g}_{C d-C d}(\mathrm{r})$ menos precisa. Para a concentração $x=0,80$ a diferença entre $d_{P b P b}$ e $d_{C d C d}$ está em torno de $0,50 \%$.

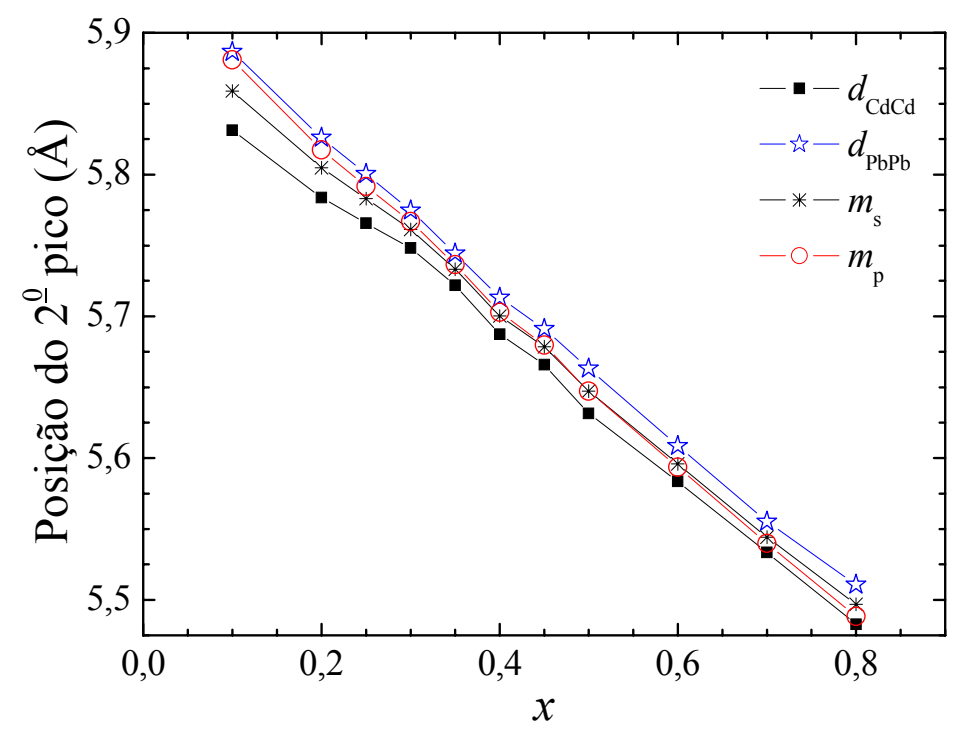

Figura 3.15: Parâmetro de rede obtido do segundo pico das $\mathrm{g}_{P b-P b}(\mathrm{r})\left(\mathrm{d}_{P b P b}\right)$ e $\mathrm{g}_{C d-C d}(\mathrm{r})$ $\left(\mathrm{d}_{C d C d}\right)$, comparados com as média simples $\left(\mathrm{m}_{s}\right)$ e a média ponderada $\left(\mathrm{m}_{p}\right)$.

\subsubsection{Número de vizinhos}

O número de vizinhos ou número de coordenação é uma importante característica do sistema que pode, assim como as $\mathrm{g}_{\alpha \beta}(r)$, ser obtida da simulação trazendo a informação de cada par de átomos do sistema. As tabelas 3.3 e 3.4 trazem os valores para os primeiros, segundos e terceiros vizinhos das SSI em $\mathrm{T}=50 \mathrm{~K}$ juntamente com alguns valores experi- 
Tabela 3.3: Número de vizinhos dos pares $\mathrm{Cd}-\mathrm{Cd}, \mathrm{Cd}-\mathrm{Pb}$ e $\mathrm{PbPb}$. A coluna identificada por EX representa os dados obtidos por EXAFS e todos os outros são obtidos da DM.

\begin{tabular}{c|ccc|cccc|cccc}
$x$ & \multicolumn{10}{c}{$\mathrm{Cd}-\mathrm{Cd}-\mathrm{Pb}$} \\
& $1^{0}$ & $2^{0}$ & $3^{0}$ & $1^{0}$ & $1^{0} \mathrm{EX}$ & $2^{0}$ & $3^{0}$ & $1^{0}$ & $1^{0} \mathrm{EX}$ & $2^{0}$ & $3^{0}$ \\
0,00 & - & - & - & - & - & - & - & 12,0 & - & 6,00 & 24,0 \\
0,10 & 1,59 & 0,59 & 2,39 & 1,60 & 1,70 & 0,61 & 2,41 & 10,8 & 10,30 & 5,41 & 21,56 \\
0,20 & 2,60 & 1,06 & 4,83 & 2,61 & - & 1,07 & 4,86 & 9,64 & - & 4,75 & 19,19 \\
0,25 & 3,10 & 1,38 & 6,03 & 3,11 & - & 1,39 & 6,05 & 9,02 & - & 4,46 & 17,99 \\
0,30 & 3,66 & 1,73 & 7,31 & 3,67 & 3,50 & 1,74 & 7,29 & 8,40 & 8,50 & 4,16 & 16,84 \\
0,35 & 4,19 & 2,07 & 8,4 & 4,21 & - & 2,07 & 8,42 & 7,80 & - & 3,88 & 15,61 \\
0,40 & 4,81 & 2,46 & 9,55 & 4,82 & - & 2,47 & 9,58 & 7,19 & - & 3,64 & 14,34 \\
0,45 & 5,39 & 2,74 & 10,72 & 5,41 & - & 2,74 & 10,74 & 6,59 & - & 3,33 & 13,11 \\
0,50 & 6,00 & 3,00 & 12,0 & 6,00 & 5,90 & 3,00 & 12,0 & 6,00 & 6,10 & 3,00 & 12,0 \\
0,60 & 7,12 & 3,64 & 14,44 & 7,13 & - & 3,65 & 14,47 & 4,66 & - & 2,46 & 9,63 \\
0,70 & 8,35 & 4,21 & 16,8 & 8,37 & - & 4,22 & 16,82 & 3,50 & - & 1,83 & 7,20 \\
0,80 & 9,60 & 4,81 & 19,19 & 9,62 & - & 4,81 & 19,22 & 2,40 & - & 1,22 & 4,73 \\
1,00 & 12,0 & 6,00 & 24,0 & - & - & - & - & - & - & - & -
\end{tabular}

mentais obtidos por EXAFS[72]. A tabela 3.3 traz informações sobre a parte catiônica do sistema e a tabela 3.4 contém as informações dos pares de átomos que envolvem os Flúors.

Para as concentrações $x=0,10, x=0,30$ e $x=0,50$ foram feitas comparações com experimentos de EXAFS para os primeiros vizinhos dos pares $\mathrm{Cd}-\mathrm{Pb}$ e $\mathrm{Pb}-\mathrm{Pb}$. Os resultados na tabela 3.3 mostram um bom acordo entre simulação e experimento para as três concentrações.

É interessante notar a simetria nos valores dos números de vizinhos quando se altera a concentração de $C d F_{2}$ para o caso de sistemas homogêneos como as SSI. Na tabela 3.3 nota-se que o par Cd-Cd tem 2,6 primeiros vizinhos para a concentração $x=0,20(20 \%$ de $\left.C d F_{2}\right)$ e o par $\mathrm{Pb}-\mathrm{Pb}$ tem 2,4 primeiros vizinhos para a concentração $x=0,80(20 \%$ de $P b F_{2}$ ). A conclusão é que em um sistema cujo fluoreto puro contribui com $20 \%$ na formação da SSI, o par de átomos formado por cátions iguais ao deste fluoreto, tem em média 2,5 primeiros vizinhos. Tal simetria também pode ser observada para as outras concentrações e pares de átomos.

Na tabela 3.4 são mostrados os números de vizinhos do par Pb-F para os quais são feitas comparações com medidas experimentais por EXAFS para os primeiros e segundos vizinhos. Não há variações expressivas do número de primeiros vizinhos como função da 
concentração de $C d F_{2}$ permanecendo com valor em torno de 8 Flúors primeiros vizinhos, tanto na DM quanto no EXAFS. Entretanto, observa-se uma grande variação no número de segundos vizinhos nas medidas de EXAFS quando a concentração de $C d F_{2}$ e nenhuma alteração na DM. As medidas EXAFS mostram que a concentração $x=0,10$ tem 25 segundos vizinhos enquanto que a $x=0,50$ tem 13,6. As medidas de EXAFS para os números de vizinhos estão relacionadas ao fator de Debye-Waller, o qual está relacionado à desordem estatística e térmica do sistema. Essa diminuição no número de segundos vizinhos do par Pb-F está associada a uma diminuição no fator de Debye-Waller, devido a alta desordem estrutural da rede aniônica. Na tabela 3.4 nota-se que os valores obtidos por DM para um dado par e uma dada esfera de coordenação não sofrem alterações com a concentração de $C d F_{2}$. Por exemplo, o par Cd-F tem 8 primeiros vizinhos, 24 segundos vizinhos e 24 terceiros vizinhos para qualquer uma das concentrações. As SSI simuladas usando DM dizem respeito a um sistema muito homogêneo e mais organizado que uma solução sólida obtida por resfriamento do líquido e por isso o número de vizinhos permanece constante.

Como o sistema tem alguns dos $\mathrm{Pb}$ do sistema original $\left(\mathrm{PbF}_{2}\right)$ substituídos por $\mathrm{Cd}$, as ligações do tipo $\mathrm{Cd}-\mathrm{F}$ e $\mathrm{Pb}-\mathrm{F}$ devem levar ao mesmo tipo de vizinhança. Tal fato é confirmado na tabela 3.4 onde nota-se que o número de coordenação na primeira, segunda e terceira esfera de coordenação dos pares $\mathrm{Cd}-\mathrm{F}$ e $\mathrm{Pb}-\mathrm{F}$ são os mesmos para qualquer concentração. As primeiras, segundas e terceiras esferas de coordenação do par F-F também apresentam a mesma vizinhança para qualquer concentração. Como o comportamento é o mesmo para qualquer concentração são mostradas apenas três delas na tabela 3.4. 
Tabela 3.4: Número de vizinhos dos pares Cd-F, Pb-F e FF. A coluna identificada por EX representa os dados obtidos por EXAFS e todos os outros são obtidos da DM.

\begin{tabular}{c|ccc|ccccc|ccc}
$x$ & \multicolumn{9}{|c}{ Cd-F } & \multicolumn{1}{c}{ Pb-F } \\
& $1^{0}$ & $2^{0}$ & $3^{0}$ & $1^{0}$ & $1^{0} \mathrm{EX}$ & $2^{0}$ & $2^{0} \mathrm{EX}$ & $3^{0}$ & $1^{0}$ & $2^{0}$ & $3^{0}$ \\
0,10 & 8,00 & 24,0 & 24,0 & 8,00 & 8,10 & 24,0 & 25,0 & 24,0 & 6,00 & 12,0 & 8,0 \\
0,30 & 8,00 & 24,0 & 24,0 & 8,00 & 8,00 & 24,0 & 22,4 & 24,0 & 6,00 & 12,0 & 8,0 \\
0,50 & 8,00 & 24,0 & 24,0 & 8,00 & 8,00 & 24,0 & 13,6 & 24,0 & 6,00 & 12,0 & 8,0
\end{tabular}

\subsubsection{Função de correlação de pares Total}

A função de correlação de pares total, g(r), traz uma informação média do sistema assim como o experimento de difração por raio-x e EXAFS que permite dizer com uma única curva se o sistema é cristalino ou não e o grau de organização. A g(r) é uma soma ponderada das $\mathrm{g}_{\alpha \beta}(\mathrm{r})$, conforme foi apresentada na introdução do método DM na seção das propriedades estruturais. Na Fig. 3.16 (a) são mostradas as g(r) para $x=0,10$ e $x=0,80$ e nas Fig. 3.16 (b) a (g) são fornecidos os dados parciais utilizados na composição da g(r). A linha contínua representa a composição $x=0,10$ e tem os seus picos identificados pelos algarismos romanos de I a VIII. Para mostrar os extremos das concentrações das SSI a Fig. 3.16 contém também a concentração $x=0,80$ representada pela linha pontilhada a qual tem os seus picos semelhantes aos da $x=0,10$, porém em distâncias menores devido a relaxação da ligação discutida anteriormente. A interpretação da $\mathrm{g}(\mathrm{r})$ total será feita utilizando a $x=0,10$, mas a mesma discussão vale para a $x=0,80$ e todas as outras concentrações.

Na Fig. 3.16 até 3,5Å não existe nenhuma ligação cátion-cátion, assim os picos I e II da g(r) na Fig. 3.16 (a) envolvem ligações com Flúor. O pico I da g(r) é formado pelos picos I da $g_{P b-F}(\mathrm{r})($ Fig. $3.16(\mathrm{~d}))$ e I da $\mathrm{g}_{C d-F}(\mathrm{r})$ (Fig. 3.16 (f)). O pico II na Fig. 3.16 (a) é formado somente pelas ligações F-F que podem ser vistas no pico I da Fig. 3.16 (c). O pico III da g(r) tem a maior contribuição proveniente das ligações cátion-cátion, sendo formado pelo pico I da $\mathrm{g}_{C d-C d}(\mathrm{r})$ (Fig. 3.16 (b)), pelo pico I da $\mathrm{g}_{P b-P b}(\mathrm{r})$ (Fig. $3.16(\mathrm{e}))$, pico I da $\mathrm{g}_{C d-P b}(\mathrm{r})$ (Fig. $\left.3.16(\mathrm{~g})\right)$ e conta ainda com a contribuição do pico II 
da $g_{F-F}(\mathrm{r})$ (Fig. $3.16(\mathrm{c})$ ). O pico IV da $\mathrm{g}(\mathrm{r})$ expressa a contribuição da segunda esfera de coordenação dos pares do tipo cátion-anion sendo formado pelo pico II da $\mathrm{g}_{P b-F}(\mathrm{r})$, pelo pico II da $\mathrm{g}_{C d-F}(\mathrm{r})$ e ainda tem a contribuição do terceiro pico $\mathrm{g}_{F-F}(\mathrm{r})$. O pico $\mathrm{V}$ constitui-se dos segundos picos da $\mathrm{g}_{C d-C d}(\mathrm{r}), \mathrm{g}_{C d-P b}(\mathrm{r})$ e $\mathrm{g}_{P b-P b}(\mathrm{r})$ e também do pico IV da da $g_{F-F}(r)$. O sexto pico da $\mathrm{g}(\mathrm{r})$ é formado pelos terceiros picos das $\mathrm{g}_{P b-F}(\mathrm{r})$ e $\mathrm{g}_{C d-F}(\mathrm{r})$ e pelo pico $\mathrm{V}$ da $\mathrm{g}_{F-F}(\mathrm{r})$. Todos os picos da $\mathrm{g}(\mathrm{r})$ que expressam a contribuição dos pares cátion-cátion (III, V, VII) contém também a contribuição de um pico da $g_{F-F}(\mathrm{r})$. A g(r) da SSI com $x=0,80$ tem picos com altura maior e são mais estreitos que os picos da SSI com $x=0,10$ indicando que o sistema com grande concentração de $C d F_{2}$ tem menor desordem estrutural.

Na Fig. 3.17 são mostradas as g(r) para todas as concentrações das SSI e também os fluoretos puros. Os picos I e II são bem definidos nos fluoretos puros, mas para as concentrações próximas de $x=0,35$ eles passam a se sobrepor. O primeiro motivo é que os pares formadores do pico I têm uma relaxação da ligação menor que o par que forma o pico II. Como discutido anteriormente o pico I da g(r) representa as ligações dos pares $\mathrm{Cd}-\mathrm{F}$, as quais têm relaxação da ligação em torno de 2,5\%, e dos pares $\mathrm{Pb}-\mathrm{F}$, os quais têm relaxação da ligação em torno de 3,1\%. Já o segundo pico representa as ligações F-F as quais tem uma relaxação de $7,8 \%$. Com o aumento de $C d F_{2}$ no sistema o pico II desloca-se mais que o pico I contribuindo para superposição. Mas o motivo mais forte que leva a superposição é a característica intrínseca do sistema em ser mais desordenado para concentrações em torno de $x=0,35$. O pico $\mathrm{V}$ também é bem definido para os fluoretos puros e tem um alargamento expressivo na região da SSI $x=0,35$. 




Figura 3.16: Funções de correlação de pares parciais e totais para as SSI $x=0,1$ e $x=0,8$ em $\mathrm{T}=100 \mathrm{~K}$. 


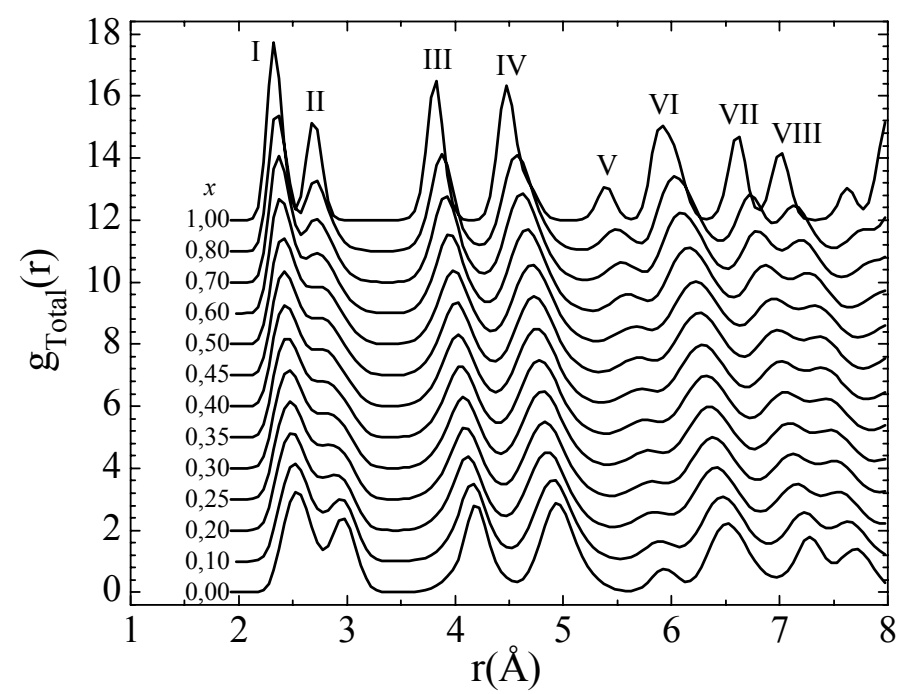

Figura 3.17: Função de correlação de pares total em função da distância para todas as SSI em $\mathrm{T}=100 \mathrm{~K}$.

\subsubsection{Posição do Flúor numa rede do tipo $P b F_{2}$.}

Numa estrutura do tipo $\mathrm{PbF}_{2}$ os Flúors são tetraedricamente coordenados com os cátions. Os cátions que são os primeiros vizinhos dos Flúors formam um tetraedro dando origem a um ponto de simetria tetraédrica, também chamado de buraco tetraédrico, que são ocupados pelos Flúors. As Fig. 3.18 e 3.19 mostram um exemplo de tetraedro formado pelos cátions e o Flúor inserido nele. Os cátions são representados pelas bolas preenchidas com a cor preta e os Flúors pelas bolas brancas. São mostrados 4 cátions que estão identificados pelos números 1, 2, 3 e 4 e estão conectados para destacar o tetraedro. As linhas pontilhadas são apenas guias para os olhos ajudando a identificar as arestas da célula unitária. Uma maneira de caracterizar a homogeneidade das SSI é identificar o tipo de tetraedro que o Flúor está inserido, ou seja qual a vizinhança do Flúor. Uma vez que o Flúor inserido no buraco tetraédrico tem 4 cátions ( $\mathrm{Pb}$ ou $\mathrm{Cd}$ ) como primeiros vizinhos, podem ocorrer cinco configurações diferentes de vizinhança. Para identificar o tipo de tetraedro foi utilizada a notação $\mathrm{Q}_{i}$ onde $i$ é o número de $\mathrm{Pb}$ ligados ao $\mathrm{F}$. Assim tipo 0, $\mathrm{Q}_{0}$, identifica a situação com nenhum $\mathrm{Pb}$ pertencente ao tetraedro, ou seja, $4 \mathrm{Cd}$. 


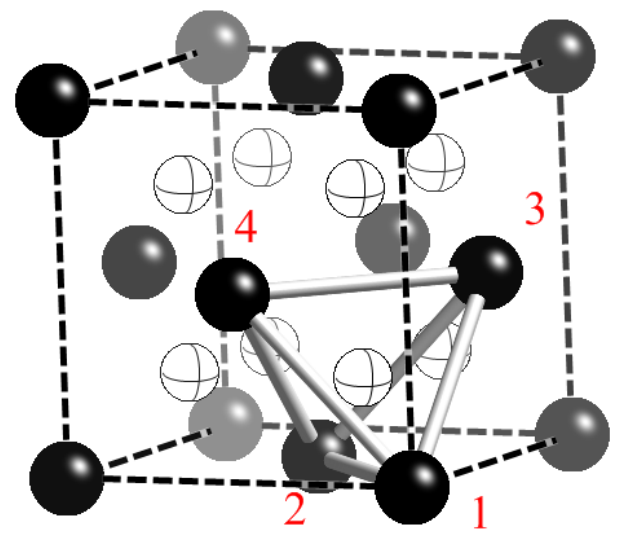

Figura 3.18: Célula unitária do $\mathrm{PbF}_{2}$ (Fig.3.1) destacando o buraco tetraédrico ocupado pelo Fluor.

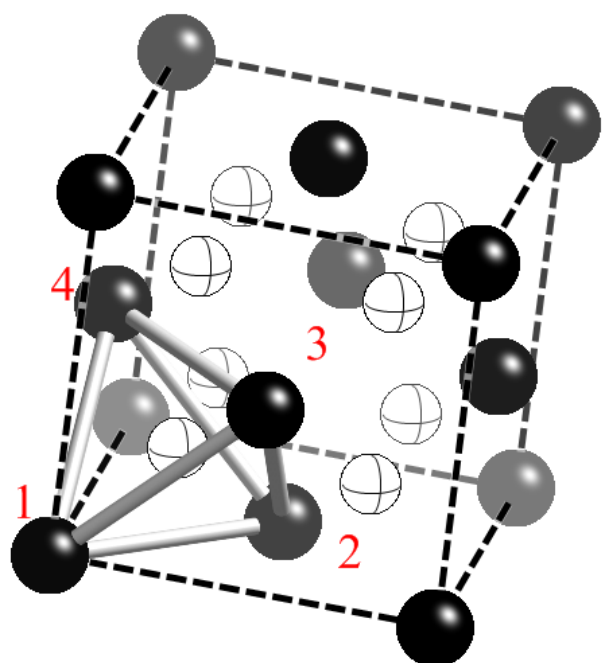

Figura 3.19: Tetraedro formado pelos cátions $1,2,3$ e 4 visto de outro ângulo.

Para o $\mathrm{Q}_{1}$ tem-se $1 \mathrm{~Pb}$ e $3 \mathrm{Cd}$, para $\mathrm{Q}_{2}$ tem-se $2 \mathrm{~Pb} 2 \mathrm{Cd}$, para o $\mathrm{Q}_{3}$ tem-se $3 \mathrm{~Pb}$ e $1 \mathrm{Cd}$ e por último o $\mathrm{Q}_{4}$ identifica a situação onde só existem $\mathrm{Pb}$ e não se tem nenhum $\mathrm{Cd}$. Para analisar a vizinhança dos Flúors, na Fig. 3.20, foi criado um histograma onde na abcissa são representados os $\mathrm{Q}_{i}$, e na ordenada a porcentagem de ocorrência desses tetraedros.

Quando o sistema é homogêneo cada um dos tetraedros segue uma distribuição estatística $d$ definida abaixo onde $x$ é a concentração de Cd e g é a degenerescência de cada caso:

Tipo do tetraedro $d=$ Distribuição estatística $\mathrm{g}$

$\begin{array}{lll}\mathrm{Q}_{0} & \mathrm{~g}(1-x)^{0} x^{4} & 1 \\ \mathrm{Q}_{1} & \mathrm{~g}(1-x)^{1} x^{3} & 4 \\ \mathrm{Q}_{2} & \mathrm{~g}(1-x)^{2} x^{2} & 6 \\ \mathrm{Q}_{3} & \mathrm{~g}(1-x)^{3} x^{1} & 4 \\ \mathrm{Q}_{4} & \mathrm{~g}(1-x)^{4} x^{0} & 1\end{array}$

Todas as composições das SSI seguem a distribuição definida acima e a ocorrência de cada tipo de tetraedro para essas SSI pode ser visto na Fig. 3.20. Para ilustrar a homogeneidade foi analisado o sistema com $x=0,50$. Nessa composição existem as mesmas proporções de $\mathrm{Cd}$ e $\mathrm{Pb}$ e os tetraedros com maior porcentagem de ocorrência 
são os do tipo $Q_{2}$ que identificam um sistema realmente misto. Para a concentração $x=0,50$ os tetraedros com menores porcentagens de ocorrência são os do tipo $\mathrm{Q}_{0}$ e $\mathrm{Q}_{4}$ indicando que não existem regiões ricas em $\mathrm{Pb}$ ou $\mathrm{Cd}$. Ainda na concentração $x=0,50 \mathrm{a}$ segunda maior porcentagem de ocorrência é observada para o caso com três cátions iguais e apenas o quarto cátion diferente que são os tetraedros do tipo $\mathrm{Q}_{1}$ e $\mathrm{Q}_{3}$. Para as outras concentrações a porcentagem dos tipos de tetraedro passa a depender da concentração de $C d F_{2}$ de acordo com a distribuição estatística definida acima. Na Fig. 3.20 quando a concentração de $C d F_{2}$ é pequena $(x=0,10)$ a grande parte dos tetraedros são do tipo $\mathrm{Q}_{4}$ devido a falta de $\mathrm{Cd}$ no sistema. Na situação oposta em $x=0,80$ a grande parte dos tetraedros é do tipo $\mathrm{Q}_{0}$.

\subsection{7 Ângulos de ligação}

Para avaliar os ângulos formados pelos átomos é necessário garantir que o cálculo seja feito somente entre primeiros vizinhos. Para isso foi utilizado um raio de corte para cada par de átomos determinado pelo primeiro mínimo da $\mathrm{g}_{\alpha \beta}(\mathrm{r})$ conforme discutido na seção de propriedades estruturais no Capítulo 2. A representação do ângulo inclui três átomos e foi utilizada a notação dada por: A-B-C, onde B é o átomo central (vértice) do ângulo. Nas Fig. 3.21, 3.22 e 3.23 são mostradas três dentre todas as concentrações estudadas para ilustrar o comportamento dos ângulos em situações onde o sistema tem pouca concentração de $C d F_{2}(x=0,10)$ e chegando ao outro extremo quando a concentração é grande $(x=0,80)$.

Na Fig. 3.21 foram analisados os ângulos formados entre os cátions e os Flúors onde os Flúors são os átomos do vértice do ângulo. Os F se encontram inseridos em tetraedros formados pelos cátions conforme discutido na seção anterior e em uma rede ideal do tipo $\mathrm{PbF}_{2}$ nota-se que o ângulo formado com os cátions quando o Flúor está no vértice é de 

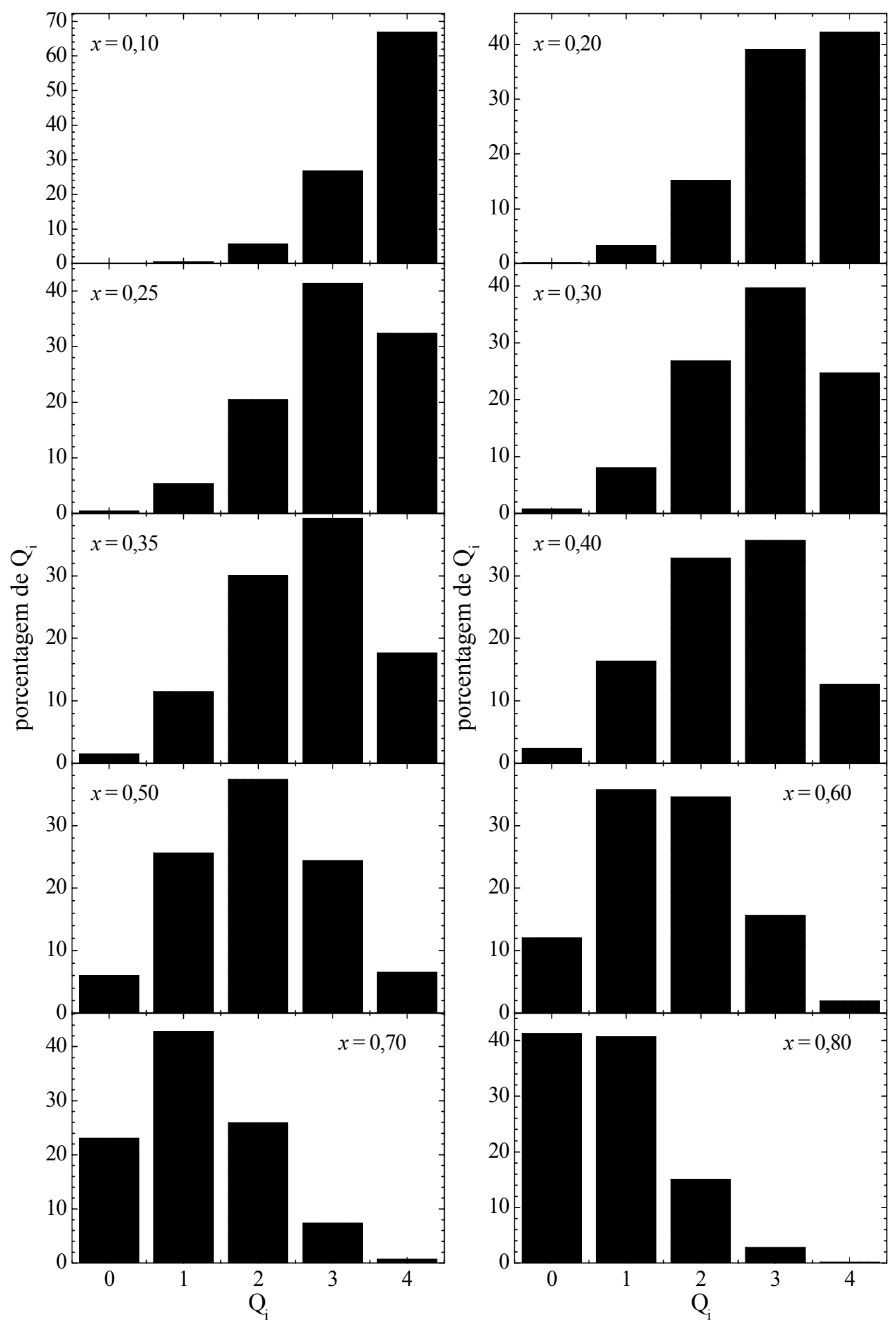

Figura 3.20: Identificação do tipo de tetraedro que o Fluor está inserido nas SSI em $\mathrm{T}=50 \mathrm{~K}$. 
109 ${ }^{\circ}$. O F pode formar o ângulo em três situações diferentes: com dois Cd (Fig. 3.21 (a), 3.21 (d) e 3.21 (g)); Com um Cd e um Pb (Fig. 3.21 (b), 3.21 (e) e $3.21(\mathrm{~h})$ ); ou ainda com dois $\mathrm{Pb}$ (Fig. 3.21 (c), 3.21 (f) e 3.21 (i)). Devido a homogeneidade das SSI esse valor de $109^{\circ}$ para o ângulo cátion-F-cátion é o mesmo quaisquer que sejam os cátions e qualquer que seja a concentração de $C d F_{2}$.
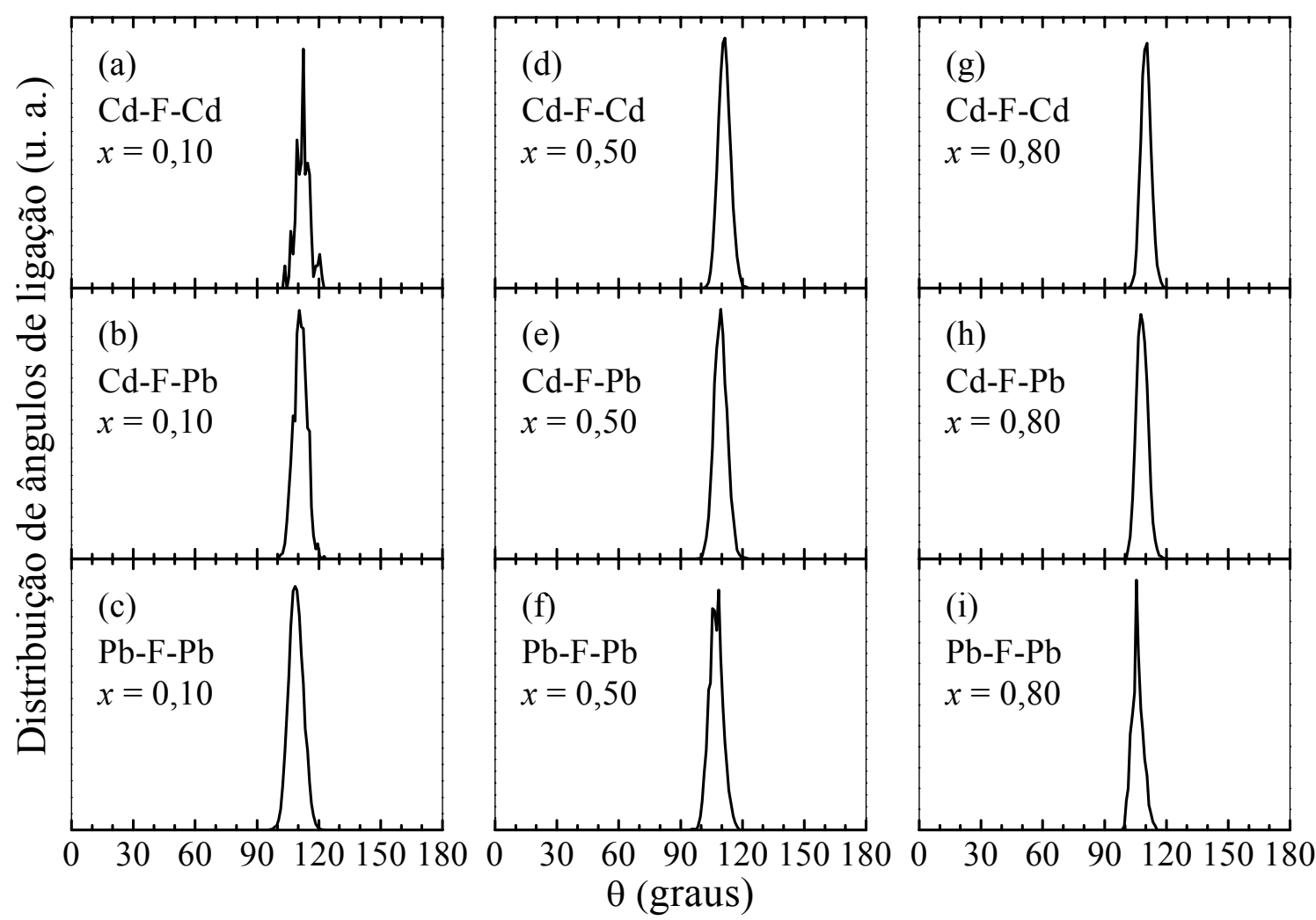

Figura 3.21: Ângulos das SSI entre os $\mathrm{F}$ e os cátions em $\mathrm{T}=50 \mathrm{~K}$.

Os ângulos formados pelos cátions caracterizam a estrutura cristalina cfc da sub-rede catiônica. A estrutura cfc tem três ângulos característicos que são: $60^{\circ}, 90^{\circ}$ e $120^{\circ}$. Esses ângulos podem ser facilmente observados na célula unitária do sistema anteriormente apresentada na Fig. 3.2. Na Fig. 3.2 alguns cátions são numerados e podem-se ter alguns exemplos dos ângulos formados. Podem-se identificar os ângulos de $60^{\circ}$ formados pelos átomos 26-18-27, 19-17-20 e 19-18-17. Os átomos 17-20-26 e 21-20-17 formam ângulo de $90^{\circ}$ e os átomos 17-19-24 e 17-18-24 formam o ângulo de $120^{\circ}$. Na Fig. 3.22 são 
mostradas duas possibilidades para a formação dos ângulos: uma com o Cd como vértice e outra sendo o Pb como vértice. O Cd é o vértice nas Fig. 3.22 (a), (b), (c), (g), (h), (i), (m), (n) e (o). O Pb é vértice nas Fig. 3.22 (d), (e), (f), (j), (k), (l), (p), (q) e (r). Nas 18 curvas mostradas na Fig. 3.22 o comportamento é sempre o mesmo, mostrando os três ângulos característicos da rede cfc não existindo diferenças devido a escolha do átomo vértice e nem dos outros dois cátions que formam o ângulo. São mostradas três SSI com concentrações diferentes que comprovam que o sistema misto analisado preserva a estrutura cristalina inicial do $P b F_{2}$ independendo da concentração analisada.

Na Fig. 3.23 os ângulos de $90^{\circ}$ e $180^{\circ}$ mostram a estrutura cúbica simples da sub-rede aniônica. Nota-se que a concentração com maior quantidade de $C d F_{2}$ tende a ter picos com maior altura e mais estreitos indicando maior organização estrutural.

\subsubsection{Cristal super-iônico}

Depois de avaliada toda a parte estrutural das SSI e dos fluoretos puros e obtendo um bom acordo com os dados experimentais, foram analisados os comportamentos do sistema como função da temperatura. Quando aquecido o sistema sofre alterações na energia, no volume e na mobilidade dos átomos. Como a simulação foi feita no ensemble NPT é possível conhecer a variação de volume além da variação de energia como função da temperatura e isso será mostrado na próxima subseção. Nesta subseção a mobilidade dos átomos das SSI e dos fluoretos puros serão amplamente discutidos. O que chama atenção nesses sistemas é a alta mobilidade dos ânions a partir de uma dada temperatura os quais passam a se deslocar entre os cátions que permanecem fixos. Devido a essa característica esses sistemas recebem o nome de condutores super-iônicos ou condutores iônicos rápidos. Estes sistemas são sólidos que exibem condutividade iônica que são típicas daquelas encontradas em sais fundidos, isto é, $\sigma=1\left(\Omega^{-1} \mathrm{~cm}^{-1}\right)$. A medida da difusão na 


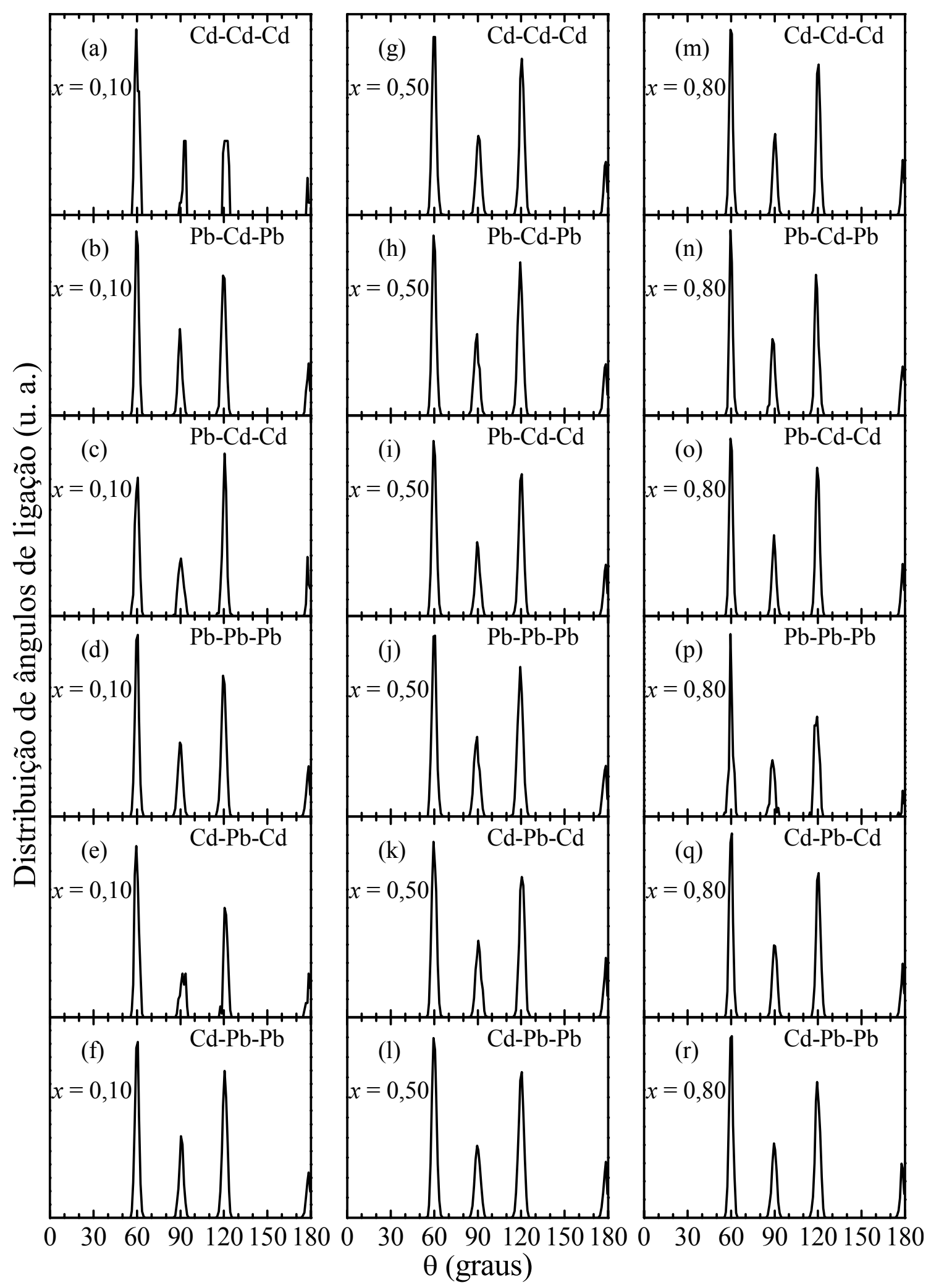

Figura 3.22: Ângulos formados pelos cátions da SSI em T=50K. 


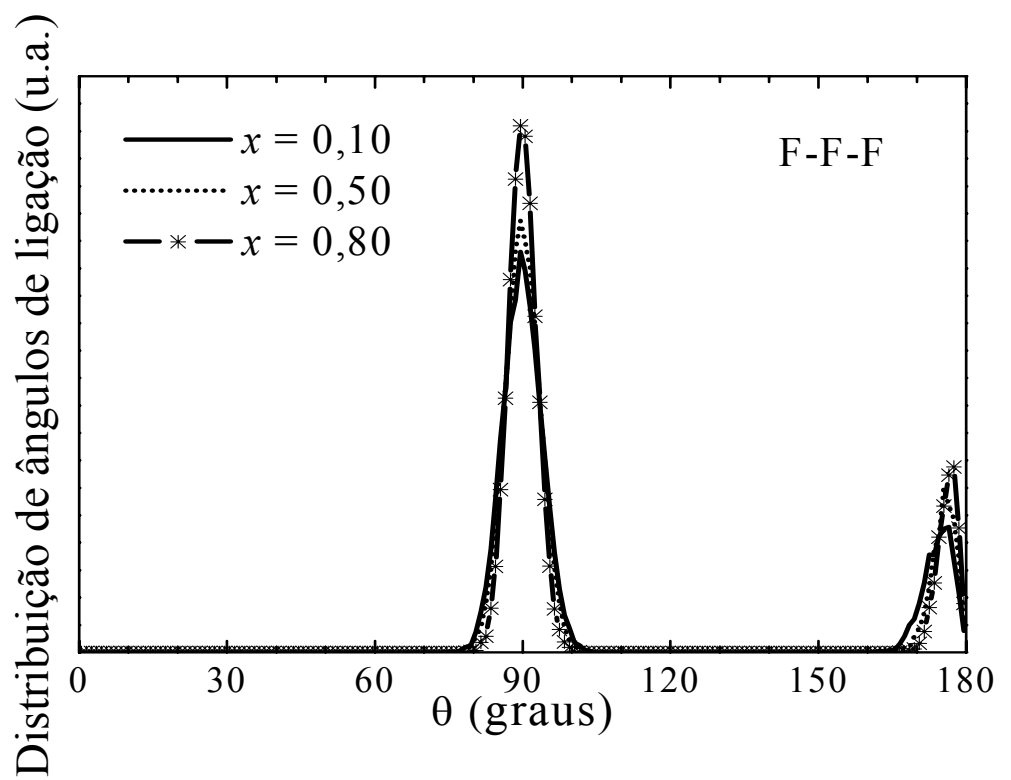

Figura 3.23: Ângulos formados pelos Fluors da SSI em T=50K para três diferentes concentrações $\mathrm{deCdF}_{2}$.

região superiônica revela valores da ordem de $D=1\left(10^{-9} m^{2} s^{-1}\right)$ que é uma magnitude tipicamente encontrada na água em temperatura ambiente[77]. A alta mobilidade dos Flúors ocorre antes da fusão do sistema determinando uma região de superionicidade. Essa região pode ser vista na Fig. 3.24 onde são mostrados os coeficientes de difusão dos três átomos do sistema como função da temperatura para a SSI $x=0,50$ aquecida com a taxa $q=0,2 \mathrm{~K} /$ ps. Na Fig. 3.24 a região de temperatura entre $600 \mathrm{~K}$ até a fusão do sistema em torno de $1300 \mathrm{~K}$ mostra valores da difusão nula do $\mathrm{Pb}$ (asteriscos) e do $\mathrm{Cd}$ (bolas abertas) enquanto os $\mathrm{F}$ (triângulos preenchidos) apresentam valores da difusão da ordem de $10^{-9} \mathrm{~m}^{2} \mathrm{~s}^{-1}$ comparáveis a difusão dos eletrólitos. Na Fig. 3.24 é mostrada a SSI $x=0,50$ e, como todas as outras concentrações das SSI e os fluoretos puros, apresentam o mesmo comportamento superiônico apenas com magnitudes diferentes estes não serão mostrados.

A desordem estrutural da sub-rede aniônica pode ser avaliada pela comparação das $g_{\alpha-\beta}(r)$ do cristal iônico e do cristal super-iônico. De acordo com a Fig. 3.24, que define a região de superionicidade para a SSI com $x=0,50$, em $\mathrm{T}=400 \mathrm{~K}$ tem-se o cristal 


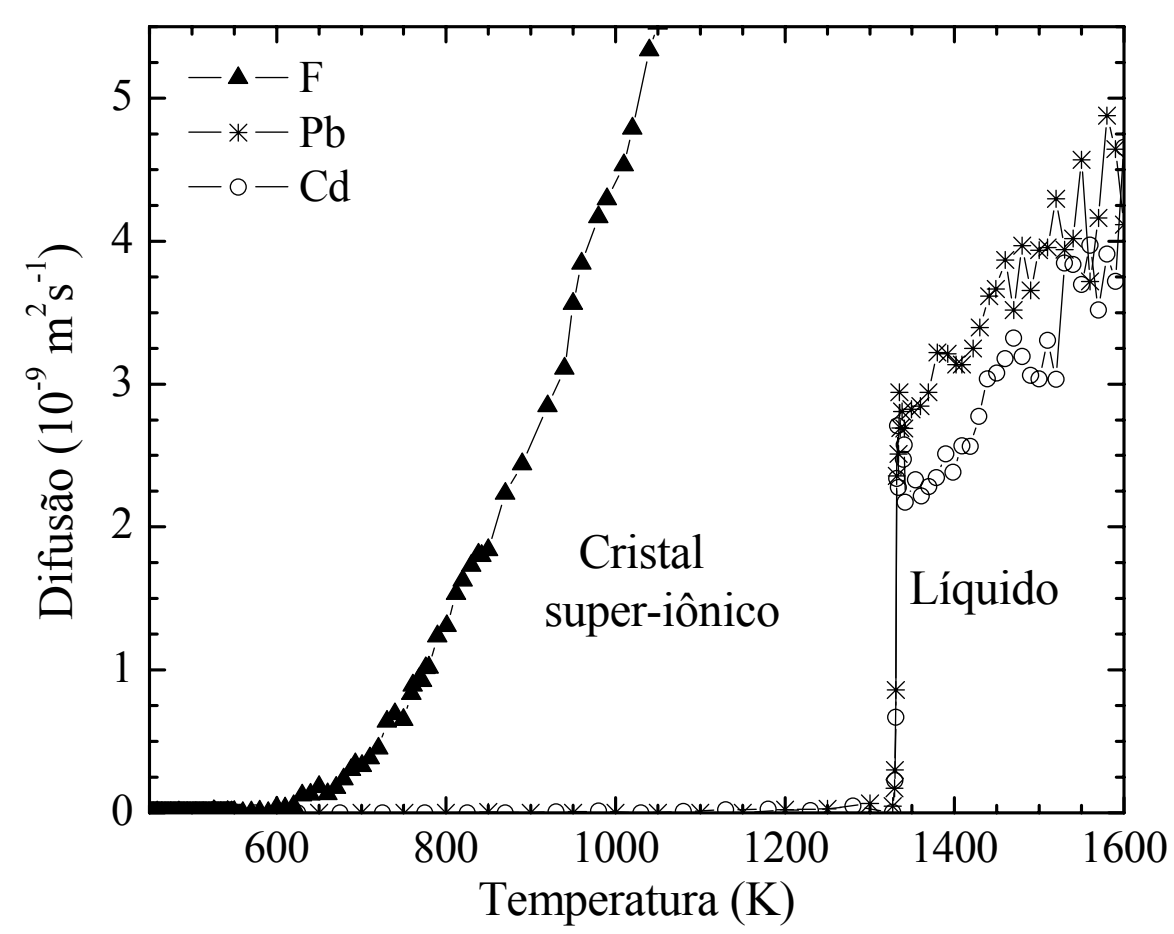

Figura 3.24: Coeficientes de difusão do $\mathrm{F}, \mathrm{Pb}$ e do $\mathrm{Cd}$ destacando a região de superionicidade da SSI $\operatorname{com} x=0,50$.

iônico e em $\mathrm{T}=800 \mathrm{~K}$ o cristal super-iônico. A Fig. 3.25 permite analisar a estrutura dos átomos para essas duas temperaturas. Na Fig. 3.25 (a) são mostradas a $g_{F-F}(r)$ e nas Fig. 3.25 (b), Fig. 3.25 (c) e Fig. 3.25 (d) a $g_{\alpha-\beta}(r)$ da sub-rede catiônica. Em ambas as temperaturas a sub-rede catiônica exibe estrutura cristalina com picos claros de primeiros, segundos e terceiros vizinhos e regiões proibidas onde a $g_{\alpha-\beta}(r)=0$. O mesmo não ocorre com a $g_{F-F}(r)$ a qual apresenta picos de estrutura cristalina em $\mathrm{T}=400 \mathrm{~K}$ incluindo terceiros e quartos vizinhos que deixam de existir em $\mathrm{T}=800 \mathrm{~K}$ quando a altura dos picos diminui e a largura aumenta consideravelmente. Para temperaturas mais elevadas a $g_{F-F}(r)$ tende a oscilar em torno do valor 1 mostrando que em média a qualquer distância sempre existe um Flúor.

Na simulação por DM a transição do cristal iônio para o super-iônico independe da taxa de aquecimento e para sistemas com um número de partículas a partir de 2592 tem-se também a independência com o número de partículas no sistema. Dada uma concentração 

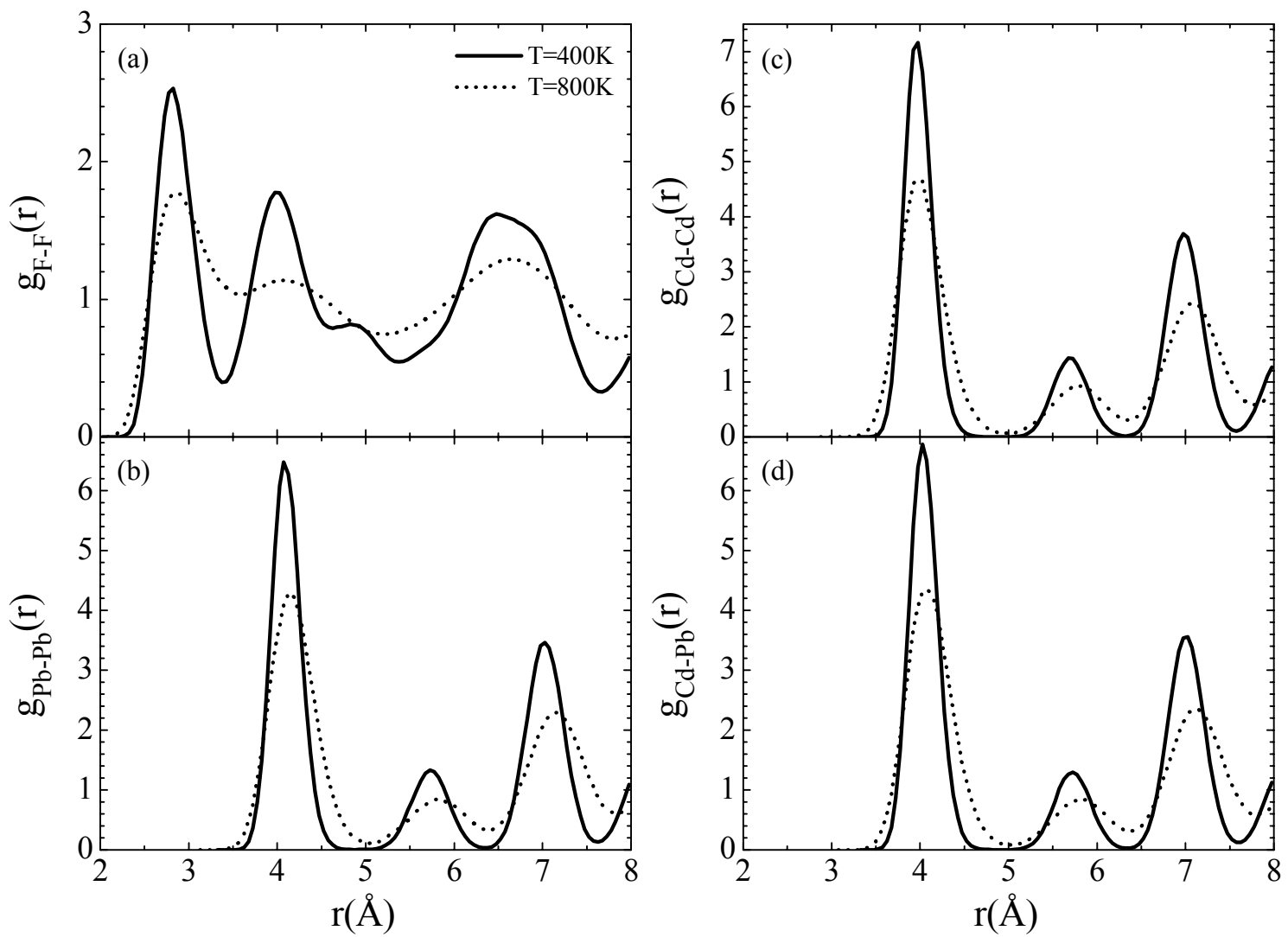

Figura 3.25: $\mathrm{g}(\mathrm{r})$ parcial da SSI $x=0,50$ mostrando o cristal iônico em T=400K (linha contínua) e o super-iônico em $\mathrm{T}=800 \mathrm{~K}$ (pontilhada). 
os Flúors passam a se difundir pela rede catiônica sempre na mesma temperatura. Foram estudados sistemas com $N=2592, N=12000, N=32928$ e taxas entre $q=0,2 \mathrm{~K} / \mathrm{ps}$ e $q=5 \mathrm{~K} /$ ps. Para sistemas com menos de 2592 partículas a região super-iônica ocorre em temperaturas mais elevadas. Tomando o exemplo de uma SSI com $x=0,10$, a difusão do $\mathrm{F}$ apresenta valores $D \approx 1\left(10^{-9} \mathrm{~m}^{2} \mathrm{~s}^{-1}\right)$ para um sistema com 768 partículas somente em $T \approx 750 K$, enquanto que o sistema com 2592 partículas atinge o mesmo valor em $T \approx 650 K$. Uma referência muito citada na literatura é a simulação pioneira do $P b F_{2}$ por DM feita por Walker[50] a qual foi feita com apenas 96 partículas e atinge a região $D \approx 1\left(10^{-9} \mathrm{~m}^{2} \mathrm{~s}^{-1}\right)$ somente em $T \approx 800 K$.

A mobilidade iônica pode ser avaliada experimentalmente através da medida do coeficiente de difusão, a qual é difícil de se medir diretamente, ou pelas taxas de transição dos próprios íons entre os sítios da rede. Através da técnica de Ressonância Magnética Nuclear (RMN) é possível fazer uma previsão da difusão dos F uma vez que ela fornece o tempo de correlação dos movimentos. Supondo uma distância de salto correspondente ao comprimento da ligação F-F e conhecendo-se o tempo de relaxação através das medidas de RMN podem ser feitas previsões da mobilidade. Também é possível avaliar a mobilidade dos ânions através da condutividade a qual pode ser medida com a aplicação de campo elétrico AC e por isso é altamente dependente da frequência do campo. A medida experimental pioneira do $\mathrm{PbF}_{2}$ feita por Benz[78] no ano de 1975 foi feita com um campo elétrico de $1 \mathrm{KHz}$ e apesar de mostrar que existe uma condutividade dos Flúors com valores em torno de $1\left(\Omega^{-1} \mathrm{~cm}^{-1}\right)$ a magnitude da dependência com a temperatura apresenta valores bem diferentes das medidas mais atuais feitas com frequências maiores conforme será visto na discussão adiante. Devido a grande desordem estrutural as medidas são também altamente dependentes dos tipos de defeitos encontrados em cada amostra e da direção cristalográfica. Esses fatos geram uma barra de erro grande entre os dados encontrados 
na literatura, Azimi[79] afirma que o erro pode chegar a $30 \%$.

A transição do cristal iônico para o super-iônico é vista de maneira diferente por diferentes autores. Entre os vários autores que contribuíram para o entendimento da superionicidade existem os que acreditam que ela seja uma transição do tipo sólido-líquido[74] e os que defendem a idéia de uma transição contínua[77],[75],[76].

As simulações usando DM mostram que a difusão se inicia com saltos dos Flúors para sítios vizinhos de mesma energia através dos canais estabelecidos pela rede catiônica. Em temperaturas elevadas o tempo de residência em um dado sítio diminui de maneira que passa-se a ter praticamente um líquido de Flúors caminhando entre os cátions fixos. Essa é uma transição gradual, ou seja, contínua e não abrupta. Os resultados da Fig. 3.26 mostram o comportamento da difusão do Flúor como função da temperatura. Existe um bom acordo entre experimento e a simulação do presente trabalho onde os resultados simulados por DM são superestimados em $7 \%$ em relação aos dados experimentais de Gordon[81] e todas as curvas mostram a região super-iônica. Uma possível maneira de identificar a suavidade da transição é observar que a difusão do F deixa de ser zero de maneira não abrupta, por exemplo, nas Fig. 3.26 e 3.24. Na Fig. 3.26 as curvas são praticamente paralelas tanto para o cristal perfeito simulado com DM quanto a curva experimental de Gordon[81]. Esse fato mostra que tanto experimento quanto simulação prevê o mesmo comportamento dos Flúors na região super-iônica que deixam de ter difusão nula gradualmente. Não existe portanto uma transição do tipo sólido-líquido pois não existe inicialmente uma transição de primeira ordem (a continuidade da energia será mostrada na próxima subseção) e nem um movimento totalmente aleatório dos F. As primeiras descrições sobre a superionicidade indicavam a fusão da sub-rede aniônica[74] e o autor afirmava que o mecanismo da superionicidade era uma questão em aberto. No entanto descrições mais recentes afirmam que não existe uma completa desordem 
da sub-rede aniônica, a discussão detalhada se encontra no artigo de Hull[75]. Uma ampla discussão do mecanismo da superionicidade é encontrada também no artigo de Buchinskaya[76], que em acordo com Hull afirmam que a desordem da sub-rede aniônica é gradual assim como previsto nas simulações do presente trabalho. Como já mencionado anteriormente os dados da simulação por DM de Walker[50] foram feitos com apenas 96 partículas que é um número muito pequeno e por isso nota-se na Fig. 3.26 que os valores para a difusão dos Flúors para uma dada temperatura fixa são subestimados. A simulação feita por Zimmer[80] foi realizada com volume constante utilizando o volume para cada uma das temperaturas dos dados de difração de nêutrons de Goff[82]. A maneira utilizada por Zimmer requer a cada nova temperatura uma interação externa alterando o volume do sistema. A maneira utilizada no presente trabalho torna as simulações mais realistas pois foram feitas no ensemble NPT no qual o volume é uma variável dinâmica que se adapta ao aumento da temperatura. Um outro diferencial em relação à simulação de Zimmer[80] é quanto ao incremento temporal para integrar as equações de movimento. No presente trabalho foi utilizado um valor dez vezes menor que o de Zimmer o que eleva a qualidade das médias quando considerado um mesmo intervalo de tempo de simulação. A comparação do parâmetro de rede da simulação do presente trabalho com os dados de Goff[82] tem uma diferença menor que 1,5\%. Tanto Zimmer[80] quanto Walker[50] em seus trabalhos citam os dados de Gordon[81] mas fazem uma interpolação dos dados de RMN (gradiente de campo pulsado) enquanto que na Fig. 3.26 são mostrados os dados originais sem interpolação. É importante salientar que na simulação foram usadas condições periódicas de contorno e não existe perda de Flúor por evaporação o que poderia resultar em valores superestimados da difusão em relação ao experimento.

A Fig. 3.27 mostra a $g_{F-F}(r)$ para várias temperaturas incluindo a região super-iônica e mostra que a desordem da sub-rede aniônica aumenta mas a estrutura cúbica simples 
é preservada. Os picos da estrutura não desaparecem por completo o que mostra que os Flúors tem mobilidade mas o movimento é de um sítio para outro de mesma energia, ou seja, os Flúors encontram uma outra posição na sub-rede aniônica. As curvas para várias temperaturas da Fig. 3.27 confirmam que a superionicidade é atingida de maneira gradual e não se vê um comportamento exatamente igual ao de um líquido nessa parte inicial da região super-iônica.

A difusão do Flúor como função da concentração de $C d F_{2}$ nas SSI é mostrada na Fig. 3.28. Na Fig. 3.28(a) foi analisada qual a temperatura necessária para atingir um dado valor fixo de difusão. São mostrados três valores fixos de difusão e nota-se um comportamento que se aproxima muito de uma reta nas três situações. Também foi analisada a dependência da difusão com a concentração de $C d F_{2}$ para uma temperatura fixa. $\mathrm{Na}$ Fig. 3.28 (b) é mostrada a dependência da difusão do Flúor como função da concentração de $C d F_{2}$ para quatro diferentes temperaturas. Para as temperaturas mais baixas as concentrações com muito $C d F_{2}$ ainda não se encontram na região super-iônica e tem difusão do Flúor nula. A curva com a temperatura $T=900 K$ mostra o comportamento linear da difusão como função da concentração. O fluoreto puro $C d F_{2}$ tem uma região de superionicidade com temperaturas mais elevadas e o $\mathrm{PbF}_{2}$ com temperaturas mais baixas e as SSI apresentam valores de difusão que formam uma reta entre os dois fluoretos puros.

A dificuldade em obter medidas precisas para a condutividade do $P b F_{2}$ é mostrada na Fig. 3.29. A linha contínua mostra os dados pioneiros de Benz[78] comprometidos pela baixa frequência de $1 \mathrm{KHz}$ utilizada no campo AC aplicado. As bolas pretas representam os dados da simulação do presente trabalho que mostram valores coerentes com as medidas experimentais de Carr[83], Gordon[81] e Azimi[79]. A simulação do presente trabalho mostra que a região super-iônica é alcançada de maneira mais suave em comparação com os experimentos. A sugestão é que isto deve acontecer devido ao sistema na simulação ser 


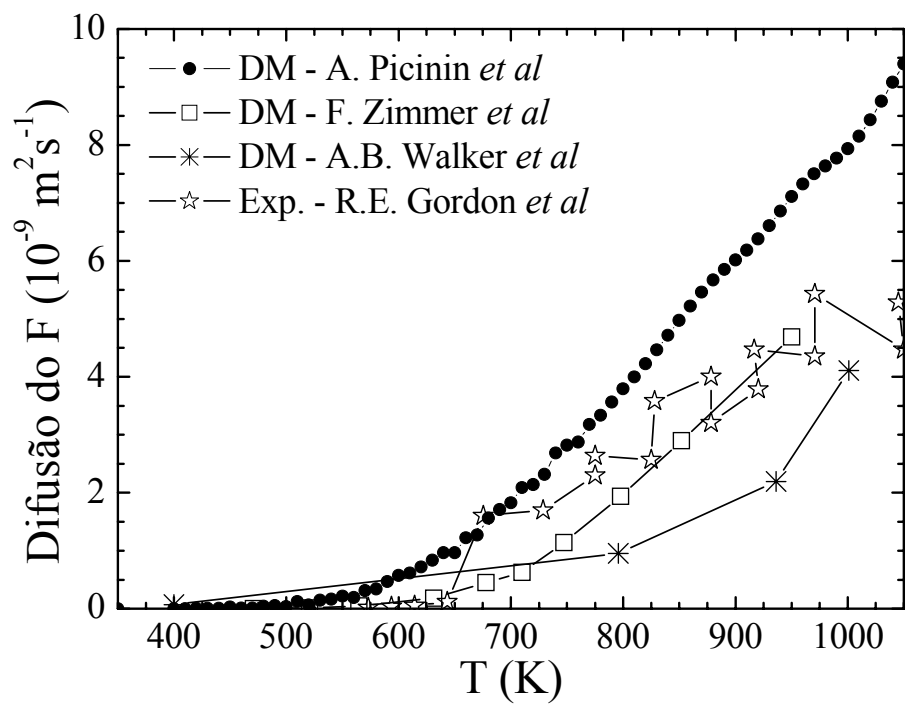

Figura 3.26: Comparação entre experimento e simulação da difusão do Fluor no $P b F_{2}$.

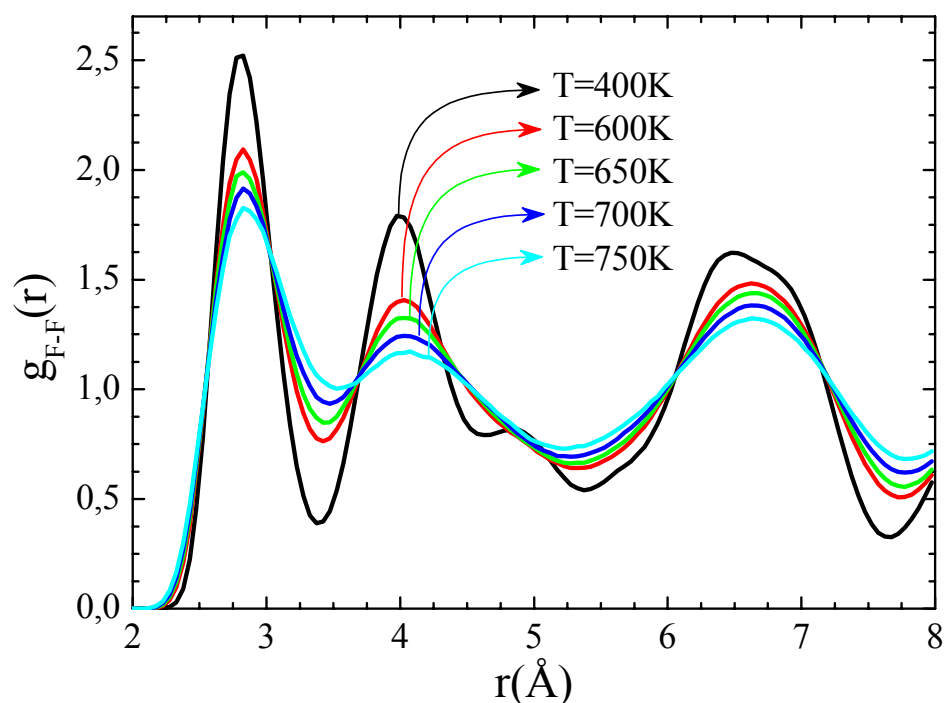

Figura 3.27: $\mathrm{g}_{F-F}(\mathrm{r})$ da SSI com $x=0,50$ para várias temperaturas na região superiônica. 

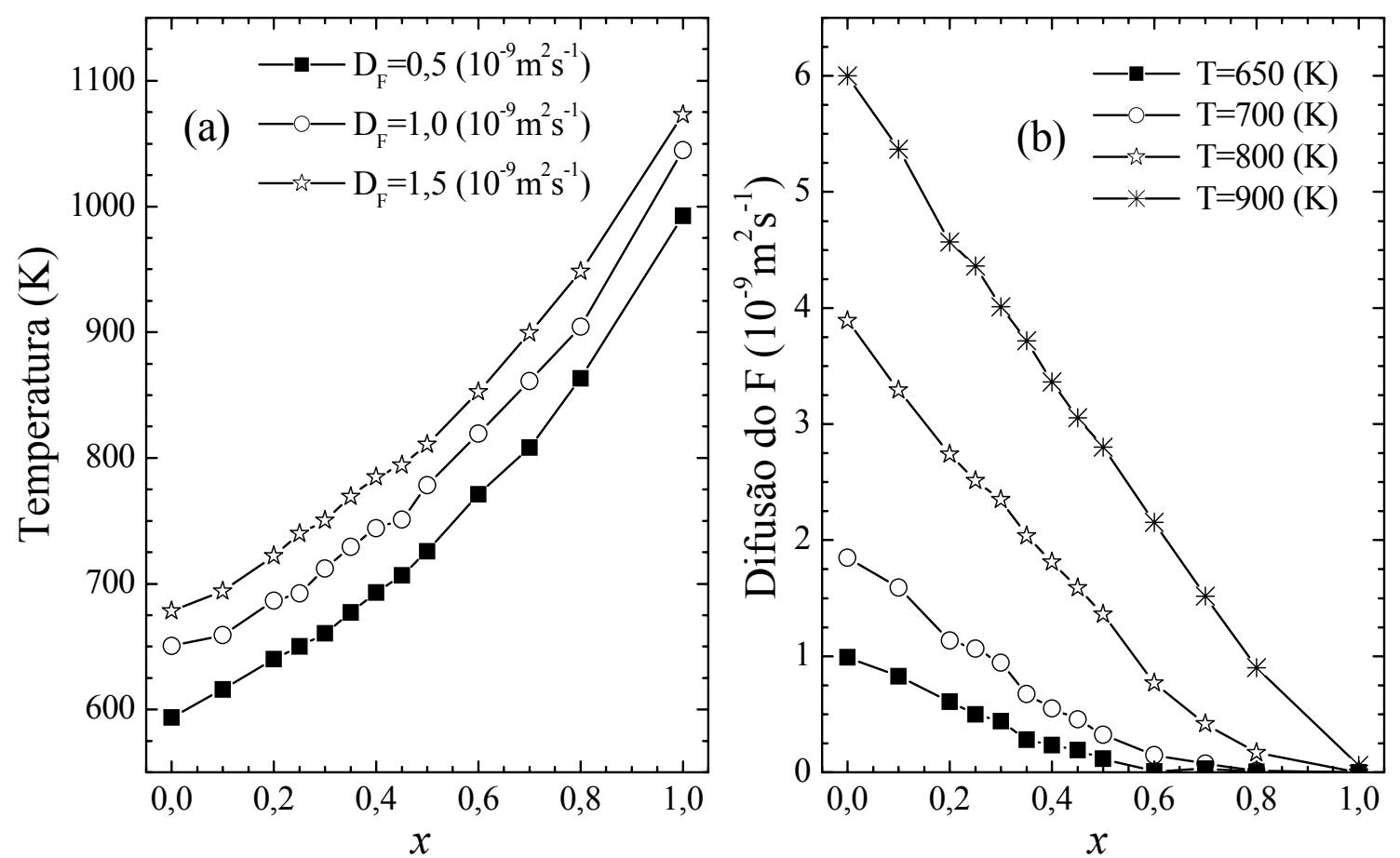

Figura 3.28: Coeficiente de difusão do $\mathrm{F}$ em função de $x$. Em (a)são mostradas as temperaturas necessárias para atingir 3 valores diferentes de difusão do F. Em (b)são mostrados os valores da difusão do $\mathrm{F}$ em 4 diferentes temperaturas.

um cristal perfeito sem defeitos estruturais e barreiras para a difusão.

Na literatura existe uma série de trabalhos com um considerável intervalo na magnitude da condutividade. Conforme já anunciado Azimi[79] discute o fato de seus resultados estarem dentro de uma barra de erro de $\pm 30 \%$ em relação a dois outros artigos que ele cita[85],[84]. A dependência com a frequência do campo aplicado é um fator importante. Carr[83] afirma que a partir de campos com $10 \mathrm{KHz}$ não existe mais dependência com a frequência do campo aplicado para o caso do $P b F_{2}$. Mas, Oberschmidt[84] discute em seu trabalho que em altas temperaturas (região superiônica) mesmo com campos de $100 \mathrm{KHz}$ não é possível obter uma boa precisão da condutividade. Carr[83] fez as medidas com duas amostras diferentes e mostrou que os seus valores obtidos para a condutividade são reprodutíveis com um erro de $\pm 3 \%$, mas muitos dos resultados encontrados podem nem ser reprodutíveis. O caso do artigo de Oberschmidt[84] dificilmente seria reprodutível 


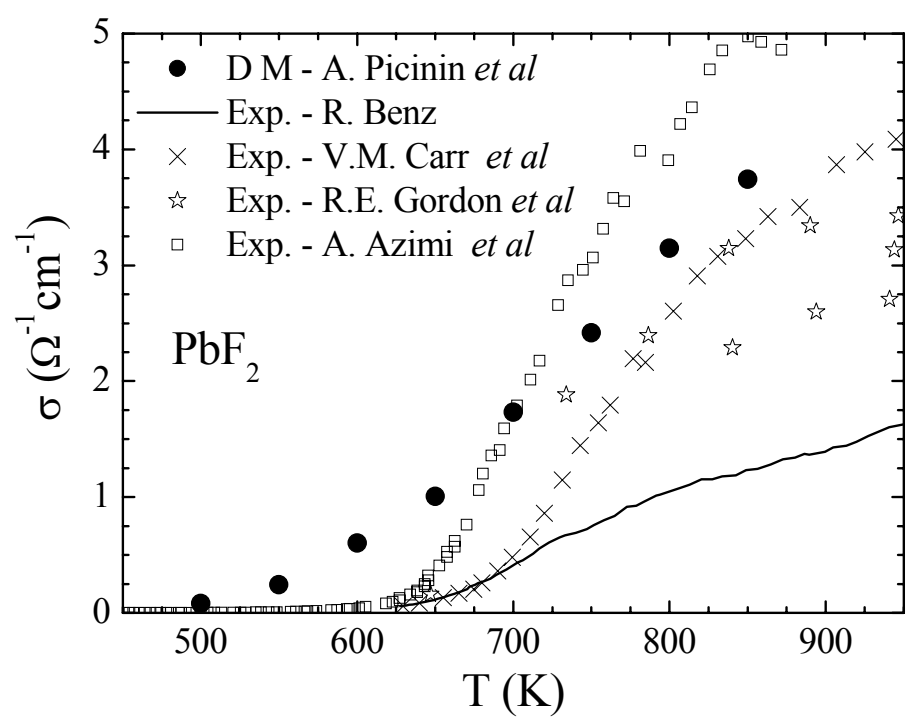

Figura 3.29: Condutividade do fluoreto puro $\mathrm{PbF}_{2}$. Comparação entre Dinâmica Molecular e resultados experimentais da literatura.

uma vez que ele afirma em seu artigo que as amostras de $P b F_{2}$ apresentam a formação de PbO. A preparação das amostras devem ser bem criteriosas para a reprodução dos resultados. Na região superiônica os mecanismos de condução não são tão claros e na literatura existem várias propostas. A concentração de defeitos, vacâncias e átomos intersticiais é alterada em altas temperaturas e os íons móveis não os únicos a se deslocarem pelo cristal.

Os resultados para a condutividade obtidos por DM são independentes da frequência do campo aplicado uma vez que são obtidos da difusão do sistema utilizando a relação de Nernst-Einstein. Na Fig. 3.30 é mostrada a condutividade como função da temperatura onde se tem um ótimo acordo entre as medidas experimentais[70] e a simulação do presente trabalho para a composição $x=0,30$. A concordância entre a SSI obtida na simulação e os experimentos se deve ao método de preparação das amostras ter sido o crescimento planar do líquido que permite a obtenção sistemas estruturalmente homogêneos. Os dados de Trnovcová[69] não incluem temperaturas na região superiônica, mas ele consegue prever a região crítica onde a condutividade tende a valores da ordem $1\left(\Omega^{-1} \mathrm{~cm}^{-1}\right)$. Talvez pelas dificuldades experimentais impostas pelas altas temperaturas existe uma grande quantidade 
de trabalhos que analisam a condutividade antes da região superiônica. Em baixas temperaturas, quando o sistema ainda não é super-iônico, resultados experimentais[88][86][87] prevêem a existência de uma região com máxima condutividade em torno de $x=0,35$ apresentando um comportamento não linear da condutividade como função da concentração de $C d F_{2}$ não observado para o caso das SSI superiônicas.

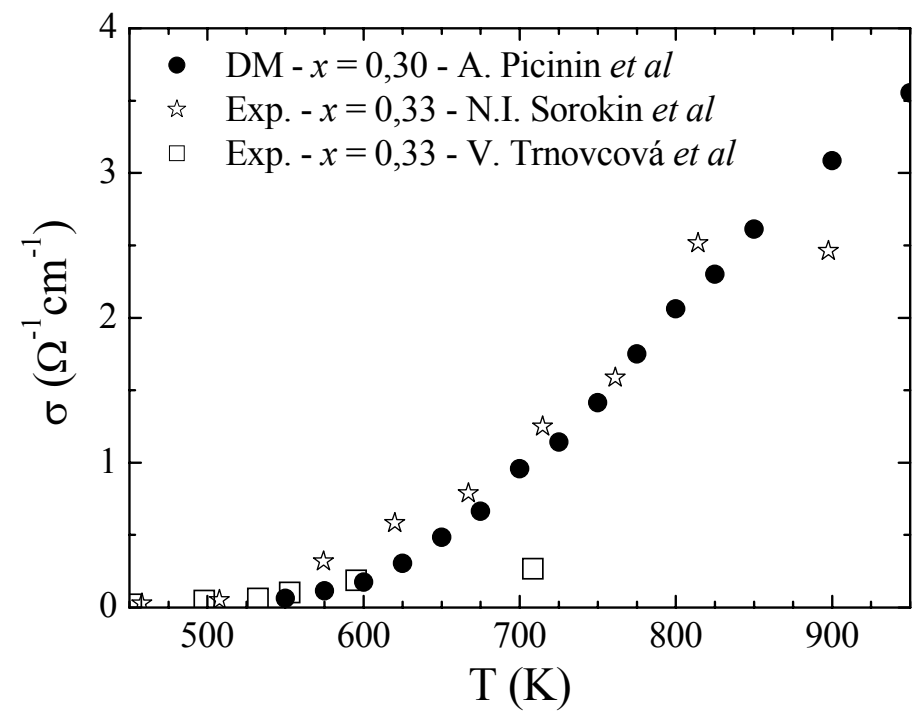

Figura 3.30: Condutividade da SSI $x=0,30$ em comparação com resultados experimentais da literatura.

A condutividade como função da concentração é mostrada na Fig. 3.31 e apresenta comportamento linear como os da difusão em função da concentração discutidos anteriormente. Os resultados da Fig. 3.31 obtidos pela simulação do presente trabalho avaliam a região de superionicidade de sistemas totalmente homogêneos e não foi observado o comportamento com condutividade máxima para a região em torno de $x=0,35$ observado nos experimentos em baixas temperaturas.

Os resultados da difusão e da condutividade do Flúor de todas as SSI foram possíveis de se obter devido à transferabilidade do potencial. Como já discutido anteriormente esta é uma característica importante para o potencial de interação segundo Brenner[20]. Uma vez que o potencial das SSI foi construído baseado nos potenciais que descrevem os 


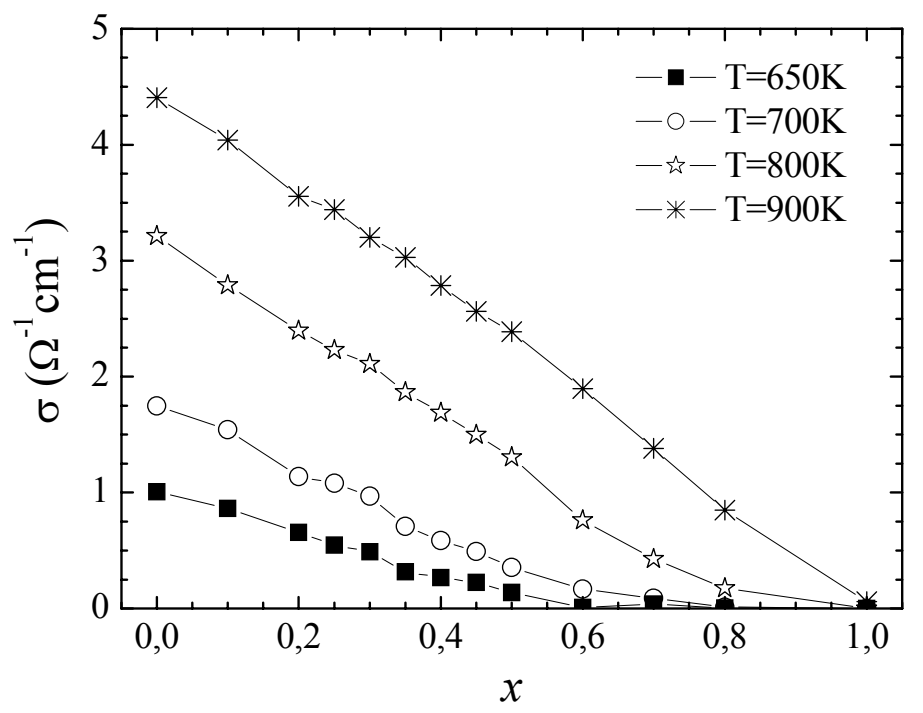

Figura 3.31: Condutividade em função da concentração para temperaturas fixas.

fluoretos puros separadamente, os resultados obtidos no presente trabalho são oriundos da representação correta das interações atômicas sem a necessidade de novos parâmetros ajustados.

Com os resultados mostrados até esta subseção foi avaliada toda a parte estrutural das SSI. Análises de dois e três corpos caracterizam a estrutura da rede cristalina. A análise de dois corpos feita com as $\mathrm{g}_{\alpha \beta}(\mathrm{r})$, caracterizou corretamente tanto as posições da rede cfc dos cátions quanto a cúbica simples formada pelos ânions. O parâmetro de rede para todas as concentrações foi descrito com um erro muito pequeno. O número de vizinhos mostrou a correta posição dos átomos em todas as esferas de coordenação. A análise de três corpos feitas com a distribuição de ângulos mostrou os ângulos típicos da rede cfc formada pelos cátions e os da cúbica simples formada pelos ânions. Numa rede cfc ideal tem-se os tetraedros formados pelos cátions onde os Flúors ocupam o buraco desse tetraedro formando um ângulo de $109^{\circ}$ com os cátions que foi corretamente descrito. Para ilustrar o fato de a SSI ser um cristal misto homogêneo, em todos os ângulos analisados foi mostrada a independência com os tipos de vizinhos considerados na distribuição angular. 
A rede cristalina fica estável para qualquer $x$ mesmo em altas temperaturas como na região super-iônica.

\subsubsection{Transição Sólido-Líquido}

As SSI foram aquecidas com a taxa $q=0,2 \mathrm{~K} / \mathrm{ps}$ e a fusão pode ser identificada de várias maneiras: através da difusão da rede catiônica que deixa de ser nula e através da descontinuidade da energia e do volume na transição como função da temperatura. As soluções sólidas $C d_{x} P b_{1-x} F_{2}$ exibem um comportamento de mínimo para uma dada concentração no que diz respeito a temperatura de fusão. Conforme discutido na sub-seções anteriores a região em torno da composição $x=0,35$ apresenta uma maior desordem estrutural o que facilita a fusão e leva a uma região de composições com temperaturas de fusão mais baixas. Para ilustrar esse comportamento foram escolhidas três das composições estudadas e são mostrados os comportamentos da difusão, da energia e do volume do sistema como função da temperatura na região da temperatura de fusão. Na Fig. 3.32 (a) é mostrado o coeficiente de difusão do Cd e na Fig. 3.32 (b) o coeficiente de difusão do $\mathrm{Pb}$ e ambas as curvas mostram uma região onde a difusão deixa de ser nula de uma maneira não suave. Além de identificar a região onde os átomos passam a ter uma grande mobilidade é possível notar que a composição $x=0,35$ tem temperatura de fusão mais baixa enquanto as composições $x=0,50$ e $x=0,10$ têm temperaturas de fusão mais altas. A descontinuidade do volume pode ser observada na Fig. 3.32 (c) e a descontinuidade da energia na Fig. 3.33. Assim como as curvas da difusão da rede catiônica como função da temperatura o volume e a energia identificam claramente o ponto de fusão e a região de mínimo da temperatura de fusão. Tanto na Fig. 3.33 quanto na 3.32 (c) a curva para a composição $x=0,35$ apresenta descontinuidade em temperatura mais baixa que as outras composições. 


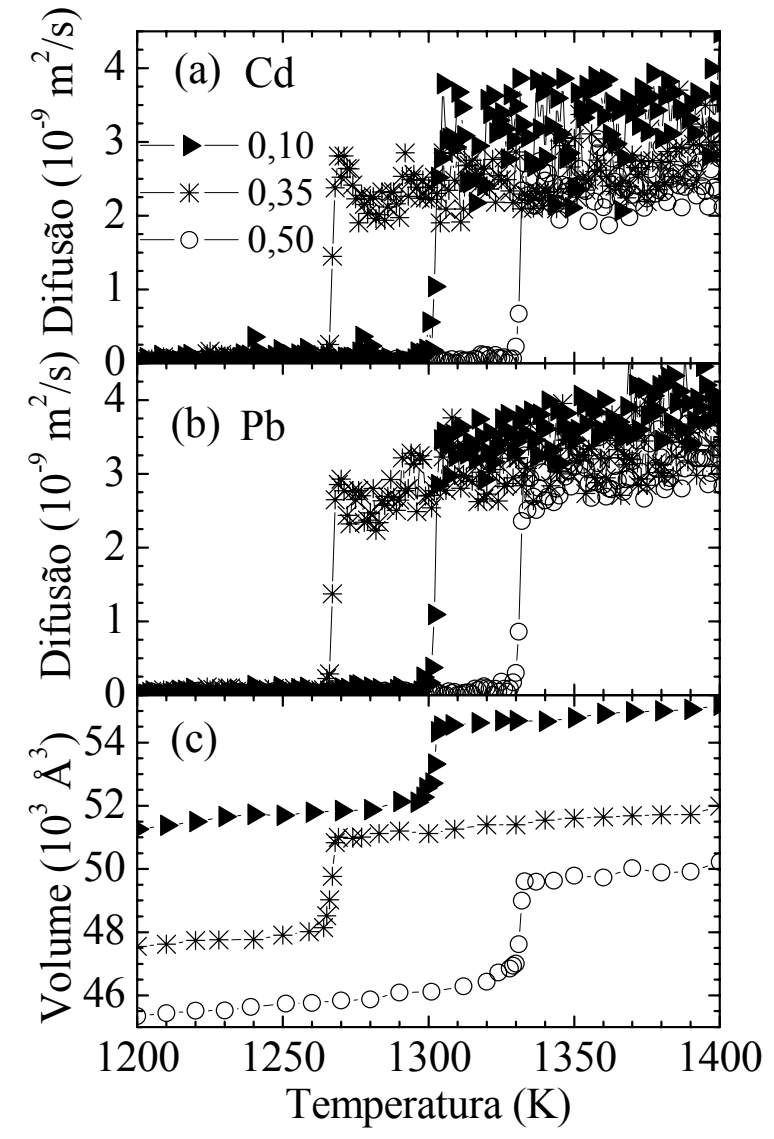

Figura 3.32: Difusão do $\mathrm{Pb}$, do Cd e a descontinuidade do volume na região de fusão.

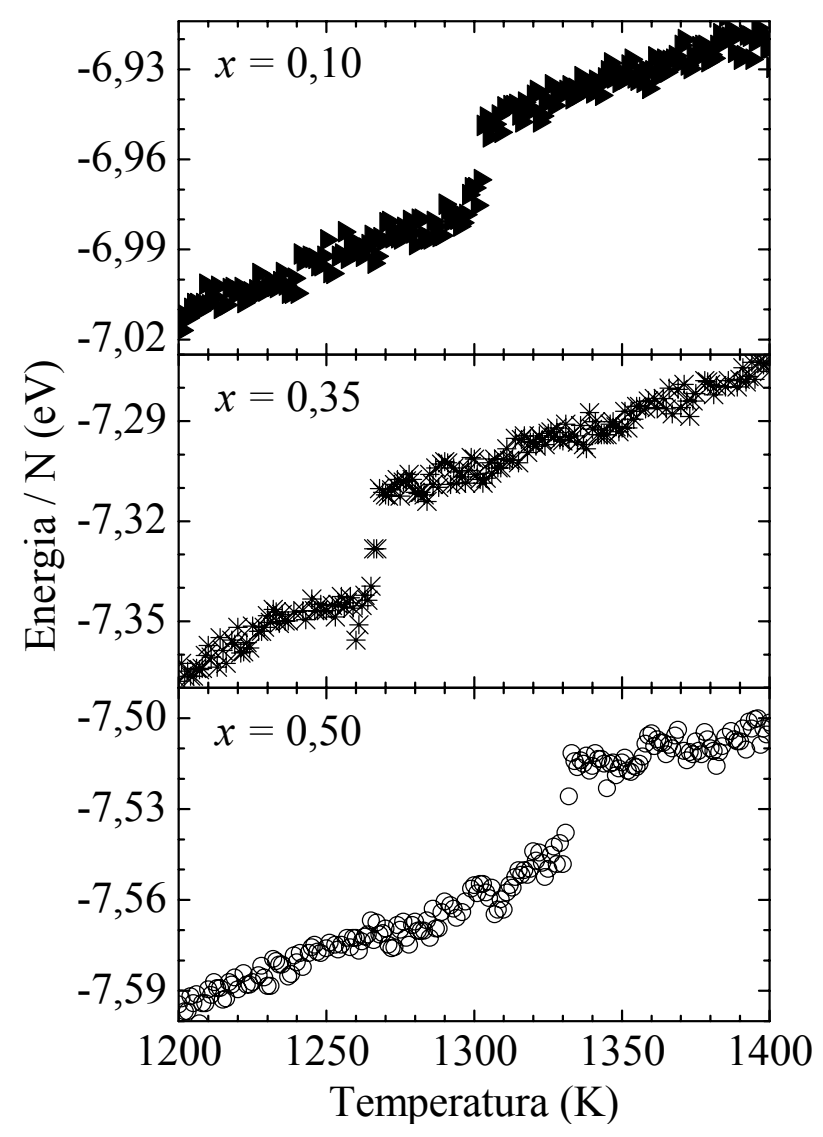

Figura 3.33: Descontinuidade da energia na região de fusão para três diferentes concentrações de $C d F_{2}$.

Na Fig. 3.34 é mostrada a dependência da temperatura de fusão como função da concentração de $C d F_{2}$ para todas as SSI e feita comparações com os dados experimentais. Na Fig. 3.34 partindo do fluoreto puro $\mathrm{PbF}_{2}(x=0)$ quando adicionado $C d F_{2}$ a temperatura de fusão diminui até a composição $x=0,35$. Se a concentração de $C d F_{2}$ continua a ser aumentada nota-se agora o aumento da temperatura de fusão. Experimento e simulação estão em pleno acordo na identificando da região eutética que ocorre em torno de $x=0,35$.

A Fig. 3.32 (b) contém as curvas normalizadas pelas respectivas temperaturas de fusão mínima e nota-se que os dados obtidos pela simulação tem curvatura semelhante a das curvaturas experimentais.

Diferente da transição superiônica a transição sólido líquido depende da taxa de aquecimento e do número de partículas no sistema e esses dois fatos contribuem para os valores 

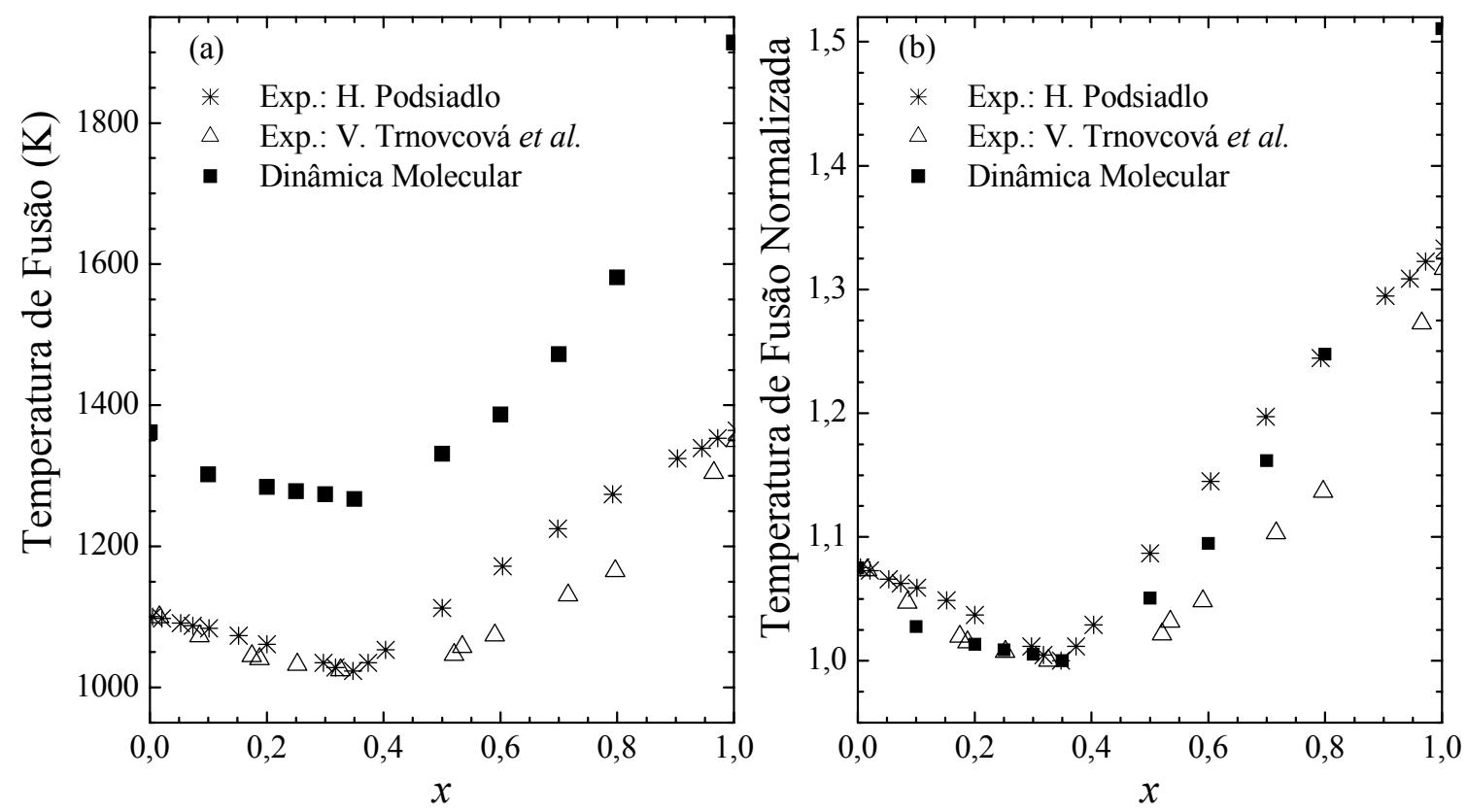

Figura 3.34: Temperatura de Fusão como função da concentração de $\mathrm{CdF}_{2}$. Os asteriscos e os triângulos são dados experimentais de Podsiadlo[68] e Trnovcová[69]. respectivamente. Os quadrados são resultados da simulação por Dinâmica Molecular.

da temperatura de fusão da DM serem maiores que os valores experimentais. Para um número de partículas maior a temperatura de fusão diminui. Foram feitos testes com 12000 e 32928 partículas. Quando aumentado o número de partículas a estatística dos cálculos melhoram e por isso a temperatura se aproxima mais do valor experimental. A diferença de temperatura de fusão para um sistema com 2592 partículas e um com 12000 partículas está próximo de 150K. Para um número maior de partículas essa diferença não se altera muito, isso indica que para o sistema avaliado a partir de 12000 partículas a dependência da simulação com o número de partículas é elimina. A simulação feita com um número maior de partículas implica em um tempo de simulação muito maior e a diferença da simulação com 2592 e 12000 partículas é apenas um deslocamento na curva do diagrama de fase mantendo o comportamento de mínimo na composição $x=0,35$.

Nesse sistema misto a difusão do Cd é sempre menor que a do $\mathrm{Pb}$, como pode ser visto mais claramente na Fig. 3.24. O Cd é mais fortemente ligado aos $\mathrm{F}$ o que leva o $C d F_{2}$ a 
ter uma região superiônica em temperaturas mais altas que o $P b F_{2}$.

Na maioria dos materiais a fusão se inicia pela superfície e se propaga para todo o resto do material. Quando utilizadas as condições periódicas de contorno nas simulações as superfícies são eliminadas e com isso a fusão ocorre quando a rede torna-se instável devido a alta agitação térmica e o sistema se rompe. Esse fato também contribui para os valores da temperatura de fusão da presente simulação serem maiores que os dos experimentos. Uma outra característica da simulação das SSI que contribui para temperaturas de fusão superestimadas é o fato de não existirem defeitos e impurezas nelas que poderiam facilitar a fusão.

\subsection{Resfriamento partindo do líquido}

Após a fusão o sistema continuou a ser aquecido até $\mathrm{T}=3500 \mathrm{~K}$ para garantir que toda ordem estrutural fosse realmente perdida e a sua memória do estado sólido inicial apagada. Foi obtido um líquido homogêneo estável que é um resultado importante, pois assim como a estabilidade da rede cristalina, esse comportamento garante a confiabilidade do potencial em prever as interações desses três tipos de átomos mesmo no estado líquido. A estabilidade do líquido ocorre para todas as concentrações e eles são homogêneos no intervalo de temperatura compreendido entre a fusão e $\mathrm{T}=3500 \mathrm{~K}$.

O líquido em $\mathrm{T}=3500 \mathrm{~K}$ é caracterizado por ser totalmente desordenado e não ter uma correlação de longo alcance. Na Fig. 3.35 são mostradas as g(r) para todas as composições deslocadas no eixo y de 0,25, típicas de um estado líquido aquecido.

O resfriamento partindo do líquido a altas temperaturas e chegando a um sistema sólido a baixas temperaturas é bastante interessante pois permite que o sistema naturalmente encontre sua estrutura. Além disso, esse é um dos métodos experimentais utilizados para se obter esses sistemas mistos. Esse foi o método empregado nas teses de Silva[21] 


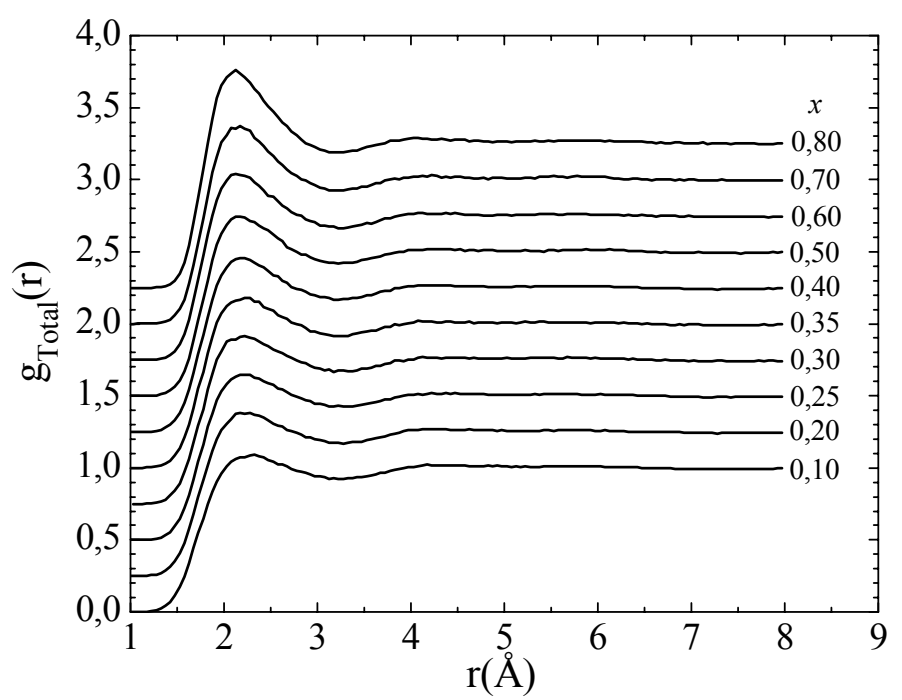

Figura 3.35: Função de correlação de pares total para os líquidos em T=3500K.

e Avallone[22] as quais forneceram dados para a comparação dos resultados simulados. Para as discussões a seguir o estudo foi iniciado com o sistema no estado líquido na temperatura 3500K após permitir uma termalização de 100000 passos de DM. São analisados os comportamentos dos sistemas para diferentes taxas de resfriamento para a concentração $x=0,40$. As outras concentrações apresentam comportamento semelhante e não serão mostradas.

Na Fig. 3.36 é mostrado o volume como função da temperatura para a concentração $x=0,40$ para quatro diferentes taxas de resfriamento. A variação do volume com a temperatura durante o aquecimento da SSI com a taxa $q=0,2 \mathrm{Kps}^{-1}$, identificado pelos triângulos preenchidos, serve como referência para avaliar quatro diferentes taxas de resfriamento. Quanto mais lenta é a taxa de resfriamento menor é o volume do sólido final em $\mathrm{T}=100 \mathrm{~K}$, as partículas tem um tempo maior para se rearranjar e encontrar posições mais estáveis com mínima energia. Com taxas mais lentas os líquidos se cristalizam com um menor número de defeitos, o que elimina espaços vazios ou preenchidos de maneira irregular resultando em menores volumes dos sistemas. Na Fig. 3.36 pode-se comparar 
duas das taxas empregadas que levam a cristalização. A descontinuidade no volume durante o resfriamento característica da cristalização do sistema ocorre em torno de $\mathrm{T}=400 \mathrm{~K}$ para a taxa $q=-0,5 \mathrm{Kps}^{-1}$ e em $\mathrm{T}=770 \mathrm{~K}$ para a taxa $q=-0,2 \mathrm{Kps}^{-1}$, mostrando que quanto mais lento é o resfriamento maior é a facilidade para ocorrer a cristalização. Para taxas de resfriamento mais lentas a cristalização ocorre em temperaturas mais altas e o volume do sistema sofre uma variação abrupta como pode ser visto pelas estrelas abertas na Fig. 3.36. Os quadrados preenchidos descrevem uma taxa mais rápida $(q=-0,5$ $\mathrm{Kps}^{-1}$ ) que mostra a variação do volume ocorrendo de maneira mais gradual sem que haja muito tempo para o sistema encontrar seu mínimo de energia.

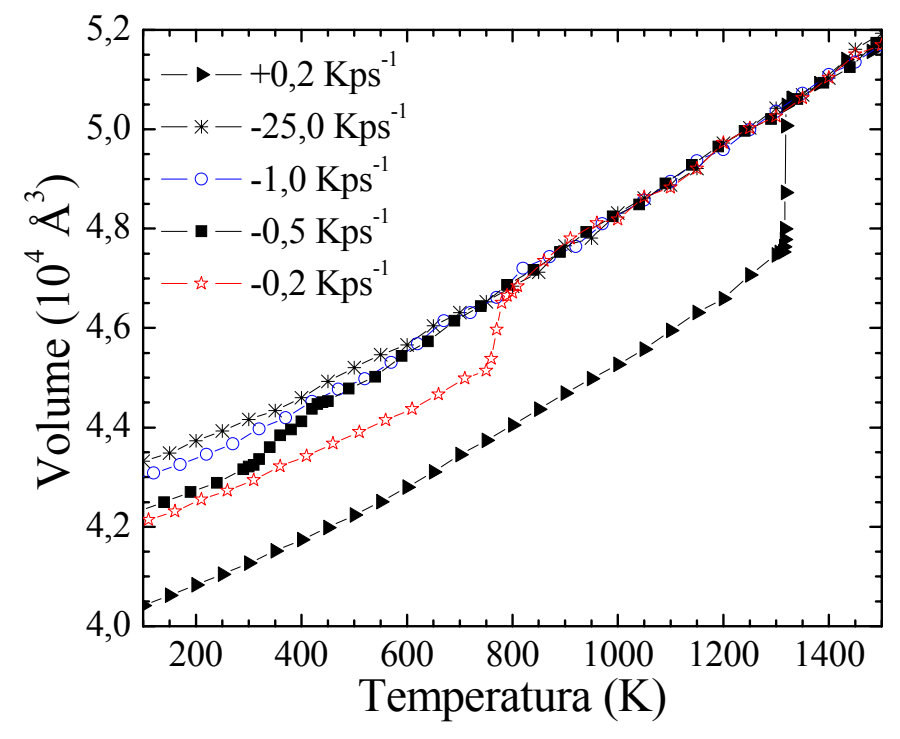

Figura 3.36: Volume como função da temperatura durante o resfriamento da concentração $x=0,40$.

Utilizando a taxa $q=-1,0 \mathrm{Kps}^{-1}$ ou alguma outra mais rápida que essa o sistema não apresenta cristalização e pode-se ver na Fig. 3.36 que o volume não apresenta descontinuidade durante o resfriamento. As taxas $q=-0,5 \mathrm{Kps}^{-1}$ e $q=-1,0 \mathrm{Kps}^{-1}$ demarcam o limite na formação de um sistema cristalino ou amorfo. Conforme será visto adiante, com as fotos do sistema, a taxa limite $q=-0,5 \mathrm{Kps}^{-1}$ leva a formação de sistemas que apresentam cristalização mas com muitos defeitos e a taxa $q=-1,0 \mathrm{Kps}^{-1}$ a formação 


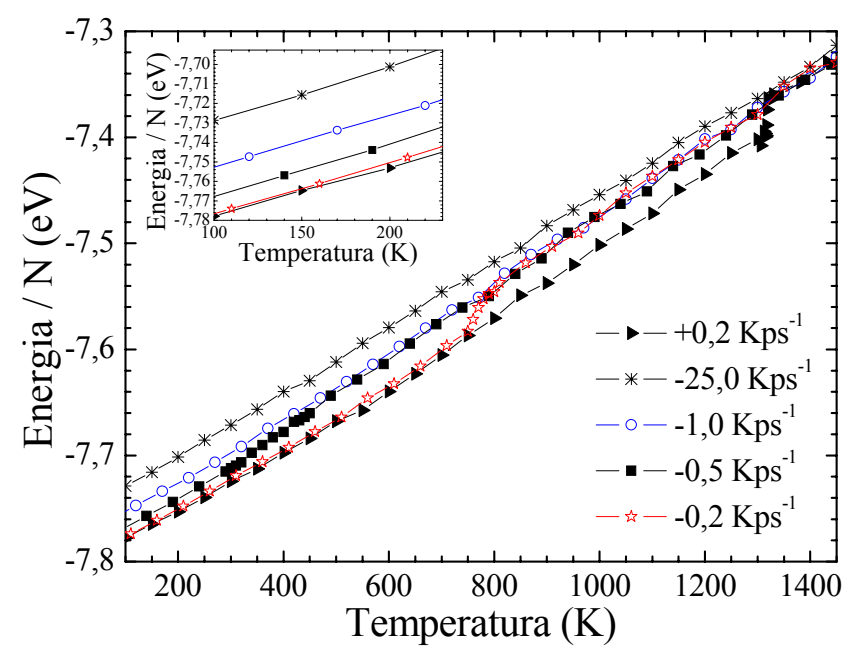

Figura 3.37: Energia por partícula da concentração $x=0,40$ para diferentes taxas de resfriamento em função da temperatura.

de um vidro com separação de fase. Para minimizar o número de defeitos no cristal foi utilizada a taxa resfriamento $q=-0,2 \mathrm{Kps}^{-1}$ e para garantir a homogeneidade no vidro foi utilizada a taxa $q=-25 \mathrm{Kps}^{-1}$.

A energia por partícula para as diferentes taxas de resfriamento para a concentração $x=0,40$ é mostrada na Fig. 3.37. Novamente a energia do aquecimento da SSI com a taxa $q=0,2 \mathrm{Kps}^{-1}$ serve como referência para as discussões. A descontinuidade da curva da energia durante o resfriamento identifica a cristalização do sistema. Nota-se que com taxas mais lentas as partículas tem um tempo maior para encontrar suas posições de mínima energia levando a diminuição da energia por partícula. Para a taxa mais lenta utilizada no resfriamento $\left(q=-0,2 \mathrm{Kps}^{-1}\right)$ o sistema se cristaliza com um número reduzido de defeitos e sua energia se aproxima muito da energia da SSI como pode ser visto na ampliação inserida na Fig. 3.37. Para a taxa mais rápida utilizada $\left(q=-25 \mathrm{Kps}^{-1}\right)$, o sólido em $\mathrm{T}=100 \mathrm{~K}$ tem uma energia por partícula alta que identifica um sistema altamente desordenado onde os átomos tiveram suas velocidades reduzidas bruscamente.

Durante o resfriamento, para temperaturas abaixo da temperatura de fusão, a homogeneidade passa a depender da taxa de resfriamento. Nas Fig. 3.36 e 3.37 foi mostrado 
que resfriando o líquido é possível tanto a formação de vidros quanto de cristais. Mas a questão essencial a ser discutida a seguir é sobre a estrutura e homogeneidade da rede catiônica desses sólidos. As simulações mostraram que as taxas lentas implicam na perca da homogeneidade. Quanto mais lenta é a taxa de resfriamento mais significativa é a separação de fase. Com este propósito os primeiros resultados a serem mostrados são fotos da caixa de simulação que mostram a formação de vidros que podem ser homogêneos ou com separação de fase e a formação de cristais que sempre apresentam separação de fase. A caracterização estrutural utilizando g(r), número de vizinhos e a ocupação dos tetraedros formado pelos cátion será mostrada na sequência. Em todas as fotos das caixas de simulação as bolas preenchidas com a cor preta representam os $\mathrm{Pb}$ e as bolas vazias os Cd. Para uma melhor visualização os átomos de F foram excluídos.

Para obter um vidro homogêneo foi necessária uma taxa de resfriamento muito rápida. Por muito rápida deve ser entendido que ela é mais de cem vezes mais rápida que a taxa mais lenta utilizada no resfriamento. A taxa de resfriamento para obter um vidro homogêneo foi $q=-25 \mathrm{Kps}^{-1}$ enquanto que a taxa mais lenta utilizada no resfriamento foi $q=-0,2 \mathrm{Kps}^{-1}$. Nas Fig. 3.38 a 3.43 é mostrado o vidro homogêneo que doravante será chamado VH. É mostrada a composição $x=0,50$ em T=50K em dois ângulos diferentes, na Fig. 3.38 tem-se a visão frontal e na Fig. 3.39 a caixa tem rotação em torno dos eixos para facilitar a visualização da homogeneidade do sistema. As Fig. 3.40 e 3.41 mostram apenas os Cd do sistema e as Fig. 3.42 e 3.43 mostram apenas os Pb e é possível ver em todas elas que qualquer que seja o tipo do átomo ele está espalhado homogeneamente por toda a caixa.

A informação quantitativa sobre a estrutura dos VH é obtida da g(r). Na Fig. 3.44 são mostradas as $\mathrm{g}(\mathrm{r})$ dos líquidos resfriados com $q=-25 \mathrm{Kps}^{-1}$ de todas as concentrações em $\mathrm{T}=100 \mathrm{~K}$, as curvas são deslocadas no eixo y de 0,5. Com a g(r) mostrada na Fig. 3.44 


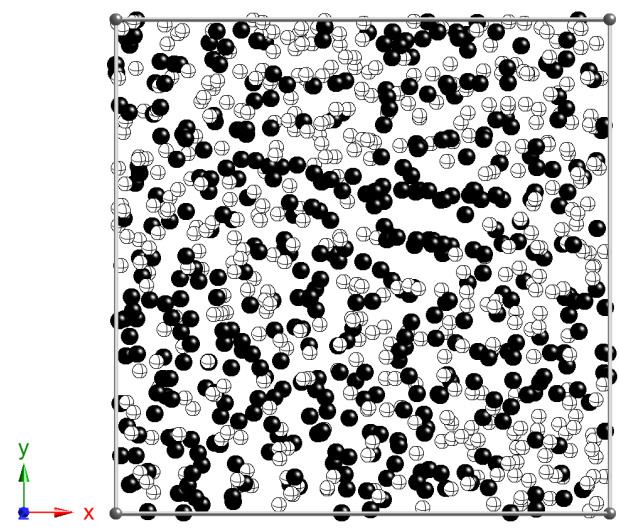

Figura 3.38: Visão frontal da caixa tridimensional do líquido com $x=0,50$ resfriado com $\mathrm{q}=-25 \mathrm{~K} / \mathrm{ps}$ em $\mathrm{T}=50 \mathrm{~K}$.

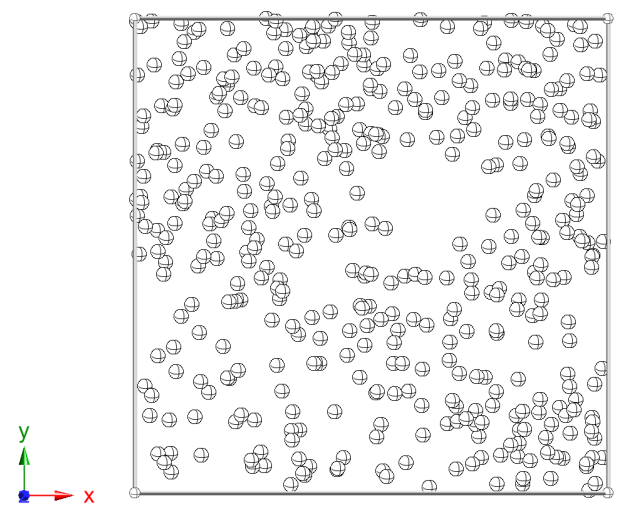

Figura 3.40: Somente os Cd da Fig. 3.38

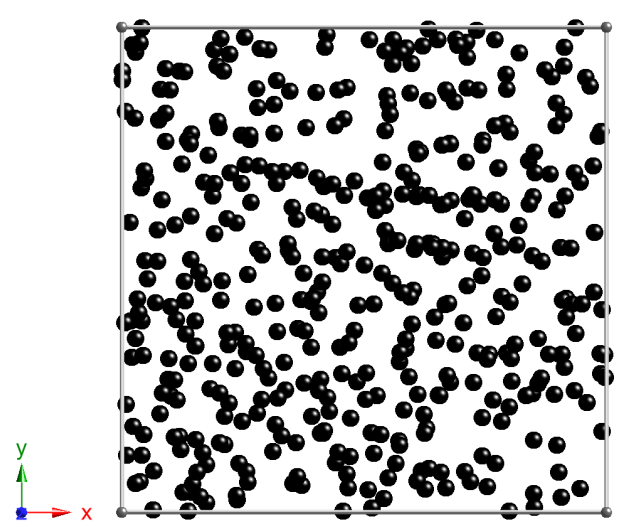

Figura 3.42: Somente os Pb da Fig. 3.38

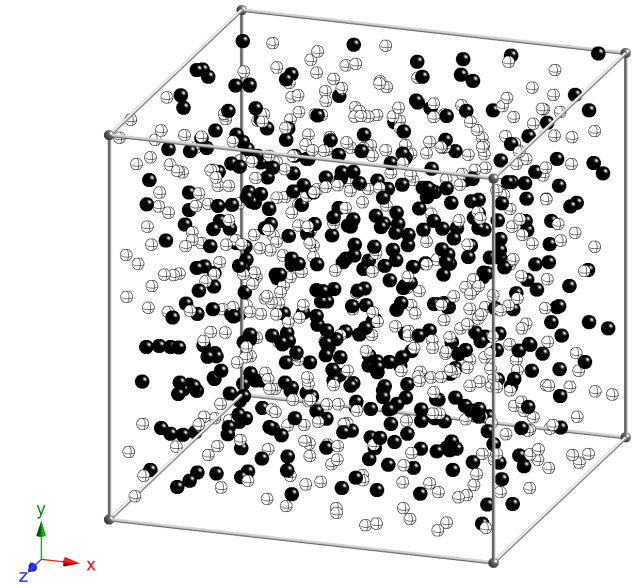

Figura 3.39: Figura 3.38 com rotação de $19^{\circ}$ para a esquerda em torno do eixo y e $19^{\circ}$ para baixo em torno do eixo $\mathrm{x}$

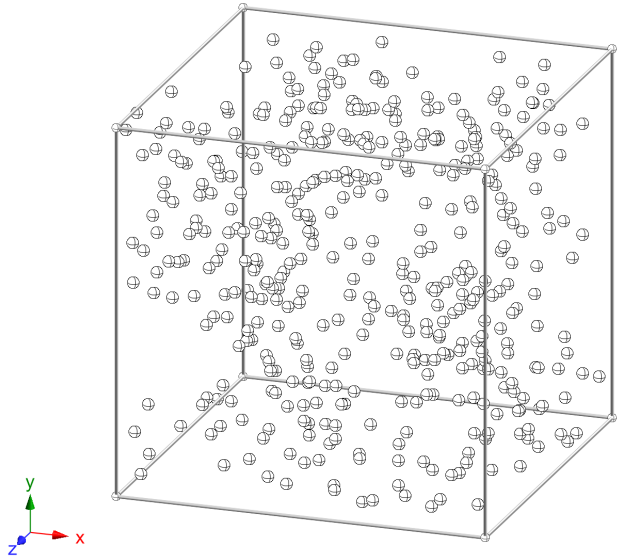

Figura 3.41: Somente os Cd da Fig. 3.39

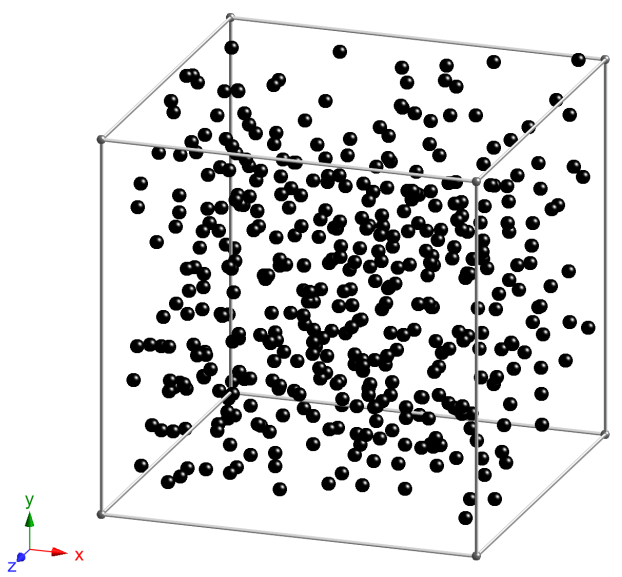

Figura 3.43: Somente os $\mathrm{Pb}$ da Fig. 3.39 
fica claro que o sistema é amorfo não apresentando picos bem definidos que indicariam a cristalização.

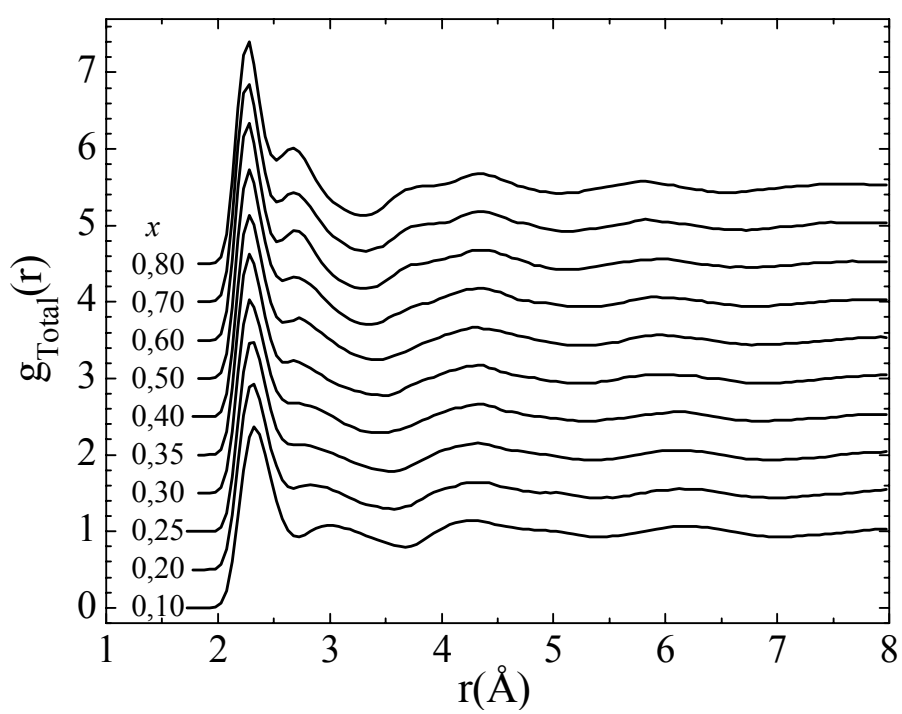

Figura 3.44: Função de correlação de pares total dos vidros homogêneos em T=100K

As Fig. 3.46 a 3.51 mostram as fotos do sistema com $x=0,40$ para as taxas limites que permitem obter um sistema cristalino ou um sistema amorfo. Como já anunciado essas fotos não mostram os Flúors e para destacar a separação de fase são mostradas fotos somente com os $\mathrm{Cd}$ e somente com os $\mathrm{Pb}$ do sistema. As Fig. 3.46, 3.48 e 3.50 mostram o vidro com separação de fase resfriado com a taxa $q=-1,0 \mathrm{Kps}^{-1}$ que apresenta algumas regiões com maior concentração de $\mathrm{Cd}$ e outras com maior concentração de $\mathrm{Pb}$. Não se observa a formação de nenhum plano cristalino para a taxa $q=-1,0 \mathrm{Kps}^{-1}$.

Utilizando-se do mesmo procedimento dos tetraedros já estabelecido para os cristais pode-se avaliar no sistema vítreo o ambiente em que os $\mathrm{F}$ se encontram. A vizinhança dos F do vidro separado é diferente da vizinhança dos F do VH. Na Fig. 3.45 são mostrados os histogramas para os VH e os não homogêneos utilizando-se da mesma notação dos $\mathrm{Q}_{i}$ já definida para as SSI embora não se tenha a ordem cristalina nessa situação. Para todas as concentrações o vidro não homogêneo sempre apresenta maiores porcentagens de $Q_{0}$ 
e $\mathrm{Q}_{4}$ em relação ao VH. Isso caracteriza que esse vidro é composto de algumas regiões ricas em $\mathrm{Cd}$ e outras em $\mathrm{Pb}$. Já os $\mathrm{VH}$ sempre apresentam maiores porcentagens de $\mathrm{Q}_{2}$ o que representa um sistema de estrutura mais homogênea em relação ao não homogêneo avaliado. Analisando a composição $x=0,50$ para o vidro não homogêneo, nota-se que a porcentagem de $\mathrm{Q}_{0}$ é consideravelmente maior que a concentração de $\mathrm{Q}_{4}$ o que indica que os $\mathrm{Cd}$ tendem a se aglomerar mais que os $\mathrm{Pb}$ uma vez que para essa composição tem-se o mesmo número de $\mathrm{Cd}$ e $\mathrm{Pb}$.

As Fig. 3.47, 3.49 e 3.51 mostram o sistema obtido pelo resfriamento com a taxa $q=-0,5 \mathrm{Kps}^{-1}$. É possível observar a formação de planos, mas os sistema apresenta separação de fase e muitos defeitos. Na Fig. 3.49 a parte que parece não cristalizada no lado direito da figura é na verdade uma cristalização com muitos defeitos em uma outra direção cristalográfica que não a da parte esquerda da figura. Para os Cd têm-se duas regiões com planos de cristalização diferentes enquanto os $\mathrm{Pb}$ tendem a ter uma única direção de cristalização. Nas Fig.3.47, 3.49 e 3.51 os Cd não formam um único cluster totalmente separado, existindo alguns Cd inseridos entre os Pb formando solução sólida mas a separação é inerente do sistema e na maior parte do cristal se observa a não homogeneidade. Pode-se obter um cristal com um menor número de defeitos com taxas de resfriamento mais lentas, mas ele sempre apresentará separação de fase se o sistema contiver grandes quantidades de Cd. Para o caso da concentração $x=0,40$ a separação de fase já existe com a taxa $q=-1 \mathrm{Kps}^{-1}$ resultando em um vidro e consequentemente para taxas mais lentas maior será a separação de fase.

Para avaliar o comportamento do sistema perante taxas mais lentas foi escolhida a taxa $q=-0,2 \mathrm{Kps}^{-1}$, que foi a taxa mais lenta utilizada nas simulações do resfriamento do líquido, a qual gerou cristais que serão amplamente discutidos e doravante serão chamados de LR. As Fig. 3.52 a 3.57 mostram as fotos para o resfriamento com $q=-0,2 \mathrm{Kps}^{-1}$ 

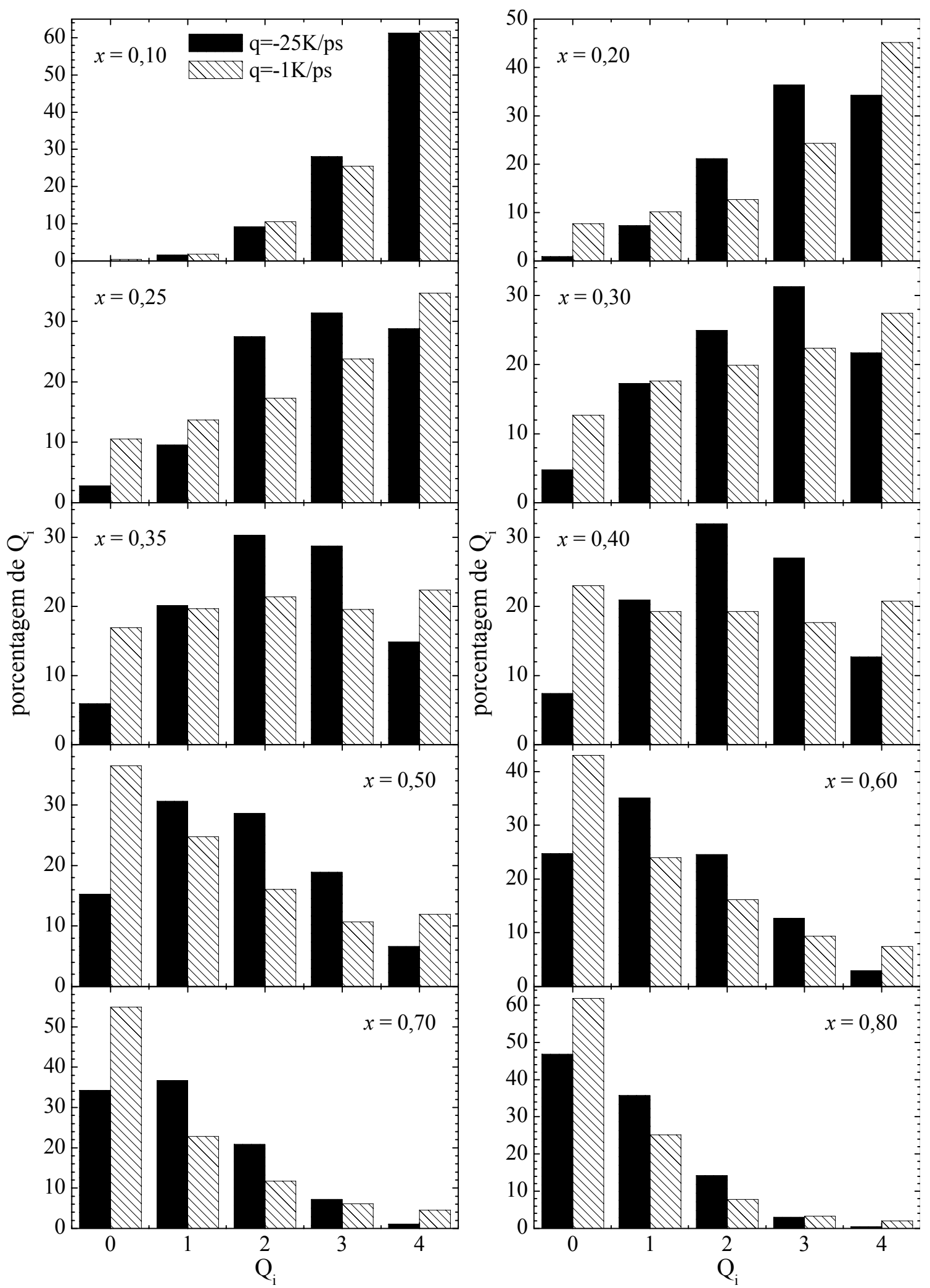

Figura 3.45: Estatística do ambiente em que os F se encontram. Comparação entre os vidros homogêneos $(q=-25 \mathrm{~K} / \mathrm{ps})$ e os não homogêneos $(q=-1 \mathrm{~K} / \mathrm{ps})$ em $\mathrm{T}=50 \mathrm{~K}$. 


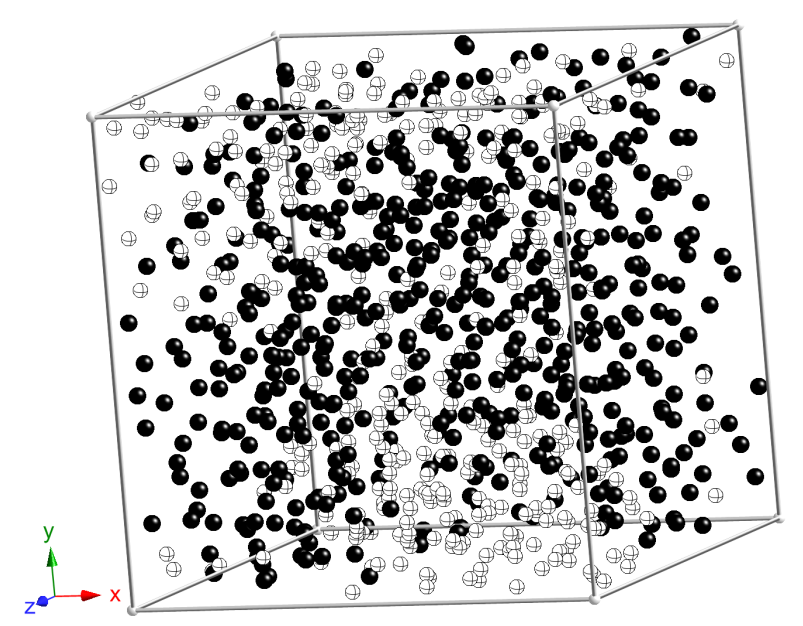

Figura 3.46: Sistema com $x=0,40$ resfriado com $\mathrm{q}=-1 \mathrm{~K} / \mathrm{ps}$ em $\mathrm{T}=50 \mathrm{~K}$.

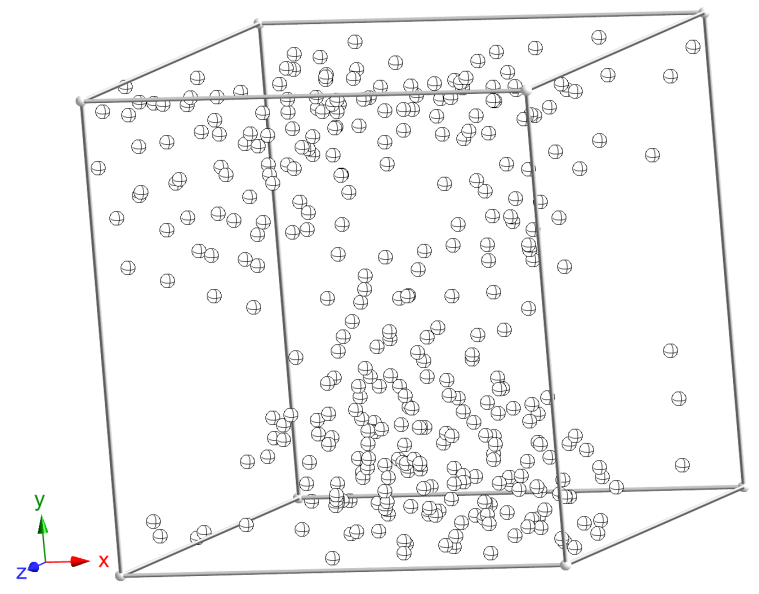

Figura 3.48: Somente os Cd da Fig. 3.46

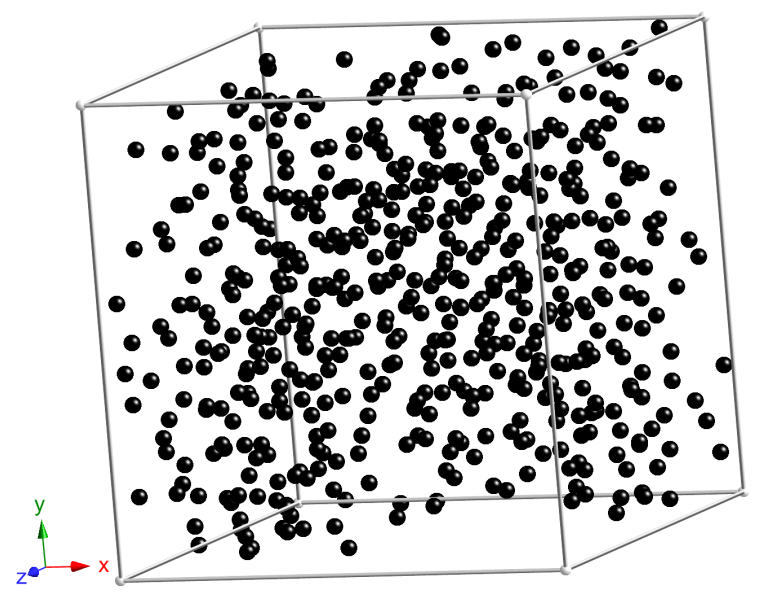

Figura 3.50: Somente os Pb da Fig. 3.46

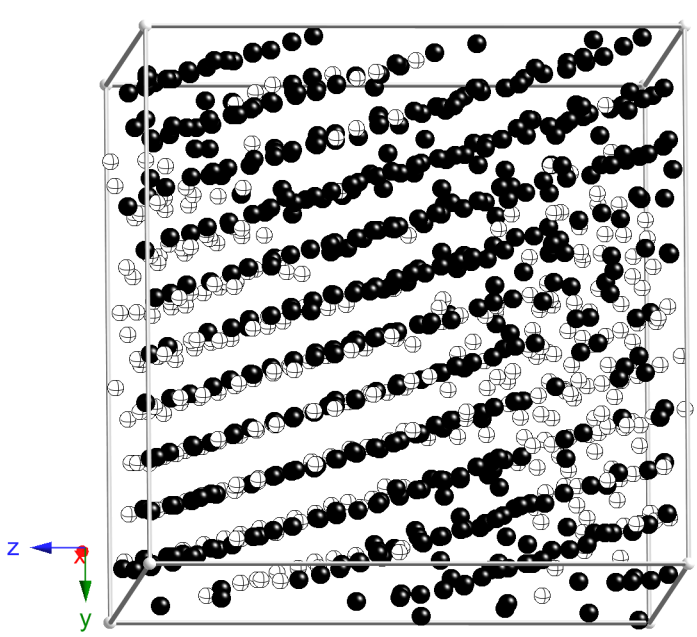

Figura 3.47: Sistema com $x=0,40$ resfriado com $\mathrm{q}=-0,5 \mathrm{~K} / \mathrm{ps}$ em $\mathrm{T}=100 \mathrm{~K}$.

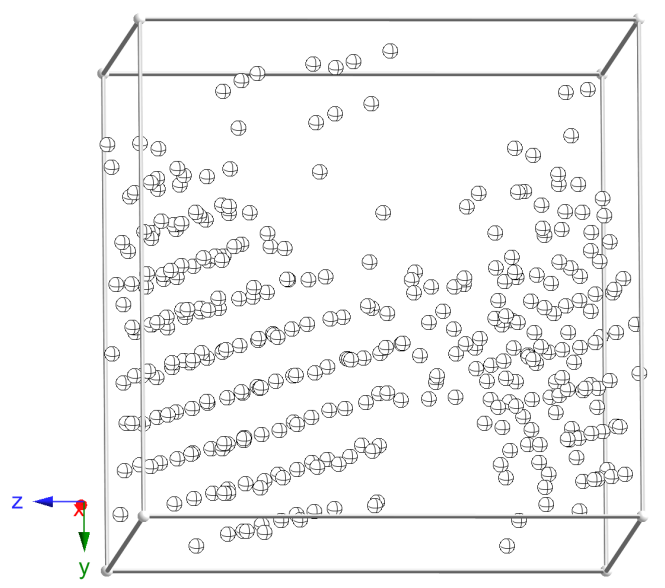

Figura 3.49: Somente os Cd da Fig. 3.47

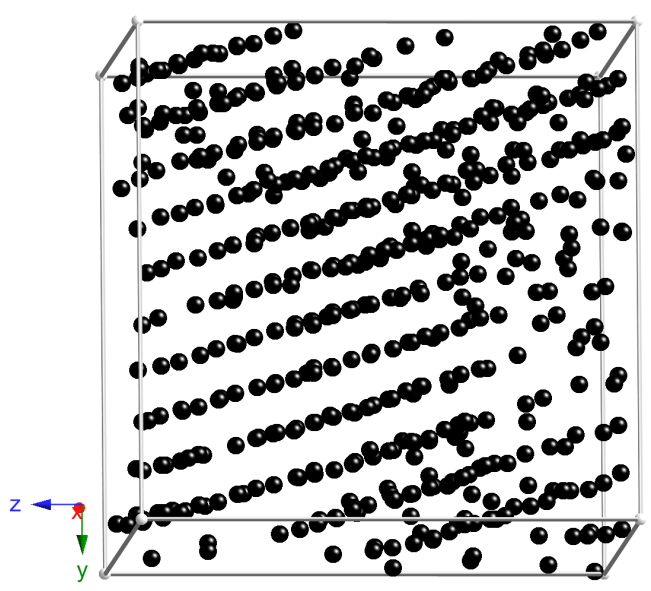

Figura 3.51: Somente os Pb da Fig. 3.47 
para as concentrações $x=0,10$ e $x=0,50$. Novamente os átomos de $\mathrm{Cd}$ e $\mathrm{Pb}$ são mostrados separadamente para permitir uma análise da homogeneidade do sistema. Para o sistema com $x=0,10$ os poucos átomos de Cd são inseridos com facilidade na rede formada pelos $\mathrm{Pb}$. A Fig. 3.54 mostra que o sistema é bastante homogêneo e quase sem defeitos. Mas quando a concentração de Cd aumenta a separação de fase é inevitável. As Fig. 3.55 e 3.57 mostram que a composição do LR com $x=0,50$ apresenta separação de fase e algumas regiões com defeitos. Um fato importante mostrado na Fig. 3.53 é que tanto os $\mathrm{Cd}$ quanto os $\mathrm{Pb}$ se cristalizam e tendem a pertencer em média aos mesmos planos de cristalização. Muitas vezes a região rica em $P b F_{2}$ se transforma em um cristal independente do cristal formado pela região rica em $C d F_{2}$ e a união desses dois cristais contém muitos defeitos. Os cristais formados pelo resfriamento dos líquidos das outras concentrações estão ilustrados nas Fig. 3.58 a 3.63.

Para as concentrações $x=0,25$ e $x=0,30$ dos LR os Cd atingem um número crítico e passam a formar aglomerados e deixam de pertencer a um único plano cristalino. Nas Fig. 3.58 e 3.59 é possível ver os Cd se agrupando e ocupando posições intersticiais na rede formada pelos $\mathrm{Pb}$. As concentrações entre $x=0,40$ e $x=0,60$ tem o comportamento já discutido da composição $x=0,50$ onde tanto os $\mathrm{Pb}$ quanto os $\mathrm{Cd}$ tendem a pertencer aos mesmos planos. Quando a concentração de Cd passa a ser maior que a de $\mathrm{Pb}$ os LR também apresentam separação de fase, mas os $\mathrm{Pb}$ é que tendem a não se cristalizar. A Fig. 3.62 mostra a composição $x=0,70$ e a Fig. 3.63 a $x=0,80$ e em ambas é possível ver que os $\mathrm{Cd}$ formam planos cristalinos enquanto os $\mathrm{Pb}$ tendem a se agrupar e ocupar posições intersticiais de maneira desordenada.

Para quantificar a separação de fase pode-se observar o comportamento das $\mathrm{g}_{\alpha \beta}(r)$ e dos $\mathrm{n}_{\alpha \beta}(r)$ dos sistemas mistos em comparação com os fluoretos puros. Na Fig. 3.64 são mostrados os comportamentos das $\mathrm{g}_{\alpha \beta}(r)$ do sistema com $x=0,50 \mathrm{em} \mathrm{T}=50 \mathrm{~K}$ para 


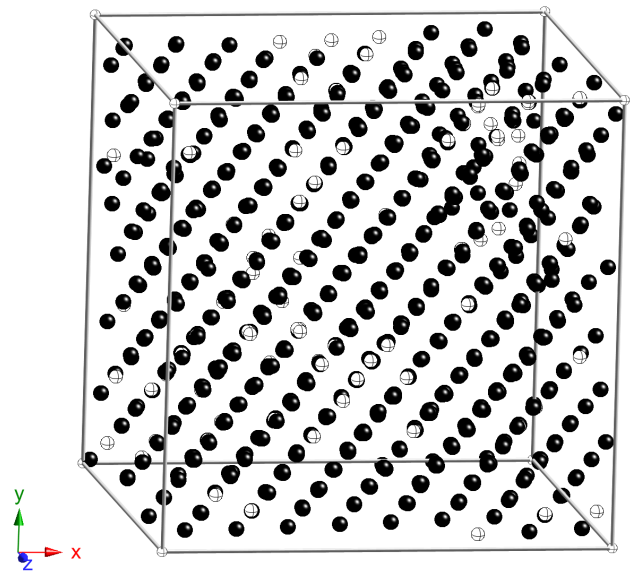

Figura 3.52: Sistema com $x=0,10$ resfriado do líquido com $\mathrm{q}=-0,2 \mathrm{~K} / \mathrm{ps}$ em $\mathrm{T}=50 \mathrm{~K}$.

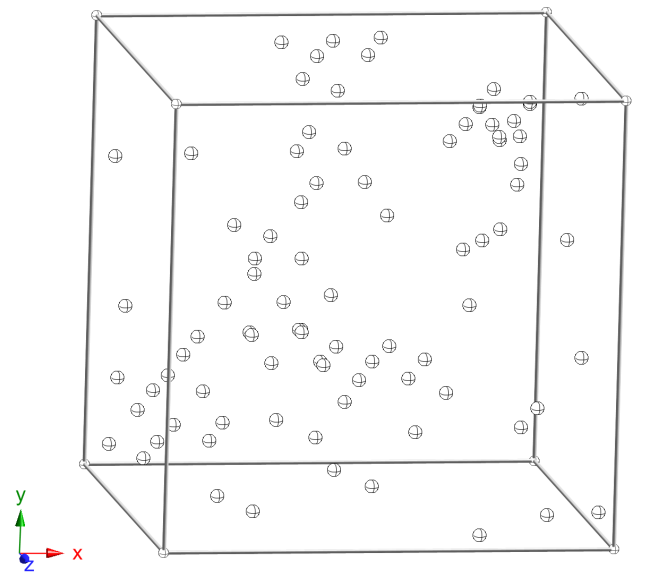

Figura 3.54: Somente os Cd da Fig. 3.52.

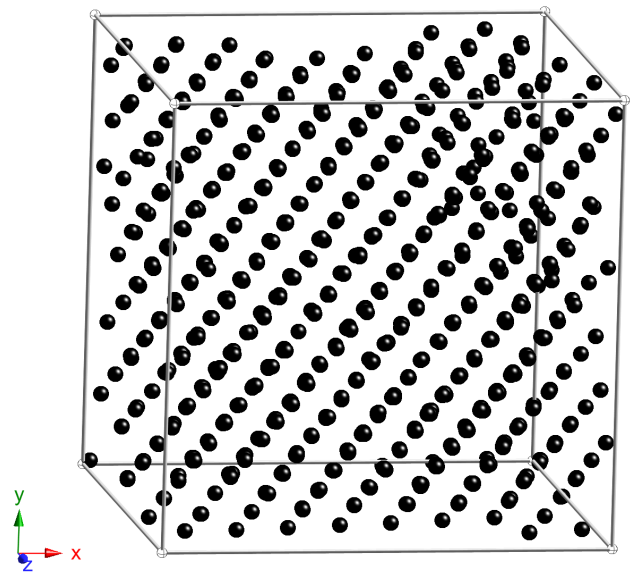

Figura 3.56: Somente os Pb da Fig. 3.52.

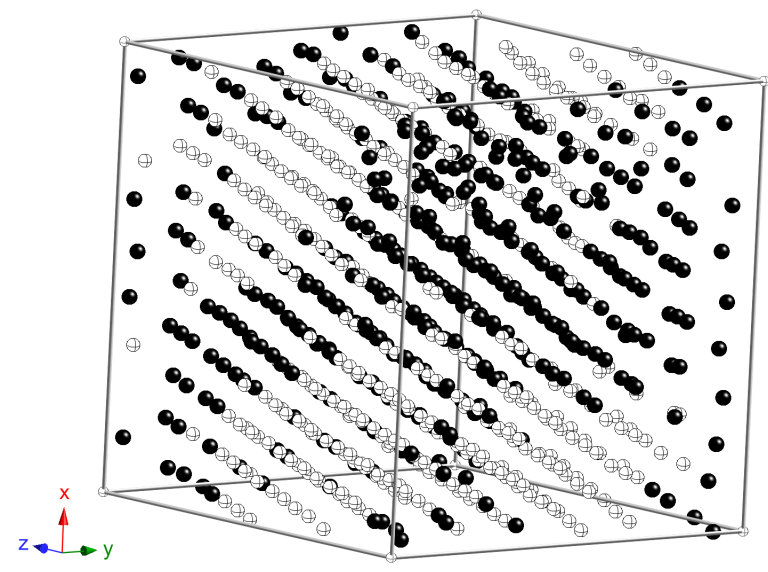

Figura 3.53: Sistema com $x=0,50$ resfriado do líquido com $\mathrm{q}=-0,2 \mathrm{~K} / \mathrm{ps}$ em $\mathrm{T}=50 \mathrm{~K}$.

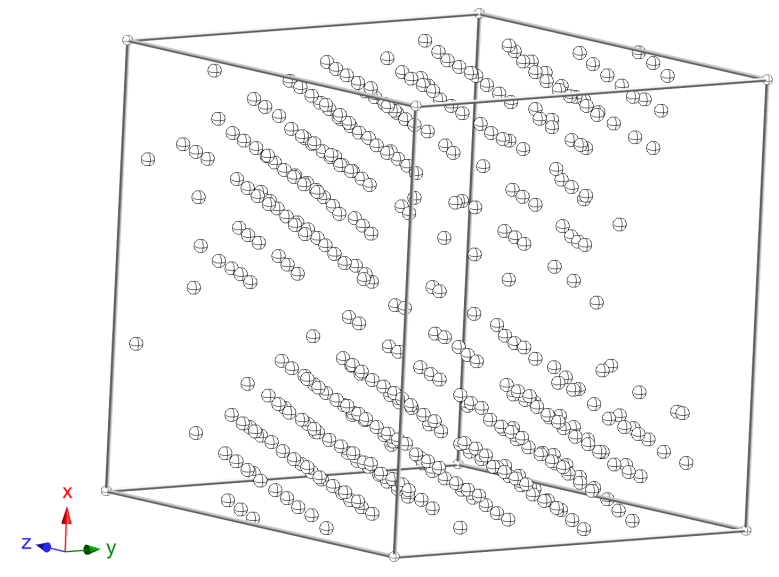

Figura 3.55: Somente os Cd da Fig. 3.53.

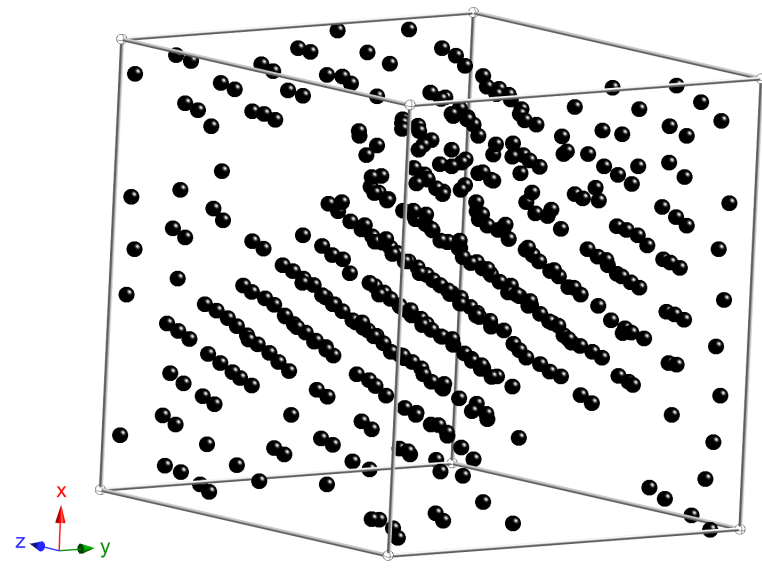

Figura 3.57: Somente os Pb da Fig. 3.53. 


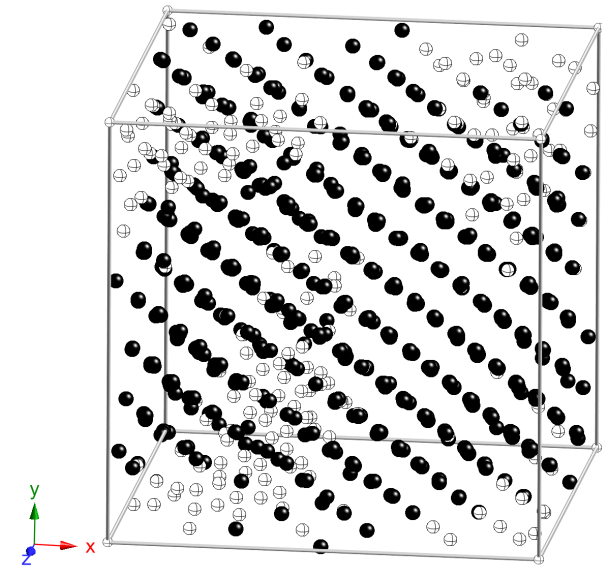

Figura 3.58: LR, $\mathrm{q}=-0,2 \mathrm{~K} / \mathrm{ps}$ e $x=0,25$.

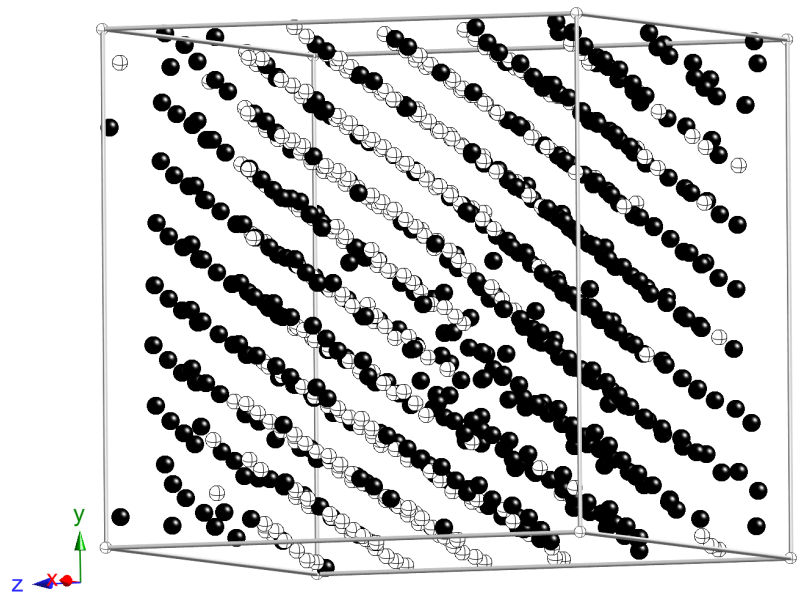

Figura 3.60: LR, $\mathrm{q}=-0,2 \mathrm{~K} / \mathrm{ps}$ e $x=0,40$.

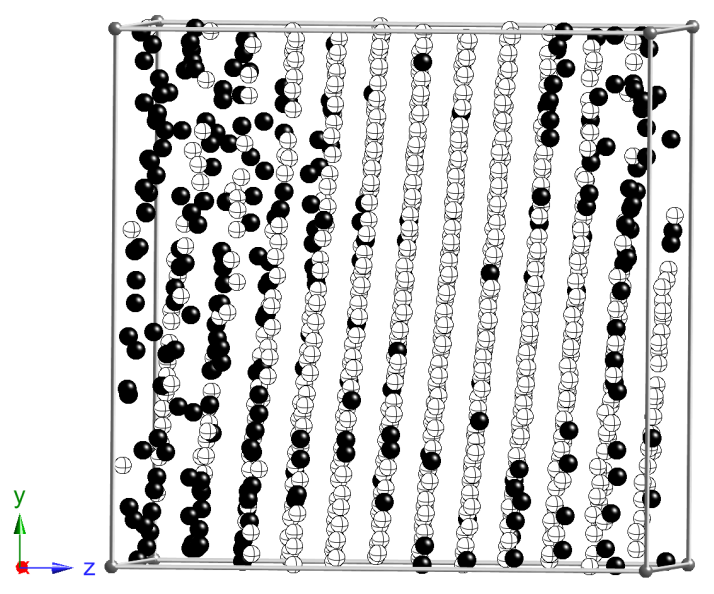

Figura 3.62: LR, $\mathrm{q}=-0,2 \mathrm{~K} / \mathrm{ps}$ e $x=0,70$.

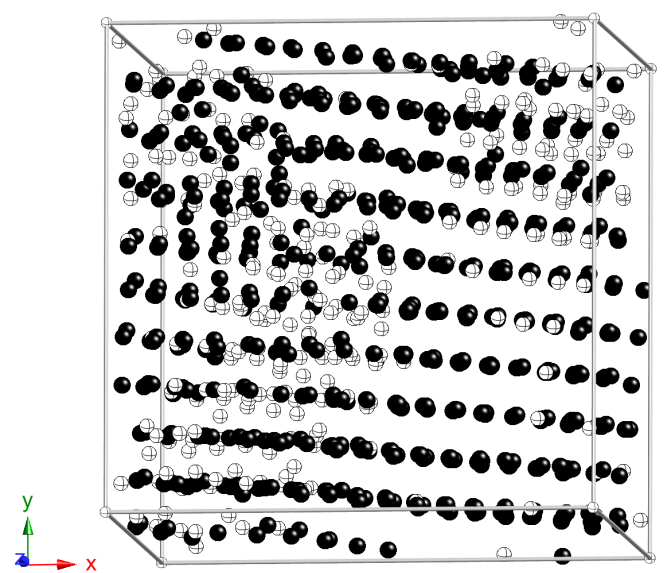

Figura 3.59: LR, $\mathrm{q}=-0,2 \mathrm{~K} / \mathrm{ps}$ e $x=0,30$.

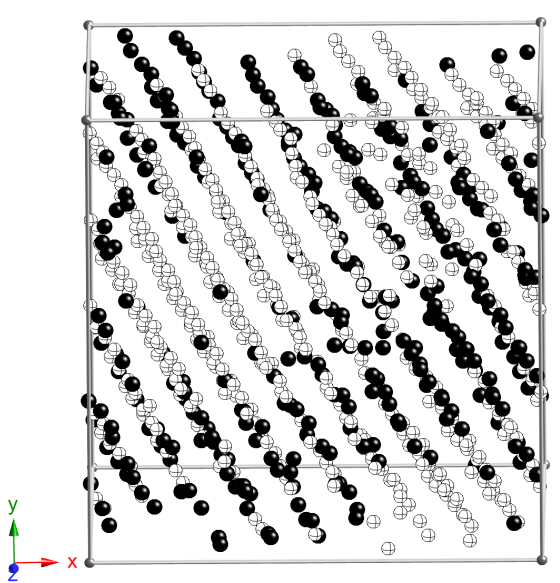

Figura 3.61: LR, $\mathrm{q}=-0,2 \mathrm{~K} / \mathrm{ps}$ e $x=0,60$.

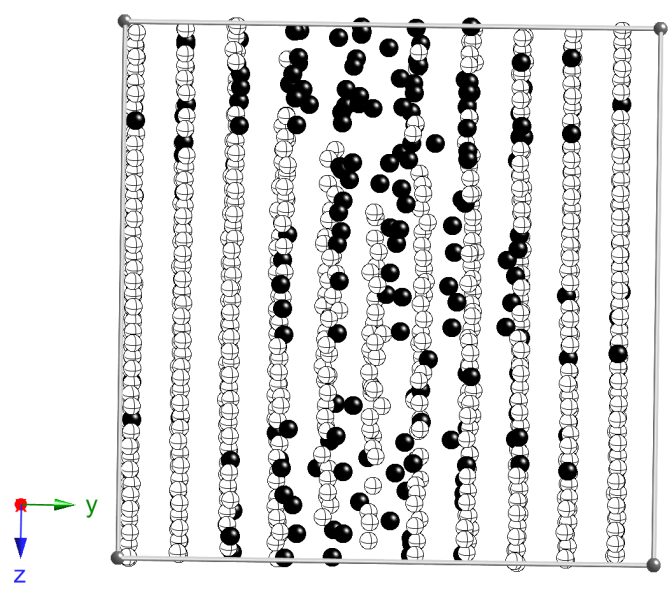

Figura 3.63: LR, $\mathrm{q}=-0,2 \mathrm{~K} / \mathrm{ps}$ e $x=0,80$. 
o LR e a SSI em comparação com os fluoretos puros. Na Fig. 3.64 (a) é avaliado o par Cd-Cd e nota-se que os picos da $\mathrm{g}_{C d-C d}(r)$ do LR tendem para posições iguais aos picos do $C d F_{2}$ puro, enquanto a SSI tem posições maiores para os mesmos picos devido à relaxação da ligação anteriormente discutida. Esse fato mostra que os pares $\mathrm{Cd}-\mathrm{Cd}$ no LR tem comportamento que se aproxima dos pares $\mathrm{Cd}-\mathrm{Cd}$ do $C d F_{2}$ puro. A situação é semelhante quando se analisa o par Pb-Pb. Na Fig. 3.64 (c) são mostradas as $\mathrm{g}_{P b-P b}(r)$ onde nota-se que os pares $\mathrm{Pb}-\mathrm{Pb}$ do $\mathrm{LR}$ tendem a ter um comportamento igual aos pares $\mathrm{Pb}-\mathrm{Pb}$ do $\mathrm{PbF}_{2}$ puro enquanto que para a SSI o pico ocorre para posições menores devido ao encurtamento das ligações como anteriormente discutido. O comportamento do LR de se aproximar dos fluoretos puros é notado também nas ligações envolvendo os F. Na 3.64 (d) e 3.64 (e) as posições dos picos do LR se assemelham às posições dos fluoretos puros. A conclusão é que os LR não formam soluções sólidas e as suas partes cristalizadas são compostas de aglomerados de $P b F_{2}$ e $C d F_{2}$.

Comparando as Fig. 3.64 (a), (b) e (c) nota-se que os Cd do LR são mais organizados que os $\mathrm{Pb}$. Na Fig. 3.64 (a) ve-se que os picos da $\mathrm{g}_{C d-C d}(r)$ do cristal LR são tão altos e estreitos quanto aos da SSI. Já os picos da $\mathrm{g}_{P b-P b}(r)$ na Fig. 3.64 (c) são mais baixos e mais largos que os da SSI. Isso influi até no comportamento dos F, os quais tendem a ter um comprimento de ligação com valores mais próximo ao do $C d F_{2}$ e não ao do $P b F_{2}$ como pode ser visto na Fig. 3.64 (f).

Conforme discutido anteriormente, nos LR para concentrações com pouco $C d F_{2} \mathrm{os} \mathrm{Pb}$ são mais organizados que os Cd enquanto que para concentrações com muito $P b F_{2}$ são os Cd é que se desorganizam. Na Fig. 3.65 são mostradas as $\mathrm{g}_{P b-P b}(r)$ e as $\mathrm{g}_{C d-C d}(r)$ para três diferentes concentrações dos LR que ilustram esse fato. Na Fig. 3.65 (a) a composição $x=0,30$ apresenta uma $\mathrm{g}_{C d-C d}(r)$ típica de um sistema desordenado enquanto que na Fig. $3.65(\mathrm{~b})$ a $\mathrm{g}_{P b-P b}(r)$ apresenta picos de cristalização e regiões proibidas entre os 

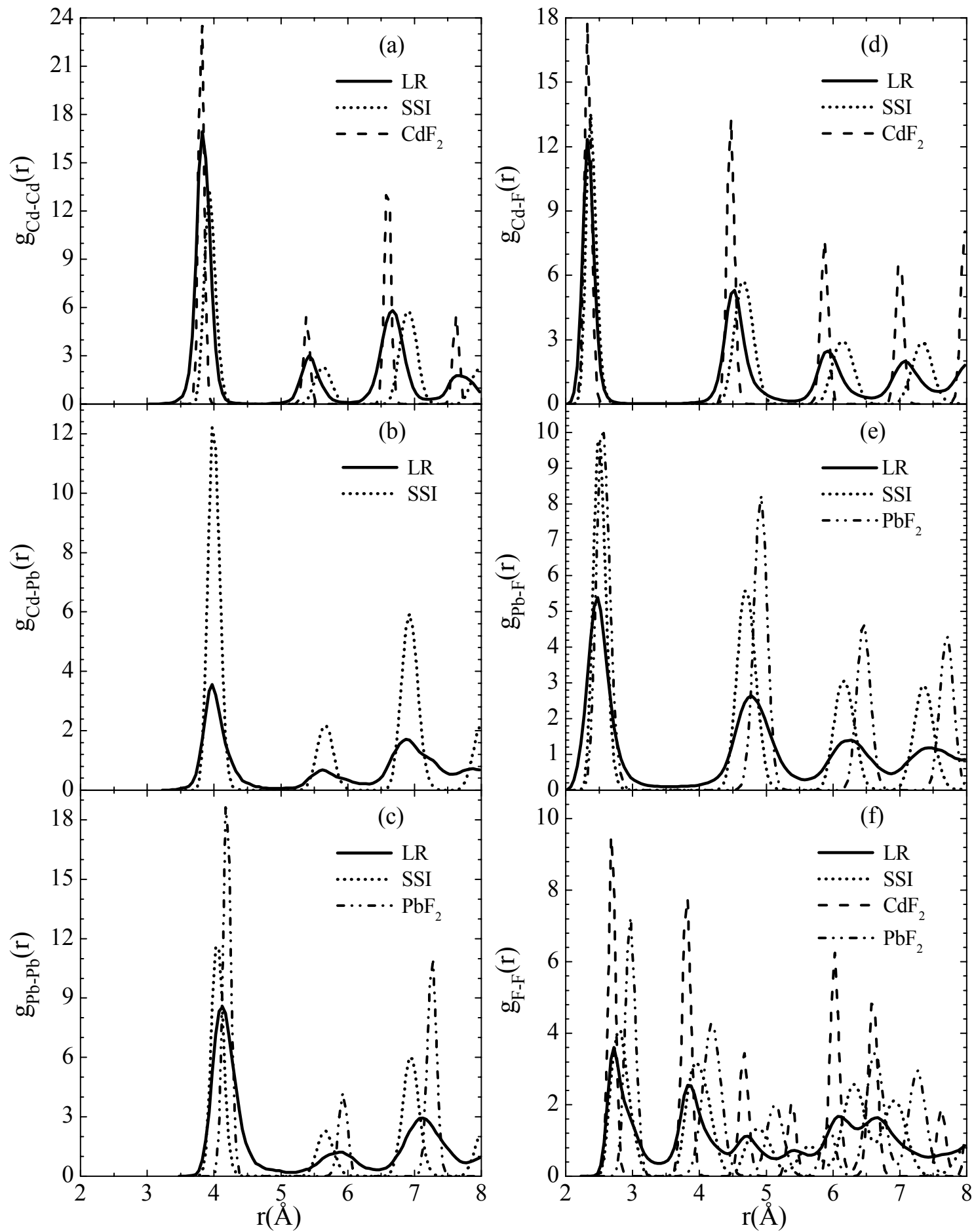

Figura 3.64: Comparação das $\mathrm{g}_{\alpha \beta}(\mathrm{r})$ em $\mathrm{T}=50 \mathrm{~K}$ para os cristais LR e SSI com $x=0,50$ e os fluoretos puros. 
picos. A composição $x=0,70$ apresenta comportamento contrário sendo que a $\mathrm{g}_{C d-C d}(r)$ é típica de sistemas cristalinos enquanto que a $\mathrm{g}_{P b-P b}(r)$ representa um sistema mais desorganizado. No LR com $x=0,50$ conforme também discutido anteriormente, tanto os $\mathrm{Cd}$ quanto os $\mathrm{Pb}$ formam planos cristalinos que são confirmados pelas $\mathrm{g}_{P b-P b}(r)$ e $\mathrm{g}_{C d-C d}(r)$ nas Fig. $3.65(\mathrm{~b})$ e (a).
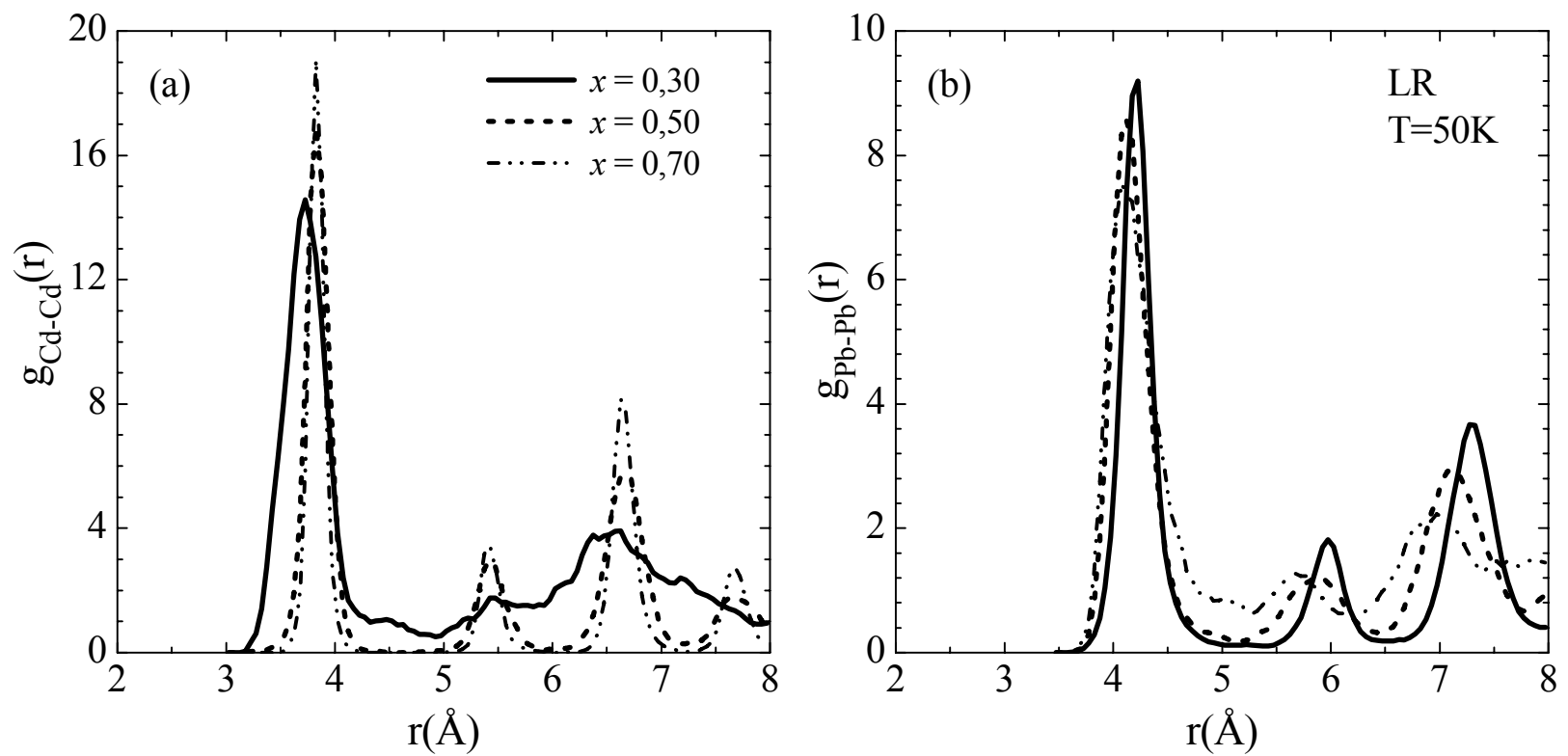

Figura 3.65: $\mathrm{g}_{\alpha \beta}(\mathrm{r})$ do líquido resfriado com $q=-0,2 \mathrm{Kps}^{-1}$ para três diferentes concentrações.

A separação de fase nos LR pode também ser vista analisando-se o número de vizinhos. $\mathrm{O} \mathrm{n}_{\alpha-\beta}(r)$ mostra o comportamento médio da vizinhança de um dado átomo do sistema que no caso dos LR implica em identificar as regiões ricas em $P b F_{2}$, as regiões ricas em $C d F_{2}$ e os contornos entre essas regiões que é interpretado como uma região de sistema misto. Na Fig. 3.66 são mostrados os números de vizinhos dos seis pares de átomos que formam a composição com $x=0,50$. Cada patamar indica uma esfera de coordenação e as curvas vão acumulando os vizinhos encontrados como função da distância. Na Fig. 3.66 foi feita uma comparação, da mesma maneira que foi feito na Fig. 3.64, com a SSI e os fluoretos puros. A Fig. 3.66 (a) mostra que o $\mathrm{n}_{C d-C d}(r)$ do LR em cada esfera de 
coordenação é maior que o da SSI e menor que o do $C d F_{2}$ puro. Isso indica que os $\mathrm{Cd}$ estão mais aglomerados no LR do que na SSI, mas em média existem $\mathrm{Pb}$ na vizinhança do Cd também pois o $\mathrm{n}_{C d-C d}(r)$ do LR é menor que o do $C d F_{2}$ puro. Os $\mathrm{Pb}$ vizinhos dos Cd são na maioria pertencentes aos contornos entre as regiões ricas em $C d F_{2}$ e $P b F_{2}$. De maneira semelhante o $\mathrm{n}_{P b-P b}(r)$ na Fig. 3.66 (c) mostra que os $\mathrm{Pb}$ no LR estão mais aglomerados que na SSI e menos aglomerados que no $P b F_{2}$ puro. $\mathrm{O} \mathrm{n}_{C d-P b}(r)$ ilustrado na Fig. 3.66 (b) mostra menores valores em relação a SSI característico do sistema separado, indicando que os $\mathrm{Cd}$ deixam de ter vizinhos do tipo $\mathrm{Pb}$. Os pares envolvidos em ligações com os F não sofrem alterações quanto a vizinhança, sendo que o LR, a SSI e os fluoretos puros apresentam os mesmos números de coordenação para um dado par. A distribuição dos F em qualquer um dos sistemas é sempre homogênea.

O resfriamento do líquido resultando em um sistema sólido pode ser analisado quanto a difusão dos átomos. Na Fig. 3.67 são mostrados os coeficientes de difusão dos três átomos que compõem o sistema com $x=0,40$. São mostradas quatro diferentes taxas de resfriamento juntamente com uma de aquecimento que serve de referência. Nas quatro situações mostradas os cátions são os primeiros a terem a difusão nula e somente em temperaturas mais baixas os Flúors encerram seus movimentos entre os cátions já fixos. Para os casos em que ocorre cristalização, primeiro a rede catiônica se estabelece e os F continuam com movimento e nota-se que essa difusão aniônica (sólido superiônico) para uma dada temperatura fixa é sempre maior que a observada para a SSI. A taxa $q=-0,5$ $\mathrm{Kps}^{-1}$ leva a formação de um cristal com muitos defeitos os quais tornam mais fácil o movimento dos Flúors. A difusão do $\mathrm{F}$ para a taxa $q=-0,5 \mathrm{Kps}^{-1}$ é comparável com a difusão nos vidros obtidos com as taxas $q=-25,0 \mathrm{Kps}^{-1}$ e $q=-1,0 \mathrm{Kps}^{-1}$. Na Fig. 3.67 (a) nota-se que as curvas para essas três taxas são praticamente idênticas. Quando utilizada a taxa $q=-0,2 \mathrm{Kps}^{-1}$ ocorre à formação de cristais com um número menor 

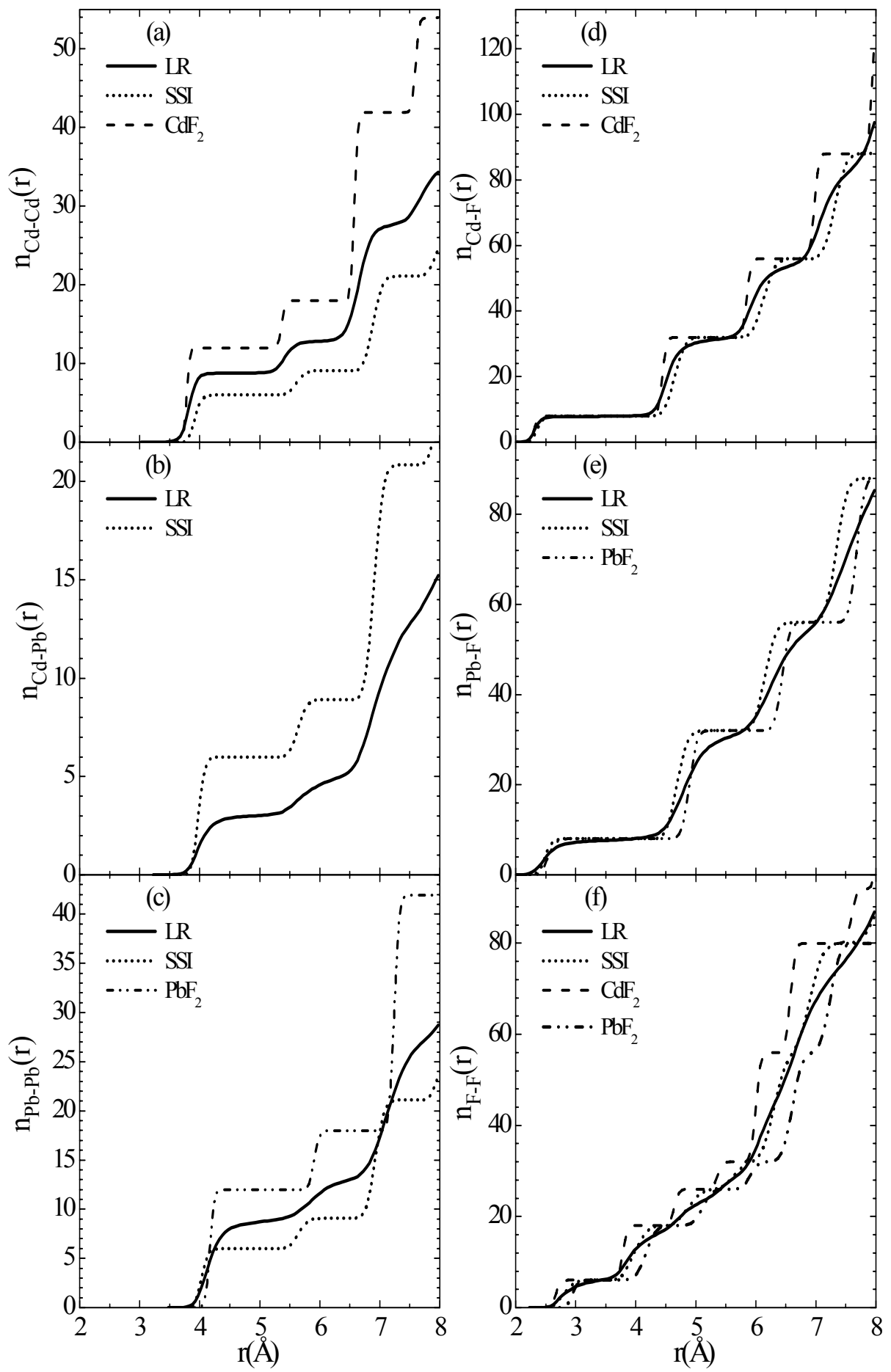

Figura 3.66: Comparação dos $\mathrm{n}_{\alpha \beta}(\mathrm{r})$ em $\mathrm{T}=50 \mathrm{~K}$ para os sistemas LR e SSI com $x=0,50$ e os fluoretos puros. 


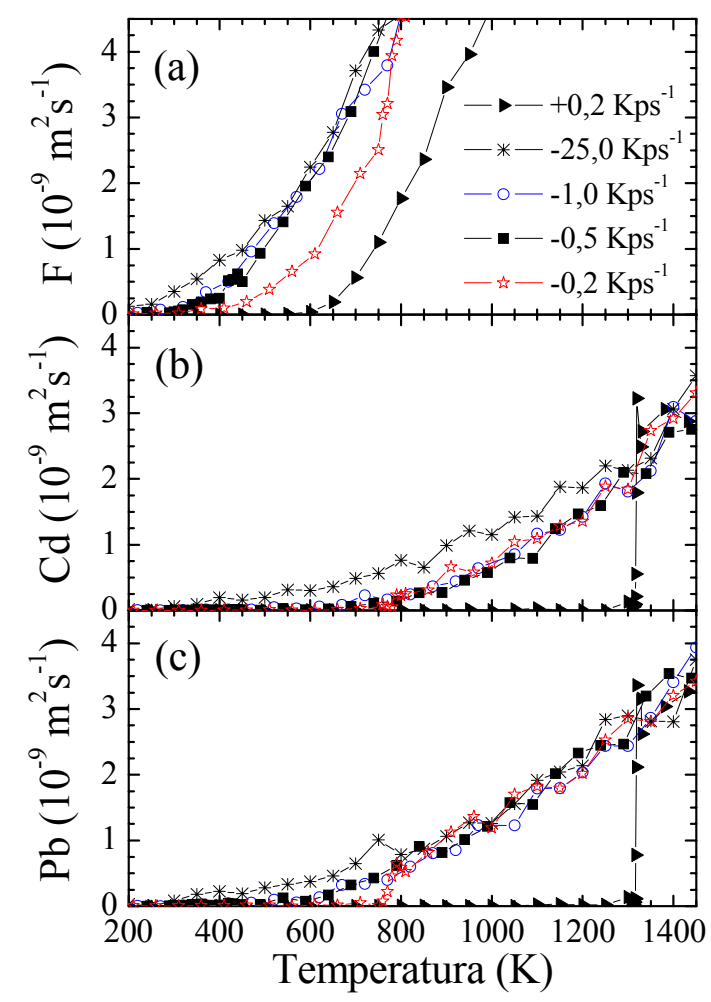

Figura 3.67: Coeficientes de difusão para a concentração $x=0,40$ em função da temperatura para diferentes taxas de resfriamento. Em (a) são mostrado os dados para o F, em (b) para o $\mathrm{Cd}$ e em (c) para o $\mathrm{Pb}$.

de defeitos e os Flúors passam a ter sítios de mesma energia bem definidos os quais eles passam a ocupar. Com a possibilidade reduzida de sítios na rede a difusão diminui como pode ser visto na Fig. 3.67 (a) na curva representada pelas estrelas.

Durante o processo de cristalização é possível observar que os Cd tendem a perder o seu movimento primeiro que os $\mathrm{Pb}$. Para ambas as taxas em que ocorreu a cristalização $\left(q=-0,5 \mathrm{Kps}^{-1}\right.$ e $\left.q=-0,2 \mathrm{Kps}^{-1}\right)$ é possível observar que os $\mathrm{Cd}$ tendem a ter a difusão nula antes dos Pb. A Fig. 3.68 ilustra a situação para a taxa $q=-0,5 \mathrm{Kps}^{-1}$ e a Fig. 3.69 para $q=-0,2 \mathrm{Kps}^{-1}$. Conforme discutido anteriormente os Cd são mais fortemente ligados aos F o que lhes impõe uma difusão menor.

Utilizando-se dos métodos anteriormente empregados para se estimar o parâmetro de rede nas SSI será mostrado que no caso de sistemas com separação de fase o parâmetro de rede único não existe. Também não se observa a relaxação das ligações da mesma 


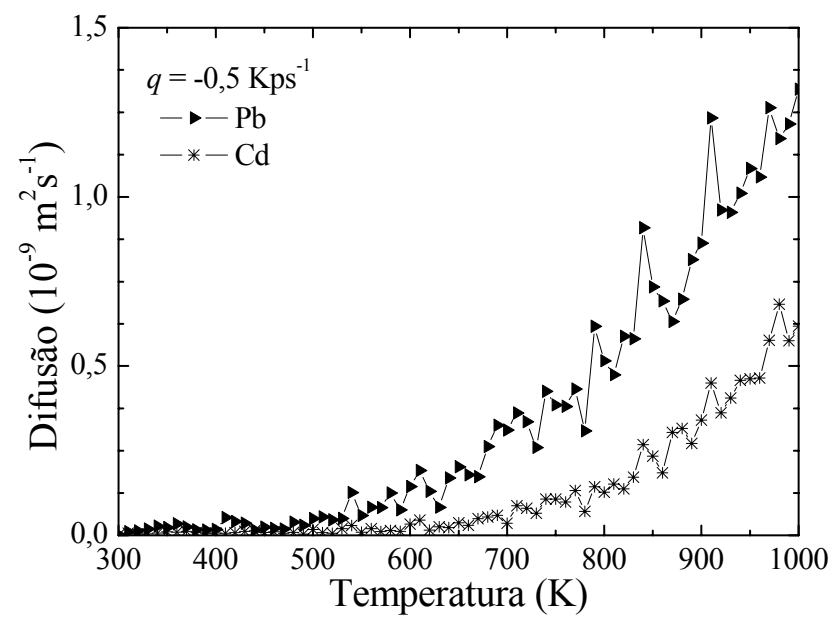

Figura 3.68: Comparação do coeficiente de difusão do $\mathrm{Cd}$ e do $\mathrm{Pb}$ durante a cristalização do resfriamento $q=-0,5 \mathrm{Kps}^{-1}$.

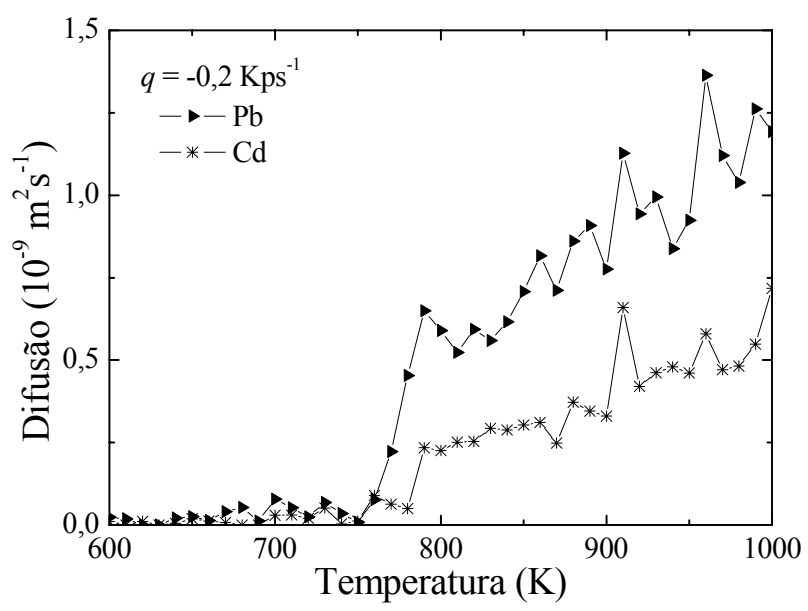

Figura 3.69: Comparação do coeficiente de difusão do $\mathrm{Cd}$ e do $\mathrm{Pb}$ durante o resfriamento com $q=-0,2 \mathrm{Kps}^{-1}$. 
maneira que foi obtida anteriormente para as SSI que apresentavam depedência linear com a concentração de $C d F_{2}$. Na Fig. 3.70 são mostradas as posições dos segundos picos da $\mathrm{g}_{\alpha \beta}(\mathrm{r})$ da rede catiônica do LR em comparação com as SSI. Para as posições dos segundos picos do LR foi utilizada a notação $d_{P b P b}$ LR e $d_{C d C d}$ LR, e para as SSI $d_{P b P b}$ SSI e $d_{C d C d}$ SSI. As curvas para os cristais LR mostram claramente que o comportamento não é mais o mesmo do observado nas SSI na Fig. 3.15. As distâncias $d_{P b P b}$ LR não apresentam diminuição com comportamento linear com a adicão de $C d F_{2}$ como nas SSI e apenas apresentam oscilação em torno do valor $d_{P b P b}$ do $P b F_{2}$ puro indicando que o sistema é realmente separado e deve conter uma região rica em $P b F_{2}$ que apresenta as características do $\mathrm{PbF}_{2}$ puro. A composição $x=0,70$ do LR, apesar de apresentar uma diminuição na $d_{P b P b}$, tem os picos da $\mathrm{g}_{P b-P b}(\mathrm{r})$ muito largo o que indica grande desordem. Para a concentração $x=0,80$ os $\mathrm{Pb}$ têm uma desordem muito grande e fica difícil determinar um valor para a posição do segundo pico da $\mathrm{g}_{P b-P b}(r)$. O mesmo comportamento é observado quanto as distâncias $d_{C d C d}$ LR. Para $x \geqslant 0,35$ as distâncias $d_{C d C d}$ LR apenas oscilam em torno da $d_{C d C d}$ do $C d F_{2}$ puro. Quando a concentração de $C d F_{2}$ é pequena $(x \leq 0,25)$ os $C d$ não se cristalizam conforme discutido anteriormente e os valores da $d_{C d C d}$ LR são diferentes do $C d F_{2}$ puro.

Quando se tenta interpretar o parâmetro de rede por meio de médias, utilizando as definições anteriores dadas pela Eq. 3.2 para a $m_{p}$ e pela Eq. 3.1 para a $m_{s}$, pode-se erroneamente observar um comportamento linear de diminuição do parâmetro de rede com a adição de $C d F_{2}$. Na Fig. 3.71 são comparadas as médias das posições dos segundos picos do sistema com separação de fase bem como a posição dos segundos picos das $\mathrm{g}_{\alpha \beta}(\mathrm{r})$ das SSI. Mas como discutido anteriormente o sistema apresenta separação de fase e não existe um parâmetro de rede real que descreva a sua ordem cristalina. A diminuição demonstrada pelas médias não representa a realidade microscópica do sistema e essas médias podem 


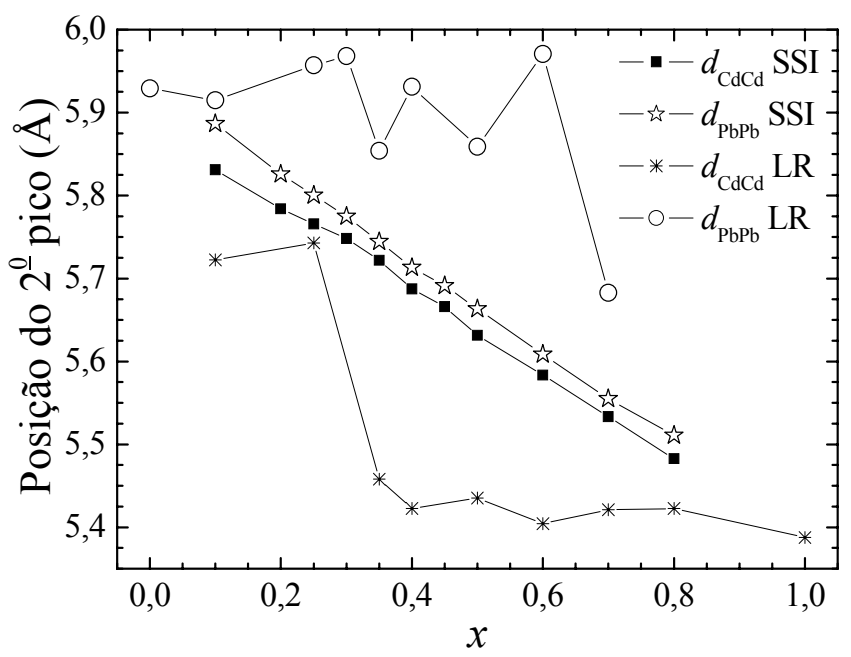

Figura 3.70: Posição dos segundos picos das $\mathrm{g}_{C d-C d}(\mathrm{r})\left(d_{C d C d}\right)$ e $\mathrm{g}_{P b-P b}(\mathrm{r})\left(d_{P b P b}\right)$ em $\mathrm{T}=50 \mathrm{~K}$ dos LR em comparação com as SSI.

também ser obtidas e interpretadas de maneira não correta experimentalmente quando se utiliza alguma medida que faça a média das distâncias dos cátions encontrados na rede. O fenômeno da relaxação das ligações inerente nas soluções sólidas não ocorre para o sistema com separação de fase.

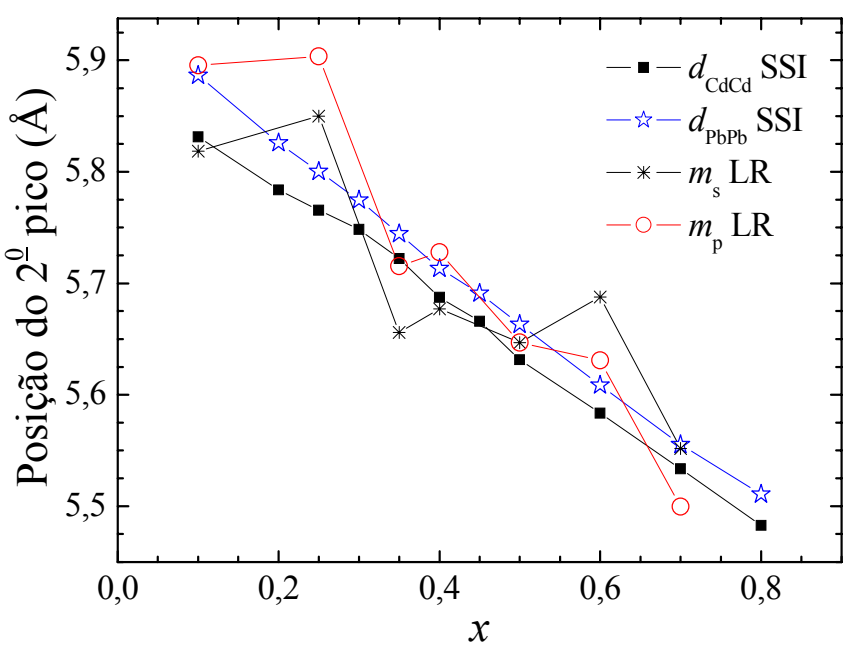

Figura 3.71: Tentativa de estimar os parâmetros de rede para os LR feita por médias em comparação com o parâmetro de rede das SSI. Todos os dados são para T=50K.

Conhecendo-se a vizinhança do Flúor tem-se mais uma maneira de identificar a separação de fase do LR. Conforme discutido anteriormente para as SSI, os Flúors são 
tetraedricamente coordenados com os cátions da rede cfc. Utilizando-se da notação dos $Q_{i}$ o sistema separado foi comparado com a SSI e foram identificados os tipos de tetraedros que os Flúors estão inseridos e os resultados estão na Fig. 3.72.

Quando a concentração de $C d F_{2}$ é pequena tanto o LR quanto a SSI apresentam grandes quantidades de tetraedros do tipo $\mathrm{Q}_{4}$ pois não há Cd para preencher os tetraedros. De maneira semelhante quando a concentração de $C d F_{2}$ é grande, os tetraedros do tipo $\mathrm{Q}_{0}$ são favorecidos tanto nos LR quanto nas SSI. Esses dois extremos, e todos os outros $\mathrm{Q}_{i}$, seguem a estatística de dois eventos independentes onde é analisada a probabilidade de que os dois ocorram conforme já discutido para o caso das SSI.

Na Fig. 3.72, todas as concentrações do LR sempre apresentam maiores porcentagens de $\mathrm{Q}_{0}$ e $\mathrm{Q}_{4}$ em relação a SSI. Essa característica identifica a separação de fase no LR informando que o sistema é composto de algumas regiões ricas em $\mathrm{Cd}$ e outras em $\mathrm{Pb}$. O LR sempre apresentam menores porcentagens de $\mathrm{Q}_{2}$ em relação à SSI o que reforça a idéia de um sistema de estrutura não homogênea. A composição $x=0,50$ por ter a mesma quantidade de $\mathrm{Cd}$ e $\mathrm{Pb}$ expressa de maneira nítida a separação quando se observa a diferença das porcentagens de ocorrência dos $Q_{i}$ que representam sistemas homogêneos e não homogêneos entre o LR e a SSI.

\subsection{Cristalização Isotérmica}

Nesta seção será mostrado o comportamento do sistema mantido em uma dada temperatura fixa por longos períodos de simulação. A região de temperatura escolhida é a do líquido super-resfriado. Essa região compreende temperaturas durante o resfriamento que se localizam abaixo da temperatura de fusão e acima da temperatura de solidificação. O sistema foi preparado com 12000 partículas, sendo 4000 cátions (Cd e Pb) e $8000 \mathrm{~F}$ e foram analisadas quatro concentrações: $x=0,10 ; x=0,35 ; x=0,50$ e $x=0,80$. 

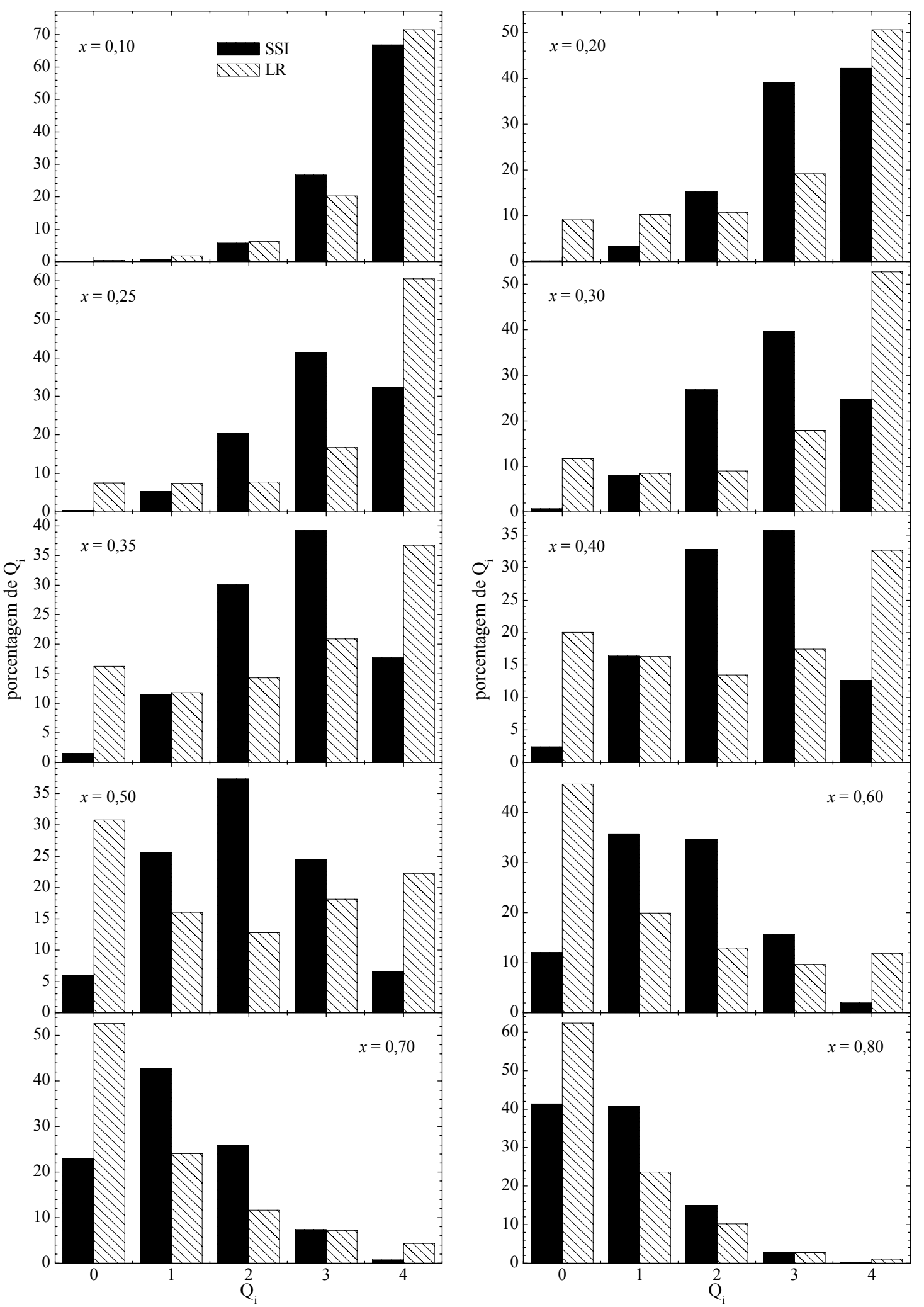

Figura 3.72: Comparação do tipo de tetraedro que o Fluor está inserido entre LR e a SSI. Ambos os sistemas estão em $\mathrm{T}=50 \mathrm{~K}$. 
Primeiramente as SSI foram aquecidas com a taxa $q=+0.2 \mathrm{Kps}^{-1}$ partindo de $\mathrm{T}=50$ K passando pela região de superionicidade, passando pela fusão do sistema e finalmente atingindo a $\mathrm{T}=3000 \mathrm{~K}$. Os sistemas em $\mathrm{T}=3000 \mathrm{~K}$ foram termalizados por 100 ps e foram observadas estruturas típicas de líquido, caracterizadas pelas g(r) oscilando em torno do valor 1 e sem picos de cristalização, e esses líquidos se mostraram homogêneos. Após termalizar o sistema no estado líquido foi feito um resfriamento rápido, com a taxa $q=-25 \mathrm{Kps}^{-1}$, até a temperatura $\mathrm{T}=800 \mathrm{~K}$ que resultou em um sistema com uma boa homogeneidade. Nesta temperatura de 800K, o sistema foi termalizado por um longo tempo, 3500 ps (3500000 passos de DM). Este líquido super resfriado termalizado será chamado doravante de LSRT.

Durante a termalização quase todos os sistemas estudados tendem a separar de fase. $\mathrm{Na}$ maioria dos sistemas ao final dos 3500 ps os $\mathrm{Cd}$ tendem a se cristalizar e os $\mathrm{Pb}$ a permanecer desordenados. Na composição $x=0,10$ os Cd têm uma leve tendência em se aglomerar mas não se cristalizam. Para essa composição com baixa concentração de Cd após os 3500 ps o sistema como um todo permanece desordenado. Os LSRT com $x=0,35 ; x=0,50$ e $x=0,80$ ao final dos 3500 ps apresentam uma expressiva separação de fase, a cristalização dos Cd e a amorfização dos Pb. As Fig. 3.73 a 3.78 mostram essas três composições ilustrando separadamente os $\mathrm{Cd}$ e os $\mathrm{Pb}$ de cada composição. Nas Fig. 3.73 e 3.75 são mostrados os Cd das composições $x=0,35$ e $x=0,50$ e em ambas os $\mathrm{Cd}$ formam aglomerados com diferentes planos de cristalização. Os Cd do LSRT $x=0,80$ tendem a formar um único cristal que pode ser visualizado na Fig. 3.77. Nas Fig. 3.74, 3.76 e 3.78 são mostrados os $\mathrm{Pb}$ para as concentrações $x=0,35 ; x=0,50$ e $x=0,80$ os quais permanecem desordenados ao final da termalização. Na composição $x=0,80 \mathrm{os} \mathrm{Pb}$ tendem a se inserir na rede formada pelos Cd e esse fato será discutido adiante quando forem mostradas as $\mathrm{g}_{\alpha \beta}(\mathrm{r})$ catiônicas. 


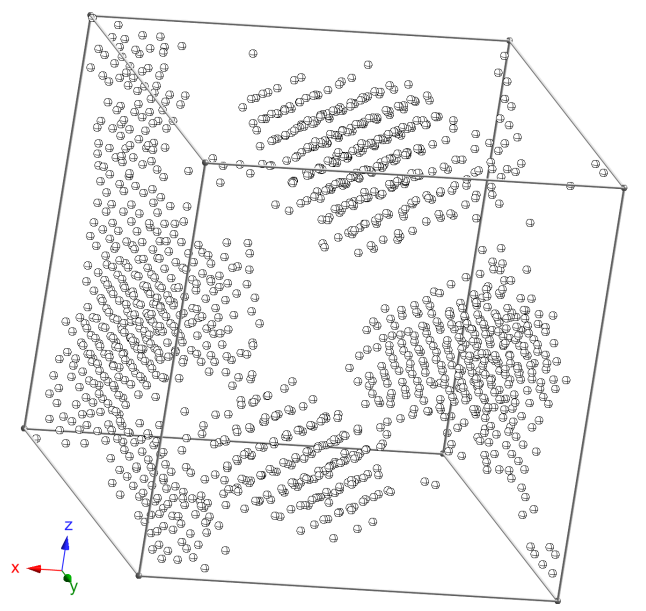

Figura 3.73: Cd após a termalização em $\mathrm{T}=800 \mathrm{~K}$ do LSRT $\operatorname{com} x=0,35$.

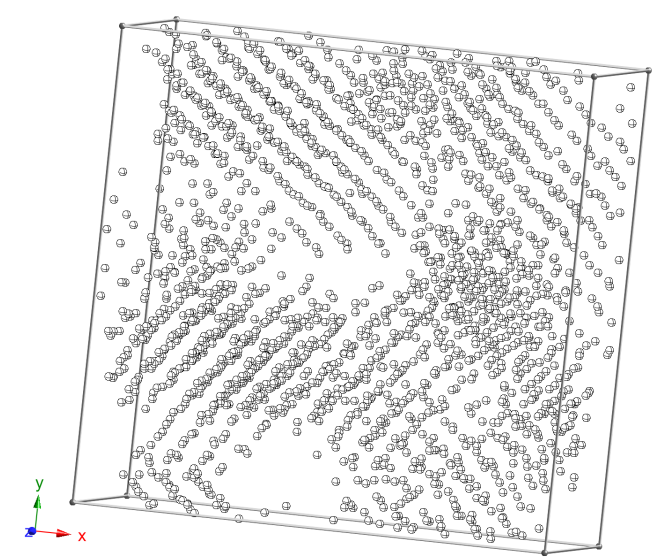

Figura 3.75: Cd após a termalização em $\mathrm{T}=800 \mathrm{~K}$ do LSRT com $x=0,50$.

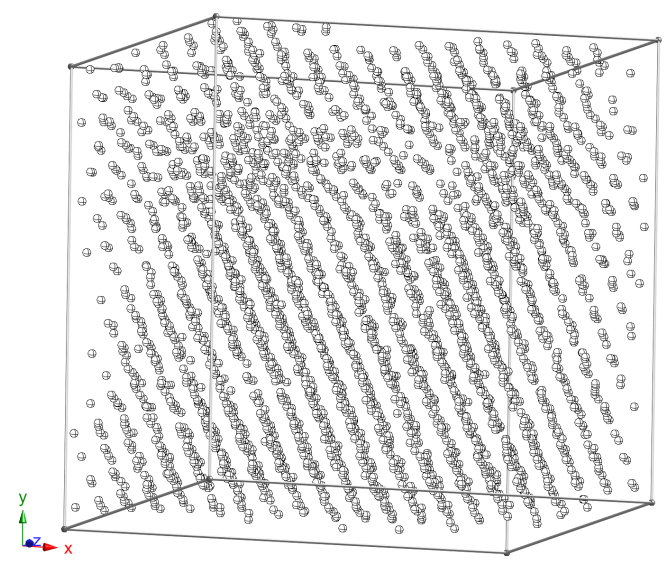

Figura 3.77: Cd após a termalização em $\mathrm{T}=800 \mathrm{~K}$ do LSRT com $x=0,80$.

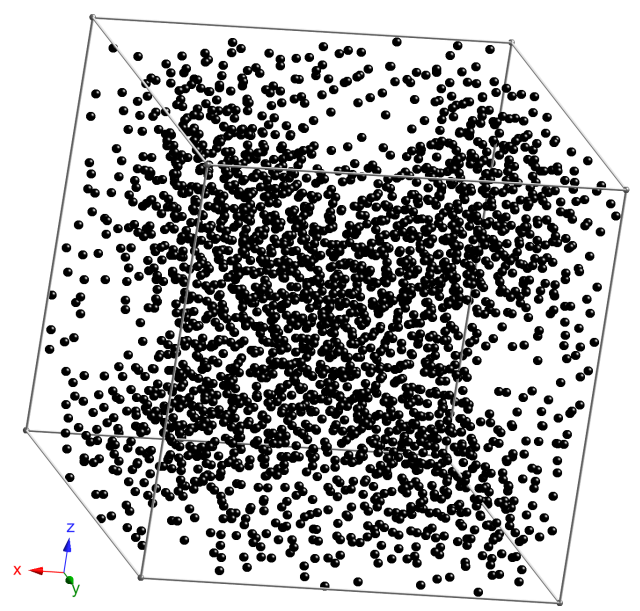

Figura 3.74: $\mathrm{Pb}$ após a termalização em $\mathrm{T}=800 \mathrm{~K}$ do LSRT $\operatorname{com} x=0,35$.

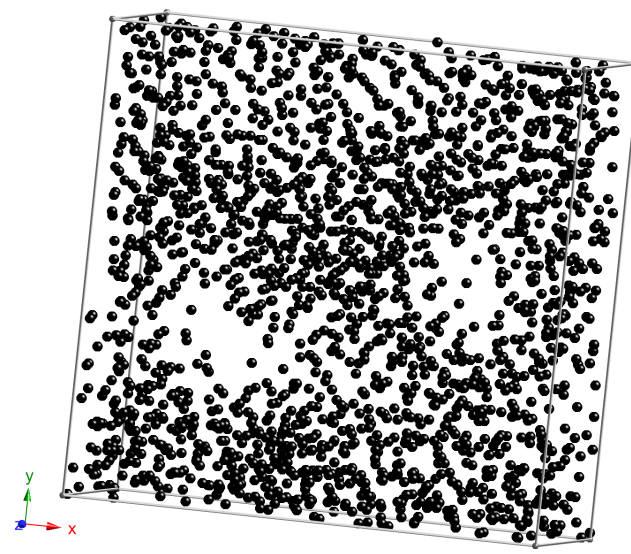

Figura 3.76: $\mathrm{Pb}$ após a termalização em $\mathrm{T}=800 \mathrm{~K}$ do LSRT $\operatorname{com} x=0,50$.

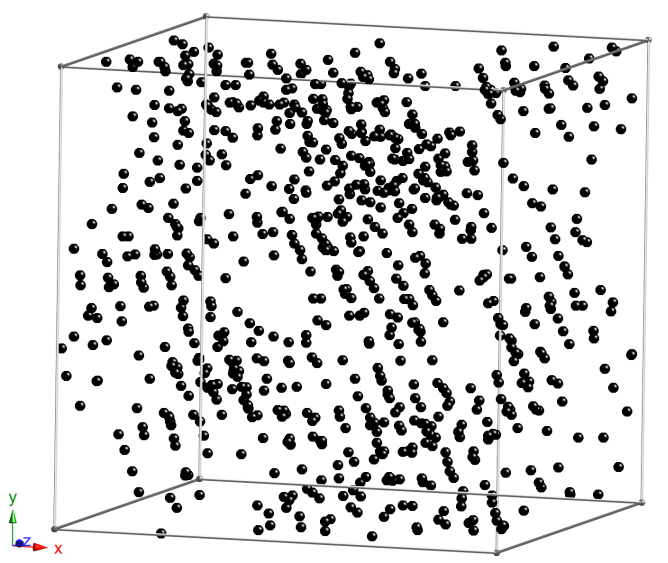

Figura 3.78: $\mathrm{Pb}$ após a termalização em $\mathrm{T}=800 \mathrm{~K}$ do LSRT $\operatorname{com} x=0,80$. 
A evolução temporal da separação de fase foi analisada observando-se a vizinhança dos F. Utilizando o método dos tetraedros e a notação dos $Q_{i}$, foi possível monitorar a homogeneidade do sistema durante os 3500 ps. Nas Fig. 3.79 e 3.80 são mostradas as porcentagens de ocorrência de cada $Q_{i}$ como função do tempo para as quatro concentrações avaliadas. Para o LSRT $\operatorname{com} x=0,35$ e $x=0,50$ a separação de fase pode ser identificada notando-se que os três $\mathrm{Q}_{i}$ que revelam a homogeneidade do sistema, sendo eles o $\mathrm{Q}_{1}, \mathrm{Q}_{2}$, $\mathrm{Q}_{3}$, têm diminuição expressiva. Além disso, a consequência é o aumento expressivo dos $\mathrm{Q}_{0}$ e $\mathrm{Q}_{4}$ os quais revelam a separação de fase do sistema. O aumento ou diminuição dos $\mathrm{Q}_{i}$ ocorre até o tempo 2000 ps que é o momento em que a cristalização dos Cd se estabiliza. As Fig. 3.79 (a) e (e) mostram que o LSRT com $x=0,10$ tem um pequeno acréscimo nos $Q_{0}$ e $Q_{4}$ indicando que a separação de fase nesse sistema é pequena. A confirmação de uma separação de fase sutil para o LSRT com $x=0,10$ está na Fig. 3.79 (c) a qual mostra que o $Q_{2}$ permanece praticamente constante. Embora a separação de fase pareça ser pequena devido a baixa concentração de $\mathrm{Pb}$, ela existe incluindo a diminuição do $\mathrm{Q}_{3}$. A separação de fase do LSRT $\operatorname{com} x=0,80$ pode ser vista na Fig. 3.80 e é identificada pelo aumento do $\mathrm{Q}_{0}$ e pela diminuição do $\mathrm{Q}_{1}$. Os outros três $\mathrm{Q}_{i}$ permanecem praticamente constantes devido a baixa concentração de $\mathrm{Pb}$ nesse sistema.

Na Fig. 3.81 pode ser visto a comparação dos $Q_{i}$ para os tempos inicial e final da termalização. As Fig. 3.81 (a) e (d) mostram a separação de fase mais amena dos LSRT com $x=0,10$ e $x=0,80$ onde os $\mathrm{Q}_{2}$ permanecem praticamente constantes. Por outro lado, as Fig. 3.81 (b) e (c) mostram a separação de fase expressiva dos LSRT para $x=0,35$ e $x=0,50$. Após $\mathrm{t}=3500$ ps ocorreu um grande aumento dos $\mathrm{Q}_{0}$ e $\mathrm{Q}_{4}$, e uma consequente grande diminuição dos $\mathrm{Q}_{2}$.

A cristalização de parte do sistema durante a termalização pode ser confirmada pela $\mathrm{g}_{\alpha \beta}(\mathrm{r})$. Nas Fig. 3.82 e 3.83 são mostradas as $\mathrm{g}_{\alpha \beta}(\mathrm{r})$ da parte catiônica dos quatro LSRT 


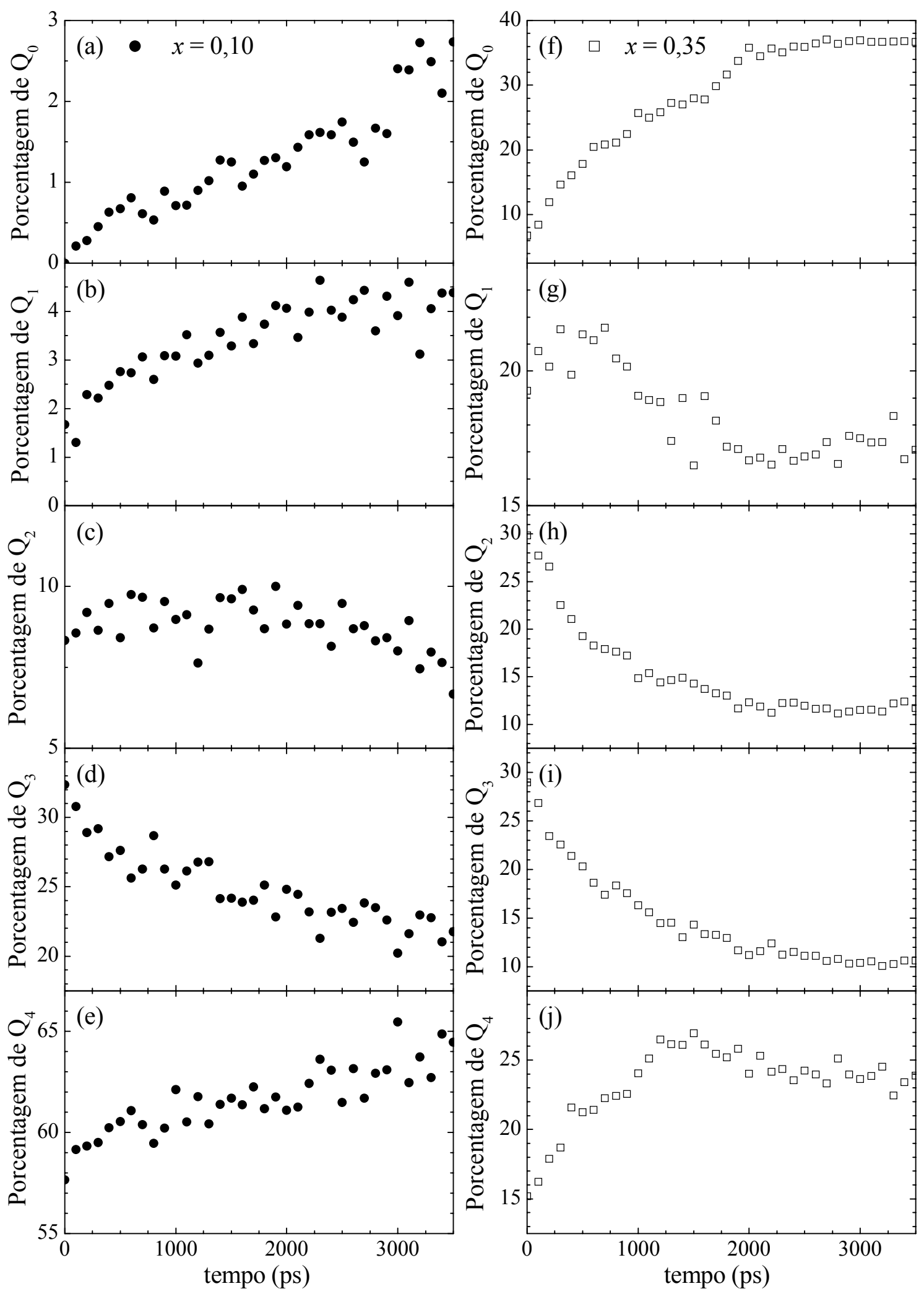

Figura 3.79: Evolução temporal da porcentagem de ocorrência dos Qi durante a termalização do líquido super-resfriado homogêneo em $\mathrm{T}=800 \mathrm{~K}$. De (a) a (e) $x=0,10$ e (f) a (j) $x=0,35$. 


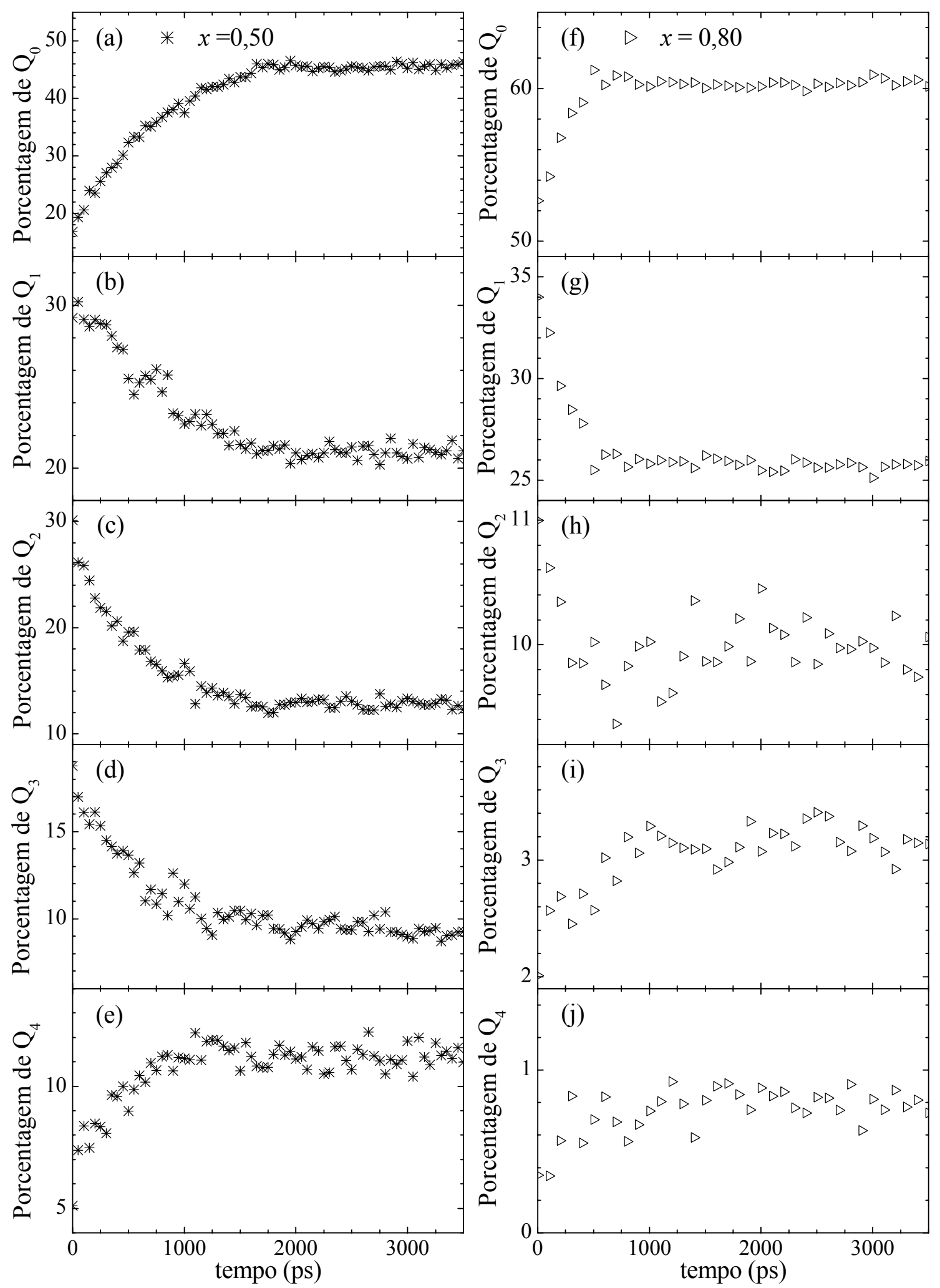

Figura 3.80: Evolução temporal da porcentagem de ocorrência dos Qi durante a termalização do líquido super-resfriado homogêneo em $\mathrm{T}=800 \mathrm{~K}$. De (a) a (e) $x=0,50$ e (f) a (j) $x=0,80$. 

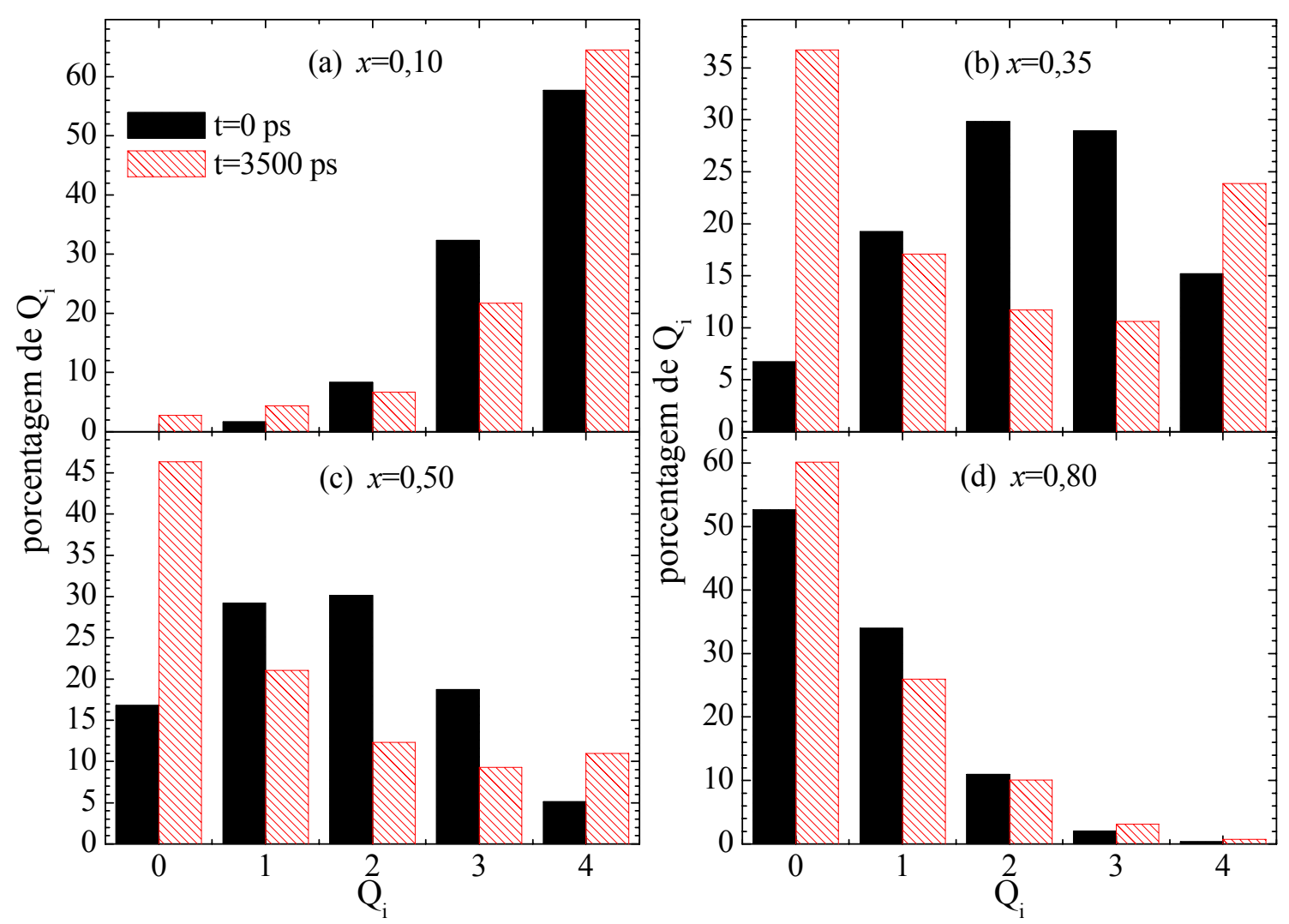

Figura 3.81: Comparação dos $\mathrm{Q}_{i}$ dos LSRT em $\mathrm{t}=0$ ps e $\mathrm{t}=3500$ ps para $\mathrm{T}=800 \mathrm{~K}$. 
analisados em comparação com as respectivas concentrações das SSI. As Fig. 3.82 (a), (b) e (c) mostram que os cátions do LSRT com $x=0,10$ não apresenta picos de cristalização. As curvas apenas oscilam em torno do valor 1 e não apresentam nenhuma semelhança as curvas das SSI.

Nas Fig. 3.82 (d), (e) e (f) estão os dados para o LSRT com $x=0,35$ e nas Fig. 3.83 (a), (b) e (c) os dados do LSRT com $x=0,50$. Em ambas as composições as $\mathrm{g}_{C d-C d}(\mathrm{r})$ apresentam picos de cristalização semelhantes aos da SSI. As posições dos picos dos LSRT são menores que os das SSI porque o sistema separado tende a um comportamento semelhante ao do $C d F_{2}$ puro o qual, conforme discutido anteriormente, tem comprimento de ligação $\mathrm{Cd}-\mathrm{Cd}$ menor. Os pares de ligações que envolvem os $\mathrm{Pb}$ não apresentam picos de cristalização. Tanto a $\mathrm{g}_{C d-P b}(\mathrm{r})$ quanto $\mathrm{a} \mathrm{g}_{P b-P b}(\mathrm{r})$ não se assemelham as respectivas SSI confirmando as discussões anteriores que somente os Cd se cristalizam.

Os dados para o LSRT com $x=0,80$ são mostrados nas Fig. 3.83 (d), (e) e (f). A $\mathrm{g}_{C d-C d}(\mathrm{r})$ apresentam picos de cristalização bem definidos indicando um número reduzido de defeitos em acordo com a discussão da Fig. 3.77. Devido aos Cd serem bem organizados eles favorecem a introdução dos $\mathrm{Pb}$ na rede e as $\mathrm{g}_{C d-P b}(\mathrm{r})$ e $\mathrm{g}_{P b-P b}(\mathrm{r})$ passam a apresentar picos de segundos e terceiros vizinhos.

Na Fig. 3.84 são mostrados os coeficientes de difusão de cada um dos átomos para as quatro concentrações avaliadas. A difusão dos $\mathrm{F}$ e dos $\mathrm{Cd}$ tende a diminuir após a cristalização. Para a composição $x=0,80$ a qual apresenta uma cristalização bem definida, nota-se uma diminuição acentuada na difusão do F e a difusão do Cd se anula. Por outro lado, os $\mathrm{Pb}$ durante a cristalização dos $\mathrm{Cd}$ tendem a um leve aumento na difusão e depois que a cristalização se estabelece a difusão se estabiliza. Para a composição $x=0,10$, a qual não exibi cristalização, os três átomos mantêm a difusão praticamente constante. 

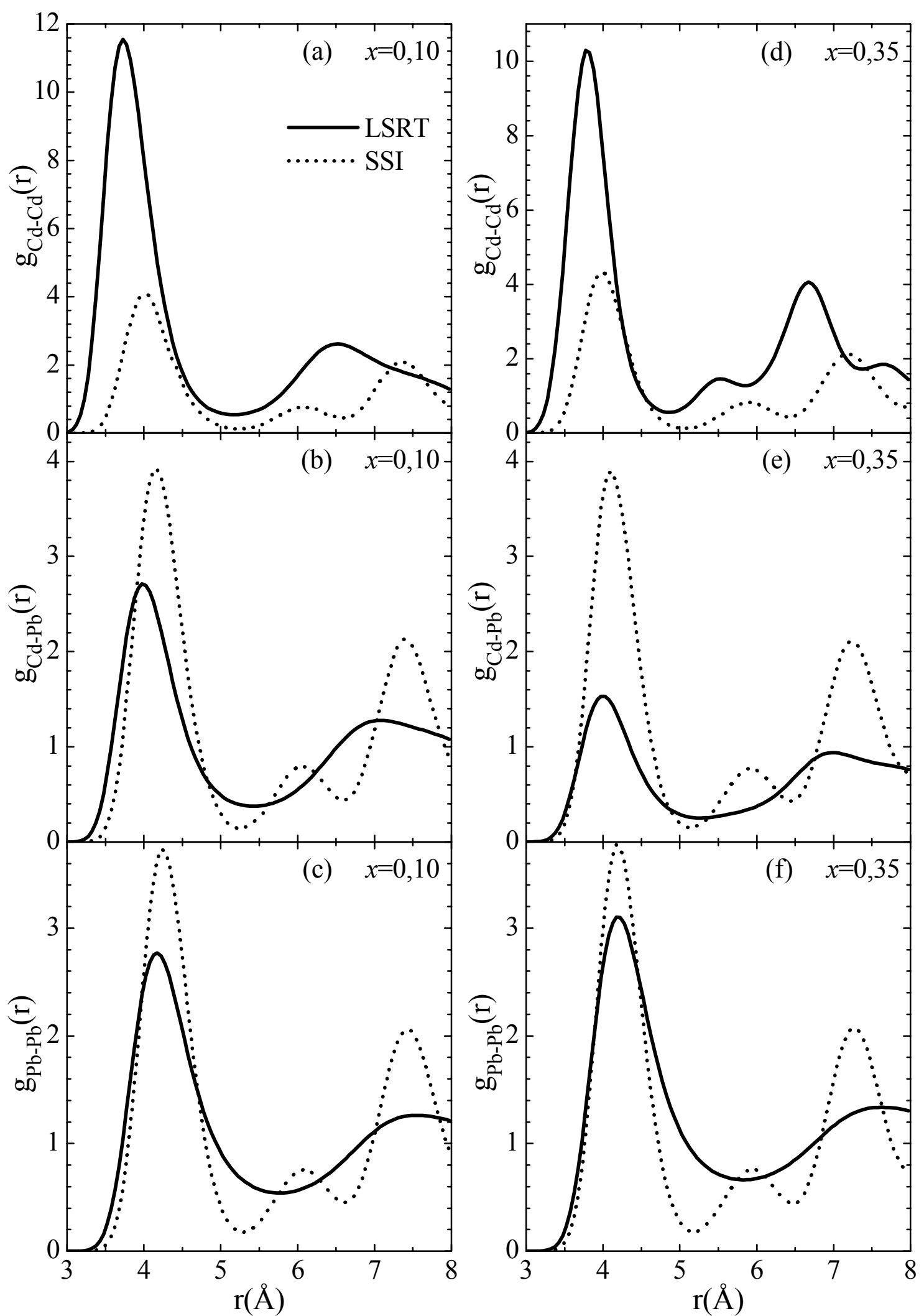

Figura 3.82: $\mathrm{g}_{\alpha \beta}(\mathrm{r})$ da parte catiônica dos LSRT em comparação com as SSI. Tanto o sistema $x=0,10$ quanto o $x=0,35$ estão em $\mathrm{T}=800 \mathrm{~K}$. 

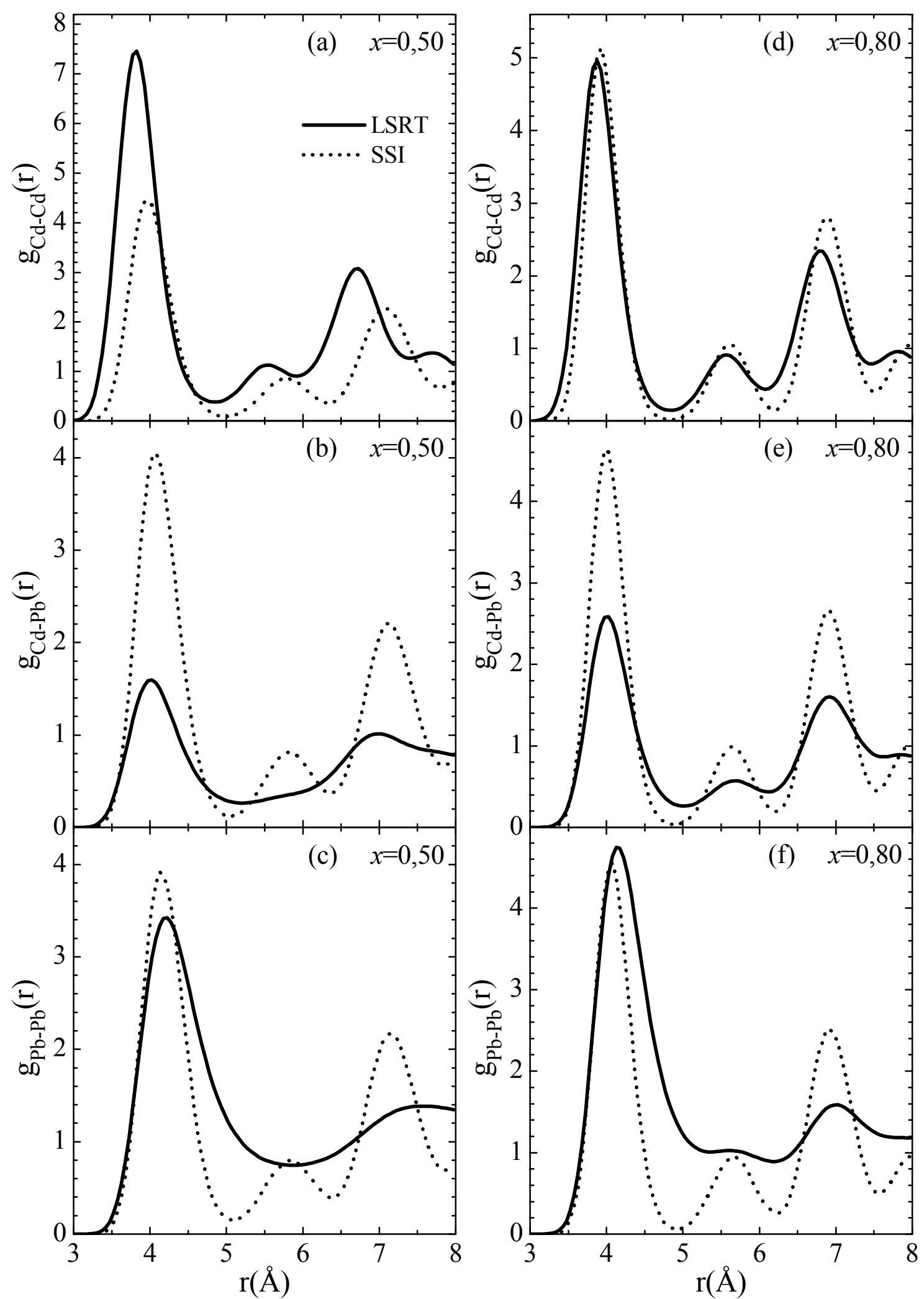

Figura 3.83: $\mathrm{g}_{\alpha \beta}(\mathrm{r})$ da parte catiônica dos LSRT em comparação com as SSI. Tanto o sistema $x=0,50$ quanto o $x=0,80$ estão em $\mathrm{T}=800 \mathrm{~K}$. 
Analisando as difusões conclui-se que os $\mathrm{Pb}$ tendem a não se cristalizar enquanto os Cd naturalmente tendem a diminuir a mobilidade e se cristalizar. Para essa temperatura escolhida, em $\mathrm{t}=0 \mathrm{ps}$ ambos os cátions tem mobilidade suficiente para formar uma estrutura com menor energia. Porém a mobilidade dos $\mathrm{Cd}$ é sempre menor que a do $\mathrm{Pb}$, conforme discutido anteriormente a maior liberdade dos $\mathrm{Pb}$ esta associada às ligações mais fracas com os F. Sendo assim os Pb somente viriam a se cristalizar em temperaturas mais baixas, pois a ordem cristalina criada pelos Cd não é suficiente para diminuir a mobilidade deles.

Para a composição $x=0,80$ após a cristalização a mobilidade do $\mathrm{F}$ é reduzida e a maior parte dos seus movimentos está associado aos saltos para sítios de mesma energia devido à temperatura ainda ser alta. O movimento dos $\mathrm{Cd}$ acompanhado dos $\mathrm{F}$ não existe após o tempo 2000 ps, sendo que os Cd ficam fixos e apenas os F saltam para as posições energeticamente favoráveis.

\subsection{Reaquecimento dos sólidos}

\subsubsection{Recristalização do vidro}

Nesta seção será discutido o reaquecimento dos VH (vidros homogêneos). Os VH após serem resfriados até $\mathrm{T}=50 \mathrm{~K}$ foram termalizados por mais 100ps. Após a termalização esses vidros foram reaquecidos. Durante o reaquecimento dos VH ocorreu uma pequena diminuição na viscosidade permitindo mobilidade aos cátions o que resultou, em muitas das vezes, na recristalização desse sistema inicialmente amorfo. A recristalização do vidro depende da taxa de aquecimento e da concentração de Cd do sistema. Dentre todas as concentrações estudadas, as mais extremas o que implica nas mais próximas do $\mathrm{PbF}_{2}$ ou $C d F_{2}$, monstraram maior facilidade em cristalizar. Usando a taxa de $q=0,2 \mathrm{Kps}^{-1}$ no 


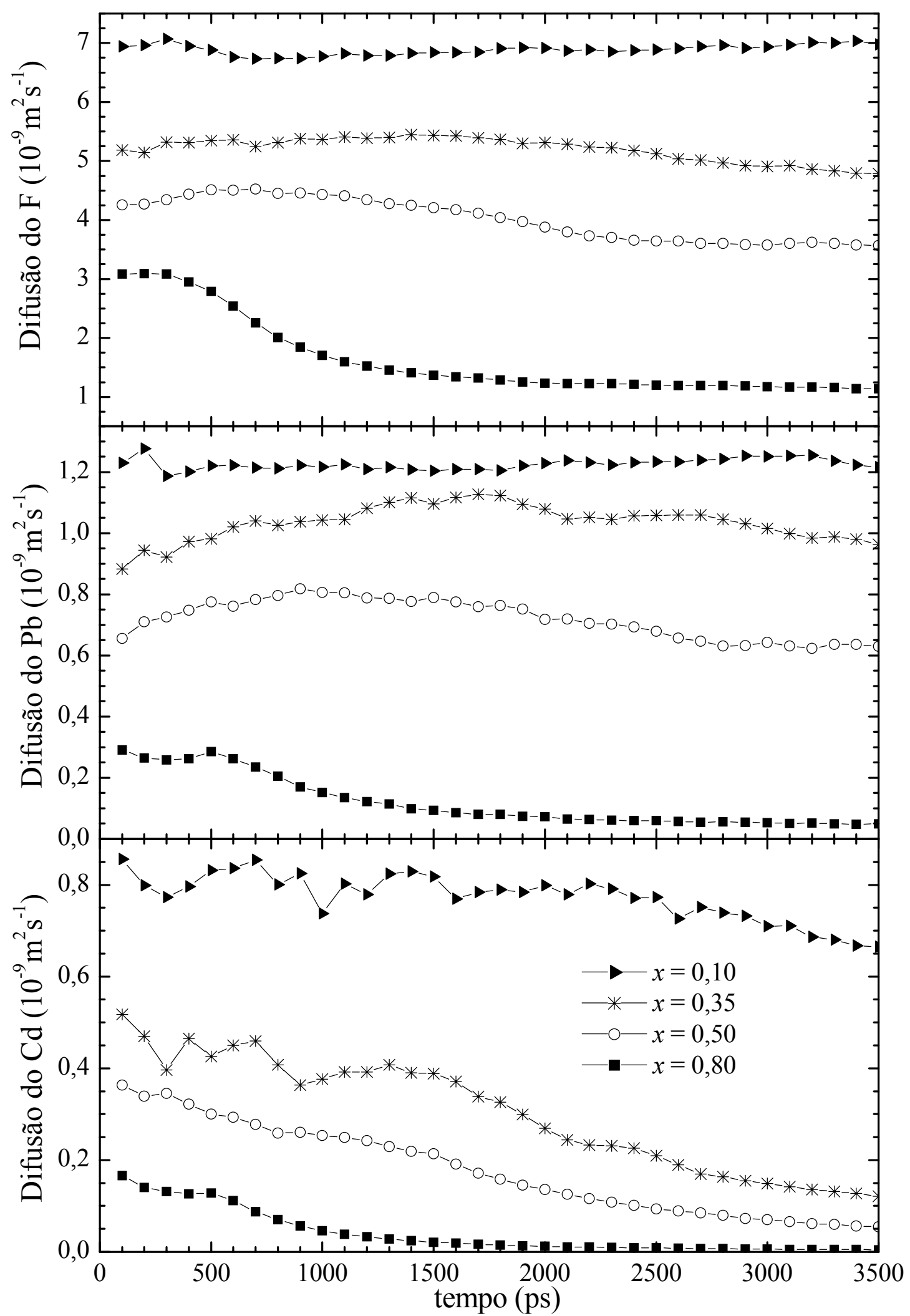

Figura 3.84: Difusão dos átomos durante a termalização do líquido super resfriado em $\mathrm{T}=800 \mathrm{~K}$. 
reaquecimento as concentrações com $x=0,10, x=0,20$ e $x=0,80$ se cristalizaram enquanto todas as outras que compreende de $x=0,25$ até a $x=0,70$ permaneceram amorfas até a sua fusão. Com uma taxa um pouco mais lenta, $q=0,05 \mathrm{Kps}^{-1}$ um número maior de concentrações tendem a se cristalizar e apenas as composições próximas da composição $x=0,35$ não se cristalizam. Para obter a cristalização de todas as concentrações foi necessário utilizar a taxa $q=0,025 \mathrm{Kps}^{-1}$. O vidro cristalizado obtido com essa taxa será doravante chamado de VC.

A Fig. 3.85 mostra todo o histórico do sistema para a composição $x=0,20$, as outras composições tem comportamento similar e não serão exibidas. Na Fig. 3.85 (a) é mostrado o comportamento da energia por partícula e na Fig. 3.85 (b) o comportamento do volume do sistema para quatro situações diferentes. A linha contínua mostra o aquecimento da SSI com a taxa de $q=0,2 \mathrm{Kps}^{-1}$ que gerou o líquido homogêneo, os asteriscos representam o resfriamento rápido com a taxa $q=-25 \mathrm{Kps}^{-1}$ que originou o VH e ainda são mostradas duas taxas de reaquecimento do VH: uma lenta e uma rápida. Com o reaquecimento rápido, onde foi utilizada a taxa $q=1,0 \mathrm{Kps}^{-1}$ representado pelas bolas abertas, não foram observadas descontinuidades nas curvas de onde se conclui que não ocorre cristalização. O aquecimento é muito rápido e o sistema não dispõe do tempo necessário para mover os átomos para uma situação mais favorável. Para essa taxa tanto o volume quanto a energia têm comportamento linear até a fusão do sistema. No entanto, o reaquecimento lento, o qual foi utilizado a taxa $q=0,025 \mathrm{Kps}^{-1}$ representado pelos triângulos preenchidos, a cristalização ocorre em torno da temperatura $480 \mathrm{~K}$ para a composição $x=0,20$. Essa taxa foi lenta o suficiente para que o sistema encontra-se uma situação mais favorável de menor energia. Tanto a energia como o volume apresentam descontinuidades. Na recristalização a energia e o volume passam a ser menores, pois o sistema deixa a configuração amorfa e passa a ter ordem cristalina. O VC quando 
comparado com a SSI apresenta energia e volume maiores, pois não é livre de defeitos e vacâncias como a SSI. É possível notar que a fusão do VC ocorre em temperaturas muito mais baixas do que a fusão da SSI. A fusão do VC é facilitada pela presença dos defeitos gerados na recristalização.
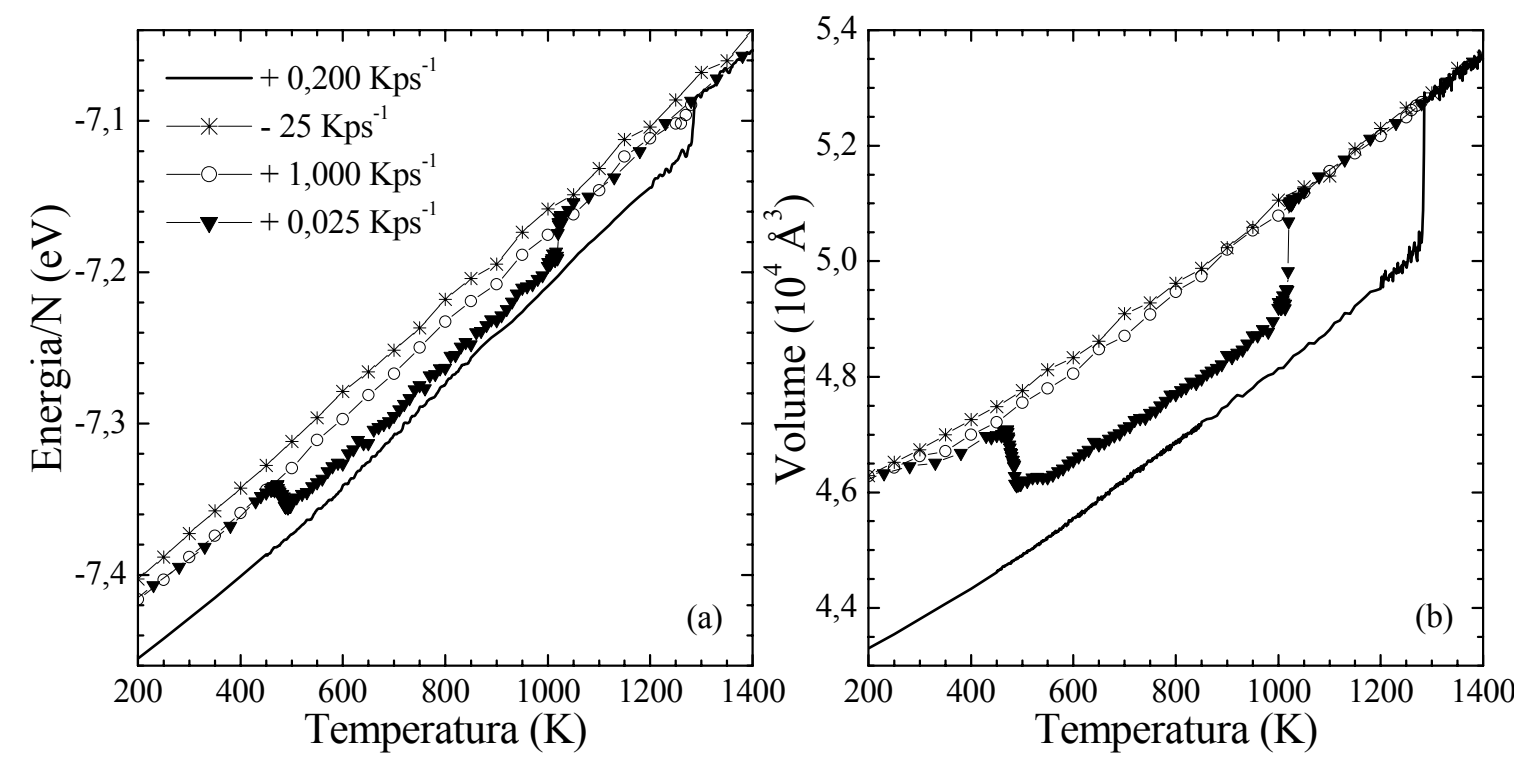

Figura 3.85: Energia e volume como função da temperatura durante a recristalização do $\mathrm{VH} \operatorname{com} x=0,20$.

Depois de obtida a recristalização, cada um dos VC foram resfriados até a temperatura $100 \mathrm{~K}$ para uma análise estrutural e posterior análise da mobilidade dos $\mathrm{F}$ durante o aquecimento. As primeiras informações extraídas em $\mathrm{T}=100 \mathrm{~K}$ foram as fotos dos sistemas exibindo a estrutura dos cátions. As Fig. 3.86 a 3.97 mostram as fotos dos VC para diferentes composições. Os VC com composições próximas aos fluoretos puros apresentam um número pequeno de defeitos e tendem a ser mais homogêneos na distribuição dos cátions. Na Fig. 3.86 é mostrado o VC com $x=0,10$ e nota-se que as bolas brancas representando os Cd estão bem espalhadas em todo o sistema. Da mesma maneira na Fig. 3.97 é mostrado o $\mathrm{VC}$ com $x=0,80$ onde os $\mathrm{Pb}$ representados pela bolas pretas tendem a existir por toda a caixa. As composições $x=0,70$ mostrada na Fig. 3.96 e a $x=0,60$ mostrada na Fig. 3.95 não apresentam separação de fase tão expressiva mas o número de 
átomos intersticiais passa a aumentar. As outras composições apresentam a formação de regiões com forte concentração de $\mathrm{Cd}$ e outras de $\mathrm{Pb}$. A quantidade de defeitos se torna grande nos $\mathrm{VC}$ com composições em torno de $x=0,35$. As Fig. 3.90 e 3.91 mostram o VC $\operatorname{com} x=0,35$ e as Fig. 3.92 e 3.93 mostram o VC com $x=, 40$ em dois ângulos diferentes destacando as composições com maior número de defeitos.

O comportamento estrutural do VC é similar ao do LR, pois ambos apresentam separação de fase em muitas das composições. Uma informação estrutural importante é a observação das posições dos picos das $\mathrm{g}_{\alpha \beta}(\mathrm{r})$ as quais auxiliam na caracterização da homogeneidade do sistema. Em particular, a posição do segundo pico da $\mathrm{g}_{C d-C d}(\mathrm{r})$ e da $\mathrm{g}_{P b-P b}(\mathrm{r})$ no caso homogêneo podem fornecer informações sobre o parâmetro de rede do sistema conforme discutido anteriormente. Na Fig. 3.98 são comparados os segundos picos das SSI, dos LR e dos VC. As SSI conforme discutido anteriormente apresentam comportamento linear diminuindo o comprimento de ligação com o aumento de Cd no sistema. Porém os sistemas com separação de fase deixam de ter esse comportamento linear e tendem ao comportamento dos fluoretos puros. Tanto o segundo pico da $\mathrm{g}_{C d-C d}(\mathrm{r})$ quanto o da $\mathrm{g}_{P b-P b}(\mathrm{r})$ mostram que os $\mathrm{VC}$ com composições em torno de $x=0,35$ ocorrem em posições muito diferentes das SSI e tendem ao comportamento dos fluoretos puros. A Fig. 3.98 (b) mostra que os VC $\operatorname{com} x=0,10, x=0,20, x=0,25, x=0,60, x=0,70$ e $x=0,80$ tendem a um comportamento que se assemelha a linearidade das SSI. Por outro lado, as composições restantes passam a ter comportamento dos fluoretos puros onde a posição do segundo pico passa a oscilar em torno do valor 5,93 Å. Na Fig. 3.98 (a) nota-se que os $\mathrm{VC} \operatorname{com} x=0,10, x=0,60, x=0,70$ e $x=0,80$ são as composições que tendem ao comportamento das SSI, enquanto que os valores das composições em torno de $x=0,35$ tendem a oscilar em torno de 5,39 A. No geral a separação de fase do VC não é tão expressiva quanto ao do LR os quais se aproximam muito dos fluoretos puros. No VC 


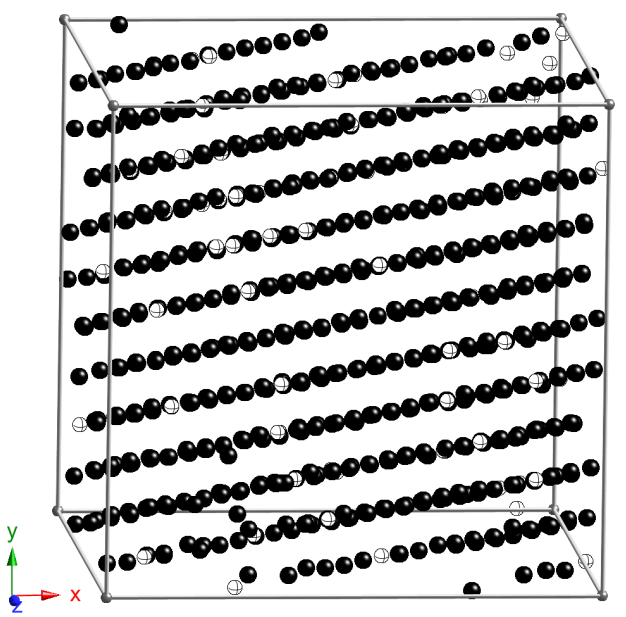

Figura 3.86: Devitrificação do sistema com $x=0,10$ em $\mathrm{T}=100 \mathrm{~K}$.

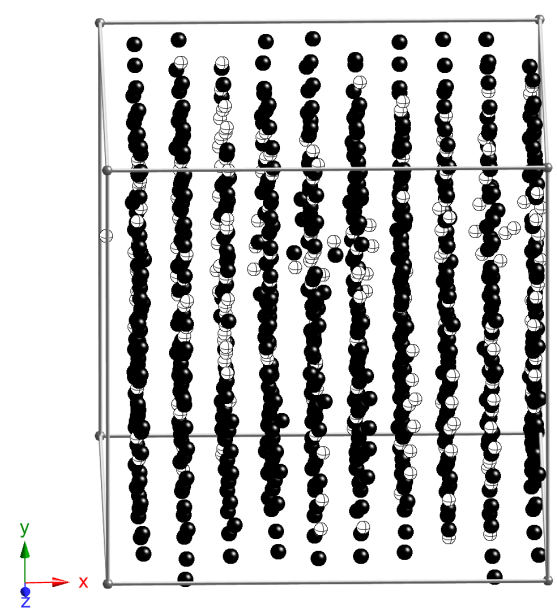

Figura 3.88: Sistema com $x=0,25$

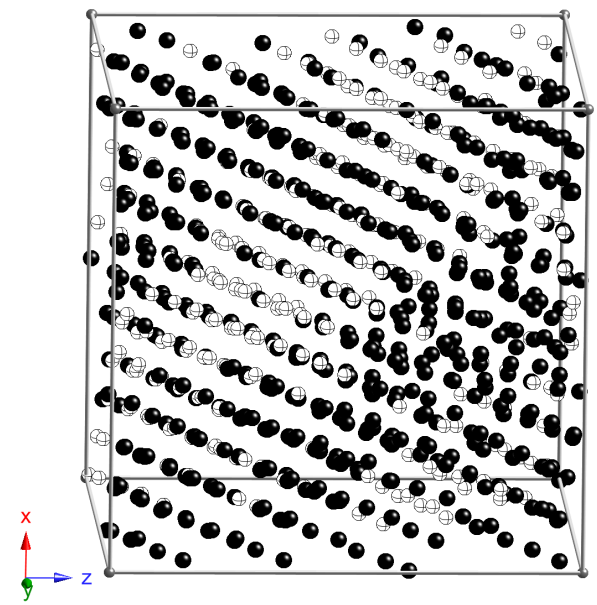

Figura 3.90: Sistema com $x=0,35$

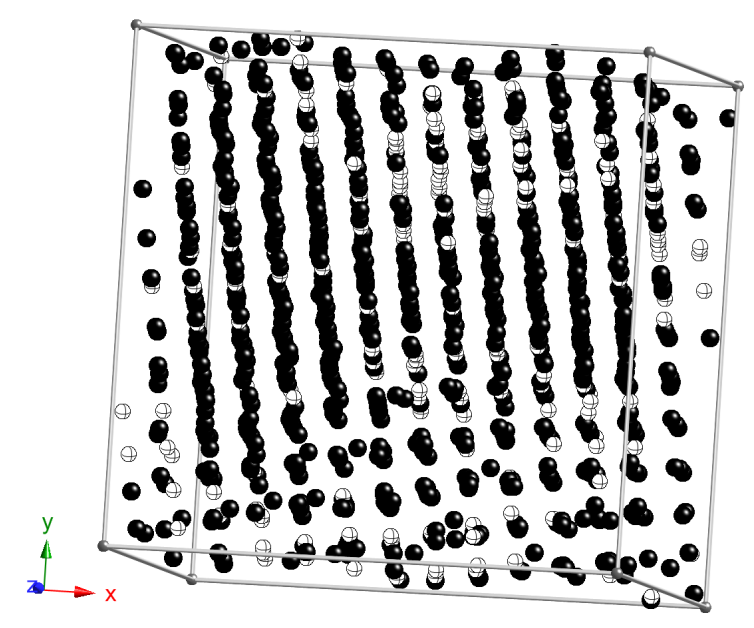

Figura 3.87: Sistema com $x=0,20$

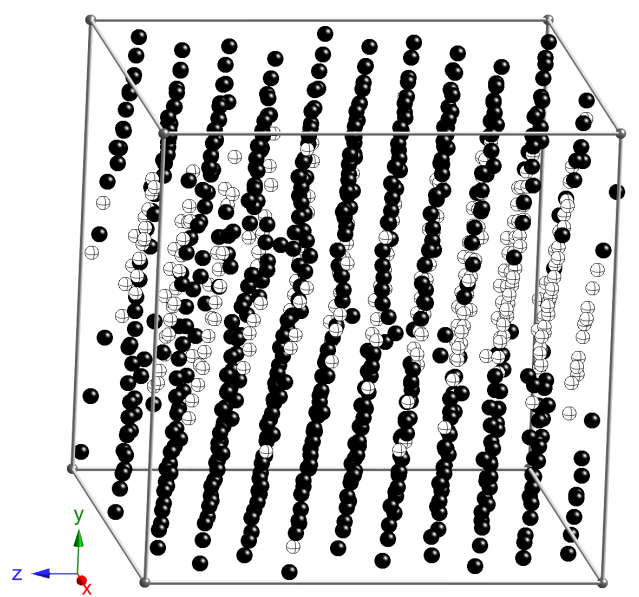

Figura 3.89: Sistema com $x=0,30$

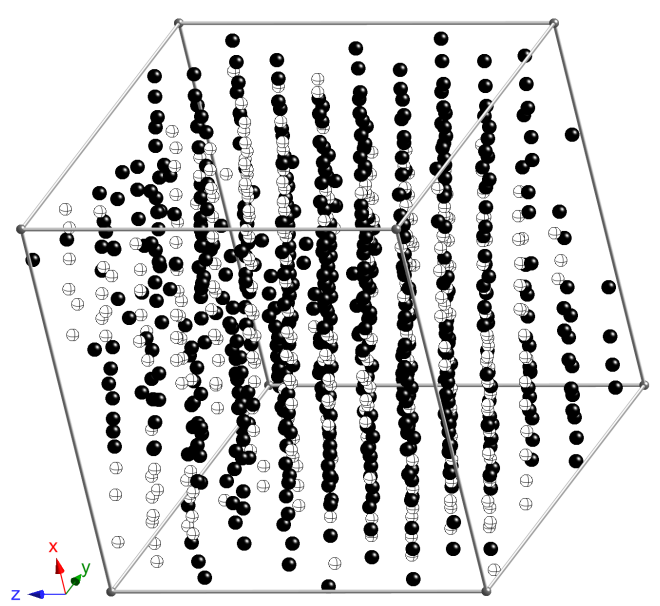

Figura 3.91: Sistema com $x=0,35$ em outro ângulo 


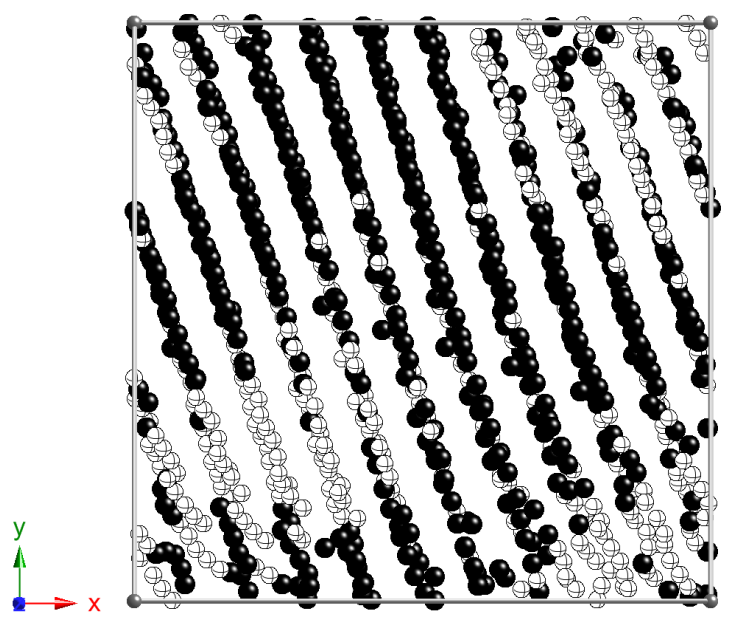

Figura 3.92: Devitrificação do sistema com $x=0,40$ em $\mathrm{T}=100 \mathrm{~K}$.

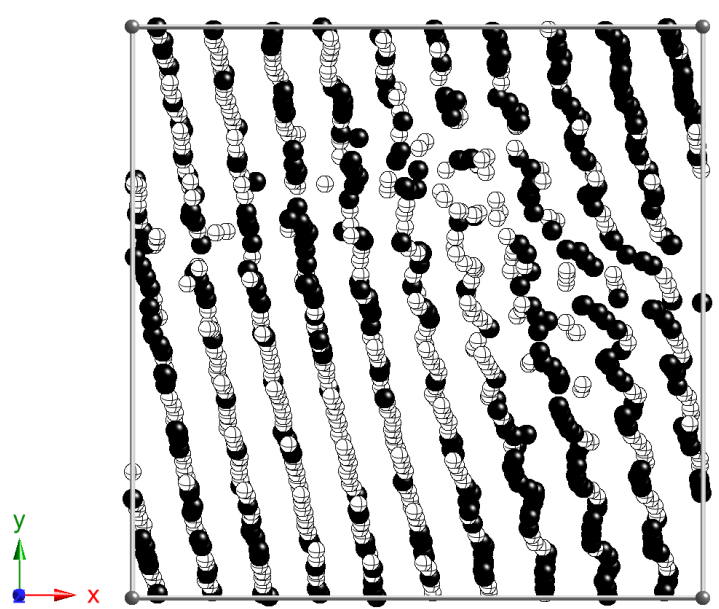

Figura 3.94: Sistema com $x=0,50$

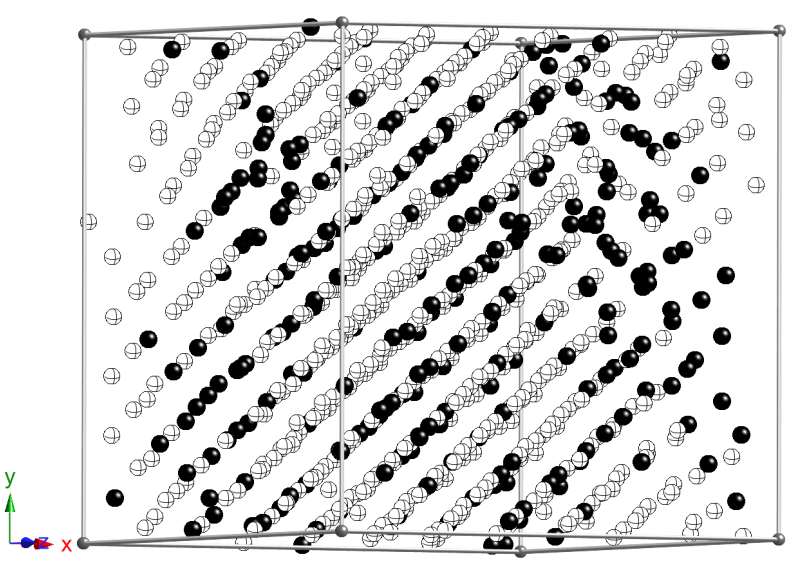

Figura 3.96: Sistema com $x=0,70$

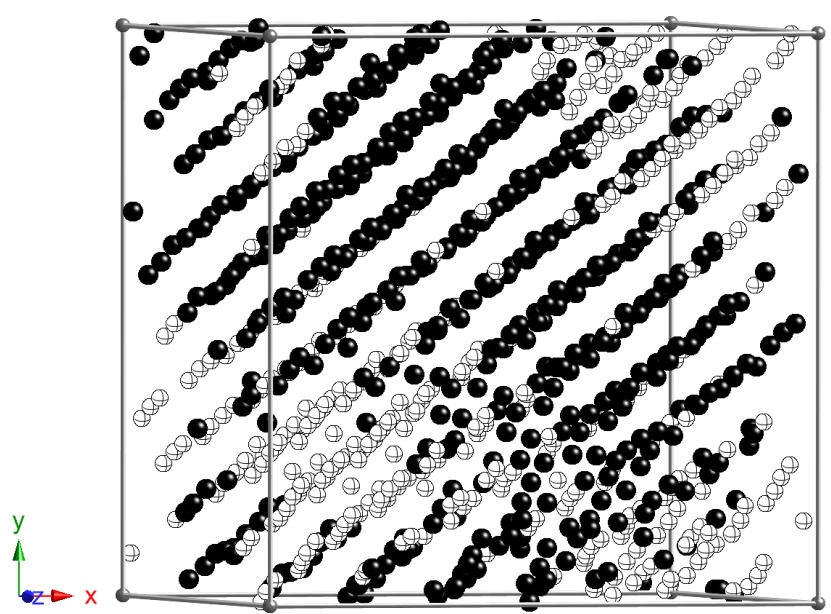

Figura 3.93: Sistema com $x=0,40$ em outro ângulo

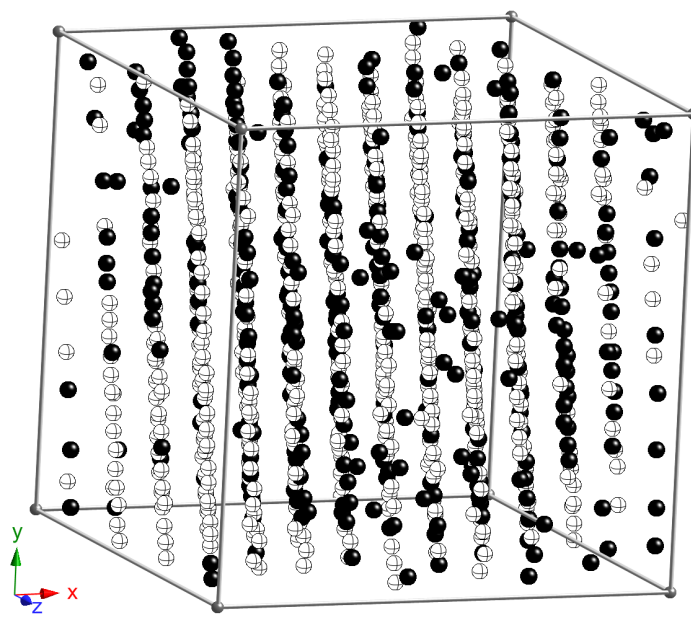

Figura 3.95: Sistema com $x=0,60$

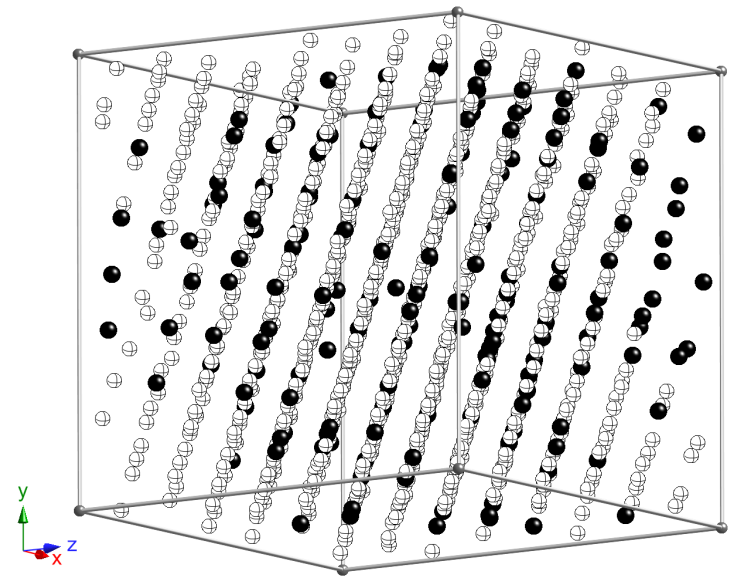

Figura 3.97: Sistema com $x=0,80$ 

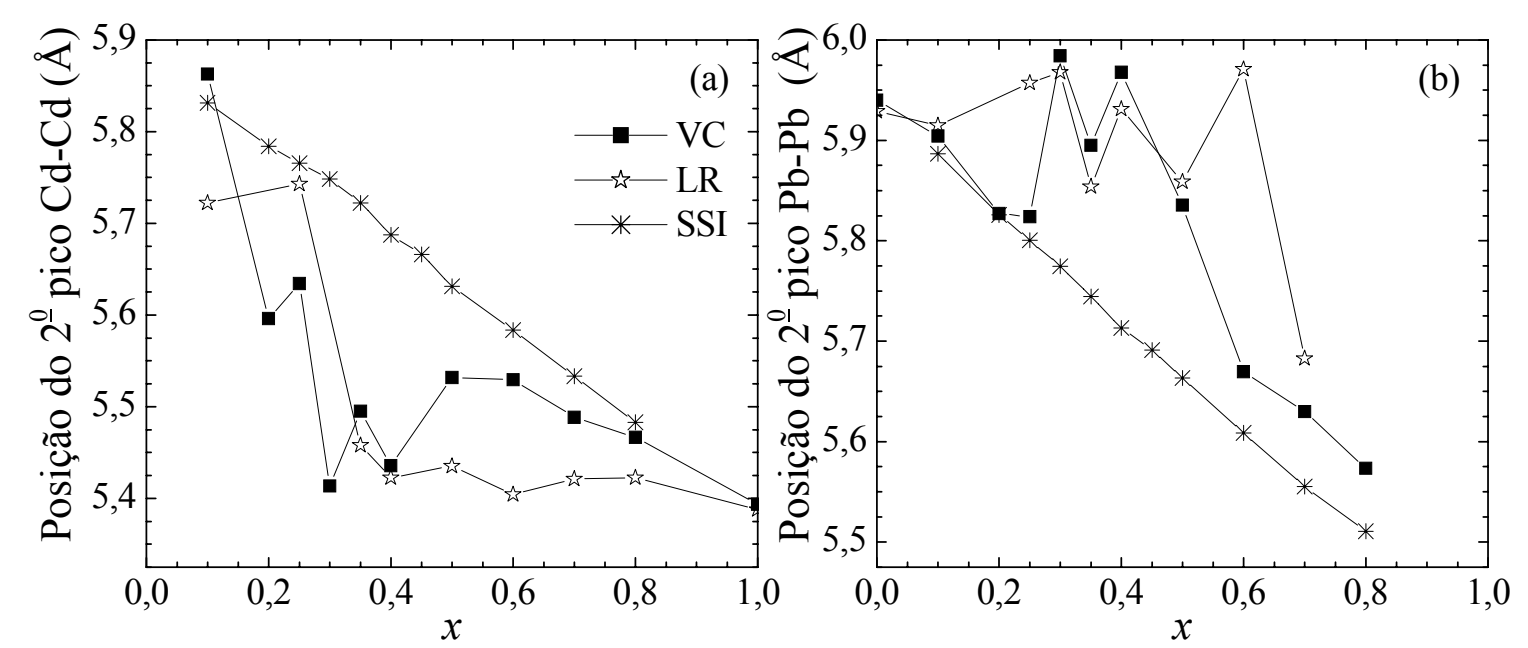

Figura 3.98: Posição dos segundos picos dos pares Cd-Cd (a) e Pb-Pb (b) em T=100K.

o movimento permitido para os cátions recristalizarem não é tão grande quanto no LR o que gera um sistema mais homogêneo nas composições extremas. Porém, a separação de fase e os defeitos na rede cristalina são inerentes ao sistema para as composições em torno de $x=0,35$ tanto nos LR quanto nos VC.

As $\mathrm{g}_{\alpha \beta}(\mathrm{r})$ de todos os seis pares dos $\mathrm{VC}$ com composições próximas a $x=0,35$ mostram comportamento semelhante ao já observado no LR onde as posições dos picos tendem as posições dos picos dos respectivos fluoretos puros. Os $\mathrm{n}_{\alpha \beta}(\mathrm{r})$ também mostram comportamento semelhante ao do LR. Como os comportamentos são semelhantes não serão mostrados em gráficos.

A comparação da homogeneidade do VC, do LR e da SSI também foi feita utilizando-se do método dos tetraedros. Através desse método, anteriormente discutido, a vizinhança dos Flúors foi avaliada utilizando-se a notação dos $Q_{i}$. Na Fig. 3.99 são comparados os histogramas dos $\mathrm{Q}_{i}$ dos três sistemas (SSI, VC e LR) para várias composições. Para uma concentração fixa de $C d F_{2}$ quando comparados os diferentes sistemas (SSI, VC e LR), os que apresentam maiores porcentagens de ocorrência de $Q_{0}$ e $Q_{4}$ são sistemas com separação de fase. Por outro lado, maiores porcentagens de $Q_{2}$ (e também $Q_{1}$ e 
$\mathrm{Q}_{3}$ ) ocorrem em sistemas homogêneos. Os $\mathrm{VC}$ com concentrações de $C d F_{2}$ próximas aos fluoretos puros, que incluem a $x=0,10, x=0,20, x=0,25, x=0,60, x=0,70 \mathrm{e}$ $x=0,80$, apresentam porcentagens de $\mathrm{Q}_{i}$ intermediárias entre os respectivos $\mathrm{LR}$ e as SSI. Esses dados mostram que os VC não são tão homogêneos quanto as SSI, pois as suas porcentagens de $Q_{1}, Q_{2}$ e $Q_{3}$ são sempre menores. Porém, para essas composições, os VC são mais homogêneos que os $L R$, pois as suas porcentagens de $Q_{1}, Q_{2}$ e $Q_{3}$ são sempre maiores. Como consequência, para essas composições, os VC quando comparados com os LR apresentam menores porcentagens de $\mathrm{Q}_{0}$ e $\mathrm{Q}_{4}$. Quando se compara o VC com as SSI as consequências são maiores porcentagens de $\mathrm{Q}_{0}$ e $\mathrm{Q}_{4}$.

Tanto no VC quanto no LR as composições próximas de $x=0,35$ apresentam porcentagens de $Q_{i}$ semelhantes indicando que ambos os sistemas apresentam separação de fase. A composição com $x=0,40$ do VC apresenta uma separação de fase mais expressiva que a do próprio LR, o que demonstra mais uma vez que a região próxima a composição $x=0,35$ apresenta anomalia quanto a cristalização mesmo com a pequena mobilidade permitida aos cátions nesses sistemas.

A Fig. 3.100 mostra a difusão do F nas quatro situações diferentes mostradas e discutidas na Fig. 3.85 para composição $x=0,20$. A curva com os triângulos na cor preta representa o reaquecimento do VH e a descontinuidade mostra a sua recristalização. Durante o reaquecimento a difusão do $\mathrm{F}$ atinge o valor $1 x 10^{-9} \mathrm{~m}^{2} \mathrm{~s}^{-1}$ antes da recristalização e logo após a recristalização esse valor diminui para $0,4 x 10^{-9} \mathrm{~m}^{2} \mathrm{~s}^{-1}$. A diminuição da difusão quando o sistema passa do sistema vítreo para o cristalino ocorre para todas as concentrações. Isso permite concluir que os F no vidro encontram uma enorme quantidade de sítios de mesma energia para o seu livre caminho médio devido a desordem e os defeitos, quantidade essa muito maior que a encontrada no cristal. Após a recristalização o sistema atinge novamente o valor de difusão do $\mathrm{F} 1 x 10^{-9} \mathrm{~m}^{2} \mathrm{~s}^{-1}$ somente com um au- 

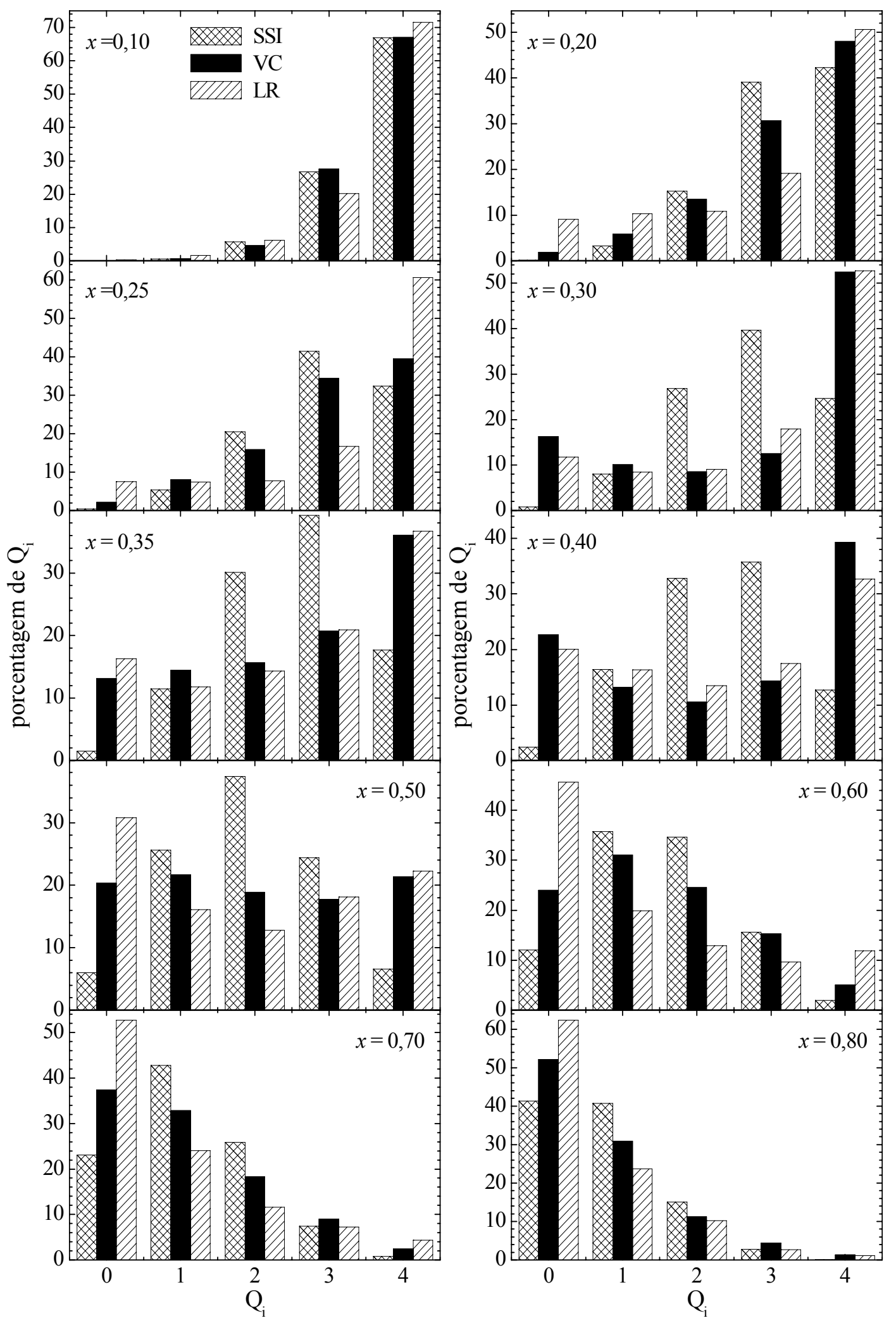

Figura 3.99: Identificação do tipo de tetraedro que o Fluor está inserido nas SSI, VC e $\mathrm{LR}$ em $\mathrm{T}=50 \mathrm{~K}$. 


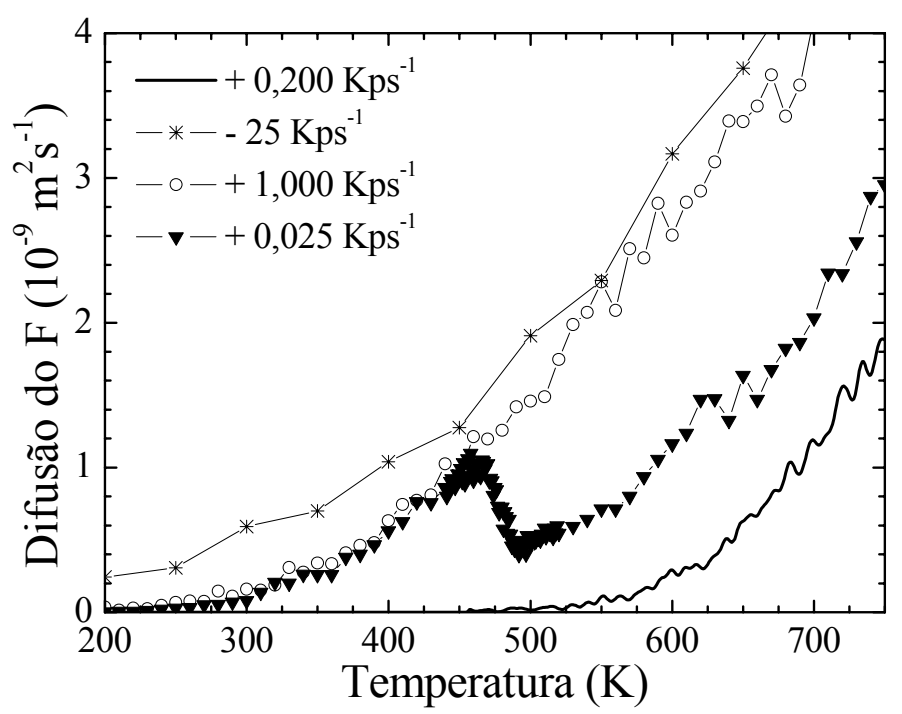

Figura 3.100: Comparação da difusão do F durante o aquecimento e resfriamento do sistema com $x=0,20$

mento na energia térmica que ocorre para temperaturas em torno de 600K. Esse resultado confirma o comportamento do sistema cristalino onde os cátions restringem o movimento dos F quando determinam um número menor de sítios.

Na Fig. 3.100 o aquecimento rápido com a taxa $q=1,0 \mathrm{Kps}^{-1}$, o qual não permitiu a recristalização do sistema, mostra o comportamento da difusão do $\mathrm{F}$ no vidro a qual chega a ser duas vezes maior que a do VC. Pode notar também que a difusão do F nos VC é sempre maior que nas respectivas concentrações das SSI devido presença de defeitos nos VC.

\subsubsection{Difusão do F nos sólidos}

Com os resultados das simulações foram gerados quatro sólidos que foram anteriormente explorados e chamados de: SSI, LR, VH, e VC. A discussão a seguir tem por objetivo descrever e comparar a mobilidade dos F nesses quatro sólidos. As composições em torno de $x=0,35$ as quais já apresentaram várias anomalias também têm um comportamento diferenciado quanto a mobilidade dos $\mathrm{F}$ nos sistemas que apresentam separação 
de fase. Para essas composições e sistemas foi observada uma mobilidade máxima em relação às outras concentrações em acordo, conforme discutido anteriormente, com resultados experimentais. Medidas experimentais em baixas temperaturas prevêem a existência de uma região com máxima condutividade em torno de $x=0,35$. [88][86][87] A máxima mobilidade dos F para uma dada concentração pode ser caracterizada de duas maneiras diferentes: a primeira é pela observação da difusão dos F que deve ser maior em relação as outras concentrações em uma dada temperatura fixa; A segunda é pela temperatura necessária para uma dada concentração atingir um dado valor fixo de difusão a qual dever menor em relação a temperatura das outras concentrações. As Fig. 3.101 (a), (b), (c) e (d) mostram os dados da mobilidade dos $\mathrm{F}$ em função da concentração de $C d F_{2}$, onde na ordenada y esquerda estão os valores da difusão para uma dada temperatura fixa ilustrados pelos quadrados pretos e na ordenada y direita a temperatura necessária para atingir um dado valor fixo de difusão ilustradas pelas bolas abertas. O valor de difusão fixa dos F para os quatro casos foi $1 x 10^{-9} \mathrm{~m}^{2} \mathrm{~s}^{-1}$. A temperatura fixa para caso é diferente devido as diferentes mobilidades dos sistemas, sendo: $700 \mathrm{~K}$ para os LR, $550 \mathrm{~K}$ para os VH, $650 \mathrm{~K}$ para os VC e 800K para as SSI. As linhas contínuas são apenas guias para os olhos e referem-se aos dados do eixo y esquerdo e as linhas pontilhadas são as guias para os dados do eixo y direito. Os dados para os $\mathrm{VC}$ foram extraídos após um tratamento térmico dos sistemas. Após a recristalização que gerou cada um dos VC, eles foram resfriados novamente até a temperatura $100 \mathrm{~K}$ e novamente aquecidos até a temperatura desejada. Os dados exibidos na Fig. 3.101 (c) foram coletados desse último aquecimento. Para o caso dos $\mathrm{VH}$ foi necessário um aquecimento rápido $\left(q=1,0 \mathrm{Kps}^{-1}\right)$ para não ocorrer a cristalização dos sistemas, mas esse procedimento não altera os resultados uma vez que a transição superiônica independe da taxa de aquecimento.

Os dados dos sólidos com separação de fase são mostrados nas Fig. 3.101 (a) e (c), e 
ambos os sistemas mostram a máxima mobilidade dos F para as composições em torno de $x=0,30$. As SSI, conforme discutido anteriormente, apresentam comportamento linear da difusão do $\mathrm{F}$ contra concentração de $C d F_{2}$ assim como os $\mathrm{VH}$ como pode ser visto nas Fig. 3.101 (d) e (b) respectivamente.

Experimentalmente se as amostras não forem homogêneas deve-se esperar um comportamento típico dos LR ou VC, com anomalias para a região de composições em torno de $x=0,30$, em medidas feitas na região de temperatura superiônica. As SSI são importantes referências pois mostram o comportamento que pode ser esperado de um cristal perfeito. Como nas amostras experimentais sempre existe a possibilidade de existir defeitos são necessários cuidados especiais na preparação das composições anômalas, pois estas tendem a ter um maior número de defeitos o que pode ir além do desejado. Porém se a necessidade tecnológica é a de um cristal composto por esses metais pesados e F com alta mobildade aniônica, a concentração promissora é a $x=0,30$.
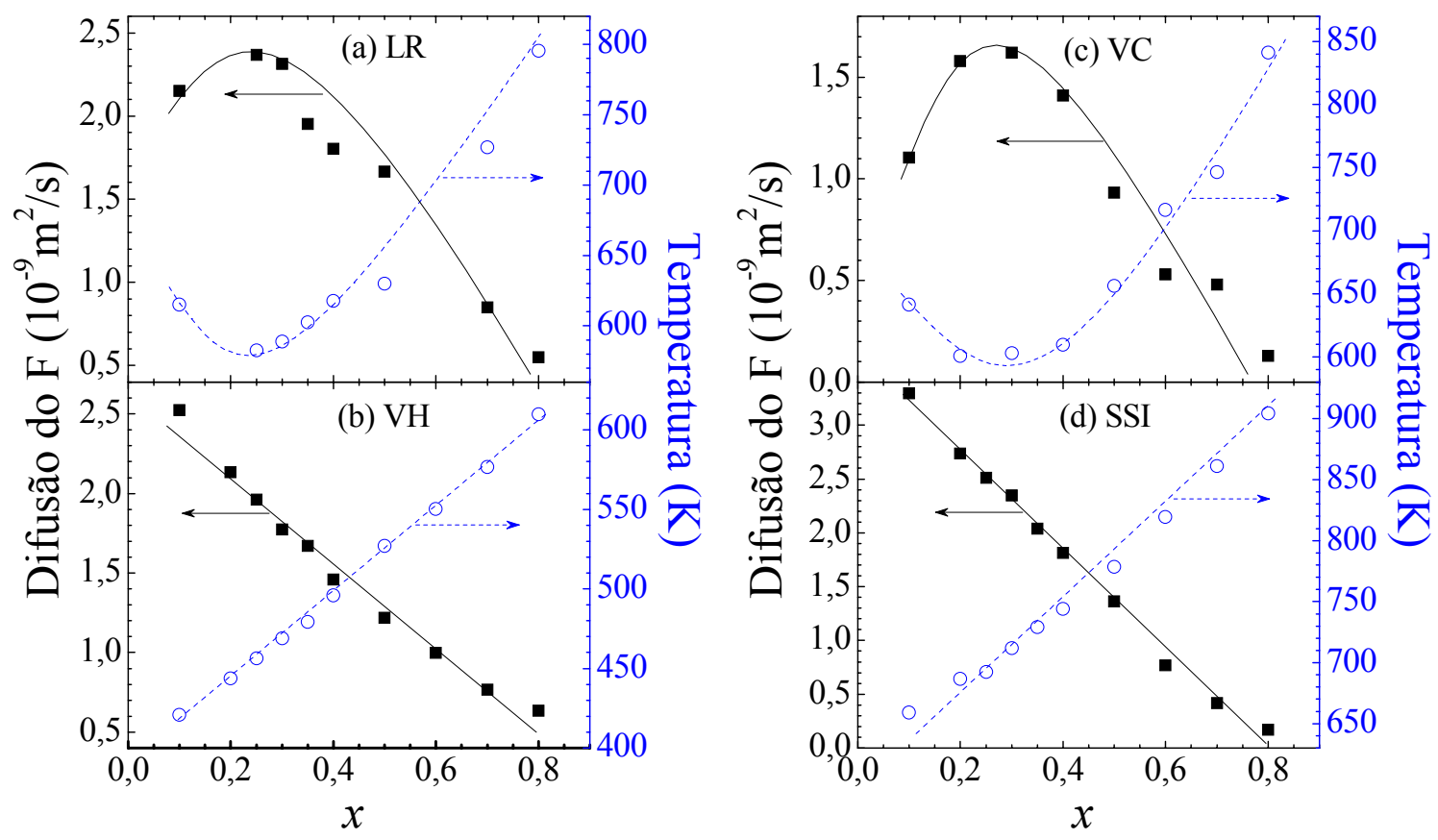

Figura 3.101: Difusão do $\mathrm{F}$ como função da concentração de $\mathrm{CdF}_{2}$ para os sólidos: SSI, $\mathrm{LR}, \mathrm{VH}$ e VC. 


\section{Capítulo 4}

\section{Conclusões e perspectivas futuras}

A simulação computacional clássica usando o método DM, mostrou ter um papel de suma importância no desenvolvimento de materiais que empregam o uso dos fluoretos $\mathrm{PbF}_{2}$ e $C d F_{2}$. De posse do ajuste do potencial para o $P b F_{2}$ e o $C d F_{2}$ foi proposto o potencial para o sistema $C d_{x} P b_{1-x} F_{2}$ e a transferabilidade do potencial permitiu obter todos os resultados estruturais, dinâmicos e propriedades térmicas para o sistema misto. A credibilidade do potencial foi assegurada quando se observou que todos os sistemas obtidos, SSI, VH,VC, LR e LSRT apresentaram estabilidade quando termalizados por longos períodos de tempo em qualquer temperatura desejada. Não se observa na literatura especializada trabalhos que abordem todas as possíveis estruturas desses sistemas mistos e ainda avalie de maneira quantitativa a homogeneidade estrutural. Desta maneira, as simulações computacionais contribuiram para diminuir a interface entre a teoria e o experimento. A simulação computacional, entendida como um experimento feito em computador, poderá ser usada pelo experimentalista como uma orientadora no sentido de prever e/ou extrair etapas desnecessárias durante a realização do experimento em laboratório. A necessidade de repetir um experimento em laboratório tem um custo que cresce vertiginosamente, incluindo gastos com reagentes, disponibilidade de aparelhos, entre outros. Por outro 
lado, o custo é o mesmo para a realização de uma simulação ou de uma série infinita de simulações. Além do baixo custo, devido a praticidade de realizar o experimento em computador, foi possível estudar uma grande quantidade de concentrações dos sistemas $C d_{x} P b_{1-x} F_{2}$ o que permitiu concluir com maior clareza as suas propriedades.

Devido as simulações terem sido realizadas no ensemble NPT foi possível observar as descontinuidades nas transições sólido-líquido e líquido-sólido que permitiram identificar a fusão do sistema. A situação usual de um experimento em um laboratório é feita com volume variável assim como foram feitas as simulações.

Uma característica fundamental da simulação foi permitir controlar as taxas de resfriamento e aquecimento. Durante o resfriamento os estudos realizados mostraram as taxas necessárias para a obtenção de vidros homogêneos, ainda que esses não foram obtidos experimentalmente até o momento, e para a cristalização com um menor número de defeitos. Na devitrificação dos $\mathrm{VH}$ o controle das taxas de reaquecimento mostrou que as composições em torno de $x=0,35$ têm maior dificuldade para se cristalizar.

A construção do sistema ideal, sem defeitos, totalmente homogêneo e com estequimometria muito precisa o qual foi chamado de SSI, serviu como importante referência durante os estudos. Os resultados estruturais, número de vizinhos e comprimento de ligação, deste sistema ideal estão em pleno acordo com medidas de EXAFS. A análise de três corpos feita com os ângulos de ligação, confirmaram neste sistema misto a formação de uma rede cfc entre os cátions e uma cúbica simples entre os íons F. O tipo de rede e a homogeneidade das SSI foram confirmadas uma vez que o valor do ângulo independe do tipo de cátion considerado.

A simulação atomística realizada permite aos átomos todo e qualquer tipo de movimento. Em situações em que é possível o movimento dos cátions, como no resfriamento do líquido com taxas lentas, na termalização do líquido super resfriado e na devitrificação do 
vidro homogêneo os sistemas exibiram a tendência de separação de fase estrutural. Essa tendência em separar de fase, a qual parece ser intrísica do sistema $C d_{x} P b_{1-x} F_{2}$, deve ser considerada quando da preparação das amostras experimentalmente. O sistema simulado usando DM corresponde a uma região da ordem de nanômetros e quando foi submetido a um resfriamento lento do líquido homogêneo ou na devitrificação dos VH resultou em cristais que não apresentam a mesma distribuição homogênea dos cátions obtida nas SSI. As simulações sugerem que o sistema real seja composto por essas nano-regiões, e as suas separações de fases talvez não podem ser dectadas experimentalmente por limitações das técnicas em uso. Sendo que as técnicas como difração de raio-x e EXAFS fazem uma média do sistema, elas não permitiram enchergar essa separação nessas nano-regiões. A homogeneidade ou a não homogeneidade dos sistemas foram quantificadas de maneira muito seletiva analizando-se a vizinhança dos íons Flúor. Devido aos íons Flúor se encontrarem em pontos de simetria tetraédrica sendo os primeiros vizinhos os cátions, foram definidas as cinco possibilidades de vizinhança. Quando o sistema é homogêneo essa vizinhança deve seguir a estatística de ocorrência de dois eventos independentes o que aconteceu em perfeito acordo para as SSI. Por outro lado, os sistemas separados apresentaram íons Fluor que não seguem a estatística do sistema homogêno e apresentam maiores probabilidades de vizinhança com quatro íons $C d$ e quatro íons $P b$. A estatística depende da concentração de $C d F_{2}$, mas as SSI em comparação aos sistemas separados, sempre apresentam maiores quantidades de íons Flúor que são vizinhos de dois íons $C d$ e dois íons $P b$. Sistemas não homogêneos também foram identificados pelos $\mathrm{n}_{\alpha \beta}(\mathrm{r})$ e $\mathrm{g}_{\alpha \beta}(\mathrm{r})$ pois as regiões ricas em um dado tipo de cátion tendem ao comportamento dos fluoretos puros.

A função de correlação de pares caracterizou de maneira clara a estrutura interna dos sistemas $C d_{x} P b_{1-x} F_{2}$. Ainda que em um sistema ideal como as SSI o comprimento 
de ligação de um dado par depende do ambiente em que este se encontra. Nas SSI os seis pares de átomos sofrem diminuição do comprimento de ligação com o aumento na concentração de $C d F_{2}$, em acordo com medidas EXAFS. As SSI iniciais apresentaram um grau de desordem maior que os fluoretos puros, sendo que as composições em torno de $x=0,35$ mostraram picos mais baixos e largos para os seis pares de átomos. A maior desordem em torno de $x=0,35$ influenciou a fusão das SSI levando a uma menor temperatura de fusão em torno dessas composições, conforme previsto experimentalmente. A comparação entre experimento e simulação normalizando os dados, mostrou diagramas de fase com curvaturas muito semelhantes.

O esclarecimento de um possível erro, que pode ser cometido ao se fazer médias dos valores das segundas esferas de coordenação dos pares catiônicos, na intenção de determinar o parâmetro de rede de um sistema separado, pode ser explicado através da função de correlação de pares. Para um sistema não homogêneo não é possível definir um único parâmetro de rede, pois a região rica em $\mathrm{PbF}_{2}$ apresenta um comportamento dos cátions que se assemelha aos dos $\mathrm{Pb}$ do $P b F_{2}$ puro. Da mesma maneira, a região rica em $C d F_{2}$ apresenta um comportamento dos cátions que se assemelha aos dos $C d$ do $C d F_{2}$ puro. Como o comprimento de ligação $\mathrm{Pb}-\mathrm{Pb}$ no $\mathrm{PbF}_{2}$ puro é maior que o $\mathrm{Cd}-\mathrm{Cd}$ no $C d F_{2}$, não é possível definir um parâmetro de rede único para o sistema. Porém, em um sistema separado quando são feitas médias com as distâncias obtidas dos segundos picos das $g_{P b-P b}(r)$ e $g_{C d-C d}(r)$ dos pares catiônicos, pode-se definir um parâmetro de rede que apresenta diminuição com comportamento linear com a adição de $C d F_{2}$. Este parâmetro representa apenas um comportamento médio e não fornece informações corretas a respeito da realidade interna do material.

Os LR apresentam separação de fase mais expressiva que os VC devido a maior mobilidade permitida aos cátions. Mas, em ambos os sistemas as composições mais próximas 
dos fluoretos puros tendem a se cristalizar com uma estrutura mais homogênea e menor número de defeitos. No entanto as composições em torno de $x=0,35$ apresentam separação de fase mais expressiva e um grande número de defeitos.

O grande intervalo de temperatura compreendido pela região superiônica foi observado em todos os sistemas e concentrações. Inicialmente o mecanismo de difusão dos íons Flúor é feito por saltos que pode ser caracterizado pela forma das $\mathrm{g}_{F-F}(\mathrm{r})$ que não assumem na transição iônico-superiônico o comportamento de um líquido desordenado. Quando a difusão se iniciou as $\mathrm{g}_{F-F}(\mathrm{r})$ mantiveram os picos apenas os apresentado mais largos e mais baixos. Os resultados das simulações mostraram que tanto a condutividade quanto difusão do íon Flúor para o $P b F_{2}$ estão em pleno acordo com os experimentos. Para a composição em torno de $x=0,30$ existem medidas experimentais da condutividade as quais as simulações também mostram concordância. O valor da difusão do íon Flúor, em uma dada temperatura fixa, para as várias concentrações de $C d F_{2}$ apresentam comportamento diferente para os sistemas homogêneos e não homogêneos. As SSI e os VH apresentam comportamento linear da difusão do íon Flúor como função da concetração de $C d F_{2}$. Porém, os $\mathrm{VC}$ e os LR não apresentam comportamento linear, sendo que as composições em torno de $x=0,30$ têm condutividades maiores. A maior mobilidade é consequência da maior desordem encontrada durante a cristalização destas composições.

A separação de fase parece ser intrínseca ao sistema $C d_{x} P b_{1-x} F_{2}$ quando é permitida alguma mobilidade aos cátions. O líquido super resfriado inicialmente homogêneo, quando termalizado apresentou separação de fase e devido a menor mobilidade dos íons Cd eles passaram a se cristalizar.

A técnica DM mostrou-se adequada para o estudo revelando vários resultados que concordam com os experimentos e sugerindo o comportamento de sistemas ainda não obtidos experimentalmente. O acesso microscópico do sistema permitiu uma descrição 
que é de grande valia e nem sempre possível experimentalmente. O sucesso obtido com a técnica DM sugere o seu uso na descrição da estrutura de outros materiais.

Os objetivos para o futuro são simulações de sistemas com um número maior de partículas para um amplo estudo da separação de fase nesses sistemas.

Quando se adiciona $\mathrm{SiO}_{2}$, ou $\mathrm{B}_{2} \mathrm{O}_{3}$, ou $\mathrm{TeO}_{2}$ no sistema $\mathrm{Cd}_{x} \mathrm{~Pb}_{1-x} \mathrm{~F}_{2}$ e promove-se o resfriamento do líquido, experimentalmente ocorre a formação de vidro. O estudo mais profundo das propriedades microscópicas destes vidros faz parte dos objetivos futuros. 


\section{Referências Bibliográficas}

[1] ABRAHAM, F.F. Computational statistical mechanics: methodology, applications and supercomputing. Advances in Physics, v. 35, n. 1, p. 1-111, 1986.

[2] RINO, J.P.; STUDART, N. Um potencial de interação para estudo de materiais e simulação por Dinâmica Molecular. Quimica Nova, v. 24, n. 6, p. 838-845, 2001.

[3] IVANOV-SHITZ, A.K. Computer simulation of superionic conductors. Crystallography Reports, v. 52, n. 1, p. 129-140, 2007.

[4] HOHENBERG, P.; KOHN, W. Inhomogeneous electron gas. Phys. Rev., v. 136, n. 3B, p. B864-B871, Nov. 1964.

[5] KOHN, W.; SHAM, L.J. Self-consistent equations including exchange and correlation effects. Phys. Rev., v. 140, n. 4A, p. A1133-A1138, Nov. 1965.

[6] CAR, R.; PARRINELLO, M. Unified approach for molecular dynamics and densityfunctional theory. Phys. Rev. Lett., v. 55, n. 22, p. 2471-2474, Nov. 1985.

[7] PAYNE, M.C.; TETER, M.P.; ALLAN, D.C.; ARIAS, T.A.; JOANNOPOULOS, J.D. Iterative minimization techniques for $a b$ initio total energy calculations: molecular dynamics and conjugate gradients. Rev. Mod. Phys., v. 64, n. 4, p. 1045-1097, Oct. 1992.

[8] GALLI, G.; PASQUARELLO, A. First principles molecular dynamics. In: ALLEN, M.P., ed.; TILDESLEY, T.J., ed. Computer Simulation in Chemical Physics, Dordchester: Kluwer, 1993, p. 261.

[9] GOEDECKER, S.; COLOMBO, L. Efficient linear scaling algorithm for tightbinding molecular dynamics. Phys. Rev. Lett., v. 73, n. 1, p. 122-125, Jul. 1994.

[10] MAURI, F.; GALLI, G. Electronic structure calculations and molecular-dynamics simulations with linear system-size scaling. Phys. Rev. B, v. 50, n. 7, p. 4316-4326, Aug. 1994.

[11] QIU, S.-Y.; WANG, C.Z.; HO, K.M.; CHAN, C.T. Tight-binding molecular dynamics with linear system-size scaling. J. Phys. Cond. Matt., v. 9, n. 43, p. 9153-9172, Oct. 1994.

[12] NAKANO, A. et al. Multiscale simulation of nano systems. Computing in Science \& Engineering, v. 3, n. 4, p. 56-66, July/August 2001. 
[13] KADAU, K.; GERMANN, T.C.; LONDAHL, P.S. Molecular dynamics comes of age: 320 billion atom simulation on BlueGene/L. International Journal of Modern Physics C, v. 17, n. 2, p. 1755-1761, 2006.

[14] NOSÉ, S. A unified formulation of the constant temperature molecular dynamics methods. J. Chem. Phys, v. 81, n. 1, p. 511-519, Jul. 1984.

[15] NOSÉ, S. A molecular dynamics method for simulation in the canonical ensemble. Mol. Phys., v. 52, p. 255-268, 1984.

[16] HOOVER, W.G. Canonical dynamics: Equilibrium phase-space distributions. Phys. Rev. A, v. 31, p. 1695-1697, 1985.

[17] HOOVER, W.G. Constant pressure equations of motion. Phys. Rev. A, v. 34, p. 2499-2500, 1986.

[18] CAMPBELL, T. J. et al. Dynamics of oxidation of aluminum nanoclusters using variable charge Molecular-Dynamics simulations on parallel computers. Physical Rev. Letters, v. 82, p. 4866-4869, 1999.

[19] PARRINELLO, M.; RAHMAN, A. Polymorhic transitions in single crystals: A new molecular dynamics method. J. Appl. Phys., v. 52, n. 12, p. 7182-7190, Dec. 1981.

[20] BREnNeR, D.W. The art and science of an analytic potential. Phys. Stat. Sol., v. 217 , p. 23,2000 .

[21] SILVA, M.A.P. Estudos estruturais em vidros e vitrocerâmicas contendo $\mathrm{PbF}_{2}$ e $C d F_{2}$. 2000. 156f. Tese (Doutorado em Química) - Instituto de Química, Unesp, Araraquara, 2000.

[22] BUENO, L.A. Vidros e vitrocerâmicas em sistemas oxifluoretos. 2003. 179f. Tese (Doutorado em Química) - Instituto de Química, Unesp, Araraquara, 2003.

[23] KOSACKI, I. Physical properties and aplicátions of $C d_{1-x} P b_{x} F_{2}$ superionic crystals. Appl. Phys. A, v. 49, p. 413-424, 1989.

[24] PICININ, A.; SILVA, M.A.P.; RINO J.P. et al. The eutectic composition on $C d_{x} P b_{1-x} F_{2}$ phase diagram: A molecular-dynamics study. Europhysics Letters, v. 071, n. 5 , p. $770-775,2005$.

[25] METROPOLIS, N.; ROSENBLUTH, A.W.; ROSENBLUTH, M.N.; TELLER, A.H.; TELLER, E. Equation of state calculations by fast computing machines. Journal of Chemical Physics, v. 21, n. 6, p. 1087-1092, 1953.

[26] ALDER, B.J.; WAINWRIGHT, T.E. Phase transition for hard sphere system. Journal of Chemical Physics, v. 27, p. 1208-1209, 1957.

[27] GIBSON, J.B.; GOLAND, A.N.; MILGRAM, M.; VINEYARD, G.H. Dynamics of radiation damage. Physical Review, v. 120, n. 4, p. 1229-1253, 1960.

[28] RAHMAN, A. Correlation in the motion of atoms in liquid Argon. Phys. Rev., v. 136, n. 2A, p. A405-A411, Oct. 1964. 
[29] LEACH, A.R. Molecular modelling principles and applications. London: Longman; 1996. 595 p.

[30] VERLET, L. Computer "experiments" on classical fluids. I. Thermodynamical properties of Lennard-Jones molecules. Phys. Rev., v. 159, n. 1, p. 98-103, Jul. 1967.

[31] VERLET, L. Computer "experiments" on classical fluids. II. Equilibrium correlation functions. Phys. Rev., v. 165, n. 1, p. 201-215, Jan. 1968.

[32] NICOLAS, J.J.; GUBBINS, K.E.; STREETT, W.B.; TILDESLEY, D.J. Equation of state for Lennard-Jones fluid. Mol. Phys., v. 37, n.5, p. 1429-1454, 1979.

[33] HARP, G.D.; BERNE, B.J. Linear- and angular-momentum autocorrelation functions in diatomic liquids. J. Chem. Phys., v. 49, n. 3, p. 1249-1254, Aug. 1968.

[34] HARP, G.D.; BERNE, B.J. Time-correlation functions, memory funcions, and molecular dynamics. Phys. Rev. A, v. 2, n. 3, p. 975-996, Sep. 1970.

[35] RAHMAN, A.; STILLINGER, F.H. Molecular dynamics study of liquid water. J. Chem. Phys., v. 55, n. 7, p. 3336-3359, Oct. 1971.

[36] RAINS, C.A.; RAY, J.R.; VASHISHTA, P. Phase transformations and polytypism in silver iodide: A molecular-dynamics study. Phys. Rev. B, v. 44, n. 17, p. 9228-9239, Nov. 1991.

[37] SHIN, S.; COLLAZO, N.; RICE, S.A. A molecular study of the packing structures in monolayers of partially fluorinated amphiphiles. J. Chem. Phys., v. 86, n. 2, p. 1352-1366, Jan. 1992.

[38] GAO, J.; RICE, S.A. Intermediate ordering in a liquid supported monolayer: A molecular dynamics study. J. Chem. Phys., v. 99, n. 9, p. 7020-7029, Nov. 1993.

[39] HAUTMAN, J.; KLEIN, M.L. Molecular dynamics simulation of the effects of temperature on a dense monolayer of long-chain molecules. J. Chem. Phys., v. 93, n. 10, p. 7483-7492, Nov. 1990.

[40] RINO, J.P.; HORNOS, Y.M.M.; ANTONIO, G.A.; EBBSJÖ, I.; KALIA, R.K.; VASHISHTA, P. Structural and dynamical correlations in $\mathrm{Ag}_{2}$ Se: A molecular dynamics study of superionic and molten phases. J. Chem. Phys., v. 89, n. 12, p. 7542-7555, Dec. 1988.

[41] OMELTCHENKO, A.; Yu, J.; KALIA, R.K.; VASHISHTA, P. Crack front propagation and fracture in a graphite sheet: A molecular dynamics study on parallel computers. Phys. Rev. Lett., v. 78, n. 11, p. 2148-2151, Mar. 1997.

[42] KALIA, R.K.; NAKANO, A.; TSURUTA, K.; VASHISHTA, P. Morphology of pores and interfaces and mechanical behavior of nanocluster-assembled silicon nitride ceramic. Phys. Rev. Lett., v. 78, n. 4, p. 689-692, Jan. 1997.

[43] LIEM, S.Y.; BROWN, D.; CLARKE, J.H.R. Molecular dynamics simulations on distributed memory machines. Comput. Phys. Commun., v. 67, p. 261-267, 1991. 
[44] HOOVER, W.G.; GROOT, A.J.De; HOOVER, C.G.; STOWERS, I.F.; KAWAI, T.; HOLIAN, B.L.; BOKU, T.; LHARA, S.; BELAK, J. Large-scale elastic-plastic indentation simulation via nonequilibrium molecular dynamics. Phys. Rev. A, v. 42, n. 10 , p. $5844-5853$, Nov. 1990.

[45] RAPAPORT, D.C. Multi-million particle molecular dynamics I. Design considerations for vector processing. Comput. Phys. Commun., v. 62, p. 198-216, 1991.; RAPAPORT, D.C. Multi-million particle molecular dynamics II. Design considerations for distributed processing. Comput. Phys. Commun., v. 62, p. 217-228, 1991.

[46] HAILE, J.M. Molecular Dynamics Simulation. New York: John Wiley, 1997. $489 \mathrm{p}$.

[47] ALLEN, M.P.; TILDESLEY, D.J. Computer simulation of liquids. Oxford: Clarendon Press, 1990. 385 p.

[48] RAPAPORT, D.C. The art of molecular dynamics simulation. 2 ed. Cambridge: Cambridge University Press, 2004. 549 p.

[49] FRENKEL, D.; SMIT, B. Understanding molecular simulation. Boston: Academic Press, 1996. 638 p.

[50] WALKER, A.B.; DIXON, M.; GILLAN M.J. Computer-simulation of ionic disorder in high-temperature $\mathrm{PbF}_{2}$. Journal of Physics C- Solid State Physics, v. 15, n. 19, p. 4061-4073, 1982.

[51] ABRAHAM, F.F. On the thermodynamics, structure and phase stability of the nonuniform fluid state. Physics Reports, v. 53, n. 2, p. 93-156, 1979.

[52] EWALD, P.P. The calculation pf optical and electrostatic grid potential. Annalen der Physik, v. 64, p. 253, 1921.

[53] LEEUW, S.W.; PERRAM, J.W.;SMITH, E.R. Simulation of electrostatic systems in periodic boundary conditions. I. Lattice sums and dielectric constants. Proc. R. Soc. Lond. A, v. 373, n. 1752, p. 27-56, 1980.

[54] LEEUW, S.W.; PERRAM, J.W.;SMITH, E.R. Simulation of electrostatic systems in periodic boundary conditions. II. Equivalence of boundary conditions. Proc. R. Soc. Lond. A, v. 373, n. 1752, p. 57-66, 1980.

[55] PANG, T. An introduction to computational physics. Cambridge: Cambridge University Press, 2a ed., 2006, 385 p.

[56] CALLEN, H. B. Thermodynamics and an Introduction to Thermostatistics. 2 ed. New York: John Wiley, 1985.

[57] SACK, R. A. Pressure-dependent partition functions. Mol. Phys., v. 2, n. 1, p. 8-22, 1959.

[58] LEBOWITZ, J. L.; PERCUS, J. K.; VERLET, L. Ensemble dependence of fluctuations with applicátion to machine computations. Phys. Rev., v. 153, n. 1, p. 250-254, 1967. 
[59] PEARSON, E. M.; HALICIOGLU, T.; TILLER, W. A. Laplace-transform technique for deriving thermodynamic equations from the classical microcanonical ensemble. Phys. Rev. A, v. 32, n. 5, p. 3030-3039, 1985.

[60] ANDERSEN, H.C. Molecular dynamics at constant pressure and/ or temperature. J. Chem. Phys., v. 72, p. 2384-2393, 1980.

[61] MELCHIONNA, S.; CICCOTTI, G.;HOLIAN B.L. Hoover NPT dynamics for systems varying in shape and size. Molecular Physics, v. 78, n. 3, p. 533, 1993.

[62] MARCH, N.H.; TOSI, M.P. Atomic dynamics in liquids. New York: Dover Publicátions, 1991. p. 101.

[63] HANSEN, J.P.; McDONALD, I.R. Theory of simple liquids. London: Academic Press, 1976. p. 92.

[64] RAHMAN, A. and VASHISHTA, P. Molecular dynamics studies of superionic conductors. In: PERRAM, J.W., ed.; The physics of superionic conductors and electrode materials. New York: Plenum Publishing Corporation, 1983. p.93.

[65] CALLISTER, W.D. Materials science and engineering: an introduction. New York: John Wiley, 2000.

[66] GROENEN, J.; CARLES, R.; LANDA, G.; GUERRET-PIÉCOURT, C.; FONTAINE, C.; GENDRY, M. Optical-phonon behavior in $\mathrm{Ga}_{1-x} \operatorname{In}_{x}$ As: The role of microscopic strains and ionic plasmon coupling. Phys. Rev. B, v. 58, n. 16, p. $10452,1998$.

[67] LANDA, G.; CARIES, R.; RENUCCI, J.B. Dynamical properties of $\mathrm{Ga}_{l}{ }_{x} \mathrm{In}_{x}$ as solid solutions: influence of local distortion effects. Solid State Communications, v. 86, n. 6, p. 351-355, 1993.

[68] Podsiadlo, H. Phase equilibria in the binary system lead fluoride $\left[\mathrm{PbF}_{2}\right]$-cadmium fluoride $\left[\mathrm{PbF}_{2}\right]$. Journal of Thermal Analysis, v. 54, p. 863-866, 1998.

[69] TRNOVCOVÁ, V.; FEDOROV, P.P.; OSVOLDOVÁ, M.; BUCHINSKAYA, I. I.; ZHUROVA, E.A. Structural features of fluoride-ion transport in $P b_{0.67} C d_{0.33} F_{2}$ single crystals. Journal of Optoelectronics and Advanced Materials, v. 5, n. 3, p. 627-634, 2003.

[70] SOROKIN, N.I.; SOBOLEV B. P.; BREITER M.W. Specific features of anion transfer in superionic conductors based on $M F_{2}(M=P b$ and $C d)$. Physics of the Solid State, v. 44, n. 8, p. 1579-1586, 2002.

[71] MATSUlEV, A.N.; IVANOV, Y.N.; LIVSHITS, A.I.; BUZNIK, V.M.; FEDOROV, P.P.; BUCHINSKAYA, I.I.; and SOBOLEV, B.P. Crystal Structure of the $C d_{0.33} P b_{0.67} F_{2}$ Solid Solution from ${ }^{19} \mathrm{~F}$ NMR Data. Russian Journal of Inorganic Chemistry, v. 45, n. 2, p. 240-242, 2000.

[72] SILVA, M.A.P.; MESSADDEQ, Y.; BRIOIS, V.; POULAIN, M.; VILLAIN F.; RIBEIRO, S.J.L. Structural studies on lead-cadmium f luoride solid solutions. Solid State Ionics, v. 147, p.135-139, 2002. 
[73] KOSACKI, I.; DYNOWSKA, E. Preparation and structure of mixed $C d_{1-x} P b_{x} F_{2}$ crystals. Journal of Crystal Growth, v. 50, n. 2, p. 575-577, 1980.

[74] CHADWICK, A. V. High-temperature transport in fluorites. Solid State Ionics, v. 8, n. 3, p. 209-220, 1983.

[75] HULL, S. Superionics: crystal structures and conduction processes. Reports on Progress in Physics, v. 67, p. 1233-1314, 2004.

[76] BUCHINSKAYA, I.I.; FEDEROV, P.P. Lead difluoride and related systems. Russian Chemical Reviews, v. 73, n. 4, p. 371-400, 2004.

[77] BOYCE, J.B.; HUBERMAN, B.A. Superionic conductors: transitions, structures, dynamics. Physics Reports, v. 51, n.4, p. 189-265, 1979.

[78] BENZ, R. Electrical Conductivity of $\mathrm{PbF}_{2}$. Z. Phys. Chem., v. 95, p. 25-32, 1975.

[79] AZIMI, A.; CARR, V. M.; CHADWICK, A. V.; KIRKWOOD, F. G.; SAGHAFIAN R. Point defect parameters for $\beta-P b F_{2}$ from a computer analysis of measurements of ionic conductivity. J. Phys. Chem. Solids, v. 45, n. 1, p. 23-31, 1984.

[80] ZIMMER, F.; BALLONE, P.; PARRINELlO, M.; MAIER, J. The conductivity anomaly in $\mathrm{PbF}_{2}$ : a numerical investigation by classical $\mathrm{MD}$ and $\mathrm{MC}$ simulations. Solid State Ionics, V. 127, P. 277-284, 2000.

[81] GORDON, R.E.; STRANGE, J.H. NMR relaxation and self-diffusion in $P b F_{2}$. J. Phys. C: Solid State Phys., v. 11, p. 3213-3223, 1978.

[82] GOFF, J.P.; HAYES, W.; HULLS, S.; HUTCHINGST, H.T. Neutron powder diffraction study of the fast-ion transition and specific heat anomaly in $\beta$-lead fluoride. J. Phys. Condens. Matter, v. 3, p. 3677-3687, 1991.

[83] CARR, V.M.; CHADWICK, A. V.; SAGHAFIAN, R. The electrical conductivity of $\mathrm{PbF}_{2}$ and $\mathrm{SrCl}_{2}$ crystals at high temperatures. J. Phys. C: Solid State Phys., v. 11, p. L637-L641, 1978.

[84] OBERSCHMIDT, J.; LAZARUS, D. Ionic conductivity, activation volumes, and high-pressure phase transitions in $\mathrm{PbF}_{2}$ and $\mathrm{SrCl}_{2}$. Physical Review B, v. 21, p. 2952-2961, 1980.

[85] SAMARA, G.A.; Pressure and temperature dependences of the ionic conductivities of cubic and orthorhombic lead fluoride $(P b F 2)$. Journal of Physics and Chemistry of Solids. v. 40, n. 7, p. 509-522, 1979.

[86] MURIN, I.V.; CHERNOV, S.V.; Electrical-properties of solid-solutions in the $\mathrm{PbF}_{2^{-}}$ $C d F_{2}$ system. Inorganic Materials, v. 18, n. 1,p. 149-150, 1982.

[87] VALAKH, M.Ya.; KOSACKI, I.; LITVINCHUK, A.P.; TARASOV, G.G. Lattice dynamics and ionic conductivity of $P b_{x} C d_{1-x} F_{2}$ mixed superionic crystal. Sov. Phys. Solid State, v.27, p. 2208, 1985.

[88] KOSACKI, I.; LITVINCHUK, A.P.; TARASOV, J.J.; VALAKH, M. Y. Anion disordering and specific heat of $C d_{1-x} P b_{x} F_{2}$ superionic crystals. J. Phys. Condens. Matter, v. 1, p. 929-934, 1989. 